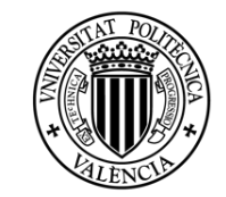

UNIVERSITAT POLITĖCNICA DE VALÈNCIA

\title{
STUDY, ANALYSIS AND DETERMINATION OF BUCKLING \\ LOAD IN DUAL GAUGE TRACKS THROUGH ANALYTICAL AND NUMERICAL METHODS
}

DOCTORANDO: IGNACIO VILLALBA SANCHIS

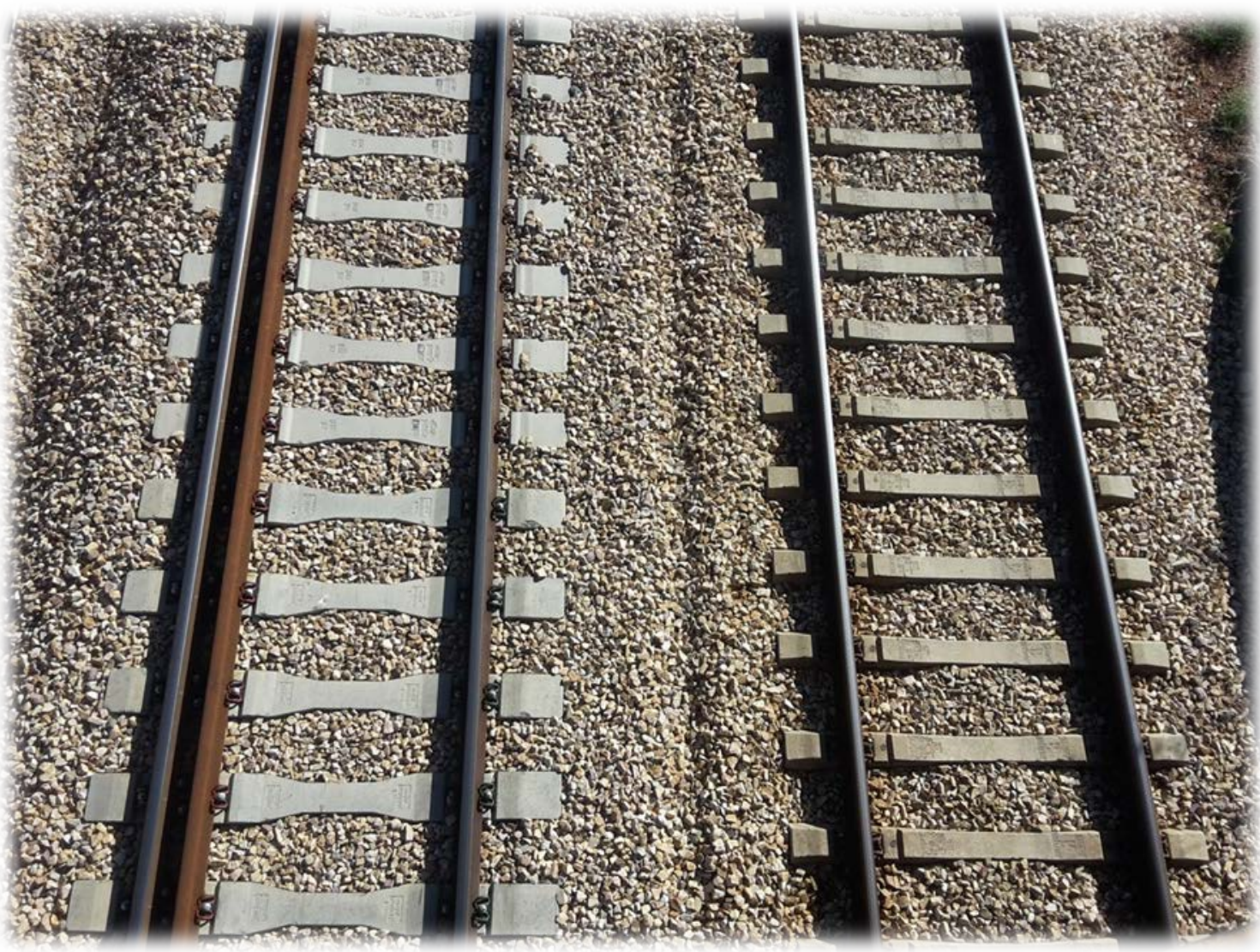

Director de Tesis: Prof. Dr. Ricardo Insa Franco

\section{UNIVERSITAT POLITÈCNICA DE VALÈNCIA}

\section{ESCUELA DE DOCTORADO}

PROGRAMA DE DOCTORADO EN INFRAESTRUCTURAS DE TRANSPORTE Y TERRITORIO Departamento de Ingeniería e Infraestructura de los Transportes

Valencia, junio de 2017 


\title{
UNIVERSITAT POLITÈCNICA DE VALÈNCIA
}

ESCUELA TÉCNICA SUPERIOR DE INGENIEROS DE CAMINOS, CANALES Y

PUERTOS

\section{PROGRAMA DE DOCTORADO EN INFRAESTRUCTURAS DE TRANSPORTE Y TERRITORIO}
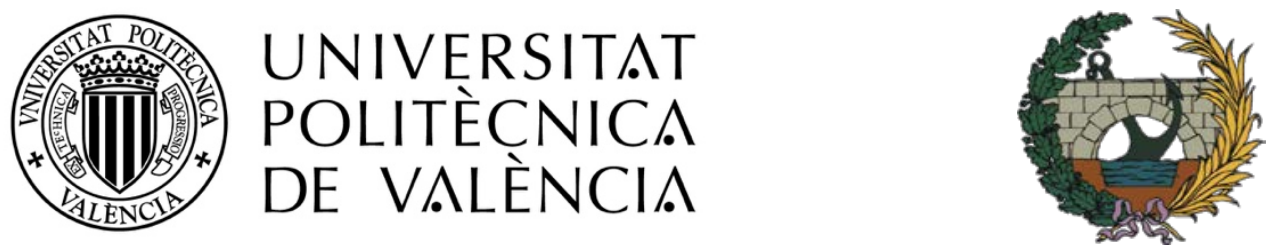

\section{TESIS DOCTORAL}

STUDY, ANALYSIS AND DETERMINATION OF BUCKLING LOAD IN DUAL GAUGE TRACKS THROUGH ANALYTICAL AND NUMERICAL METHODS ESTUDIO, ANÁLISIS Y DETERMINACIÓN DE LA CARGA DE PANDEO EN VÍAS DE DOBLE ANCHO MEDIANTE MÉTODOS ANALÍTICOS Y NUMÉRICOS

\author{
DOCTORANDO: \\ IGNACIO VILLALBA SANCHIS
}

DIRECTOR DE TESIS:

PROF. DR. RICARDO INSA FRANCO

Realizada dentro del Programa de Doctorado en Infraestructuras de Transporte y Territorio para la obtención del título de Doctor por la Universidad Politécnica de Valencia Departamento de Ingeniería e Infraestructura de los Transportes 
TESIS DOCTORAL

Study, analysis and determination of buckling load in dual gauge tracks through analytical and numerical methods

Estudio, análisis y determinación de la carga de pandeo en vías de doble ancho mediante métodos analíticos y numéricos

Presentada por: D. Ignacio Villalba Sanchis

Dirigida por: Prof. Dr. D. Ricardo Insa Franco

Facultad o Escuela: Escuela Técnica Superior de Ingenieros de Caminos, Canales y Puertos

Departamento: Dep. de Ingeniería e Infraestructura de los Transportes

MIEMBROS DEL TRIBUNAL CALIFICADOR

Presidente: Dr. D.

Firma:

Vocales: Dr. D.

Firma:

Dr. D.

Firma:

Dr. D.

Firma:

Secretario Dr. D.

Firma:

En Valencia, a de de 2017 


\section{NOTE FOR ENGLISH READERS}

De acuerdo con el Artículo 15 del RD 99/2011, esta Tesis Doctoral reúne los requisitos para optar a la mención «Doctor internacional», al concurrir, entre otras, las siguientes circunstancias:

a) Que, durante el periodo de formación necesario para la obtención del título de doctor, el doctorando haya realizado una estancia mínima de tres meses fuera de España en una institución de enseñanza superior o centro de investigación de prestigio, cursando estudios o realizando trabajos de investigación. La estancia ha sido realizada en "Sapienza-Università di Roma" (Italia).

b) Que parte de la tesis doctoral, al menos el resumen y las conclusiones, se haya redactado y sea presentado en una de las lenguas habituales para la comunicación científica en su campo de conocimiento, distinta a cualquiera de las lenguas oficiales en España. A estos efectos, se incluye las siguientes partes en inglés:
i. Resumen
ii. Introducción
iii. Conclusiones

According to point 15 of RD 99/2011, this Doctoral Thesis may opt to the mention «International Doctor», complying, among others, the following conditions:

a) During the training period necessary to obtain doctor's degree, the student has made a minimum stay of three months outside Spain, in a higher education institution or prestigious research centre, studying or developing research works. The stay has been made in "Sapienza-Università di Roma" (Italy).

b) A part of the doctoral Thesis, at least summary and conclusions has been written and presented in an accepted language for scientific communication, other than any official languages in Spain. With these purpose, the following parts are included in English:
i. Summary
ii. Introduction
iii. Conclusions 
Si yo hubiera inventado el ferrocarril no habría consentido que nadie montara en él sin mi permiso.

Gustave Flaubert 


\section{EXPOSITION AND SUMMARY OF DOCTORAL THESIS}

Conventional railway track is the structure consisting of the ballast or slab track, upon which sleepers, fasteners and two rails are laid, allowing the passage of trains equipped with a certain gauge. Due that trains cannot pass from a line with one track gauge to another (only possible where the difference between the two gauges is small), track gauge is a dominant parameter determining interoperability, used as a descriptor of a route or network. Where trains encounter a different gauge, a break-of-gauge occurs, which entails delays, costs, and inconveniences.

However, special situations such as the Spanish rail network can occur, where new interoperability and connection facilities have resulted in the construction of certain lines with dual gauge track. A dual gauge track configuration consists of three rails, where the two adjacent outer rails provide each of the gauges $(1435 \mathrm{~mm} / 1668 \mathrm{~mm}$ ), while the single outer rail is common to trains of both gauges.

This new track structure is an important modification of the classical rail track with two rails and one gauge. In addition, long stretches of dual gauge tracks have not been implemented yet, so it is necessary to develop new methodologies and studies to understand its behaviour. Specifically, with the use of continuous welded rails, variations in rail temperature produce compression stresses that, under certain circumstances, can led to dangerous lateral track displacements and train derailment.

With that motivation, this $\mathrm{PhD}$ Thesis is focused on an appropriate theoretical framework for conducting a study that evaluates the potential risk of buckling in dual gauge tracks. To accomplish this task, different methods and techniques in order to improve the knowledge of this phenomenon and track design. This approach will allow us to establish track conditions and maintenance works that ensures the stability of the dual gauge track under thermal and train loads. In addition, a risk based methodology allows us to revise and redefine conventional track design methods in order to increase track stability under thermal loads. 


\section{PLANTEAMIENTO Y RESUMEN DE LA TESIS DOCTORAL}

La superestructura de vía clásica está compuesta por una serie de capas portantes en las que se sitúan las traviesas o losas de hormigón y sobre las cuales se disponen 2 carriles que permiten la circulación de los vehículos, en base a su utilización con un único ancho de vía. Debido a que los vehículos ferroviarios no pueden circular desde una línea con un ancho de vía a otra con un ancho diferente (solo es posible si la diferencia de ancho es muy reducida) el ancho de vía se establece generalmente como un único valor común para toda una determinada red, pues de lo contrario se crean una serie de "fronteras" entre las líneas con diferente ancho de vía, lo que provoca importantes problemas en la explotación y gestión de la red.

No obstante, existen situaciones especiales como la que se produce en España, donde las circunstancias y las nuevas necesidades de conexión e interoperabilidad han dado como resultado la construcción de tramos ferroviarios de doble ancho o ancho mixto. La característica fundamental de este tipo de vías es la dotación de un tercer carril, de tal forma que se parte de una vía de ancho ibérico $(1.668 \mathrm{~mm})$ sobre la que se dispone en su interior un tercer carril para conseguir el ancho estándar (1.435 mm).

Así pues, esta nueva configuración de vía supone una importante modificación respecto a la vía clásica de un ancho y 2 carriles. Además, el uso del tercer carril en tramos largos es totalmente novedosa, lo que obliga al estudio y análisis del comportamiento de esta nueva superestructura de vía. En especial, la vía debe resistir los esfuerzos longitudinales, pues el uso de la barra larga soldada genera esfuerzos térmicos en los carriles que pueden ocasionar, bajo unas ciertas condiciones de vía, la desestabilización y, como resultado, importantes deformaciones laterales con efectos muy perjudiciales.

Por ello, la presente tesis tiene por objeto el estudio teórico del riesgo de pandeo en vías de doble ancho mediante el uso de diferentes métodos y técnicas que permitan una mejor comprensión de este fenómeno y el diseño seguro de este tipo de vías. El análisis permitirá establecer las condiciones que aseguran el correcto funcionamiento de la superestructura de vía antes las diferentes solicitaciones que debe soportar. Además, el planteamiento de una metodología de evaluación del riesgo de pandeo en vías de doble ancho permitirá la revisión y reformulación de criterios de diseño, aplicables a vías existentes o de nueva construcción, según las oscilaciones térmicas a las que esté sometida. 


\section{PLANTEJAMENT Y RESUM DE LA TESIS DOCTORAL}

La superestructura de via tradicional està composta per una sèrie de capes portants en què se situen les travesses o lloses de formigó i sobre les que es disposen 2 carrils que permeten la circulació dels vehicles, segon l'ús d'un únic ample de via. Pel fet que els vehicles ferroviaris no poden circular des d'una línia amb un ample de via a una altra amb un ample diferent de la primera (només és possible si la diferència d'amples és molt reduïda), l'ample de via s'estableix generalment com un únic valor comú per a tota una determinada xarxa, ja que en cas contrari es generen una sèrie de "fronteres" entre línies amb diferent ample de via, el que produeix importants problemes tant en l'explotació com en la gestió de la xarxa.

No obstant això, existeixen situacions especials com la que es produeix a Espanya, on les circumstàncies i les noves necessitats de connexió i interoperabilitat han donat com a resultat la construcció de trams ferroviaris de doble ample o ample mixt. La característica fonamental d'aquest tipus de via d'ample mixt és la col·locació d'un tercer carril, de tal forma que partint d'una via d'ample ibèric $(1.668 \mathrm{~mm})$ es disposa a l'interior un tercer carril que permet aconseguir l'ample estàndard (1.435 mm).

Així, aquesta nova configuració de via suposa una important modificació respecte de la via clàssica d'un sol ample i 2 carrils. A més a més, l'ús del tercer carril en trams llargs és totalment nova, el que obliga a estudiar i analitzar el comportament d'aquesta nova estructura. En especial, la via ha de resistir els esforços longitudinals, degut a que l'ús del carril continu soldat genera càrregues d'origen tèrmic en els carrils que poden ocasionar, baix unes certes condicions de via, la desestabilització i, com a resultat, importants deformacions laterals amb efectes molt perjudicials.

Per açò, la present Tesi té com a objectiu l'estudi teòric del risc de pandeig en vies d'ample mixt (amb 3 carrils) a través de l'ús de diferents mètodes i tècniques tal que permeten un major coneixement d'aquest fenomen i el disseny segur d'aquest tipus de via. L'anàlisi permetrà establir les condiciones que asseguren el correcte funcionament de la superestructura de via enfront de les diferents càrregues que deu suportar. A més, el plantejament d'una metodologia d'avaluació del risc de pandeig en vies d'ample mixt permetrà la revisió i reformulació dels criteris de disseny, aplicables a vies existents o de nova construcció, d'acord amb les oscil-lacions tèrmiques a les quals estarà sotmesa. 


\section{APPROCCIO E SINTESI DELLA TESIS}

La sovrastruttura ferroviaria classica è costituita dagli strati di supporto e la massicciata su cui si appoggiano le traverse o una fondazione in calcestruzzo sopra la quale si dispongono le rotaie che consentono la circolazione di treni secondo un determinato scartamento. Poiché i veicoli ferroviari non possono passare da una linea a un'altra con scartamento diverso (è possibile soltanto se la differenza è piccola), questo parametro si stabilisce generalmente come un unico valore per tutta la rete ferroviaria, altrimenti si formano le cosiddette "frontiere" tra le diverse linee con scartamento diverso, generando importati problemi per la gestione e l'uso della rete.

Tuttavia, ci sono situazioni particolari come quella che si verifica in Spagna, dove le circostanze e le nuove connessioni e requisiti di interoperabilità hanno portato alla coesistenza di tratte ferroviarie con doppio scartamento. La caratteristica fondamentale di questo tipo di binario è la presenza di una terza rotaia, in modo che, a partire da un binario a scartamento iberico $(1.668 \mathrm{~mm})$, si installa una terza rotaia all'interno che consente anche il passaggio di treni a scartamento standard $(1.435 \mathrm{~mm})$.

Si tratta quindi di una soluzione che modifica sostanzialmente la struttura classica che ha soltanto due rotaie. Inoltre, l'uso di una terza rotaia in tratte di linee ferroviarie di lunghezza rilevante richiede lo studio e l'analisi del comportamento di questa nuova sovrastruttura. Specialmente, la via deve essere in grado di resistere a importanti sforzi longitudinali, dato che la lunga rotaia saldata genera tensioni interne dovute alle variazioni di temperatura nelle rotaie che, sotto determinate condizioni, possono comportare deformazioni laterali e indurre effetti avversi.

Pertanto, questa Tesi propone la valutazione teorica del rischio del "buckling" termico per un'infrastruttura ferroviaria a doppio scartamento, utilizzando metodi e tecniche differenti che permettono una migliore comprensione di questo fenomeno e un miglior disegno della sovrastruttura. L'analisi stabilirà le condizioni per garantire il corretto funzionamento della sovrastruttura tenendo conto delle sollecitazioni previste. Inoltre, l'uso di una metodologia per il calcolo del rischio di instabilità in linee a doppio scartamento permetterà una migliore la revisione e riformulazione dei criteri di progettazione applicabili alle linee esistenti o di nuova costruzione, in base agli sforzi termici ai quali saranno sottoposte. 


\section{AGRADECIMIENTOS}

Tras el largo, complejo y duro camino que supone llevar a cabo una tesis doctoral, es momento de agradecer a todas aquellas personas que, de una u otra forma, han ayudado a que este trabajo haya sido posible y que el tren llegue, finalmente, a su destino.

En primer lugar, quería agradecer la ayuda y dedicación proporcionada por mi tutor, el Dr. Ricardo Insa, así como por haberme dado la oportunidad recorrer este camino que culmina una etapa importante de mi aprendizaje científico y personal. Sin su colaboración, es evidente que no habría sido posible completar este camino.

Mi mayor gratitud a mi familia, pues su actitud frente a los estudios ha sido clave en mi formación. En especial a mi madre y cómo no, a mi padre, pues él estaba muy orgulloso de lo que había conseguido y, con este trabajo, su satisfacción será mayor. Tampoco puedo dejar de agradecer el apoyo de una gran persona y compañera de viaje, pues su paciencia y confianza ha sido un soporte fundamental durante este trabajo. Su apoyo irracional tanto en los buenos como en los malos momentos no puede cuantificarse en ninguna fórmula matemática. El haber realizado y completado esta Tesis se debe a ella. Gracias Victoria!

También quiero agradecer la paciencia y apoyo que han mostrado todos mis compañeros de trabajo durante estos años. En especial destacar a Pablo Salvador, Pablo Martínez, Carla García y Rafael Sanchez, pues el GIIF es un grupo especial gracias a todos ellos. No quiero olvidarme de Rosa, pues sin formar parte del grupo ferroviario, ha sido la que en mayor grado ha debido soportarme en el departamento $\odot$. . También extiendo mi agradecimiento a aquellos compañeros y profesores que durante este período han compartido algún momento en el departamento (Sebastián, Roser, Jaime, José Vicente, Pedro y Tomás) así como a Michela, quien en la lejanía siciliana ha estado presente en varias etapas del doctorado, así como en Roma. No quiero olvidarme de otros amigos que, no por su corta estancia, han sido menos importantes como Juan Diego, Iñaqui y Javi. Extender mi agradecimiento a los compañeros de puertos, cuyos almuerzos han servido especialmente para recargar las pilas ante el trabajo diario.

No posso finire senza ringraziare tutti quegli amici e compagni di Roma. In primo luogo, grazie ad Agnese per la sua accoglienza. Un grazie particolare anche a tutti gli amici della Sapienza (Stefano, Eros, Daniele, Agnese, Jelly e tanti altri). Finalmente, ringrazio ai professori Ricci, Malavasi, Rizzetto, Brunner, Antognoli, e gli altri compagni del DITS. 
Senza il loro supporto, la mia stanza a Roma non sarebbe stata così soddisfacente. Mi sono sentito come a casa. Grazie ragazzi!

Finalmente, mi más sincero agradecimiento para los que, en algún modo, siempre han creído en mí.

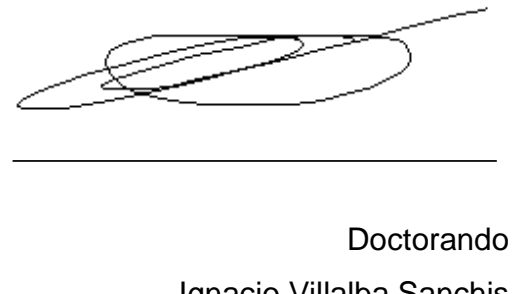

Ignacio Villalba Sanchis 


\section{ÍNDICE}

EXPOSITION AND SUMMARY OF DOCTORAL THESIS

LISTADO DE TABLAS

LISTA DE ABREVIATURAS Y SÍMBOLOS.

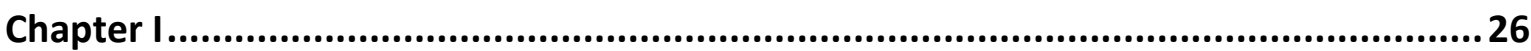

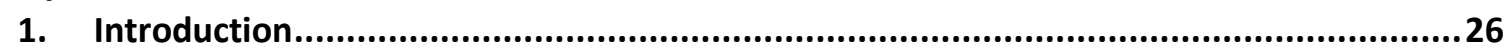

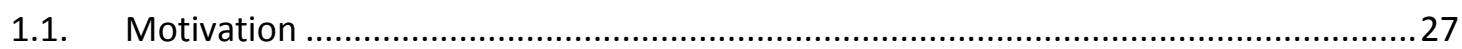

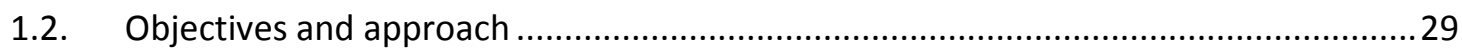

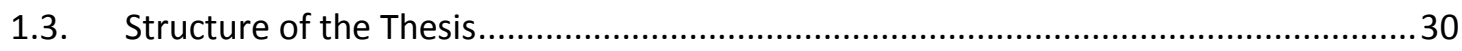

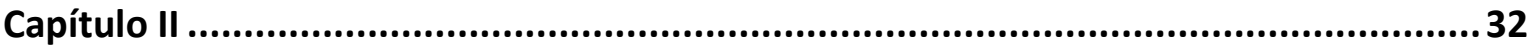

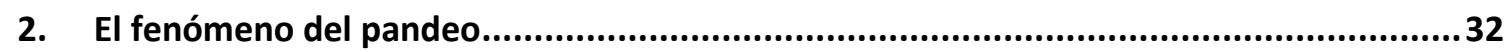

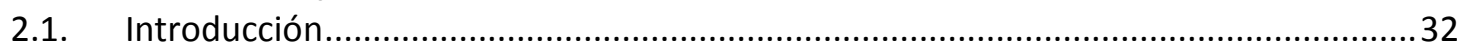

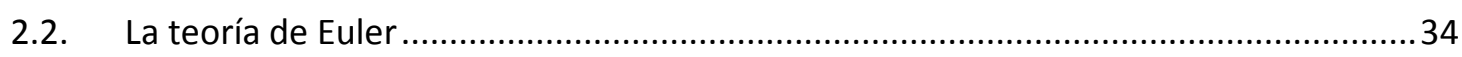

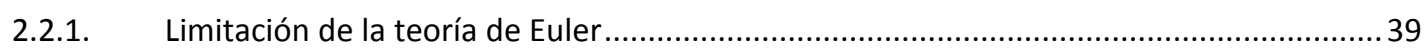

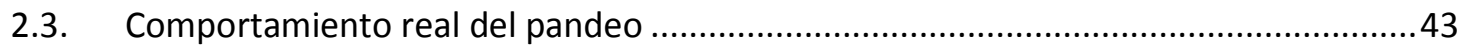

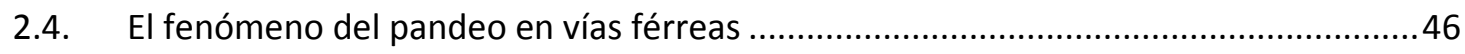

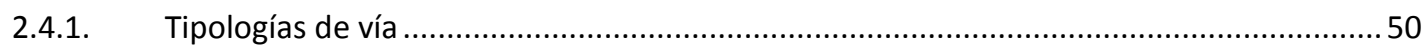

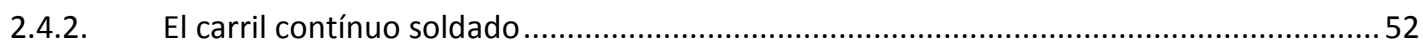

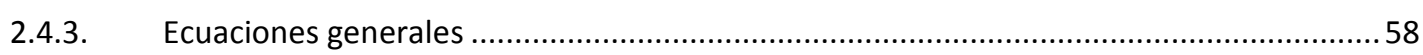

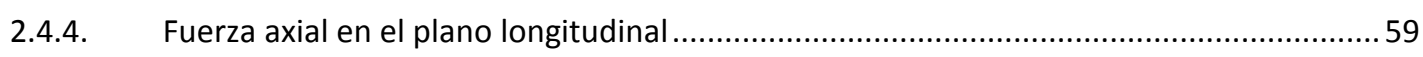

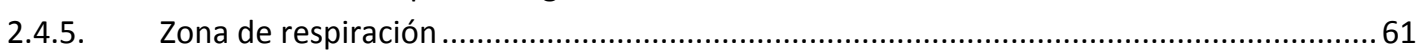

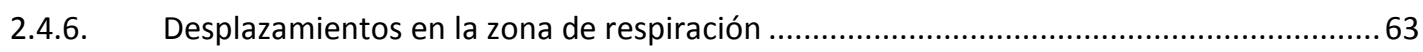

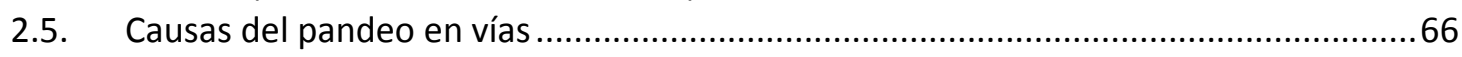

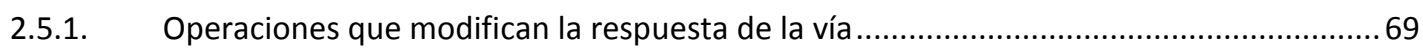

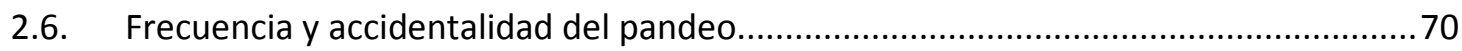

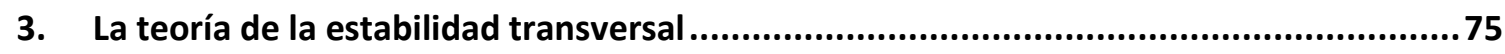

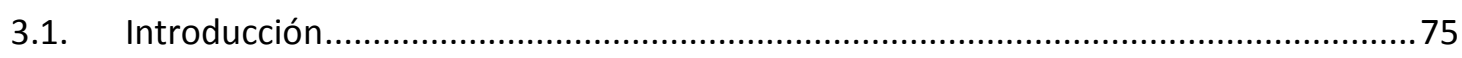

3.2. Vía sin defectos de alienación. Carga teórica de pandeo ………….............................. 78

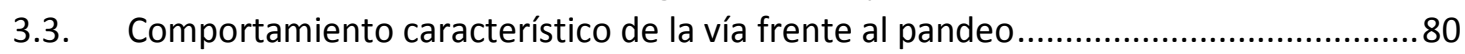

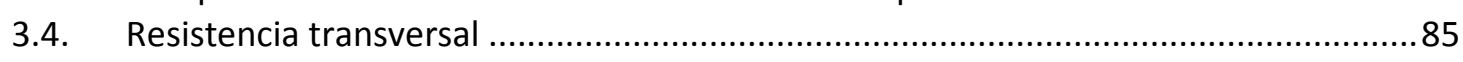

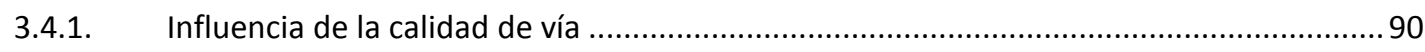

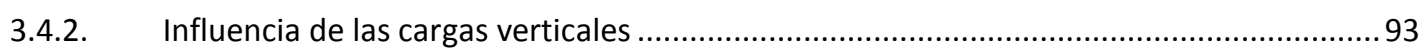

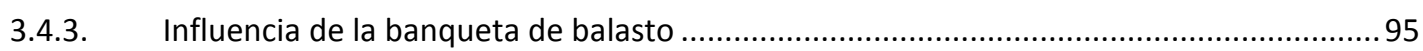

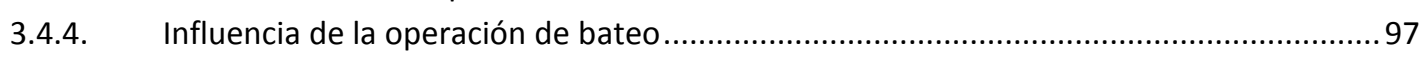

3.4.5. Influencia del tipo de traviesas ................................................................................... 99 
3.4.6. Influencia del coeficiente de rozamiento traviesa-balasto ........................................ 101

3.5. Metodologías para la evaluación de la resistencia transversal ...............................102

4. Estudios previos y modelización del pandeo de vía ............................................ 105

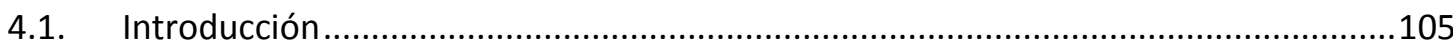

4.2. Modelos para la determinación de la carga de pandeo .......................................107

4.3. Software para el cálculo del pandeo...............................................................115

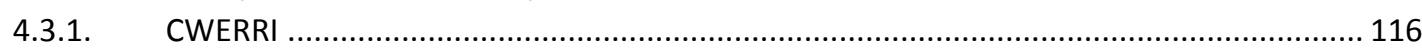

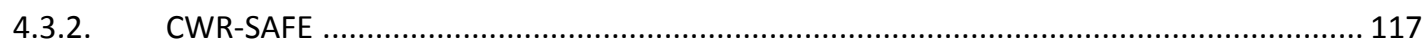

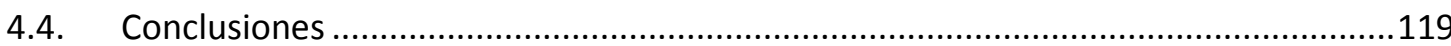

Capítulo III .................................................................................................... 122

5. La vía de doble ancho................................................................................ 122

5.1. Introducción.............................................................................................. 122

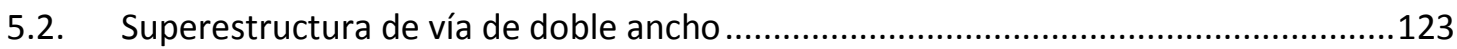

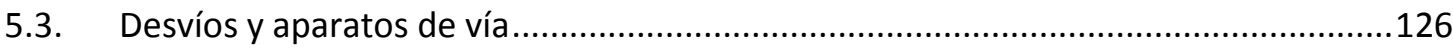

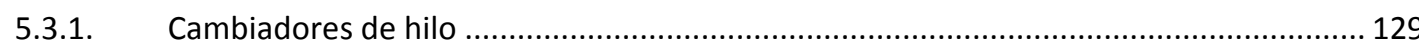

Capítulo IV .......................................................................................... 131

6. Modelo analítico........................................................................................ 131

6.1. Descripción del modelo ...........................................................................131

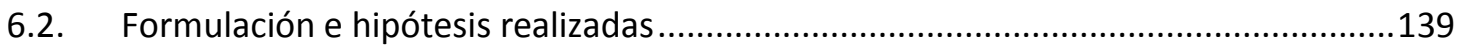

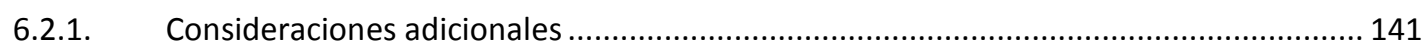

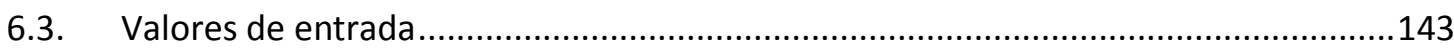

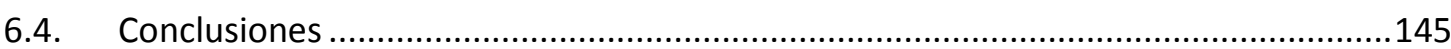

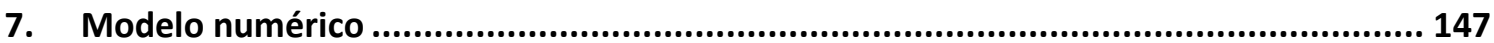

7.1. Descripción del modelo .................................................................... 148

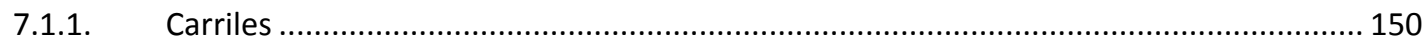

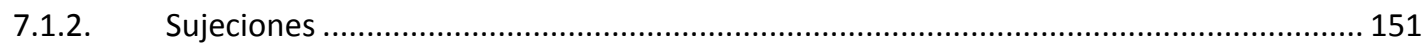

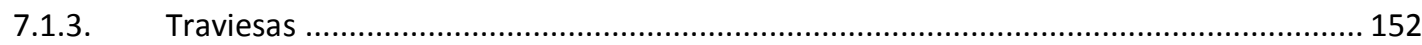

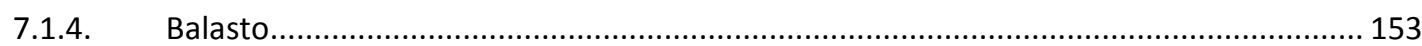

7.2. Metodología e hipótesis consideradas ................................................................. 154

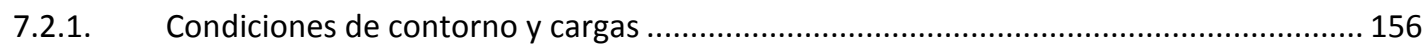

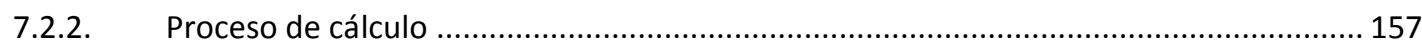

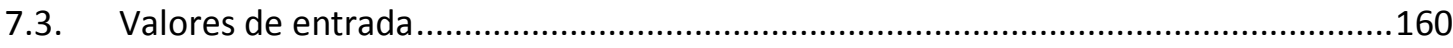

7.4. Conclusiones .......................................................................................... 162

Capítulo V ....................................................................................................163

8. Estudio de resultados y riesgo de pandeo ....................................................... 163

8.1. Metodología de estudio y variables estudiadas ...................................................164

8.2. Análisis del pandeo en función de la resistencia lateral ..........................................167

8.2.1. Variación del tipo de carril .................................................................................... 168

8.2.2. Variación del tipo de traviesa ..................................................................................... 170

8.2.3. Variación de tipo de defecto ............................................................................... 173 


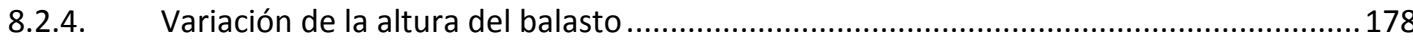

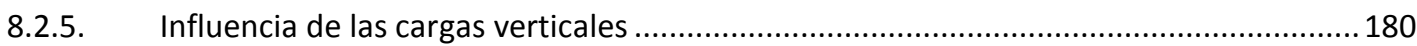

8.3. Análisis del pandeo en función de la amplitud del defecto....................................182

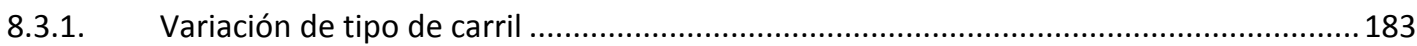

8.3.2. Variación tipo de traviesa.................................................................................... 185

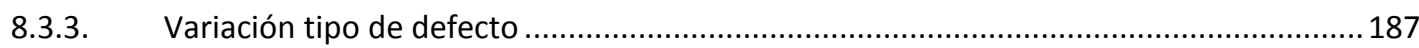

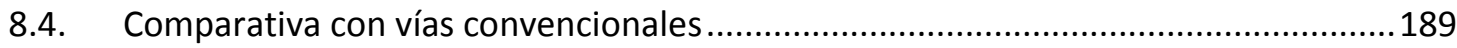

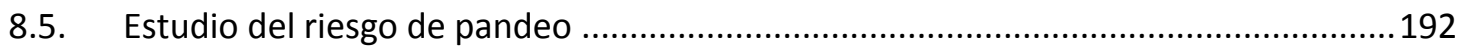

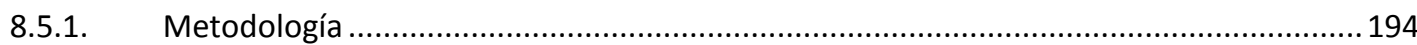

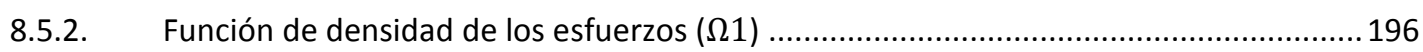

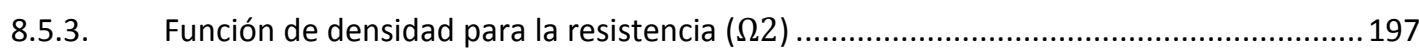

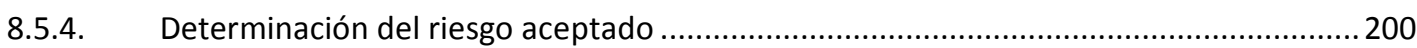

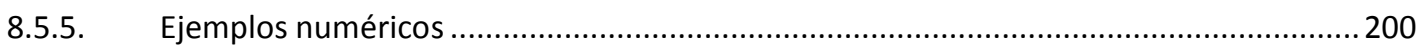

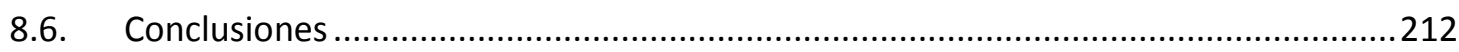

Capítulo VI ...........................................................................................218

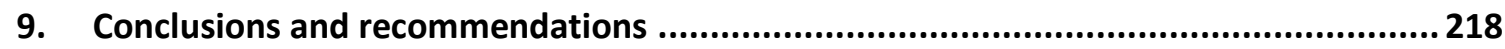

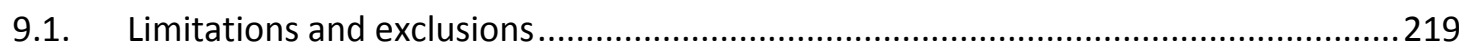

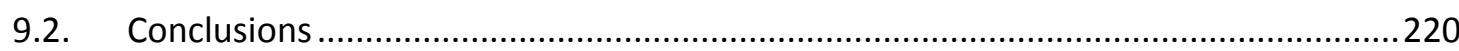

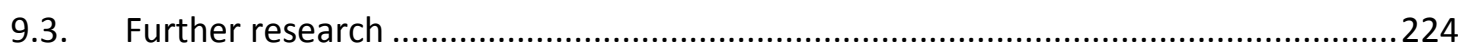

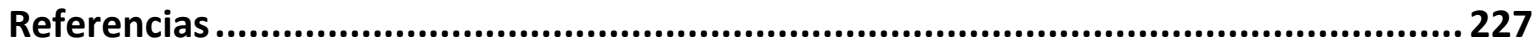

Anexo I. Artículos publicados en relación con la Tesis ............................................. 234

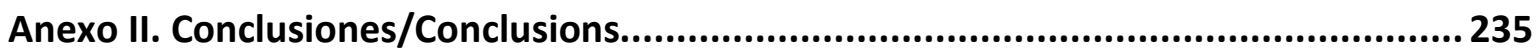




\section{LISTADO DE FIGURAS}

Figura 2.1: Representación esquemática del pandeo en un elemento esbelto. Fuente: Elaboración propia. . 33 Figura 2.2: Representación de la columna ideal de Euler. Fuente: Elaboración propia................................. 35 Figura 2.3: Representación de comportamiento de pandeo. a) Comportamiento ideal (Euler). b) Comportamiento no lineal del pandeo. Fuente: Elaboración propia......................................................... 40 Figura 2.4: Representación de la validez de la teoría de Euler. Fuente: Elaboración propia.......................... 41 Figura 2.5: Representación de la teoría de Engesser. Fuente: Elaboración propia...................................... 41 Figura 2.6: Curvas de pandeo en función del coeficiente de imperfección ( $a$ o, $a, b$ c y d). Fuente: Instrucción

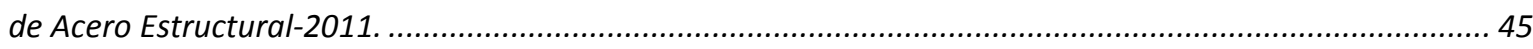
Figura 2.7: Representación del pandeo. Fuente: Modern Rail Track, Esveld, C. (2001)................................. 46 Figura 2.8: Imágenes de pandeo de vía. Fuente: Volpe National Transportation Systems Center. Track buckling research, research and innovative technology administration. Washington: U.S. Department of Transportation, 2003.

Figura 2.9: Imágenes de pandeo de vía. Fuente: Transportation Safety Board of Canada.......................... 48 Figura 2.10: Imágenes de pandeo de vía, a) Pandeo con pequeño desplazamiento lateral, b) Pandeo con gran desplazamiento lateral. Fuente: Manual integral de vía, Nuevo Central Argentino, 2014. Figura 2.11: Desplazamiento senoidal representativo del pandeo en tramos rectos. Fuente: Elaboración propia...

Figura 2.12: Desplazamiento en forma de " $\mathrm{C}$ " representativo del pandeo en tramos curvos. Fuente:

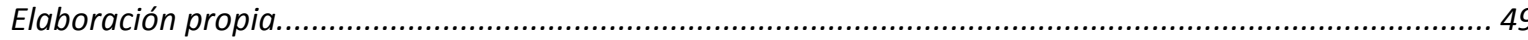

Figura 2.13: Representación del movimiento de los carriles en la cala. Fuente: Elaboración propia..............50 Figura 2.14: Esquema representativo del efecto de la temperatura sobre carril continúo soldado. Fuente: Elaboración propia.

Figura 2.15: Esquema de vías con juntas (arriba) y con carril continuo soldado (abajo). Fuente: Elaboración

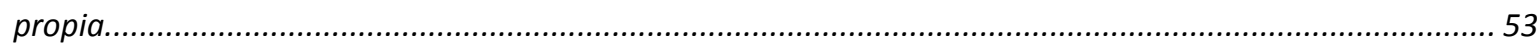

Figura 2.16: Soldadura aluminotérmica de carriles. Fuente: Metro Madrid. ............................................5 53 Figura 2.17: Imágenes de carriles. Soldadura (izquierda), junta embridada (derecha). Fuente: Elaboración

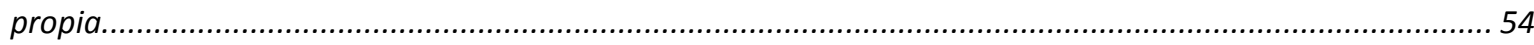

Figura 2.18: Representación de la temperatura de neutralización. Fuente: Elaboración propia. ....................56

Figura 2.19: Calentamiento de carriles artificial. Fuente: Volker Rail.........................................................5 57

Figura 2.20: Tensor para neutralización de tensiones. Fuente: FCS Railway equipment...............................5 57

Figura 2.21: Esquema de segmento de carril aislado. Fuente: Elaboración propia........................................ 58

Figura 2.22: Representación de los esfuerzos y deformaciones en el carril. Fuente: Elaboración propia........ 60

Figura 2.23: Esquema de tensiones en carril continúo soldado. Fuente: Elaboración propia......................... 62

Figura 2.24: Ley de esfuerzos en carril continúo soldado. Fuente: Elaboración propia................................. 63

Figura 2.25: Área resultante de la ley de esfuerzos en el carril. Fuente: Elaboración propia......................... 64

Figura 2.26: Valores del desplazamiento máximo del carril en los extremos. Fuente: Elaboración propia..... 65

Figura 2.27: Esquema de factores que condicionan el pandeo. Fuente: Elaboración propia. .........................67

Figura 2.28: Medida de temperaturas en carriles. Fuente: Elaboración propia...........................................6.6.

Figura 2.29: Esquema de factores que condicionan el pandeo. Fuente: Elaboración propia. .........................68 68

Figura 2.30: Causas principales de incidentes ferroviarios y numero de eventos registrados. Fuente: Railway safety performance in the European Union (2016), European Railway Agency (ERA). ............................... 71

Figura 2.31: Número de incidentes debidos a defectos de vía. Fuente: European Railway Agency (ERA). ..... 72

Figura 2.32: Número de incidentes debidos a defectos de vía. Fuente: European Railway Agency (ERA). ..... 73 Figura 2.33: Número de incidentes debidos a defectos de vía en España y temperatura media de verano. Fuente: European Railway Agency (ERA). 
Figura 3.1: Resistencias en el plano de vía. Fuente: Elaboración propia.

Figura 3.2: Niveles de resistencia longitudinal y transversal en la vía. Fuente: Elaboración propia................ 77

Figura 3.3: Vista de vía sin defectos de alineación. Fuente: Elaboración propia. ........................................... 78

Figura 3.4: Esquema de esfuerzos en elemento diferencial de vía. Fuente: Elaboración propia. .................... 78

Figura 3.5: Vista de vía con defectos de alineación. Fuente: Elaboración propia...........................................81

Figura 3.6: Representación del comportamiento frente a pandeo. Fuente: Elaboración propia.................... 82

Figura 3.7: Representación del comportamiento frente a pandeo. Fuente: Elaboración propia..................... 83

Figura 3.8: Representación del comportamiento frente a pandeo. Fuente: Elaboración propia.....................84

Figura 3.9: Zonas de riesgo de pandeo. Fuente: Elaboración propia. ........................................................85

Figura 3.10: Resistencia transversal en función de la calidad de vía. Fuente: Elaboración propia...................88

Figura 3.11: Idealización del comportamiento de la vía. Fuente: Elaboración propia.....................................88

Figura 3.12: Relación entre la resistencia transversal (izquierda) y la curva de pandeo (derecha). Fuente:

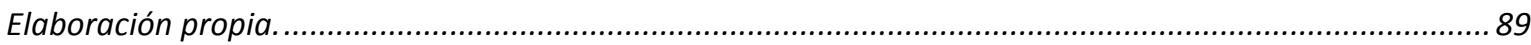

Figura 3.13: Componentes de la resistencia transversal. Fuente: Elaboración propia. .................................90

Figura 3.14: Comportamiento frente al pandeo en función de la calidad de vía y resistencia lateral. Fuente:

Elaboración propia.

Figura 3.15: Onda de levante debido a cargas verticales. Fuente: Lim, W.H.(2004). Mechanics of Railway Ballast Behaviour.

Figura 3.16: Influencia de la carga vertical en la resistencia transversal. Fuente: Elaboración propia. ..........94

Figura 3.17: Esquema de la hombrera de balasto. Fuente: Elaboración propia. ............................................ 95

Figura 3.18: Influencia de la hombrera de balasto en la resistencia transversal. Fuente: Recuperado de Le

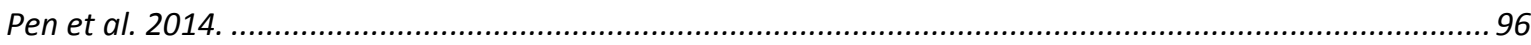

Figura 3.19: Influencia del bateo en la resistencia transversal. Fuente: Elaboración propia...........................98

Figura 3.20: Influencia del bateo en la resistencia transversal. Fuente: Recuperado de Kish et al. 2003........98

Figura 3.21: Tipo de traviesa y resistencia transversal. Fuente: Elaboración propia..................................... 100

Figura 3.22: Elementos de anclaje en traviesas. Fuente: De lorio, Pucillo \& Alii, (2014). ............................. 100

Figura 3.23: Resistencia transversal pico frente a carga vertical. Fuente: Recuperado de Zand y Moraal,

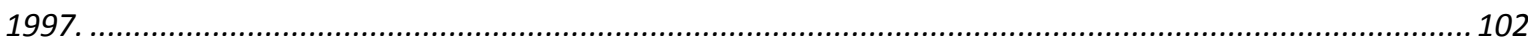

Figura 3.24: Resistencia transversal pico y tipo de vía. Fuente: Elaboración propia..................................102

Figura 3.25: Ensayo STPT. Fuente: Recuperado de Kish, On the Fundamentals of Track Lateral Resistance,

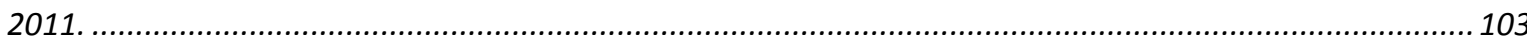

Figura 4.1: Esquemas de modelos de vía. Fuente: Eddy Current Brake Compatibility Project....................... 106

Figura 4.2: Esquemas de modelos de vía. Fuente: Elaboración propia......................................................108

Figura 4.3: Cronograma con las principales contribuciones científicas en el campo del pandeo de vía. Fuente:

Elaboración propia............................................................................................................................ 115

Figura 4.4: Salida de datos del módulo CWR-BUCKLE. Fuente: Track Buckling Prevention: Theory, Safety

Concepts, and Applications (FRA, 2013). ......................................................................................... 118

Figura 4.5: Distribución estadística para la resistencia lateral considerada en CWR-RISK. Fuente: Track Buckling Prevention: Theory, Safety Concepts, and Applications (FRA, 2013).

Figura 5.1: Imágenes de las diferentes tipologías de vías de doble ancho. Fuente: Elaboración propia a partir

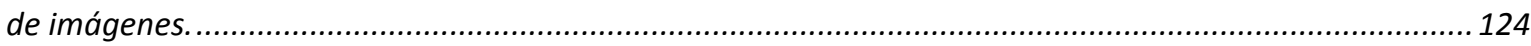

Figura 5.2: Elementos de una vía de doble ancho. Fuente: Elaboración propia. ....................................... 125

Figura 5.3: Detalle de zona que aloja los dos carriles, para traviesa AM-05 Fuente: Antrasa S.A................ 125

Figura 5.4: Imágenes de desvíos de 3 carriles. Fuente: Vossloh Cogifer Australia...................................... 126 
Figura 5.5: Imágenes de desvío en vía de 3 carriles, para el ancho ibérico, sobre el lado de los 2 carriles.

Fuente: ADIF.

Figura 5.6: Esquema de cambiador de hilo. Fuente: Elaboración propia. .................................................. 129

Figura 5.7: Imágen de cambiador de hilo. Fuente: Vossloh Cogifer Australia. ........................................... 130

Figura 5.8: Imagen de desvío y cambiador de hilo. Fuente: ADIF........................................................ 130

Figura 6.1: Esquema de la divergencia del equilibrio. Fuente: Elaboración propia.................................... 132

Figura 6.2: Forma de los defectos considerados. Fuente: Elaboración propia.............................................. 133

Figura 6.3: Forma de los defectos considerados. Fuente: Elaboración propia............................................ 133

Figura 6.4: Elemento diferencial de vía. Fuente: Elaboración propia. .......................................................... 136

Figura 6.5: Esquema para la resistencia lateral considerada, en el modelo analítico. Fuente: Elaboración

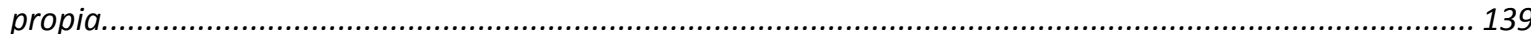

Figura 6.6: Comparativa de expresiones, para media senoide. Fuente: Elaboración propia....................... 142

Figura 6.7: Comparativa de expresiones, para un ejemplo con senoide. Fuente: Elaboración propia. ......... 143

Figura 7.1: Vista esquemática del modelo considerado. Fuente: Elaboración propia..................................149

Figura 7.2: Vista de elementos utilizados. a) BEAM b) SOLID c) COMIBN. Fuente: Manual Ansys................ 149

Figura 7.3: Vista de carril real y modelos utilizados. Fuente: Villalba et al. (2017).................................... 151

Figura 7.4: Vista real y esquema representativo de la sujeción. Fuente: Elaboración propia. ....................... 152

Figura 7.5: Vista y esquema representativo de la traviesa AM-05. Fuente: Elaboración propia................... 152

Figura 7.6: Esquema representativo del modelo numérico. Fuente: Elaboración propia............................. 153

Figura 7.7: Vista general del modelo numérico. Fuente: Elaboración propia.............................................. 154

Figura 7.8: Comportamiento lateral del balasto. Fuente: Elaboración propia. ........................................... 156

Figura 7.9: Representación de convergencia en el método Newton-Raphson. Fuente: Elaboración propia. 158

Figura 7.10: Ejemplo de divergencia en el método Newton-Raphson. Fuente: Elaboración propia............... 158

Figura 7.11: Ejemplo de convergencia en el método Arc-length. Fuente: Elaboración propia. ..................... 159

Figura 7.12: Ejemplo de curva temperatura-desplazamiento, para el cálculo de pandeo. Fuente: Elaboración propia.

Figura 8.1: Temperatura de pandeo según el tipo de carril y de la resistencia lateral. Fuente: Elaboración propia.

Figura 8.2: Temperatura de pandeo según el tipo de carril y de la resistencia lateral. Fuente: Elaboración propia.

Figura 8.3: Resistencia lateral, para cada uno de los tipo de traviesa considerados. Fuente: Elaboración propia.

Figura 8.4: Temperatura de pandeo según el tipo de traviesa y dl coeficiente de empuje al reposo k0. Fuente: Elaboración propia.

Figura 8.5: Temperatura de pandeo según el tipo de defecto y de la resistencia lateral. Fuente: Elaboración propia.

Figura 8.6: Imagen de vía con 3 carriles, representativa de la asimetría. Fuente: Elaboración propia......... 174

Figura 8.7: Esquemas representativos del tipo de defecto considerado. Fuente: Elaboración propia. .......... 175 Figura 8.8: Vista del modelo numérico de 3 carriles con el defecto inicial, en cada caso (escala 50:1). Fuente: Elaboración propia

Figura 8.9: Temperatura de pandeo en función del lado del defecto, según la resistencia transversal. Fuente: Elaboración propia. 
Figura 8.10: Resistencia lateral resultante, según la altura de la capa de balasto sobre la base de la traviesa.

Fuente: Elaboración propia.

Figura 8.11: Temperatura de pandeo en función de la altura de la capa de balasto. Fuente: Elaboración propia.

Figura 8.12: Temperatura de pandeo en función de la carga vertical aplicada (modelo analítico). Fuente:

Elaboración propia.

Figura 8.13: Temperatura de pandeo en función de la carga vertical aplicada (modelo numérico). Fuente: Elaboración propia.

Figura 8.14: Temperatura de pandeo en función del tipo de carril (modelo analítico). Fuente: Elaboración propia..

Figura 8.15: Temperatura de pandeo en función del tipo de carril (modelo numérico). Fuente: Elaboración propia. .

Figura 8.16: Temperatura de pandeo según el tipo de traviesa y de la amplitud del defecto. Fuente:

Elaboración propia.

Figura 8.17: Temperatura de pandeo según el tipo de traviesa y de la amplitud del defecto. Fuente:

Elaboración propia. 186

Figura 8.18 Temperatura de pandeo en función del tipo y de la amplitud del defecto. Fuente: Elaboración propia......

Figura 8.19: Temperatura de pandeo en función del lado del defecto, según la amplitud. Fuente: Elaboración propia.

Figura 8.20: Comparativa de temperaturas de pandeo para vías de 2 y 3 carriles, en función de la resistencia transversal. Fuente: Elaboración propia.

Figura 8.21: Comparativa de temperaturas de pandeo para vías de 2 y 3 carriles, en función del defecto, para diversos modelos. Fuente: Elaboración propia.

Figura 8.22: Esquema de distribución y zona de interferencia. Fuente: Elaboración propia..........................194

Figura 8.23: Ejemplo de distribución de densidad para la carga. Fuente: Elaboración propia........................ 197

Figura 8.24: Ejemplo de distribución de resistencia lateral. Fuente: Elaboración propia. ............................. 198

Figura 8.25: Valores máximos pico permitidos, según calidad de vía. Fuente: UIC-518............................... 199

Figura 8.26: Ejemplo de distribución de defectos de alineación. Fuente: Elaboración propia.......................199

Figura 8.27: Ejemplo de curva de probabilidad de pandeo. Fuente: Elaboración propia. .............................200

Figura 8.28: Distribuciones según las variables, para el caso 1. Fuente: Elaboración propia........................ 202

Figura 8.29: Probabilidad de pandeo, en función de la temperatura de los carriles, para el caso 1. Fuente:

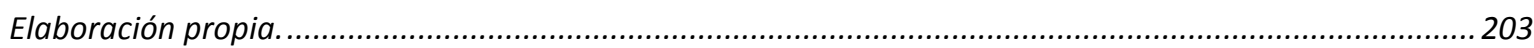

Figura 8.30: Distribuciones según las variables, para el caso 2. Fuente: Elaboración propia.........................204

Figura 8.31: Probabilidad de pandeo, en función de la temperatura de los carriles, para el caso 2. Fuente:

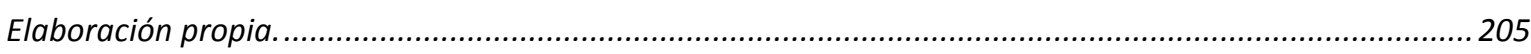

Figura 8.32: Distribuciones para el caso 3. Fuente: Elaboración propia. ....................................................... 206

Figura 8.33: Probabilidad de pandeo, en función de la temperatura de los carriles, para el caso 3. Fuente:

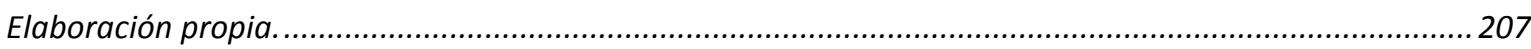

Figura 8.34: Distribuciones para el caso 4. Fuente: Elaboración propia. ..................................................208

Figura 8.35: Probabilidad de pandeo, en función de la temperatura de los carriles, para el caso 4. Fuente:

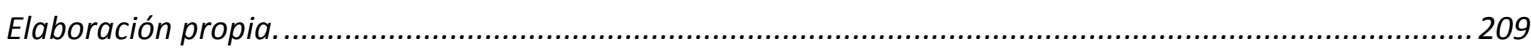

Figura 8.36: Probabilidad de fallo, para todos los casos de estudio. Fuente: Elaboración propia.................211 


\section{LISTADO DE TABLAS}

Tabla 2.1: Expresiones de la carga crítica de pandeo (carga de Euler), en función de las condiciones de contorno. Fuente: Elaboración propia.

Tabla 2.2: Expresiones de la carga crítica de pandeo, en función del campo de aplicación. Fuente:

Elaboración propia.

Tabla 2.3: Valores de la apertura de calas, en función de la temperatura. Fuente: N.R.V. 3-3-0.0. Junta de carriles, Bridas y tornillos de brida (Renfe).

Tabla 2.4: Valores del esfuerzo generado en los carriles ( $\mathrm{kN} /$ carril), en función del incremento de temperatura. Fuente: Elaboración propia.

Tabla 2.5: Expresiones de la carga crítica de pandeo, en función del campo de aplicación. Fuente:

Elaboración propia

Tabla 3.1: Factores que condicionan la resistencia transversal. Fuente: Lichtberger, B: Manual de vía, Hamburg, Eurailpress (2011).

Tabla 3.2: Efecto de las componentes de la resistencia transversal. Fuente: Elaboración propia a partir de Zakeri and Bakhtiary (2014).

Tabla 5.1: Nomenclatura de desvíos de 3 carriles. Fuente: Elaboración propia.

Tabla 5.2: Nomenclatura de desvíos de 3 carriles. Fuente: ADIF.

Tabla 5.3: Esquemas de desvíos de 3 carriles. Fuente: Elaboración propia.

Tabla 6.1: Valores de los diferentes factores considerados. Fuente: Elaboración propia 144

Tabla 7.1: Comportamiento del balasto considerado, para cada dirección. Fuente: Elaboración propia..... 156

Tabla 7.2: Condiciones de contorno para el modelo numérico. Fuente: Elaboración propia. 157

Tabla 7.3: Variables y valores utilizados en el modelo numérico. Fuente: Elaboración propia. 161

Tabla 8.1: Condiciones de referencia utilizadas en el cálculo, en función de la resistencia lateral. Fuente: Elaboración propia

Tabla 8.2: Condiciones de referencia utilizadas en el cálculo, en función de la amplitud del defecto. Fuente:

Elaboración propia

Tabla 8.3: Valores de referencia utilizados en el cálculo, para vías de 2 y 3 carriles. Fuente: Elaboración

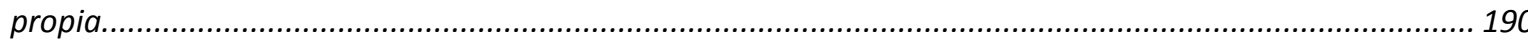

Tabla 8.4: Distribuciones utilizadas en cada caso. Fuente: Elaboración propia. ........................................ 201

Tabla 8.5: Valores de temperatura de pandeo asociados a cada caso y probabilidad de fallo. Fuente: Elaboración propia.

Tabla 8.6: Propuesta de actividades para reducir el riesgo de pandeo. Fuente: Elaboración propia. 


\section{LISTA DE ABREVIATURAS Y SÍMBOLOS}

CWR Continuous Welded Rail

EC European Community

ERRI European Rail Research Institute

EHE Instrucción de Hormigón Estructural

EAE Instrucción de Acero Estructural

ERA European Railway Agency

QR Queensland Rail

FRA Federal Railroad Administration

ETI Especificación Técnica de Interoperabilidad

CCS Carril Continuo Soldado

MEF Método de los Elementos Finitos
$A \quad$ Área de la sección transversal
E Módulo de elasticidad o módulo de Young
$E_{t} \quad$ Módulo de elasticidad tangente o reducido
M Momento flector
I Momento de inercia
$I_{1} \quad$ Momento de inercia de la zona traccionada
$I_{2} \quad$ Momento de inercia de la zona comprimida
$I_{h} \quad$ Momento de inercia respecto del plano horizontal
W Módulo resistente a compresión
d Deformación
$\mathrm{P}_{\text {crit }} \quad$ Carga crítica de Euler
$\sigma_{\text {crit }} \quad$ Tensión crítica de Euler
$k \quad$ Factor de longitud
$S_{k} \quad$ Longitud de pandeo
$\lambda \quad$ Esbeltez mecánica
$\lambda_{p} \quad$ Esbeltez límite de la validez de la teoría de Euler
$\sigma_{\text {limite }}$ Tensión crítica límite de la validez de la teoría de Euler
$\sigma_{p} \quad$ Tensión de proporcionalidad
$\sigma_{f} \quad$ Tensión de fluencia
$\sigma_{\text {res }} \quad$ Tensión residual
$T$ Módulo plástico de pandeo de Von Karman o Engesser-Karman. 
$k_{1} \quad$ Coeficiente de amplificación de la tensión de Euler

$\chi \quad$ Coeficiente de reducción de pandeo

$f_{y d} \quad$ Resistencia de cálculo

$\alpha \quad$ Coeficiente de imperfecciones

$\gamma_{M 1} \quad$ Coeficiente parcial de resistencia frente a la inestabilidad

$\Delta L \quad$ Variación de longitud

$\Delta T \quad$ Variación de temperatura

$\Delta T_{\min }$ Incremento de temperatura mínima de pandeo

$\Delta T_{\max }$ Incremento de temperatura máxima de pandeo

$\alpha_{T} \quad$ Coeficiente de dilatación térmica

$L \quad$ Longitud

$d l \quad$ Diferencial de longitud

$T_{\max }$ Temperatura máxima del carril

$T_{\min } \quad$ Temperatura mínima del carril

$T_{\text {ambiental }}$ Temperatura ambiental

$t_{n} \quad$ Temperatura de neutralización

$t_{0} \quad$ Temperatura inicial

$t_{c p} \quad$ Temperatura crítica de pandeo

$K_{x} \quad$ Factor de proporcionalidad de la resistencia al desplazamiento

$X \quad$ Longitud de la zona de respiración

$\delta \quad$ Alargamiento de los carriles

$\zeta \quad$ Acortamiento de los carriles

$r \quad$ Resistencia longitudinal de la vía

X Zona de respiración

$\delta_{R_{1}} \quad$ Desplazamiento longitudinal de un punto de la zona de respiración

$\delta_{\max }$ Desplazamiento del punto extremo de la zona de respiración

$F \quad$ Esfuerzo axial de origen térmico

C Esfuerzos contenidos en el plano de la vía

$\tau \quad$ Reacción, por unidad de longitud, del balasto

R Momento, por unidad longitud, debido a la unión carril-traviesa

$\alpha_{\text {giro }} \quad$ Giro entre carril y traviesa

$\Gamma \quad$ Constante de proporcionalidad entre giro y momento de la sujeción 
$\Psi \quad$ Constante de proporcionalidad entre desplazamiento y reacción del balasto

K Constante de integración

$F_{\text {critico }}$ Esfuerzo crítico de pandeo

$\mathrm{R}_{\text {pico }}$ Resistencia lateral máxima

$\mathrm{R}_{\text {limite }}$ Resistencia lateral residual o límite

$\delta_{0} \quad$ Amplitud del defecto inicial de alineación

$L_{0} \quad$ Mitad de la longitud del defecto inicial de alineación

$\varpi_{B} \quad$ Amplitud del defecto de vía

$\varpi_{C} \quad$ Amplitud crítica del defecto de vía

$\mu \quad$ Coeficiente de fricción traviesa-balasto

$\xi \quad$ Constante de proporcionalidad entre esfuerzos y desplazamientos laterales

P Esfuerzo axial

$f_{0} \quad$ Amplitud del defecto de vía

$L_{\text {def }} \quad$ Longitud onda del defecto de vía

$V(y)$ Energía potencial total de un sistema elástico

$U(y)$ Energía potencial de los esfuerzos internos, en un sistema elástico

$\Omega(y) \quad$ Energía potencial de las fuerzas externas, en un sistema elástico

$U_{\text {flexion }}$ Energía de deformación por flexión

$U_{\text {balasto }}$ Energía de deformación en el balasto

y Posición de la vía respecto del plano horizontal

$\varphi_{\text {base }}$ Resistencia por la base de la traviesa

$\varphi_{\text {laterales }}$ Resistencia debida al rozamiento lateral de la traviesa

$\varphi_{\text {punta }}$ Resistencia debida a la punta de la traviesa

$h \quad$ Altura de la banqueta de balasto sobre la base de la traviesa

$K_{0} \quad$ Coeficiente de empuje al reposo del balasto

$K_{p} \quad$ Coeficiente de empuje pasivo del balasto

$\gamma^{\prime} \quad$ Peso específico del balasto

a Longitud de la traviesa

$b \quad$ Ancho de la traviesa

$c^{\prime} \quad$ Cohesión del balasto

$L_{\text {zimm }}$ Longitud elástica

c $\quad$ Rigidez elástica, por metro lineal

$R_{\text {carga }}$ Resistencia lateral bajo cargas verticales 


\section{RESEARCH PUBLICATIONS}

\section{Journal Papers}

A. NavarRo, I. Villalba, I. Martínez, P \& InSA, R. (2015). "Analytical model for predicting the buckling load of continuous welded rail tracks" Proceedings of the Institution of Mechanical Engineers, Part F: Journal of Rail and Rapid Transit; Vol. 229 (5), pp: 542-552 (10.1177/0954409713518039)

B. Villalba, I. InSA, R. Salvador, P. \& Martínez, P. (2017). "Methodology for evaluating thermal track buckling in dual gauge tracks with continuous welded rail". Proceedings of the Institution of Mechanical Engineers Part F Journal of Rail and Rapid Transit; Vol. 231 (3), pp: 269-279 (doi:10.1177/0954409715626957)

Paper A describes an analytical model that can be used to calculate the buckling load of a CWR track. This model accounts for the contributions of base, crib and shoulder ballast and includes the effect of vertical loading on each of these components. In addition, a parametric study was developed, in order to understand how and the extent to which the considered factors affect track stability.

In Paper B, a three-dimensional continuous welded rail model was developed to be used for dual gauge track buckling analysis on straight tracks subjected to temperature load.

These two papers are summarized in Appendix I. 


\section{Chapter I \\ 1. Introduction}

Railway track system plays an important role in the modern society, and its maintenance is essential to reach a sustainable transport system. Over the past 20 years, the European Community (EC) has been involved in restructuring and improving the rail transport and their networks, considering that the need to shift a substantial volume of passenger and freight traffic to rail is an issue that requires special attention and policies.

In addition to recent measures, the EC policy objective is to achieve a long-term, sustainable transport system, improving interoperability within the European Union and in relation to third countries. The goals set by EC for the rail mode can be summarised as:

- $30 \%$ of road freight over $300 \mathrm{~km}$ should shift to other modes, such as rail or waterborne transport, by 2030 , and more than $50 \%$ by 2050 , facilitated by efficient, green freight corridors.

- By 2050, a European high-speed rail network should be completed; the length of the existing high-speed rail network should triple by 2030 and maintain a dense railway network in all Member States.

- By 2050, the majority of medium-distance passenger transport should be by rail.

In order to achieve these ambitious objectives, current research attempts to determine from a technical and operational point of view practices that aim to improve the overall efficiency of the rail system. 
Focusing on rail infrastructure, when a train runs on a track some important static and dynamic effects are developed. However, the track is not only affected by train induced loads: extreme heat causes steel rails to expand and, under poor track conditions, tracks may buckle.

Bearing these targets in mind, the purpose of the research described in this PhD Thesis was to improve our understanding of factors related to rail track buckling on dual gauge tracks with continuous welded rails (CWR), and to provide modeling tools to assist in risk analysis due to lateral buckling of the track. To accomplish this task, this research develops two different models that predict dual gauge track buckling temperatures in advance. Therefore, the first step is to clearly understand how dual gauge track factors and conditions influence track stability. The second step is to accurately predict rail temperatures in advance so that management procedures can be put in place.

\subsection{Motivation}

Ballast rail track is formed by stable components consisting of rails, fasteners, sleepers, ballast and other soils layers that ensure system safety, reliability, and profitability to compete with other transportation modes for the movement of freight and passengers.

Under this particular transport infrastructure, a key aspect for rail connectivity is the track gauge, which is the distance between inner edges of the two parallel rails. In principle, trains and rolling stock cannot pass from one gauge to another without some conversion or operation. Around fifty-five percent of the world's railways including most of the European rail networks uses the standard gauge of $1435 \mathrm{~mm}$, allowing the passage from one network to another.

However, different historical reasons (such as the idea that wider gauge would make more powerful locomotives) influenced the Spanish government to construct their rail network to a $1668 \mathrm{~mm}$ gauge, which is greater than standard track gauge used in the principal European countries. In addition, the 1988 decision to construct all new Spanish high-speed lines to the standard track gauge led to new communication problems.

Interoperability problems with Europe due to the existence of rail networks with different gauges have been recently addressed by the Spanish government, thought the construction of $1300 \mathrm{~km}$ (from Algeciras to the French border) of the Mediterranean Corridor with a dual 
gauge track, connecting the principal Spanish harbors with the principal European rail networks.

The proposed dual gauge solution consists of a track with three rails, fixed to concrete sleepers by fastenings and disposed on a ballast layer. Hence, the two adjacent outer rails provide each of the gauges $(1435 \mathrm{~mm} / 1668 \mathrm{~mm})$, while the single outer rail is common to trains of both gauges. Whit dual gauge track costs can be reduced, and infrastructure shared, but other problems appear.

Focusing on lateral track stability, dual gauge track also maintains the use of CWR for their three rails, where longitudinal movements are restricted. Therefore, rails are laid and fixed at the so-called neutral temperature (temperature at which the rail is neither in tension nor in compression). Consequently, rail temperatures below the neutral one cause traction while rail temperatures above results in compressive stress regime.

Rail track conditions have an enormous influence not only on the behavior of the train-track connection but also on lateral instability. In addition, considering that thermal loads are the most important longitudinal stresses, maintaining a stable track condition is critical for buckling prevention. However, the difficulty in this area is that it is physically impossible to eliminate track irregularities and obtain optimum track resistances along the entire length of the rail track. In addition, track resistance and thermal loads cannot be measured with the precision and frequency required.

Under these particular conditions, when rail temperatures reach a critical value the track may buckle. Furthermore, the presence of three rails increases the steel area subjected to temperature variations, modifying longitudinal loads and track behavior.

During the past few decades, several authors have focused on the study of lateral instability under temperature variations, proposing different theories and models. These studies frequently focus only on few rail track parameters, but the existing methods are somewhat ineffective or cumbersome to be applied on dual gauge tracks due to the presence of the third rail. Therefore, it is necessary to study and understand how dual gauge tracks with CWR behave to form the basis of a rational design, particularly when the nonlinear and dynamic responses are analyzed. 
Taking into account this lack of knowledge and considering that railway companies normally use programs for design and maintenance purposes, this Thesis dissertation presents two new models, based on analytical and numerical formulations. Their application to a dual gauge tracks will allow us to estimate the rail temperature that may induce track buckling when surpassed and to predict the buckling resistance with respect to different rail track parameters, such as lateral resistance or lateral imperfections. This would be an important step towards an intelligent and sustainable rail system, in which rail track stresses and resistances due to thermal loads are known. The associated benefit is that lengths of dual gauge tracks subjected to a high risk of buckling can be identified, and thus incidents can be prevented. By having a better insight in the behavior of dual gauge tracks, maintenance works and procedures to be applied on the rail infrastructure can be further fine-tuned.

\subsection{Objectives and approach}

As described previously, railway industry plays a vital role. To provide a better service and satisfy their users, railway companies try to achieve more regular and reliable train services. Consequently, a better understanding of the relationship between influencing factors and track instability on dual gauge tracks can be determined. It is essential to represent the track geometry and their resistances.

Therefore, the present Thesis is a scientific contribution to extend the applicability of the rail track buckling models and the calculation of critical temperatures in dual gauge tracks. Furthermore, the aim is to compare different developed models, resulting in a high accuracy for the predicted temperatures and better knowledge of its behavior. The focus is on accurate prediction of the rail critical temperatures in dual gauge tracks.

To accomplish these objectives, two different approaches will be developed. The analytical model has been implemented in Mathematica ${ }^{\circledR}$, while the numerical model has been solved using Ansys ${ }^{\circledR}$ software. The main buckling parameters to be defined in the models are: rail and sleeper dimensions, lateral track resistance and initial misalignments. Although the approach is mainly theoretical, some practical situations will be evaluated to support and explain some of the theoretical findings achieved.

To reach the proposed objectives, this research has the following approach: 
- Review of the classic track buckling models in order to determine what has been published and what models have been proposed for rail track buckling analysis.

- Form an understanding of key factors in the control of lateral buckling phenomena.

- Develop analytical and numerical thermal buckling model for theoretical determination of the buckling temperatures in dual gauge tracks, under different track conditions.

- Conduct a methodological analysis of dual gauge track buckling parameters that describe track behavior.

- Develop a probabilistic approach to predict the risk of buckling on dual gauge tracks, subjected to temperature loads.

It is expected that the results of the Thesis will provide a substantial contribution for the establishment of a methodology that can be used by rail companies for the improvement and performance of the safety of CWR dual gauge tracks.

\subsection{Structure of the Thesis}

In order to detail the structure of the present work, a short description of each chapter is presented below:

- Chapter 1 corresponds to this Introduction.

- Chapter 2 introduces the literature review, providing an overview of the buckling phenomena, particularized to rail tracks. This chapter also describes the difficulties of defining rail track resistance. This chapter starts with an introductory part, which gives the relevant basis of buckling phenomena. The aim is to have as much information as possible to define the simulations in the most accurate manner. Finally, principal contributions in conventional tracks are presented, including constitutive models, force calculation, etc.

- Chapter 3 describes dual gauge tracks and its particularities.

- Chapter 4 presents two mathematical models that calculate dual gauge track behavior under thermal loads. The first one is the analytical model, in which rails, sleepers and ballast are represented by means of beams and springs. The second one is the numerical model, where track components are represented by means of finite 
elements. The fundamentals of analytical and numerical methods are also presented.

- Chapter 5 presents a parametric analysis to evaluate the effects of the considered factors on the dual gauge track buckling load and compares the two buckling models developed in term of model results and performance. In order to accomplish this task, several thermal load situations are analyzed. The definition of the track parameters and initial conditions of the simulations is also displayed. In addition, a comparative analysis with conventional tracks is performed, allowing the comparison between critical temperatures in conventional and dual gauge tracks. To complete this section, a probabilistic approach is developed, resulting in a risk analysis that allows the development of a simplified and comprehensive dual gauge buckling safety approach. This risk based buckling approach is particularly useful for dealing with statistical variability in the track parameters.

- Finally, Chapter 6 present the conclusions and suggestions for further work, concluding the Thesis.

In addition to the main body, there are two appendixes for future references:

- Appendix I includes two papers, which correspond to different parts of the present Thesis.

- Appendix II provide Spanish and Valencian versions of the conclusions of this Thesis. 


\section{Capítulo II 2. El fenómeno del pandeo}

Para poder estudiar en profundidad el pandeo en las vías férreas es necesario comprender los mecanismos y factores que gobiernan dicho fenómeno. Por ello, el propósito del presente capítulo es el de introducir al lector en el fenómeno del pandeo, facilitando de esta forma el seguimiento del documento.

En el presente apartado se pretende dar una descripción detallada del fenómeno de pandeo y las causas que lo producen, introduciendo la teoría en campo elástico desarrollada por Leonard Euler en el siglo XVII, así como sus limitaciones. Para ello, la determinación de los factores que gobiernan el fenómeno, las fuerzas y la resolución del problema son vitales para poder llevar a cabo la simulación.

Posteriormente, se analizará el pandeo esta vez particularizado al campo ferroviario, desde la definición más básica hasta el estudio de los parámetros y las acciones que lo condicionan, destacando aquellos que se consideran vitales y apuntando los considerados de menor relevancia.

\subsection{Introducción}

Desde el punto de vista ingenieril, el fenómeno del pandeo es un problema de inestabilidad elástica que se produce, generalmente, en elementos estructurales esbeltos (pilares, columnas, perfiles metálicos, etc.) sometidos a esfuerzos de compresión relativamente importantes. Dicho fenómeno se manifiesta por la aparición de grandes desplazamientos transversales respecto de la directriz del elemento (o de la dirección de aplicación de la fuerza). Generalmente, el plano de pandeo es aquél en el que el momento de inercia de la 
sección de la pieza respecto a un eje ortogonal a dicha sección es mínimo, pues es la dirección para la cual se obtiene una menor resistencia.

De forma más concreta, cuando un elemento esbelto (se entiende por esbeltez al cociente entre la sección de un elemento y su longitud) sometido a una fuerza axial de compresión supera un cierto valor denominado carga crítica de pandeo, es posible que se produzca una situación de inestabilidad elástica, la cual se manifiesta con el aumento de la deformación. Esta situación genera a su vez nuevas tensiones, lo que acaba provocando el colapso y rotura del elemento para una carga cuyo valor es inferior al que, teóricamente, la pieza o elemento es capaz de resistir a compresión.

Debe tenerse en consideración que, en la práctica, existen numerosos elementos estructurales que se pueden ver afectados por el pandeo. En este tipo de elementos, el pandeo limita la carga máxima admisible, situación que debe ser considerada explícitamente en el cálculo.

Es por ello que la limitación anteriormente descrita se traduce en la mayoría de normas estructurales mediante la aplicación de coeficientes de minoración, cuya aplicación reduce notablemente la resistencia del elemento a dimensionar cuando los esfuerzos son de compresión (este hecho no se produce cuando los esfuerzos son de tracción). De acuerdo con esta metodología, cuanto más esbelto sea un elemento, mayor será el coeficiente que reduce la resistencia por el posible efecto de pandeo sobre el mismo.
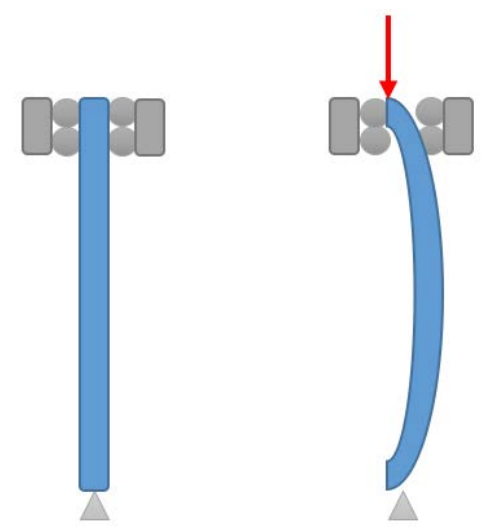

Figura 2.1: Representación esquemática del pandeo en un elemento esbelto. Fuente: Elaboración propia. 
Es necesario destacar que el fenómeno de pandeo puede manifestarse de diferentes formas, según el mecanismo que se produce durante el fallo del elemento. Por ello, es posible distinguir los siguientes modos de fallo:

- Pandeo flexional. Se produce cuando un elemento flecta lateralmente, sin producirse ningún giro ni deformación en su sección transversal.

- Pandeo torsional. Se produce cuando un elemento gira alrededor de su centro de corte.

- Pandeo flexo-torsional. Se produce cuando un elemento flecta y gira simultáneamente, sin cambios en su sección transversal. Es un modo que aglutina los dos modos anteriores.

- Pandeo lateral-torsional. Se produce cuando en un elemento se genera una flexión que produce una deflexión normal al plano de flexión y, de manera simultánea, un giro alrededor del centro de corte del propio elemento.

Si bien el fenómeno del pandeo es un problema generalmente no lineal, seguidamente se describirá la teoría de Euler como paso previo al estudio del pandeo en vías que se desarrollará en capítulos posteriores de la presente Tesis.

\subsection{La teoría de Euler}

El primero en abordar el fenómeno de inestabilidad elástica en elementos esbeltos fue el matemático y físico suizo Leonhard Euler [1707-1783], por lo que la carga crítica de pandeo se conoce también como carga de Euler. La formulación de Euler, todavía empleada hoy en día en el cálculo elástico de columnas por su gran simplicidad, es una de las fórmulas más antiguas de la ingeniería, puesto que su definición y formulación se remonta al año 1757.

Para analizar la teoría de Euler partimos del caso más simple de inestabilidad en cuerpos elásticos: una barra esbelta vertical comprimida axialmente. Para abordar el problema, Euler asumió que la curvatura en cualquier punto del elemento de estudio es proporcional al momento en ese mismo punto. Con esta suposición, Euler examinó el caso de una columna ideal, con las siguientes hipótesis:

- La columna es perfectamente recta y el material es perfectamente homogéneo y elástico (verifica la Ley de Hooke). 
- Se encuentra perfectamente empotrada en uno de sus extremos, mientras que el otro extremo es libre.

- La carga axial (de valor P) se aplica a lo largo del eje vertical, perfectamente centrada y en el apoyo deslizante.

- La columna posee un módulo de elasticidad $E$, una longitud L y un momento de inercia $I$.
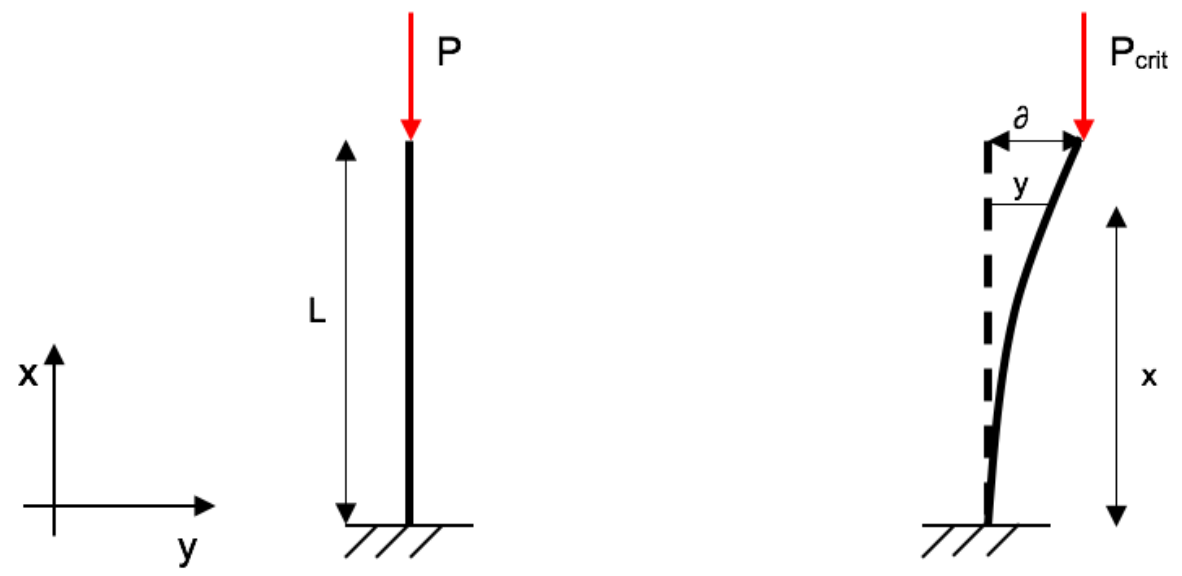

Figura 2.2: Representación de la columna ideal de Euler. Fuente: Elaboración propia.

Bajo las condiciones anteriormente descritas, mientras la carga $P$ sea inferior a la carga crítica $\mathrm{P}_{\text {crit }}$ la columna permanecerá recta, únicamente sometida a una compresión axial. Si se incrementa de forma progresiva el valor de la carga $\mathrm{P}$, la columna se dejará de ser estable, apareciendo una fuerza lateral (sobre el eje y) que producirá el fallo de la columna, para un valor de la carga $\mathrm{P}=\mathrm{P}_{\text {crit. }}$ Dicho valor de carga es el valor conocido como carga crítica de pandeo o carga de Euler.

Para poder calcular la carga crítica de pandeo o carga de Euler, es necesario considerar la ecuación diferencial de la deformada. En la posición deformada, es posible expresar el momento flector $M$ en un punto como:

$$
M=P(\partial-y)
$$

La ecuación diferencial pues puede expresarse según la ecuación 2.2: 


$$
\frac{d^{2} y}{d x^{2}}=\frac{M}{E I}=\frac{P(\partial-y)}{E I} \Rightarrow E I \frac{d^{2} y}{d x^{2}}=P(\partial-y)
$$

Considerando que el extremo superior de la columna no tiene ninguna restricción al desplazamiento, es correcto asumir la hipótesis de que el pandeo, de producirse, se realizará en el plano donde la rigidez a flexión sea menor.

Con esta consideración, se tiene que:

$$
k^{2}=\frac{P}{E I}
$$

Así pues, combinando las ecuaciones 2.2 y 2.3 se tiene:

$$
\frac{P}{k^{2}} \cdot \frac{d^{2} y}{d x^{2}}=P(\partial-y) \Rightarrow \frac{d^{2} y}{d x^{2}}=k^{2} \partial-k^{2} y \Rightarrow \frac{d^{2} y}{d x^{2}}+k^{2} y=k^{2} \partial
$$

La ecuación 2.4 resulta ser una ecuación diferencial de coeficientes constantes, cuya solución general de la homogénea es del tipo:

$$
y=A \sin k x+B \cos k x+\partial
$$

En la solución anterior, los coeficientes A y B representan las constantes de integración, cuyo valor es posible obtener considerando las condiciones de contorno del problema (un extremo empotrado y otro libre). Así pues, considerando el extremo empotrado, se tiene:

$$
\begin{aligned}
& \text { En } x=0 \Rightarrow y=0 \\
& 0=A \sin 0+B \cos 0+\partial \\
& B=-\partial
\end{aligned}
$$


$\operatorname{En} x=0 \Rightarrow \frac{d y}{d x}=0$

$$
\begin{gathered}
\frac{d y}{d x}=A k \cos k x-B k \sin k x \\
0=A k-0 \Rightarrow A=0
\end{gathered}
$$

Del anterior resultado, se tiene:

$$
y=\partial(1-\cos k x)
$$

Por otro lado, considerando el extremo libre, es posible obtener lo siguiente:

$\operatorname{En} x=L \Rightarrow y=\partial$

$$
\begin{gathered}
\partial=\partial(1-\cos k L)=\partial-\partial \cos k L \\
\partial \cos k L=0
\end{gathered}
$$

La ecuación 2.7 requiere que se verifiquen una de las dos siguientes condiciones de contorno:

$$
\partial=0 \quad \text { ó } \quad \cos k L=0
$$

La primera de las restricciones no es conveniente, pues en ese caso no existiría ninguna deformación en el elemento bajo estudio y, por lo tanto, no sería posible el pandeo. Considerando la segunda restricción, se tiene:

$$
k L=(2 n-1) \frac{\pi}{2}, \forall n
$$

Considerando $\mathrm{n}=1$ (el valor de $\mathrm{n}=1$ proporciona la menor de las cargas de pandeo, la cual dominará el problema de deformación), es posible obtener la carga crítica de pandeo, con: 


$$
k L=\frac{\pi}{2} \Rightarrow k=\frac{\pi}{2 L}
$$

$\mathrm{Y}$, finalmente, la carga crítica $\mathrm{P}_{\text {crit }}$ tiene la expresión de la ecuación 2.10.

$$
\left(\frac{\pi}{2 L}\right)^{2}=\frac{P}{E I} \Rightarrow P_{c r i t}=\frac{\pi^{2}}{4 L^{2}} E I
$$

La ecuación 2.10 para la carga crítica únicamente se cumple cuando las condiciones de contorno del elemento son las consideradas en las hipótesis (un extremo empotrado y el otro libre).

Cabe destacar que es posible utilizar la solución obtenida para el caso descrito para otras condiciones de apoyo. Por ello, si se generaliza dicha expresión la fórmula de Euler toma la siguiente forma:

$$
P_{\text {crit }}=\frac{\pi^{2}}{k L^{2}} E I=\frac{\pi^{2} E I}{S_{k}^{2}}
$$

donde el factor $k$ o factor de longitud depende de las condiciones de contorno, tomando las expresiones indicadas en la Tabla 2.1.

Además, al producto de $k L$ se le conoce como longitud de pandeo $\left(S_{k}\right)$, siendo dicho parámetro muy práctico, pues representa la longitud de un elemento ideal recto, de forma prismática y biarticulado en sus extremos que posee la misma carga crítica que la pieza real considerada.

\begin{tabular}{|c|c|c|}
\hline \multicolumn{3}{|c|}{ Expresión de la carga crítica de pandeo de Euler } \\
\hline Empotramiento-libre & Rótula-Rótula & Empotramiento-Rótula \\
\hline$P_{c r i t}=\frac{\pi^{2}}{4 L^{2}} E I$ & $P_{c r i t}=\frac{\pi^{2}}{L^{2}} E I$ & $P_{c r i t}=\frac{2.045 \pi^{2}}{L^{2}} E I$ \\
\hline
\end{tabular}

Tabla 2.1: Expresiones de la carga crítica de pandeo (carga de Euler), en función de las condiciones de contorno. Fuente: Elaboración propia. 
Por su parte, la tensión crítica de Euler $\left(\sigma_{\text {crit }}\right)$ puede obtenerse como el cociente entre la carga crítica de pandeo y la sección transversal A del elemento, obteniéndose la conocida hipérbola cuadrática de Euler:

$$
\sigma_{c r i t}=\frac{P_{c r i t}}{A}=\frac{\pi^{2} E I}{S_{k}^{2}}=\frac{\pi^{2}}{\lambda^{2}} E
$$

Cabe destacar que la esbeltez de la pieza $\lambda$, definida como el cociente entre la luz de pandeo $L$ y el radio de giro $i$ de la sección transversal de la pieza, es un factor importante en el estudio del problema de pandeo, pues cuanto mayor esbeltez posea un elemento, mayor es el riesgo de pandeo del mismo.

En este sentido, si consideramos la Instrucción de Hormigón Estructural española (EHE08), para elementos estructurales habituales sometidos a compresión se recomienda que no se supere el valor de $200(\lambda<200)$. Además, por debajo de $35(\lambda<35)$, es posible despreciar los efectos del pandeo y no es necesario llevar a cabo un cálculo de pandeo.

\subsubsection{Limitación de la teoría de Euler}

Si bien la teoría de Euler descrita anteriormente proporciona una expresión simple para el cálculo del pandeo de elementos sometidos a esfuerzos axiales de compresión, la realidad es mucho más compleja.

Teóricamente, una columna sometida a un esfuerzo de compresión creciente no debería presentar ninguna deformación transversal hasta que la carga axial iguale a la carga crítica de pandeo. No obstante, una columna real no responde nunca a las condiciones ideales supuestas por Euler, puesto que las columnas reales no son estrictamente rectas, ni están compuestas de un material perfectamente homogéneo, ni la carga aplicada se sitúa perfectamente sobre el eje de la pieza, entre otros aspectos.

Así pues, los elementos sometidos a cargas axiales de compresión reales adquieren desde el inicio de la aplicación de la carga deformaciones transversales reducidas que se vuelven más importantes a medida que la carga aumenta y se aproxima a la carga de pandeo. 

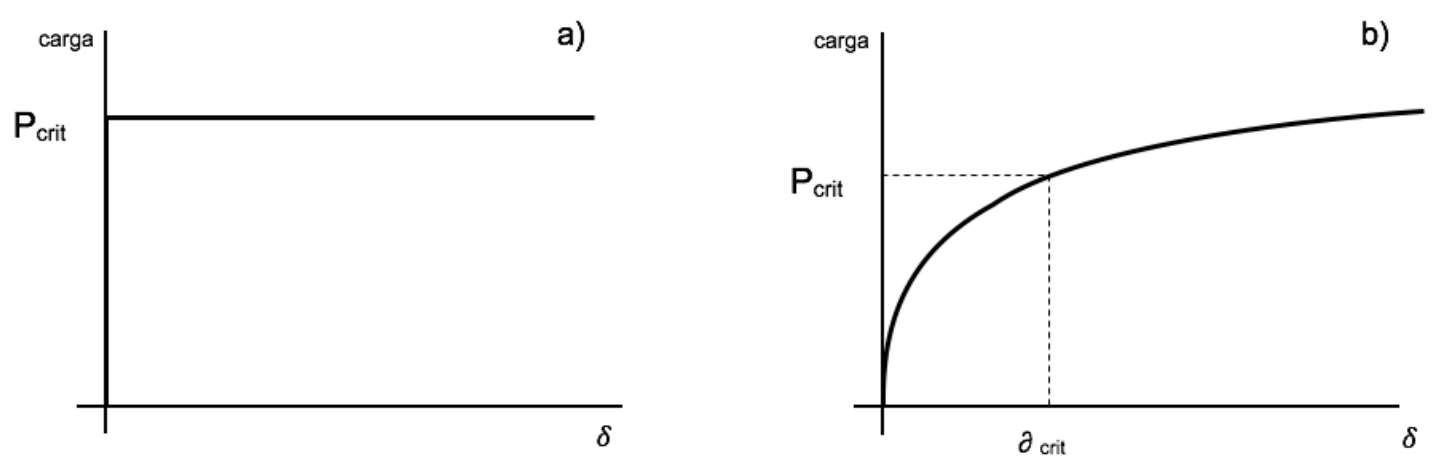

Figura 2.3: Representación de comportamiento de pandeo. a) Comportamiento ideal (Euler). b) Comportamiento no lineal del pandeo. Fuente: Elaboración propia.

Este comportamiento no lineal genera el riesgo de que en un elemento sometido a una carga axial de compresión cercana al valor de la carga crítica de pandeo se produzcan desplazamientos importantes con pequeños incrementos de carga, llegando al colapso del elemento si se aumenta ligeramente la carga.

Por otro lado, la teoría de Euler fue construida considerando la validez ilimitada de la ley de Hooke, por lo que cuando la esbeltez tiende a cero, la tensión crítica de Euler tiende a infinito. Este hecho hace que la teoría de Euler no sea válida para valores de esbeltez comprendidos entre 0 y un determinado valor $\lambda_{\mathrm{p}}$, en función del material del que esta formado el elemento.

Así pues, la esbeltez límite o mínima por debajo de la cual no tiene validez la teoría de Euler se obtiene de la siguiente forma:

$$
\sigma_{i}=\frac{\pi^{2} E}{\lambda^{2}}=\sigma_{p} \rightarrow \lambda_{p}=\pi \sqrt{\frac{E}{\sigma_{p}}}
$$

Por lo tanto, para que sea válida la teoría de Euler, debe verificarse pues la siguiente expresión:

$$
\lambda_{p} \geq \pi \sqrt{\frac{E}{\sigma_{p}}}
$$




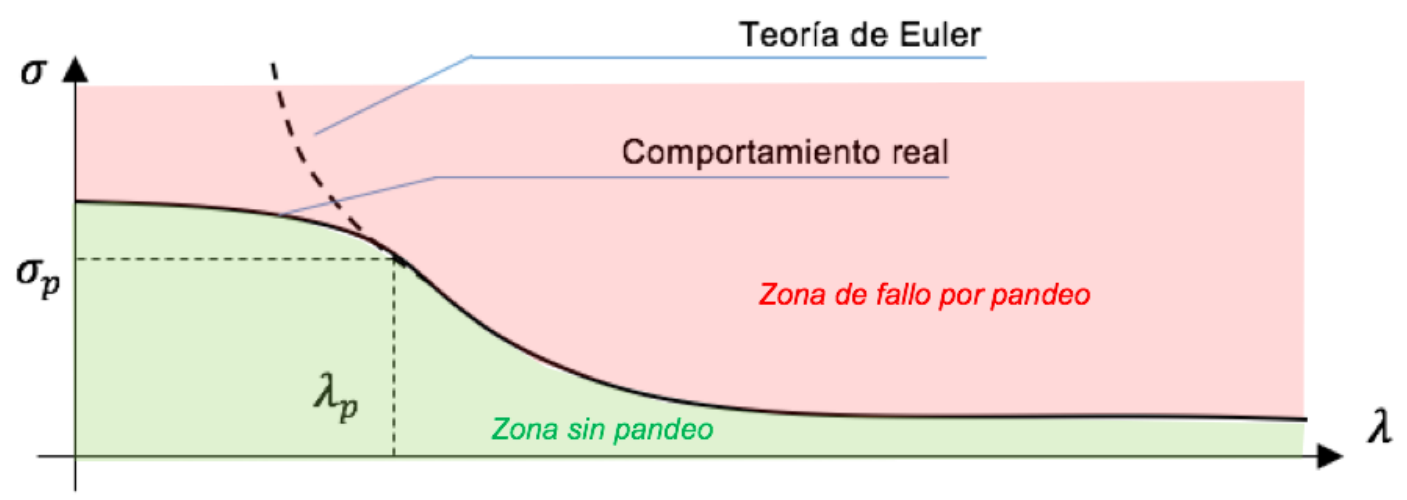

Figura 2.4: Representación de la validez de la teoría de Euler. Fuente: Elaboración propia.

Teniendo en consideración el comportamiento plástico del pandeo, el ingeniero ferroviario F. Engesser [1848-1931] fue el primero en desarrollar una teoría basada la fase plástica del pandeo en el año 1889, conocida como teoría del módulo tangente.

Para desarrollar su formulación se parte de la teoría de Euler, utilizando un módulo de elasticidad tangente $E_{t}$. Asumiendo que las secciones se mantienen planas durante la flexión, la ecuación tiene la misma forma que la propuesta por Euler, con la excepción de que el módulo de elasticidad $E$ viene sustituido por un módulo de elasticidad tangente $E_{t}$ que depende la tensión producida por la carga aplicada.

$$
E_{t}=\operatorname{arctg} \alpha=\frac{d \sigma}{d \varepsilon}
$$

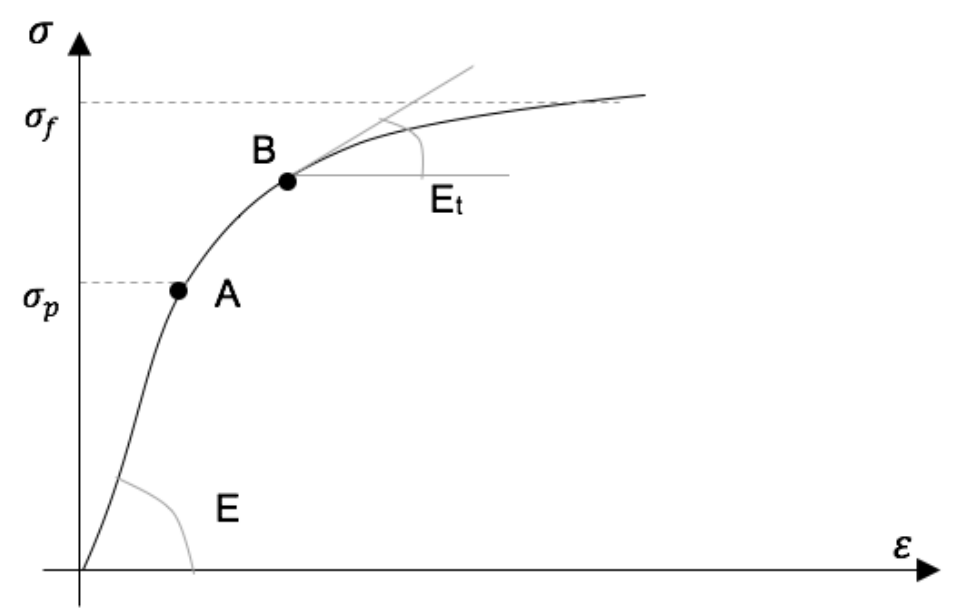

Figura 2.5: Representación de la teoría de Engesser. Fuente: Elaboración propia. 
Bajo estas consideraciones el valor del módulo de elasticidad tangente es función de la tensión, cuyo rango de variabilidad se encuentra acotado entre la tensión de proporcionalidad $\sigma_{p}$ y la tensión de fluencia $\sigma_{f}$.

La tensión critica de pandeo en este caso (para valores de $\sigma>\sigma_{\mathrm{p}}$ ) toma pues la siguiente forma:

$$
\sigma_{\text {crit }}=\frac{\pi^{2} E_{t}}{\lambda^{2}}
$$

Con posterioridad, en 1895 el mismo Engesser propone una expresión similar, esta vez utilizando un módulo de elasticidad diferente, definido con ello lo que hoy en día se conoce como teoría del doble módulo o teoría del módulo reducido. Esta nueva formulación considera que, cuando el elemento sometido a compresión pasa a una posición deformada, el momento flector generado origina compresiones en la parte cóncava que se suman a las producidas por la propia compresión y tracciones en la parte convexa, que se restan a las de la carga axial.

Bajo estas consideraciones, la carga crítica y la tensión crítica toman las expresiones siguientes:

$$
\begin{gathered}
P_{\text {crit }}=\frac{\pi^{2} T I}{L^{2}} \\
\sigma_{\text {crit }}=\frac{P_{\text {crit }}}{A}=\frac{\pi^{2} E I}{S_{k}^{2}}=\frac{\pi^{2} T}{\lambda^{2}}
\end{gathered}
$$

donde $T$ es el módulo plástico de pandeo de Von Karman o módulo de pandeo de Engesser-Karman.

Este módulo, para una sección cualquiera, toma la siguiente expresión:

$$
T=E \frac{I_{1}}{I}+E_{t} \frac{I_{2}}{I}
$$

donde $I_{1}$ e $I_{2}$ representan el momento de inercia de la zona traccionada y de la zona comprimida, respectivamente. 
Así pues, a modo de resumen, se tiene la Tabla 2.2:

\begin{tabular}{|c|c|}
\hline \multicolumn{2}{|c|}{ Carga crítica de pandeo } \\
\hline Campo elástico $\left(\sigma \leq \sigma_{\mathrm{p}}\right)$ & Campo plástico $\left(\sigma>\sigma_{\mathrm{p}}\right)$ \\
\hline$P_{\text {crit }}=\left(\frac{\pi}{\lambda}\right)^{2} A E$ & $P_{\text {crit }}=\left(\frac{\pi}{\lambda}\right)^{2} A T$ \\
\hline
\end{tabular}

Tabla 2.2: Expresiones de la carga crítica de pandeo, en función del campo de aplicación. Fuente: Elaboración propia.

Además de la teoría desarrollada por Engesser, existen otras muchas teorías con diferentes hipótesis y aproximaciones al problema del pandeo, si bien no se tratarán en esta Tesis en aras de la brevedad, así como por no ser el objetivo de la misma.

\subsection{Comportamiento real del pandeo}

Tanto la teoría de Euler descrita como el resto de modelos de comportamiento de elástico e inelástico se basan en condiciones idealizadas sobre las que poder desarrollar la formulación. No obstante, en el estudio del comportamiento real de los elementos esbeltos sometidos a cargas axiales hay que tener en consideración los siguientes efectos:

- El comportamiento de los materiales es generalmente heterogéneo, con diagramas tensión-deformación, en algunos casos, complejos.

- Existen imperfecciones geométricas iniciales, por lo los elementos presentan curvaturas que favorecen el pandeo.

- Las cargas aplicadas no están perfectamente centradas en el eje del elemento.

- Es posible que existan, debido a los procesos de fabricación, tensiones residuales.

- La teoría de Euler permite obtener la carga de pandeo, pero no es posible obtener las deformaciones y tensiones tras el pandeo.

De entre los factores citados anteriormente, son la existencia de imperfecciones y la presencia de tensiones residuales los factores que tienen un efecto más significativo en el fenómeno del pandeo. Por ello, a las tensiones generadas por las cargas axiales hay que considerar las tensiones producidas a la flexión (debido a las imperfecciones) y las tensiones residuales. 
Así pues, una forma sencilla de abordar el pandeo se obtiene modificando la expresión de Euler, tomando la siguiente expresión:

$$
\sigma_{\text {crit }}=\underbrace{\frac{P_{\text {crit }}}{A}+\frac{M}{W}+\sigma_{\text {res }}}_{\substack{\text { Tensión Tensión Tensión } \\ \text { Euler por flexión residual }}}=\frac{P_{\text {crit }}}{A}+\frac{P_{\text {crit }} \delta_{\text {max }}}{W}+\sigma_{\text {res }}=\sigma+\frac{(\sigma A) \delta}{W}+\sigma_{\text {res }}=k_{1} \sigma
$$

En la expresión generalizada anterior, el valor de $k_{1}$ se le conoce como coeficiente de amplificación de la tensión y considera, entre otros aspectos, los efectos que tiene la flexión y las tensiones residuales en el pandeo.

Bajo estas consideraciones, la fórmula planteada por la Instrucción de Acero Estructural EAE-2011 (de aplicación a todas las estructuras y elementos de acero estructural de edificación o de ingeniería civil) es la siguiente:

$$
\sigma_{\text {crit }}=k_{1} \sigma=k_{1} \frac{P_{\text {crit }}}{A} \leq f_{y d} \rightarrow P_{\text {crit }} \leq \frac{1}{k_{1}} A f_{y d}=\chi A f_{y d}
$$

donde $\chi$ es el coeficiente de reducción por pandeo (inverso al coeficiente de amplificación de tensiones $k_{1}$ ).

Con esto, se tiene que un elemento sometido a una carga axial centrada constante cumple el criterio de pandeo si:

$$
\sigma_{\text {crit }}=k_{1} \sigma=k_{1} \frac{P_{\text {crit }}}{A} \leq f_{y d} \rightarrow P_{\text {crit }} \leq \frac{1}{k_{1}} A f_{y d}=\chi A f_{y d}
$$

El valor $\chi$ depende de la curva de pandeo elegida (la cual depende del tipo de sección, del proceso de fabricación de la pieza y del eje de pandeo) y del valor de la esbeltez reducida de la pieza $\bar{\lambda}$ (que a su vez depende de las características del elemento). En elementos con sección transversal constante bajo una carga axial constante, el valor de $\chi$ toma la siguiente expresión:

$$
\chi=\frac{1}{\phi+\sqrt{\phi^{2}-\bar{\lambda}^{2}}}
$$

donde $\phi=0.5\left[1+\alpha(\bar{\lambda}-0.2)+\bar{\lambda}^{2}\right]$, siendo $\alpha$ el coeficiente de imperfección. 


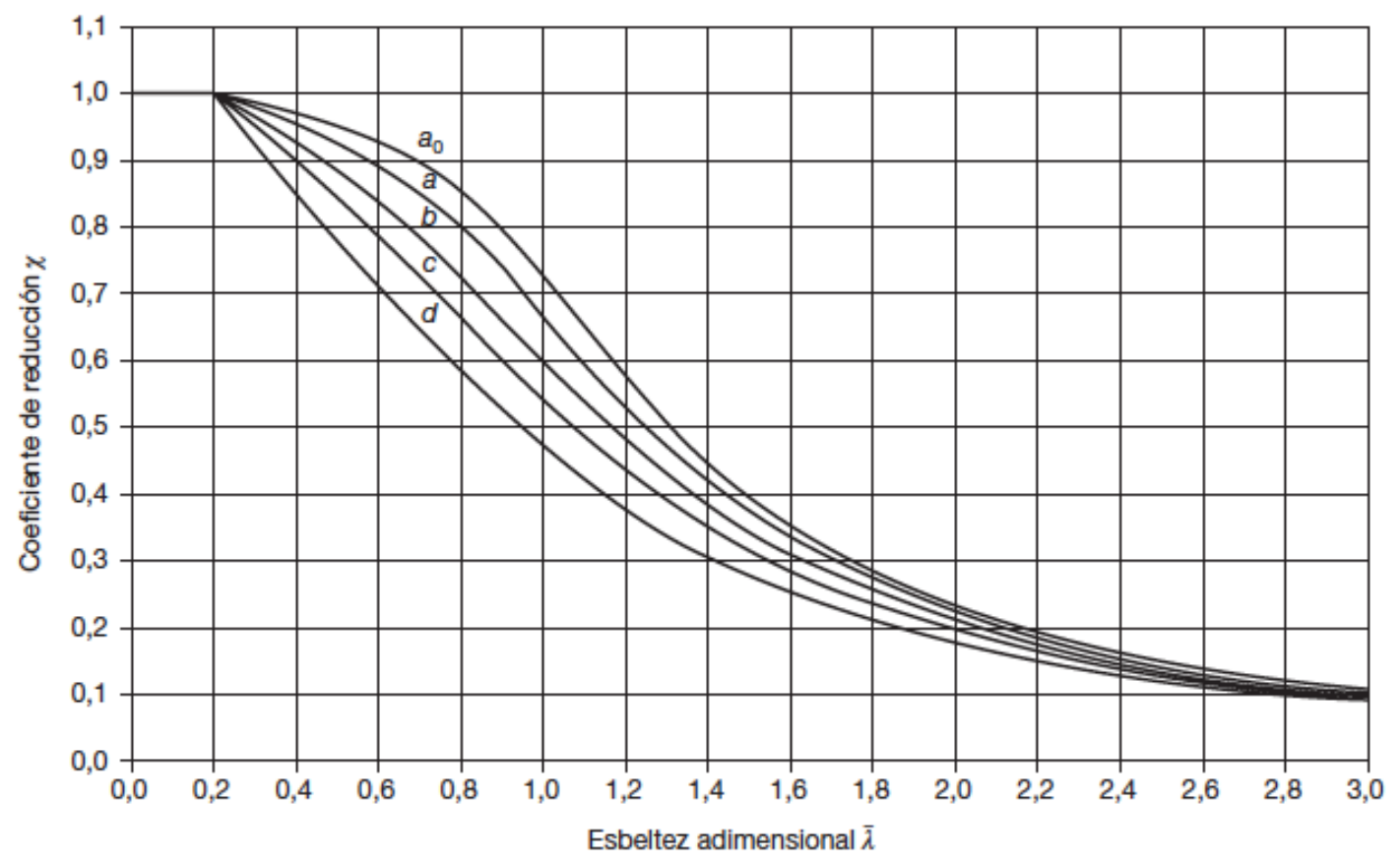

Figura 2.6: Curvas de pandeo en función del coeficiente de imperfección ( $a_{0}$, a, b c y d). Fuente: Instrucción de Acero Estructural-2011.

Así pues, de forma esquemática, el cálculo de pandeo en elementos de acero con sección transversal y carga axil constante sigue el siguiente proceso:

1. Cálculo de la esbeltez reducida $\bar{\lambda}$ :

$$
\bar{\lambda}=\sqrt{\frac{N_{E}}{N_{c r}}}=\sqrt{\frac{A f_{y}}{\frac{\pi^{2} E I}{L^{2}}}}=\sqrt{\frac{\frac{L^{2}}{I / A}}{\frac{\pi^{2} E}{f_{y}}}}=\frac{\lambda}{\lambda_{E}}
$$

donde $\lambda_{E}$ se obtiene como $\lambda_{E}=\pi \sqrt{E / f_{y}}$

2. Elección de la curva de pandeo adecuada (Figura 2.6).

3. Obtención del coeficiente de reducción $\chi$ en base a la curva seleccionada y la esbeltez reducida $\bar{\lambda}$, según la ecuación 2.23 .

4. Cálculo del axil máximo que es capaz de resistir el elemento, con la siguiente expresión: 


$$
P_{c r i t}=\frac{\chi A f_{y}}{\gamma_{M 1}}
$$

donde $\gamma_{M 1}$ es el coeficiente parcial de resistencia frente a inestabilidad.

Para elementos más complejos o por flexión en otros ejes, las normativas de dimensionamiento estructural prevén procedimientos en los que se tienen en cuenta las diferentes particularidades de cada caso, si bien no profundiza en ellos por no ser objeto de la presente Tesis.

\subsection{El fenómeno del pandeo en vías férreas}

Hasta el momento el análisis del pandeo se ha llevado a cabo en elementos estructurales aislados y sometidos únicamente a una carga axial. Si bien esta aproximación ha permitido plantear la resolución desde el punto de vista teórico, el pandeo suele ser un problema mucho más complejo, tal y como en el ámbito ferroviario.

Antes de entrar a analizar en profundidad el fenómeno cabe plantearse es que se entiende por pandeo en vías de ferrocarril. Una definición reciente puede encontrarse en la normativa Civil Engineering Track Standards of Queensland Railways (2008), donde el pandeo de vía viene definido como "una desalineación repentina de la vía causada por el incremento de temperatura y/o la fluencia del carril, el cual requiere la disposición de una limitación de velocidad y/o la intervención del personal de mantenimiento de vía para poder seguir ofreciendo el servicio en condiciones seguras".

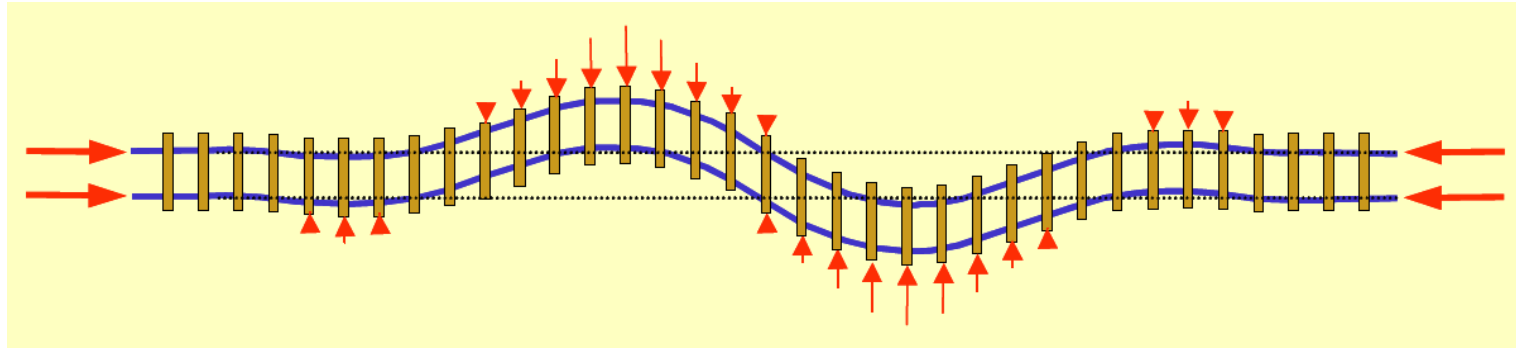

Figura 2.7: Representación del pandeo. Fuente: Modern Rail Track, Esveld, C. (2001).

Por otro lado, según la ficha UIC 720-R (de diciembre de 2002) sobre "Instalación y mantenimiento de la barra larga soldada", el pandeo se describe como: "El pandeo y la deformación de la vía se producen cuando los esfuerzos de compresión inducidos en los carriles 
por el calor son suficientemente elevados, sobrepasando la resistencia al desplazamiento transversal de la vía" (p.18).

De la definición anterior se deduce que el pandeo en vías se origina como consecuencia del incremento elevado de los esfuerzos axiales en los carriles. Cuando estos esfuerzos alcanzan un determinado valor, la vía no es capaz de ofrecer mayor resistencia y se produce una deformación en la alineación de la vía que puede afectar gravemente a la circulación. El origen o mecanismo por el que se generar los esfuerzos axiales que conllevan al pandeo puede ser muy diverso, tal y como se verá posteriormente, si bien es posible afirmar que las fuerzas de origen térmico son las principales causantes de la desestabilización transversal de la vía.

Con ello, es posible afirmar que el pandeo se produce cuando se verifica la siguiente condición:
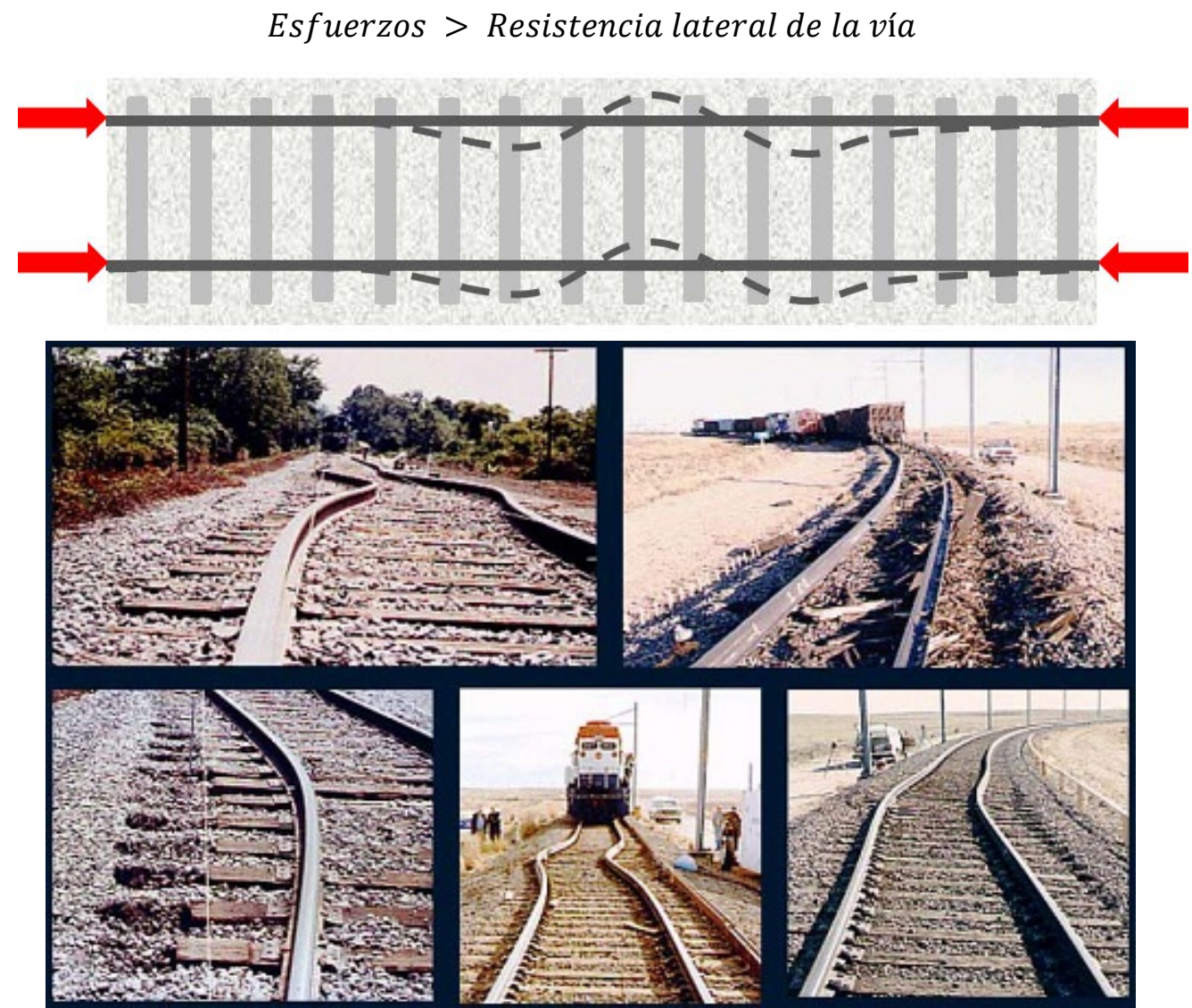

Figura 2.8: Imágenes de pandeo de vía. Fuente: Volpe National Transportation Systems Center. Track buckling research, research and innovative technology administration. Washington: U.S. Department of Transportation, 2003. 

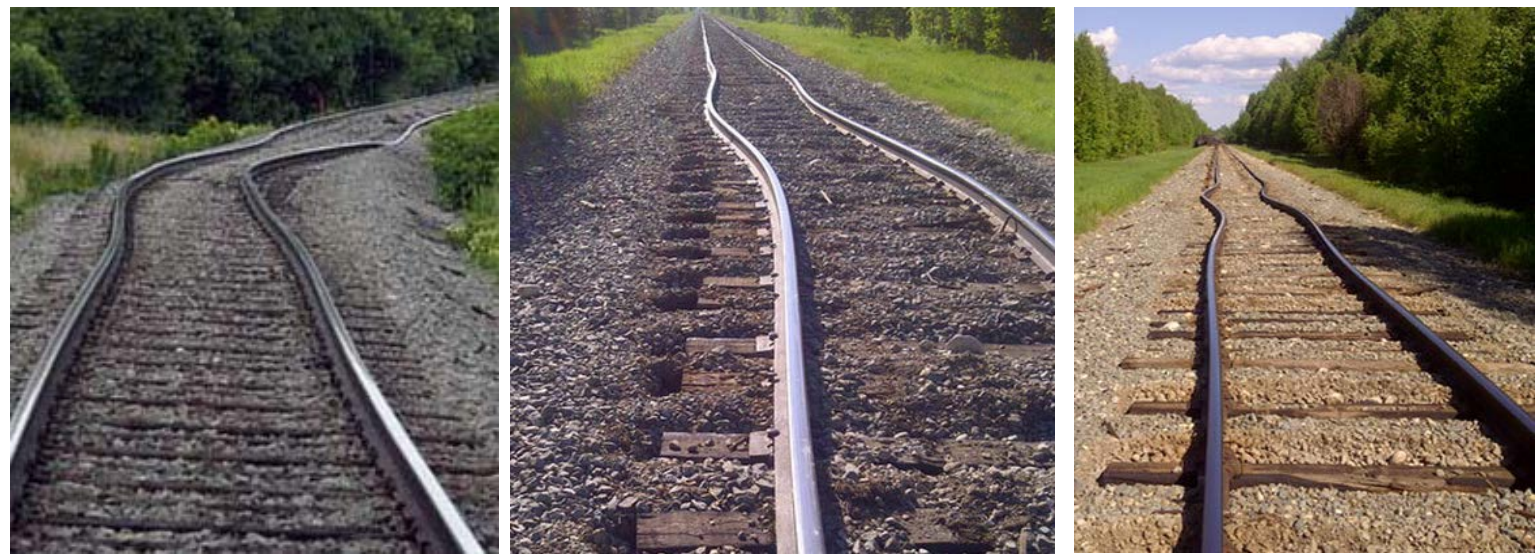

Figura 2.9: Imágenes de pandeo de vía. Fuente: Transportation Safety Board of Canada.

Otro de los aspectos presentes en la definición de la ficha UIC es el hecho de que el pandeo puede generar pequeños desplazamientos laterales de la vía (estos defectos comportan generalmente limitaciones de velocidad) o, en los casos más graves, un desplazamiento importante de la vía que resulta (pueden causar el cierre temporal de la línea y su inmediata reparación).

Estas deformaciones se producen, generalmente en el plano horizontal de la vía, pues la inercia de los carriles en el plano vertical es superior a la del plano horizontal, sumado al peso de la vía, lo que contribuye notablemente a mantener estable la vía en el plano vertical.

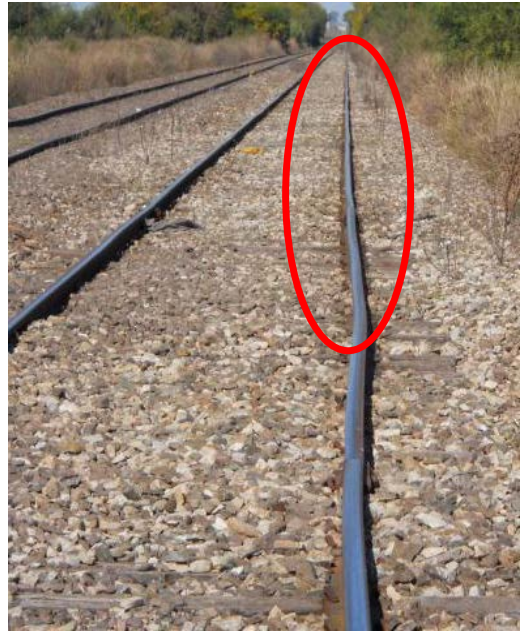

a)

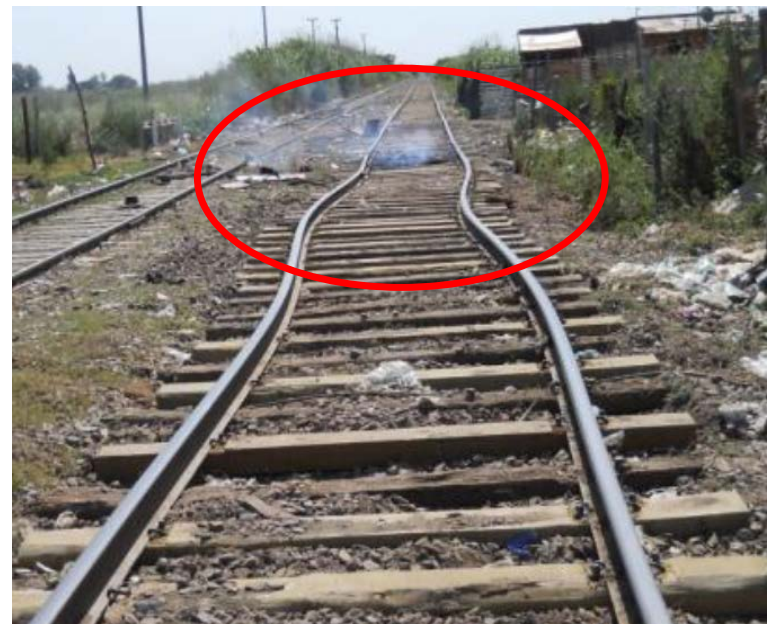

b)

Figura 2.10: Imágenes de pandeo de vía, a) Pandeo con pequeño desplazamiento lateral, b) Pandeo con gran desplazamiento lateral. Fuente: Manual integral de vía, Nuevo Central Argentino, 2014. 
En cuanto al comportamiento de la vía, la experiencia adquirida por las administraciones ferroviarias muestra que el fenómeno del pandeo se comporta de forma de forma diversa cuando se analiza un tramo de vía curva respecto de un tramo recto.

En tramos rectos, el pandeo se produce normalmente de forma repentina, por lo que las deformaciones crecen considerablemente en un instante de tiempo reducido (pandeo explosivo), pudiendo producirse hacia cualquier de los dos lados de la vía, en función de los defectos existentes y/o el lado que menos resistencia ofrezca. En estos casos, la vía suele adoptar una forma de onda senoidal, con una amplitud central relativamente mayor respecto la amplitud de las ondas de los extremos.

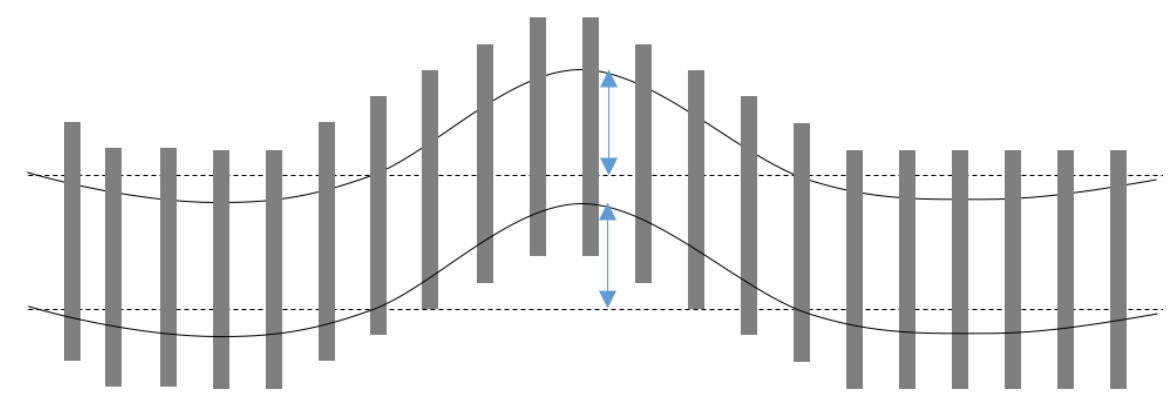

Figura 2.11: Desplazamiento senoidal representativo del pandeo en tramos rectos. Fuente: Elaboración propia.

En cambio, en tramos curvos la vía tiende a adoptar una forma más bien de "C", con una única amplitud central, debido a la curvatura inicial que presenta la vía.

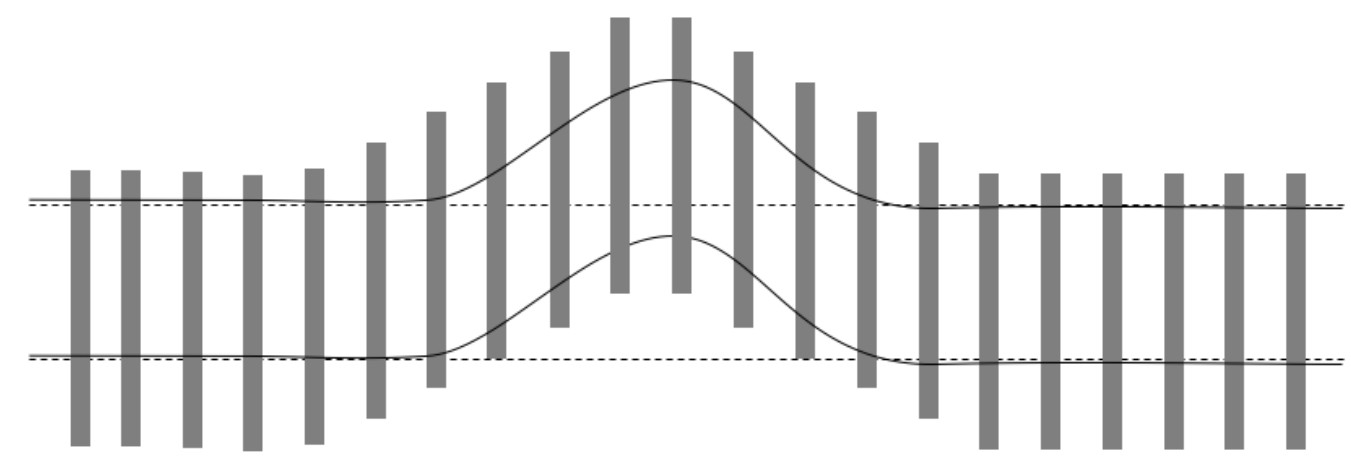

Figura 2.12: Desplazamiento en forma de "C" representativo del pandeo en tramos curvos. Fuente: Elaboración propia. 
Otro aspecto importante a considerar es el hecho de que, en tramos curvos, el pandeo suele producirse de forma progresiva y no explosiva, especialmente en aquellas curvas que presentan una reducida resistencia lateral y radios de curvatura importantes. Las variaciones de temperatura en este tipo de tramos producen un movimiento radial del emparrillado hacia el exterior de la curva cuando la variación de temperatura es positiva y hacia el interior, cuando la variación es negativa. Estos movimientos radiales reducen la resistencia lateral, lo que sumado a posibles defectos de alienación pueden ser el desencadenante del pandeo.

\subsubsection{Tipologías de vía}

Una vez descrito el fenómeno del pandeo y sus consecuencias, es momento de analizar en profundidad el comportamiento de una vía frente a variaciones de temperatura. Para ello, es posible distinguir claramente dos tipos de vía diferentes según su respuesta, mediante:

- Vía con expansión libre (o vía con juntas).

- Vía con expansión restringida (o vías con carril continuo soldado).

En el caso de las vías con expansión libre, los carriles pueden dilatarse o contraerse en función del aumento o disminución de la temperatura (ver Figura 2.13), por lo que el pandeo se produce muy raramente.

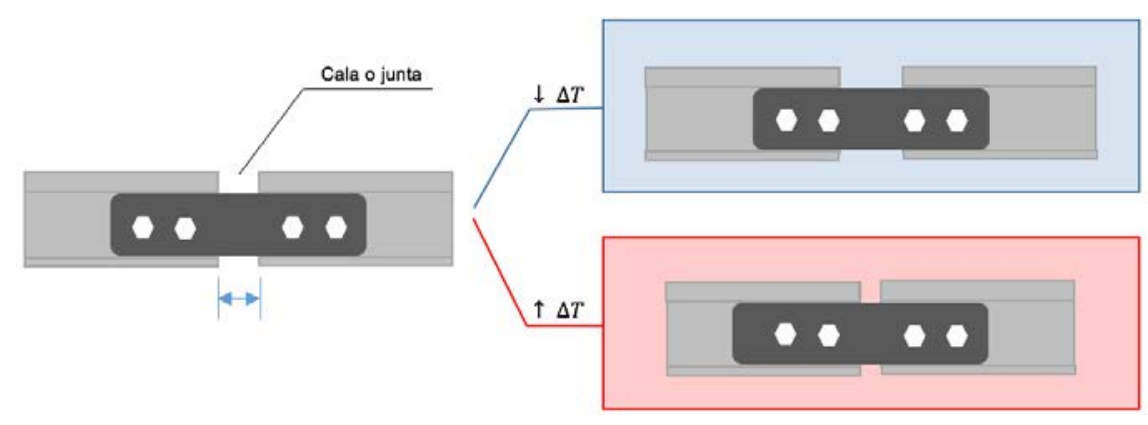

Figura 2.13: Representación del movimiento de los carriles en la cala. Fuente: Elaboración propia. 
En efecto, en este tipo de vías los carriles están conformados por una serie de barras o tramos relativamente cortos (unas decenas de metros) unidos entre sí mecánicamente mediante elementos denominados bridas, lo que permite disponer de un espacio entre ambos carriles enfrentados denominado junta o cala.

La dimensión de la cala es un factor importante y viene influenciada por la longitud de los tramos de carril que se unen, así como por la temperatura máxima que pueden alcanzar, respecto de la temperatura de montaje o neutralización. Según la norma N.R.V. 3-3-0.0. "Junta de carriles, Bridas y tornillos de brida" de Renfe, las calas deben tener las siguientes dimensiones (ver Tabla 2.3).

\section{APERTURA DE CALAS EN FUNCION DE LA TEMPERATURA}

\begin{tabular}{|c|c|c|c|c|c|}
\hline \multirow{2}{*}{$\begin{array}{l}\text { TEMPERATURA DEL CARRIL } \\
\text { DURANTE EL MONTAJE }\end{array}$} & \multicolumn{5}{|c|}{ CALAS EN mm. PARA CARRILES DE } \\
\cline { 2 - 6 } & $12 \mathrm{~m}$ & $18 \mathrm{~m}$ & $24 \mathrm{~m}$ & $32 \mathrm{~m}$. & $33 \mathrm{~m}$. \\
\hline$-20^{\circ} \mathrm{a}-10^{\circ}$ & 11 & - & - & - & - \\
\hline$-10^{\circ} \mathrm{a} 0^{\circ}$ & 10 & - & - & - & - \\
\hline $0^{\circ} \mathrm{a}+10^{\circ}$ & 8 & 12 & - & - & - \\
\hline$+10^{\circ} \mathrm{a}+20^{\circ}$ & 7 & 10 & 13 & - & - \\
\hline$+20^{\circ} \mathrm{a}+30^{\circ}$ & 6 & 8 & 11 & - & - \\
\hline$+30^{\circ} \mathrm{a}+40^{\circ}$ & 4 & 6 & 8 & 11 & 12 \\
\hline$+40^{\circ} \mathrm{a}+50^{\circ}$ & 3 & 4 & 6 & 8 & 8 \\
\hline$+50^{\circ} \mathrm{a}+60^{\circ}$ & 2 & 2 & 3 & 4 & 4 \\
\hline $\mathrm{mas} \mathrm{de}+60^{\circ}$ & 0 & 0 & 0 & 0 & 0 \\
\hline
\end{tabular}

Tabla 2.3: Valores de la apertura de calas, en función de la temperatura. Fuente: N.R.V. 3-30.0. Junta de carriles, Bridas y tornillos de brida (Renfe).

Con el espacio disponible entre carriles que marca la normativa se evita que la expansión de los mismos por efecto térmico genere esfuerzos axiales en el emparrillado, pues la dilatación que se produce es menor al espaciado disponible en la junta. Por el contrario, en las vías con expansión restringida (o vías con carril continuo soldado) se eliminan las calas, por lo que son vías susceptibles de sufrir el pandeo, tal y como se verá a continuación. 


\subsubsection{El carril contínuo soldado}

Si bien la existencia de calas permite que los carriles se dilaten y contraigan una determinada magnitud, las discontinuidades que plantea la presencia de juntas a lo largo del camino de rodadura tienen asociados una serie de problemas importantes. En efecto, las juntas soportan unos esfuerzos elevados al paso de los vehículos (especialmente deformaciones a flexión y golpes), induciendo una excitación al vehículo. Este hecho se traduce en una fatiga adicional tanto al propio vehículo como a los elementos de la vía que acarrea mayores costes de mantenimiento y una reducción importante del confort de la marcha.

Para solventar estos problemas en la década de los años 1930 se introdujo el carril continuo soldado, gracias a las primeras pruebas realizadas en Hungría, Alemania, Inglaterra y EE.UU. con tramos de carril de unos 200-300 m.

Desde el punto de vista teórico, el planteamiento del problema es altamente complejo. En cuanto a su definición, es posible definir el carril continuo soldado como aquél que posee una longitud suficiente como para que uno de sus puntos se mantenga fijo, independientemente de la temperatura que puedan alcanzar los carriles.

Bajo estas condiciones, los únicos puntos en los que es posible el desplazamiento se sitúan en los extremos del mismo (las llamadas zonas de respiración), mientras que el tramo central resta inmóvil gracias a la resistencia que proporciona el balasto y las sujeciones, manteniendo el carril fijo a la vía (ver Figura 2.14).

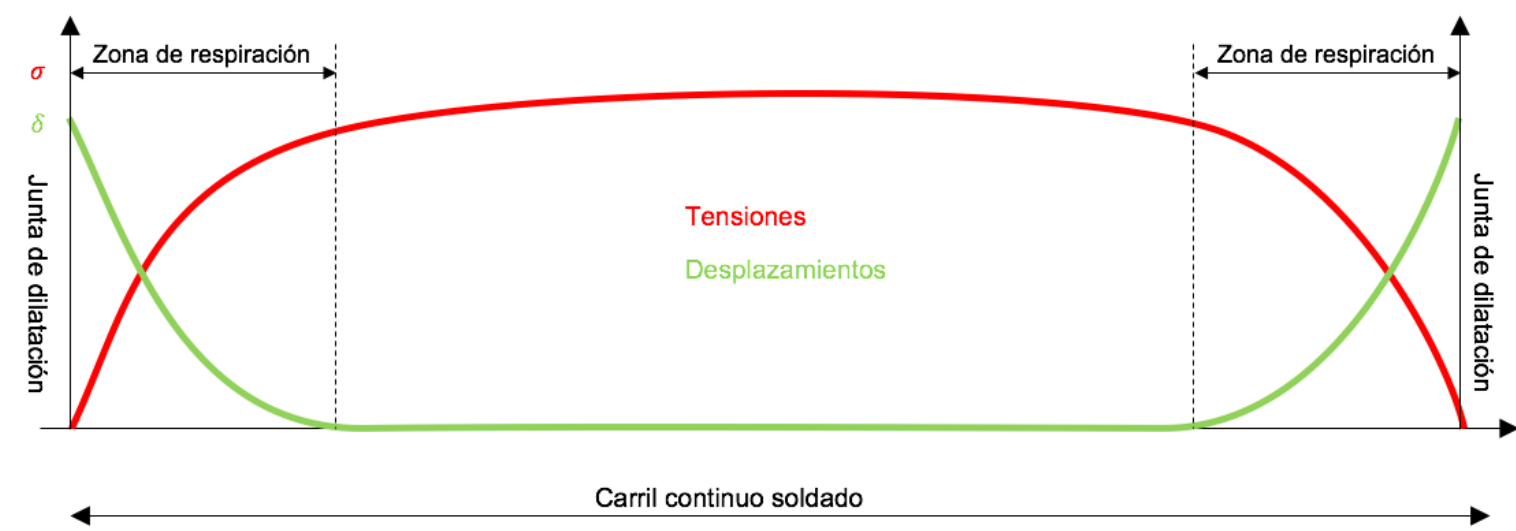

Figura 2.14: Esquema representativo del efecto de la temperatura sobre carril continúo soldado. Fuente: Elaboración propia. 
Este tipo de carriles se obtiene mediante la unión de un conjunto de tramos de carril más cortos por soldadura aluminotérmica en vía, lo que da como resultado un elemento de una longitud considerable, sin ninguna discontinuidad. La unión de carriles crea una superficie continua de rodadura con juntas de dilatación únicamente presente en sus extremos, de tal manera que se eliminan las juntas y gran parte de sus problemas asociados.
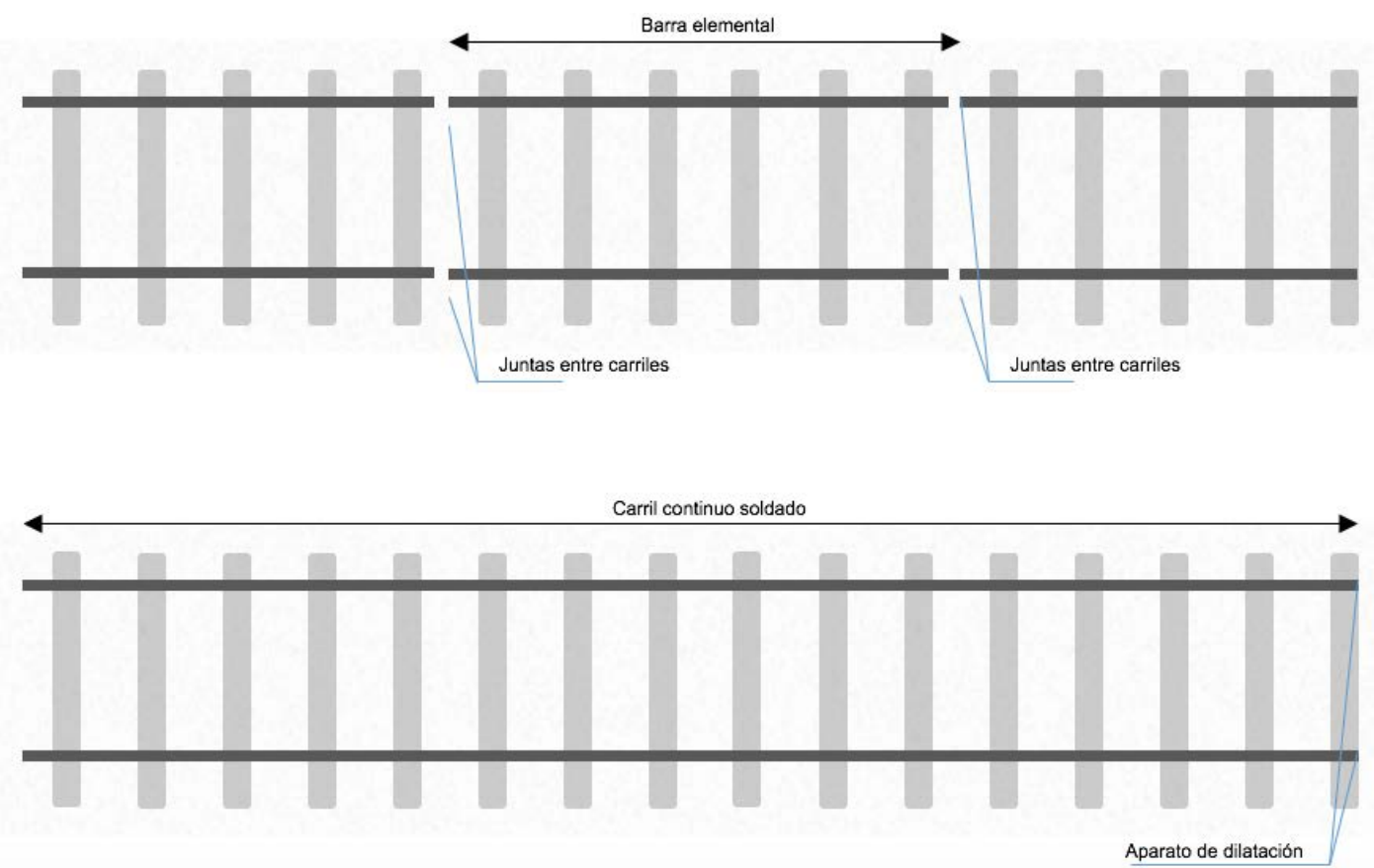

Figura 2.15: Esquema de vías con juntas (arriba) y con carril continuo soldado (abajo). Fuente: Elaboración propia.

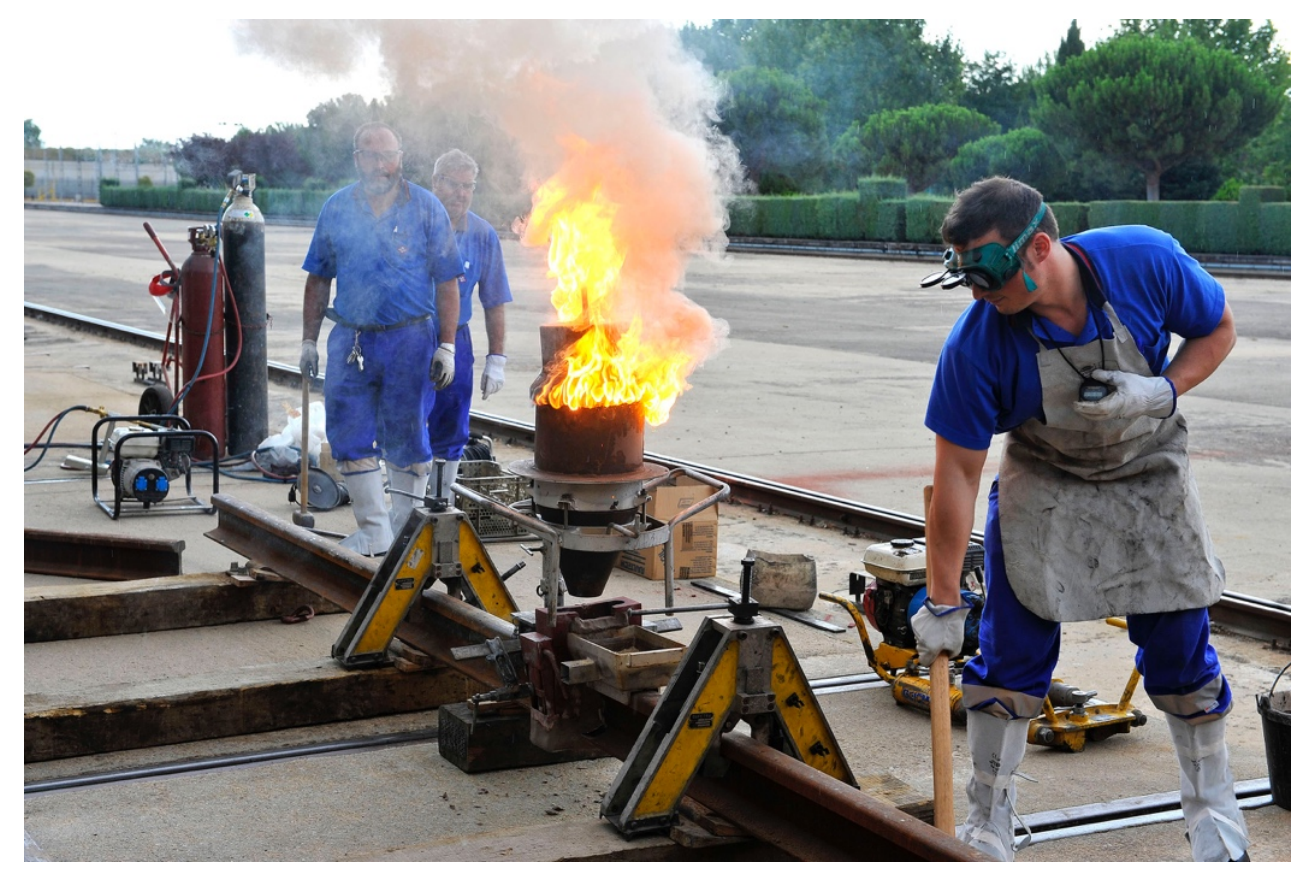

Figura 2.16: Soldadura aluminotérmica de carriles. Fuente: Metro Madrid. 

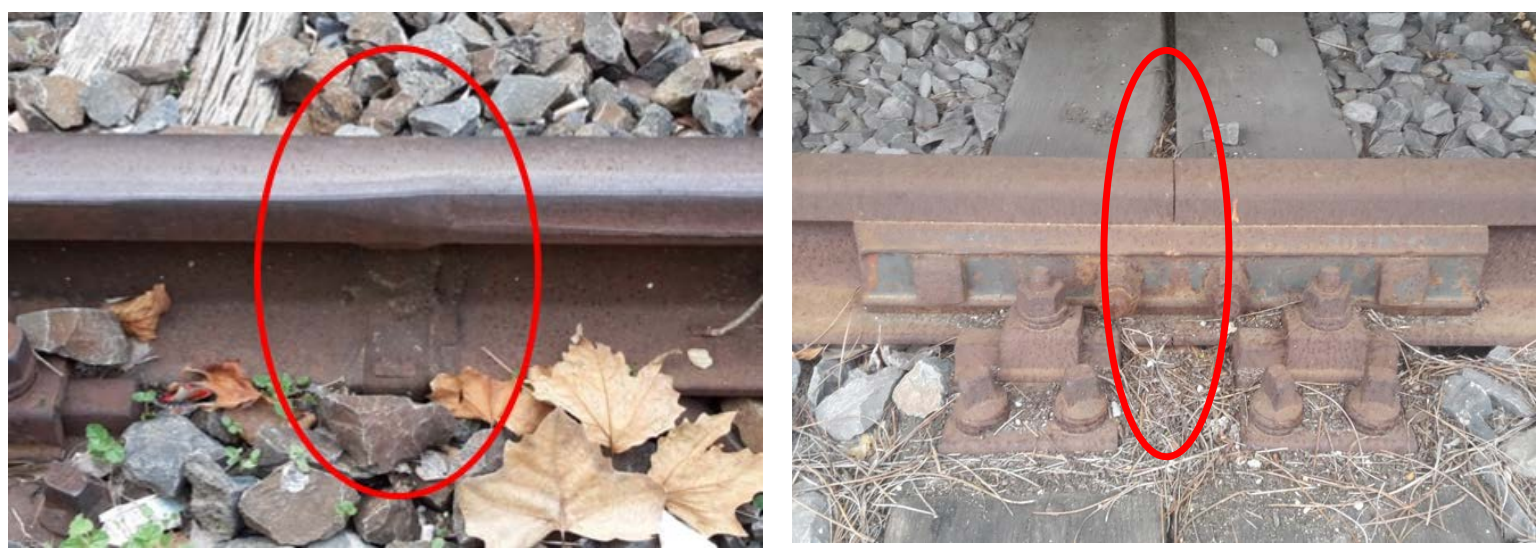

Figura 2.17: Imágenes de carriles. Soldadura (izquierda), junta embridada (derecha). Fuente: Elaboración propia.

De forma específica, las ventajas que presenta este tipo de vías frente a las tradicionales vías con juntas son:

- Reducción de los costes de mantenimiento.

- Reducción de los defectos y problemas en los carriles.

- Reducción del desgaste de los vehículos.

- Reducción del ruido y de las emisiones sonoras.

- Mejora del confort de la marcha.

- Reducción de los costes energéticos para la tracción.

- Mejora de la puesta en vía y del mantenimiento.

Gracias a las ventajas que presenta el carril continuo soldado, su uso se hizo muy común en la mayoría de las principales líneas ferroviarias a partir del 1950. No obstante, hasta la década del 1970 la longitud máxima de los carriles continuos soldados se limitaba a los 800 metros, con el fin de poder efectuar la liberación de tensiones y poder instalar en la vía juntas aislantes necesarias para el bloqueo automático cada $1.500-1.700 \mathrm{~m}$ (situadas cada dos tramos de carril de unos $800 \mathrm{~m}$ ).

Hoy en día y con la mejora de las técnicas de montaje de vía, de los circuitos de vía (en los que ya no es necesario la presencia de juntas aislantes) y de las sujeciones es posible alcanzar longitudes mayores. Por ello, en la actualidad es habitual emplear carriles continuos soldados de unos 2.000 m (Aparicio, 2004), con el fin de minimizar las juntas o aparatos de dilatación necesarios. 
Pese a que el carril continuo soldado permite evitar los problemas generados por las calas, su uso plantea otro tipo de inconvenientes que deben ser controlados. En este sentido, para que su instalación sea adecuada hay que tener en consideración los siguientes aspectos:

- Para su instalación se requieren ciertos radios de curvas mínimos (alrededor de 300 $\mathrm{m}$ ), con el objetivo de evitar que se presenten fenómenos de inestabilidad elástica.

- La plataforma de vía debe ser estable y el balasto debe alcanzar una mínima resistencia transversal.

- Las sujeciones deben proporcionar una elevada resistencia al movimiento del carril.

- Se debe realizar una inspección periódica y llevar a cabo un mantenimiento adecuado.

- Hay que realizar un proceso de neutralización de las tensiones internas del carril (montaje con neutralización en zonas donde se superan los $25^{\circ} \mathrm{C}$ ).

- Los puentes sin balasto no deben transmitir esfuerzos de origen térmico al carril.

- No deben situarse zonas de dilatación en las cercanías los cambios de tipo de carril, en zonas de frenado o de arranque habitual ni en pasos a nivel.

Además de los aspectos anteriores, un factor fundamental para el correcto funcionamiento del carril continuo soldado es la técnica de montaje. Hay que tener en consideración que en el instante en que se fija el carril a las traviesas la temperatura puede ser bastante heterogénea. Ante esta situación, es posible que las tensiones generadas por las variaciones de temperatura no estén repartidas adecuadamente y se superen ciertos límites admisibles. En ese caso, pueden producirse desplazamientos laterales diferenciales induciendo serpenteo en el carril y que disminuyen la comodidad, llegando a desestabilizar el emparrillado por exceso de compresión. En el caso opuesto, si las temperaturas se reducen mucho, es posible que pueda producirse la rotura de los carriles por excesivos esfuerzos de tracción.

Para evitar estos problemas, durante la fase de montaje en vía se realiza una operación denominada liberación de tensiones. La finalidad es la de conseguir que todo el tramo de carril continuo soldado sea fijado a las traviesas a una misma temperatura y que, además, dicha temperatura sea tal que los esfuerzos máximos de tracción y/o compresión producidos por las variaciones de temperatura a las que estarán sometidos se mantengan dentro de unos valores tal que puedan ser soportados convenientemente. 
Para poder neutralizar un tramo de carril es necesario, en primer lugar, calcular la temperatura de neutralización $t_{n}$. Dicha temperatura se establece como un valor cercano al valor medio de las temperaturas del carril durante un ciclo completo de un año y para la que, teóricamente, el carril se encuentra en un estado tensional nulo. Por lo tanto y de acuerdo con la normativa N.A.V. 7-1-4.1 "Montaje de vía - Neutralización y homogeneización de tensiones en la vía sin junta", la temperatura de neutralización se obtiene como el resultado de sumar $5^{\circ} \mathrm{C}$ a la media de las temperaturas extremas del carril (con una tolerancia de $\left.\pm 3^{\circ} \mathrm{C}\right)$.

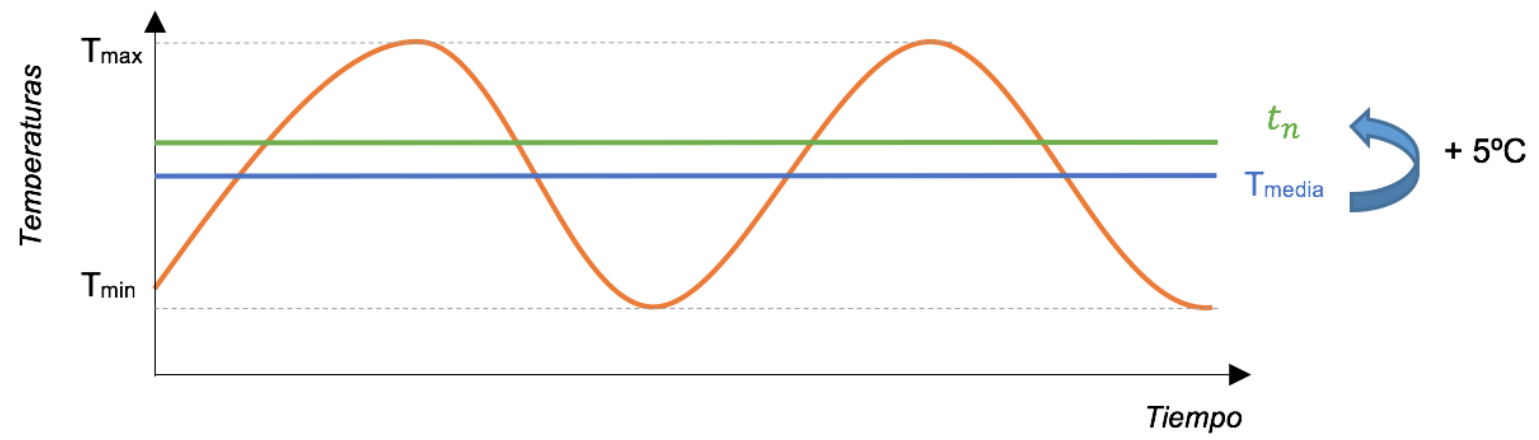

Figura 2.18: Representación de la temperatura de neutralización. Fuente: Elaboración propia.

$$
t_{n}=\frac{\Delta T}{2}+5=\frac{T_{\max }+T_{\min }}{2}+5
$$

donde las temperaturas están expresadas en grados centígrados.

En un primer momento, se adoptó un valor de $21^{\circ} \mathrm{C}$ como valor de referencia obtenido a través de los ensayos realizados por el British Rail Research en los años 50. Posteriormente, esta temperatura fue elevándose, para adaptarse a las condiciones climáticas. Como ejemplo, en España las temperaturas medias de los carriles oscilan entre los $17^{\circ} \mathrm{C}$ y los $27^{\circ} \mathrm{C}$, por lo que las temperaturas de neutralización se sitúan entre los $22^{\circ} \mathrm{C}$ y los $32^{\circ} \mathrm{C}$.

Una vez obtenida la temperatura de neutralización y asumiendo que el carril previo a su montaje se encuentra por debajo de esta temperatura, existen dos formas diferentes de instalación: por calentamiento del carril (natural o artificial) o por tracción mecánica. 
En el primero de los casos, el calentamiento puede realizarse bien sea por acción solar (calentamiento natural), bien sea por calentamiento artificial mediante dispositivos adecuados a dicho fin. En ambos casos y una vez alcanzada la temperatura de neutralización previamente calculada, las dos semibarras neutralizadas vienen fijadas a las traviesas y la cala central soldada, conformando un tramo de carril continuo soldado.

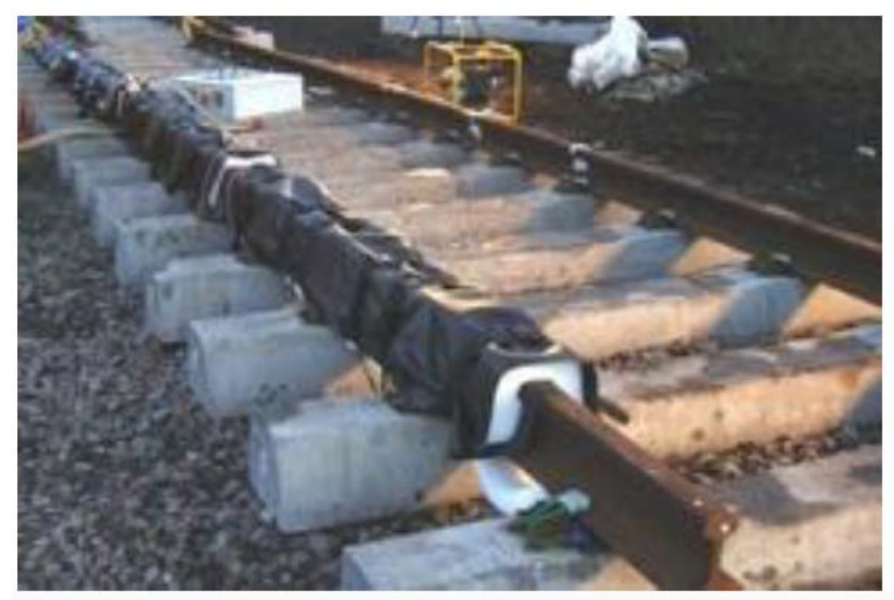

Figura 2.19: Calentamiento de carriles artificial. Fuente: Volker Rail.

En el segundo de los casos, la liberación de tensiones se alcanza alargando el carril mediante un esfuerzo mecánico a través de la tracción aplicada por tensores hidráulicos. Una vez alcanzado el alargamiento en cada semibarra, la cala central se suelda, al igual que se realiza en los casos anteriores.

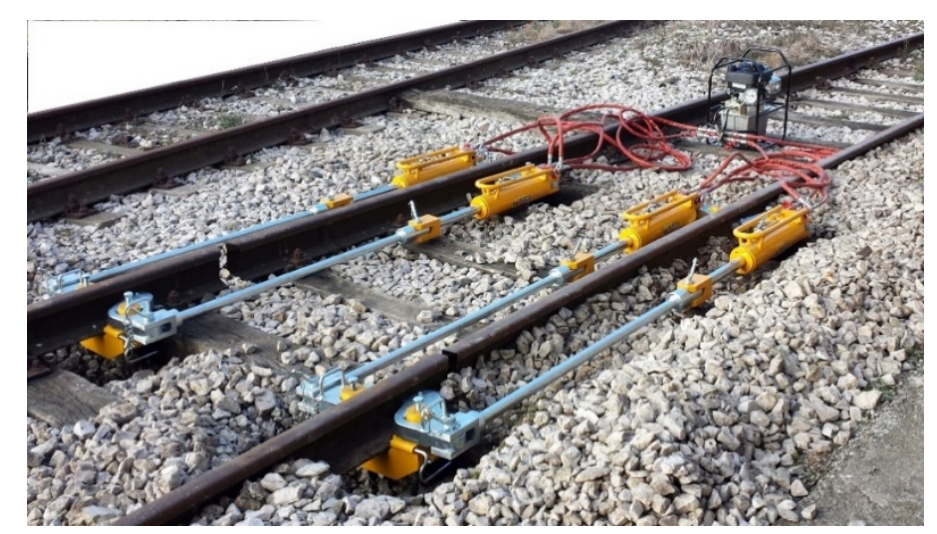

Figura 2.20: Tensor para neutralización de tensiones. Fuente: FCS Railway equipment.

Además de la propia temperatura de neutralización, un valor importante de temperatura sobre el cual se discutirá en capítulos posteriores lo constituye la temperatura crítica de pandeo $\left(t_{c p}\right)$. Ésta temperatura es aquella para la cual existe un riesgo muy importante de 
que la vía pueda pandear, en ausencia de cualquier otra acción externa. Constituye, por lo tanto, un valor límite por encima del cual el pandeo es muy probable que se produzca y que, por lo tanto, no debe ser alcanzado.

\subsubsection{Ecuaciones generales}

Para poder obtener la ecuación general se considera un segmento de carril $\overline{A B}$, con una longitud $d x$, considerando sus sujeciones bien apretadas y para un estado de equilibrio térmico (a la temperatura $T_{0}$ ). En este estado y aplicando el equilibrio se tiene:

$$
P-(P+d p)+d \delta=0
$$

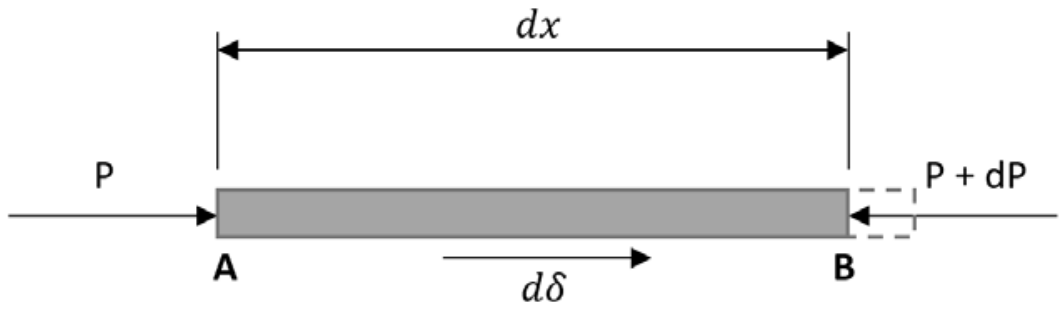

Figura 2.21: Esquema de segmento de carril aislado. Fuente: Elaboración propia.

En el segmento anterior, el valor $d \delta$ es proporcional al $d x$ así como a la resistencia unitaria longitudinal $\rho(x)$, por lo que $d \delta=\rho(x) d x$. Considerando que $\rho(x)=K_{x} q(x)$ se corresponde con la ley de rozamiento del conjunto carril/traviesas con el balasto (donde $q(x)$ representa la ley de desplazamientos longitudinales y $K_{x}$ es el factor de proporcionalidad de la resistencia al desplazamiento longitudinal), se ha observado que el factor $K_{x}$ toma valores entre los $10 \mathrm{~N} / \mathrm{mm}^{2}$ y $12 \mathrm{~N} / \mathrm{mm}^{2}$.

Con esto y ante una variación de temperatura $\Delta T$, el segmento $d x$ varia su longitud de acuerdo con la ley de Hooke, tal que:

$$
d q(x)=\left(\frac{P}{E A}+\alpha \Delta T\right) d x
$$

Si se despea de la ecuación anterior la carga $P$ se tiene: 


$$
P=\left(\frac{d q(x)}{d x}-\alpha \Delta T\right) E A=\left[q^{\prime}(x)-\alpha \Delta T\right] E A
$$

Además, tenemos:

$$
K_{x} q(x)=\frac{d P}{d x}=\frac{d \delta}{d x}
$$

Combinando las ecuaciones 2.26 y 2.27 se tiene:

$$
q^{\prime \prime}(x)=\frac{K_{x}}{E A} q(x)
$$

\subsubsection{Fuerza axial en el plano longitudinal}

Una vez descrito el procedimiento montaje y las ecuaciones generales, cabe preguntarse cuál es el alargamiento y esfuerzo que se produce en los extremos del mismo, pues dicho valor debe ser tomado en consideración en los aparatos de dilatación existentes en los extremos.

Desde el punto de vista teórico (Prud'Homme, 1969), la formulación puede establecerse considerando un carril apoyado en las traviesas a una temperatura inicial $t_{0}$, con una dilatación libre en sus extremos. Si al carril de dimensión $L$ se le aplica un incremento de temperatura $\Delta T$, el elemento sufre una elongación de valor igual a la ecuación 2.29:

$$
\delta=\alpha L \Delta T
$$

donde $\alpha_{T}$ es el coeficiente de dilatación del acero, con valores comprendidos entre $10,5 \times 10^{-6}$ y $11,5 \times 10^{-6}\left({ }^{\circ} \mathrm{C}^{-1}\right)$.

Por otro lado, considerando la aplicación de una fuerza de valor total $F$ en los extremos del carril, se produciría un acortamiento $\zeta$ tal que:

$$
\sigma=F / A=E \zeta /_{L} \rightarrow \zeta=\frac{F L}{E A}
$$



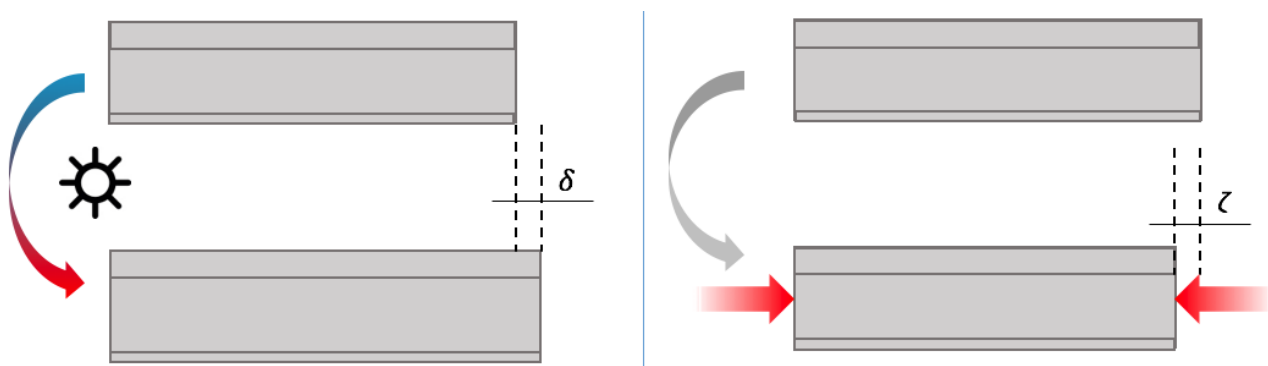

Figura 2.22: Representación de los esfuerzos y deformaciones en el carril. Fuente: Elaboración propia.

Considerando ambas solicitaciones (ecuaciones 2.29 y 2.30 ) y estableciendo un equilibrio para un elemento de dimensión $L$ se tiene:

$$
\Delta L=\delta-\zeta=\alpha L \Delta T-\frac{F L}{E A}
$$

Por lo que el esfuerzo $F$ capaz de anular o compensar el efecto térmico adquiere el siguiente valor:

$$
\Delta L=0 \rightarrow F=E A \alpha \Delta T
$$

Así pues, en una barra larga soldada de gran longitud y, considerando sus sujeciones debidamente apretadas, si sufre un incremento de $1^{\circ} \mathrm{C}$ (bien sea positivo o negativo) y considerando que $E_{\text {acero }}=2,1 \times 10^{5} \mathrm{MPa}$, la tensión resultante en el carril es de:

$$
\frac{F}{A}=E \alpha \Delta T=2,1 \times 10^{5} * 1,15 \times 10^{-5} * 1=2,415 \frac{\mathrm{N}}{\mathrm{mm}^{2}}
$$

Con este valor y considerando que, en los carriles, las tensiones residuales de fabricación se limitan generalmente a $250 \mathrm{~N} / \mathrm{mm}^{2}$ y las provocadas por el tráfico a $130 \mathrm{~N} / \mathrm{mm}^{2}$, para un incremento de $50^{\circ} \mathrm{C}$ se tiene:

$$
\text { Tension máxima carril }\left(\Delta T=50^{\circ} \mathrm{C}\right)=(2,415 * 50)+250+130 \approx 500 \frac{\mathrm{N}}{\mathrm{mm}^{2}}
$$

Puesto que el límite elástico del acero del carril es aproximadamente de unos $570 \mathrm{~N} / \mathrm{mm}^{2}$ y su carga de rotura de $930 \mathrm{~N} / \mathrm{mm}^{2}$, las tensiones máximas previstas no superan el límite elástico del material, quedando las solicitaciones en su zona elástica. 
En cuanto a los esfuerzos en función de la temperatura y para las secciones $(A)$ de los carriles habitualmente empleados, se tiene:

Valores del esfuerzo generada (kN/carril) por aumento de temperatura

\begin{tabular}{|c|c|c|c|}
\hline Carril & $\Delta T=1{ }^{\circ} \mathrm{C}$ & $\Delta T=25^{\circ} \mathrm{C}$ & $\Delta T=50^{\circ} \mathrm{C}$ \\
\hline RN 45 & 13,77 & 344,44 & 688,88 \\
\hline UIC 54 & 16,76 & 418,64 & 837,28 \\
\hline UIC 60 & 18,56 & 464,04 & 928,08 \\
\hline UIC 71 & 21,92 & 548,14 & 1096,28 \\
\hline
\end{tabular}

Tabla 2.4: Valores del esfuerzo generado en los carriles (kN/carril), en función del incremento de temperatura. Fuente: Elaboración propia.

Como valor orientativo medio puede considerarse una tasa aproximada de $20 \mathrm{kN} / \mathrm{carril}$, al variar la temperatura en $1^{\circ} \mathrm{C}$.

\subsubsection{Zona de respiración}

A parte del valor del esfuerzo máximo generado por un determinado incremento de temperatura anteriormente descrito, uno de los factores importantes en el carril continuo soldado lo constituye la longitud de respiración.

Esta longitud comprende la zona en la cual, debido al aumento de temperatura, se produce un movimiento de la vía en dirección longitudinal. En consecuencia, teóricamente el resto del carril que no sufre ningún tipo de movimiento se le conoce como zona neutra (en la zona neutra el carril permanece fijo), quedando sometido a tensiones axiales de valor $\sigma=$ $E \alpha \Delta T$ [ver Figura 2.23]. 


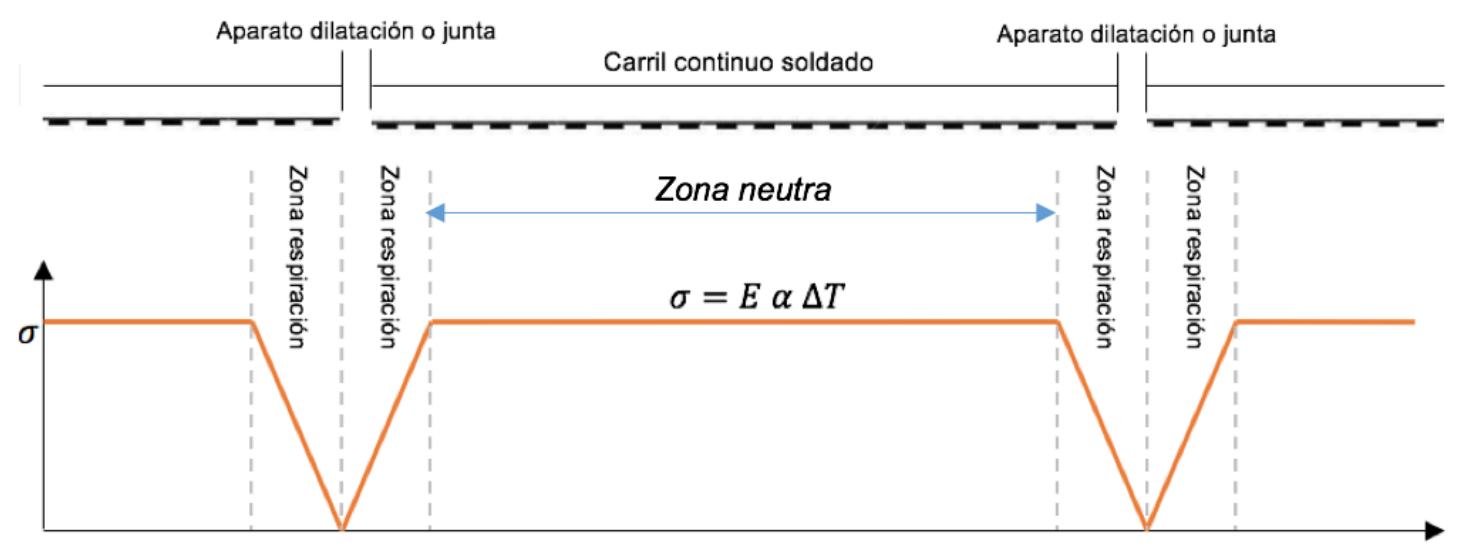

Figura 2.23: Esquema de tensiones en carril continúo soldado. Fuente: Elaboración propia.

Asumiendo que las tensiones debido a la variación térmica en los carriles varían de forma lineal desde cero (en el extremo) hasta el máximo de la fuerza $F=E A \alpha \Delta T$ (en la zona neutra), la longitud $X$ a partir de la cual la vía no se mueve cumple la siguiente desigualdad:

$$
r X \geq E A \alpha \Delta T
$$

donde $r$ es la resistencia longitudinal de la vía por metro de vía (expresada normalmente en daN/m o N/mm), generada por la oposición del balasto al desplazamiento.

El valor de la resistencia longitudinal de la vía depende de algunos factores como tipo de traviesa o del estado de consolidación del balasto, entre otros aspectos. Si se toma en consideración que la resistencia de una vía estándar varía entre 2,5 y $6 \mathrm{~N} / \mathrm{mm}$, la longitud de respiración toma los siguientes valores (ver Tabla 2.5).

\begin{tabular}{|c|c|c|}
\hline \multicolumn{3}{|c|}{ Valores de la longitud o zona de respiración (m) } \\
\hline Carril & $\mathrm{r}=2,5 \mathrm{~N} / \mathrm{mm}$ & $\mathrm{r}=6 \mathrm{~N} / \mathrm{mm}$ \\
\hline UIC 45 & 240 & 100 \\
\hline UIC 54 & 260 & 108 \\
\hline UIC 60 & 312 & 130 \\
\hline
\end{tabular}

Tabla 2.5: Expresiones de la carga crítica de pandeo, en función del campo de aplicación. Fuente: Elaboración propia.

Con esto, para que un tramo de vía posea una zona central inmóvil y, por tanto, pueda considerarse como un tramo con barra larga soldada, debe cumplir la siguiente desigualdad: 
2.4.6. Desplazamientos en la zona de respiración

Uno de los factores más importantes en la barra larga soldada es el valor de los desplazamientos longitudinales que experimenta un punto de la zona de respiración. Para poder llevar a cabo su determinación se parte del diagrama de tensiones generado en el carril (ver Figura 2.24).

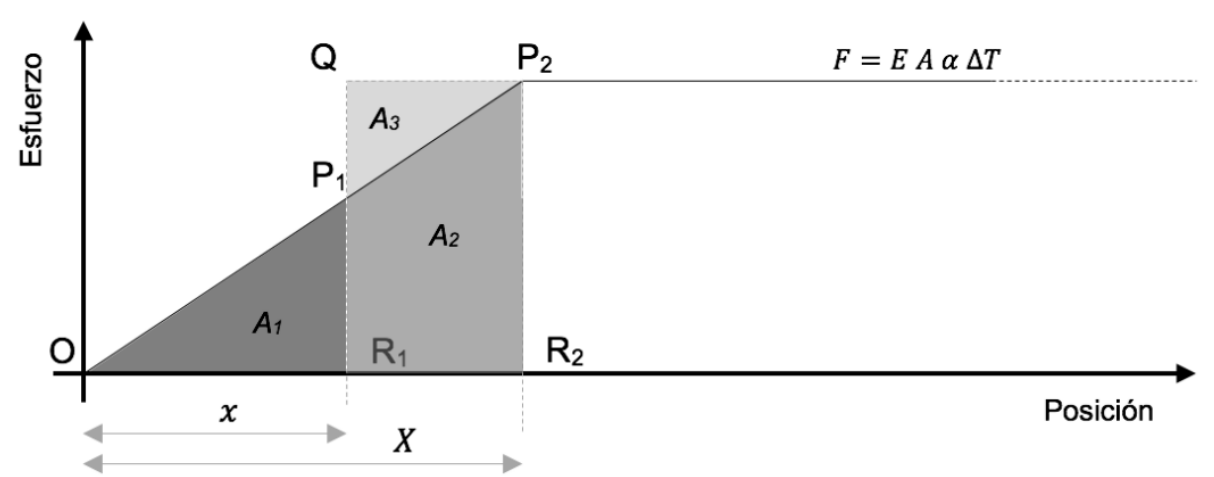

Figura 2.24: Ley de esfuerzos en carril continúo soldado. Fuente: Elaboración propia.

Bajo esta ley de esfuerzos, un punto cualquiera $\left(P_{1}\right)$ comprendido en la zona de respiración y localizado a una cierta distancia del extremo $\left(R_{1}\right)$ se moverá de acuerdo a la siguiente expresión:

$$
\delta_{R_{1}}=\int_{R_{2}}^{R_{1}} \Delta(d l)=\int_{R_{2}}^{R_{1}} \alpha \Delta T d l-\frac{\sigma d l}{E}=\alpha \Delta T \int_{R_{2}}^{R_{1}} d l-\int_{R_{2}}^{R_{1}} \frac{\sigma d l}{E}
$$

Considerando que $\int_{R_{2}}^{R_{1}} d l=\overline{R_{2} R_{1}}$ se tiene:

$$
\delta_{R_{1}}=\alpha \Delta T \overline{R_{2} R_{1}}-\int_{R_{2}}^{R_{1}} \frac{F d l}{E A}
$$

Operando con la ecuación anterior y multiplicando por $E A$ se obtiene:

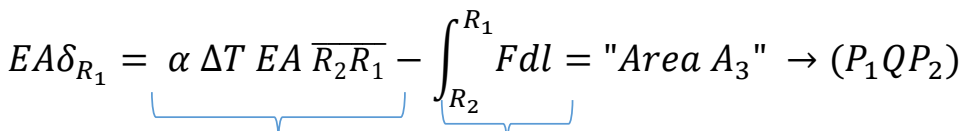

$$
\begin{aligned}
& A_{2}+A_{3} \quad A_{2}
\end{aligned}
$$




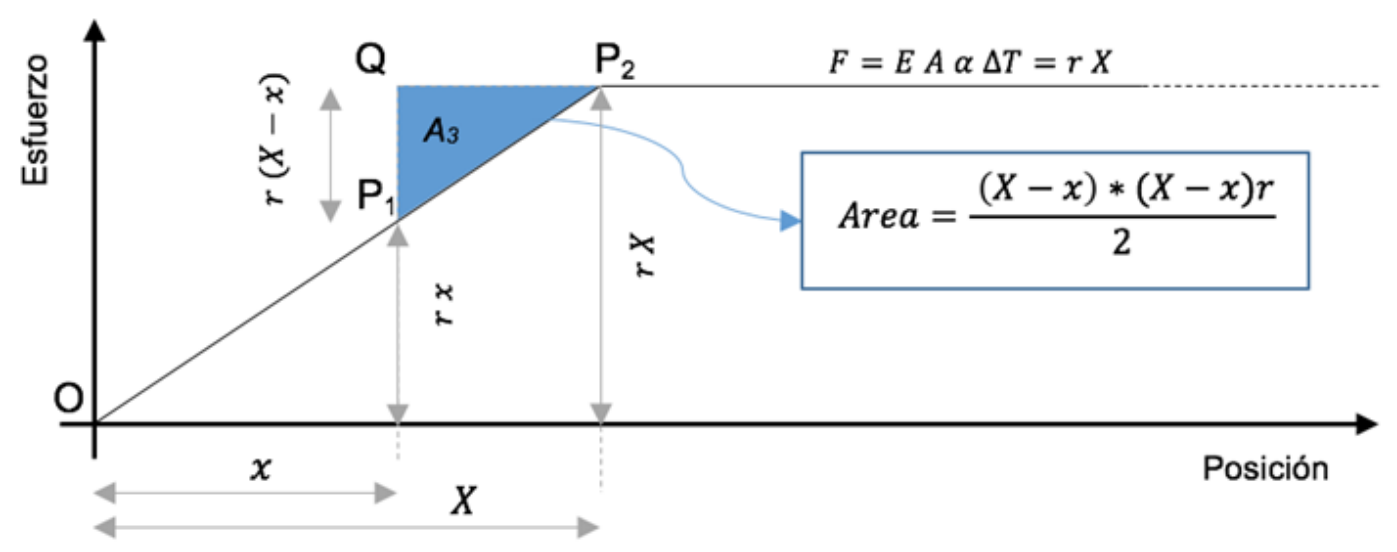

Figura 2.25: Área resultante de la ley de esfuerzos en el carril. Fuente: Elaboración propia.

Y, por lo tanto:

$$
E A \delta_{R_{1}}=\frac{(X-x)(X-x) r}{2}
$$

De la ecuación 2.38 es posible obtener finalmente el desplazamiento de un punto cualquiera de la zona de respiración $\delta_{R_{1}}$ como:

$$
\delta_{R_{1}}=\frac{(X-x)(X-x) r}{2 E A}=\frac{r}{2 E A}(X-x)^{2}
$$

La función anterior $\delta_{R_{1}}=f(x)$, es una parábola, cuyo vértice se localiza en el punto entre la zona neutra y la zona de respiración. Finalmente, la dilatación o movimiento del extremo $(x=0)$ puede obtenerse como:

$$
\delta_{\max }=\frac{X^{2} r}{2 E A}=\frac{E A \alpha^{2} \Delta T^{2}}{2 r}
$$




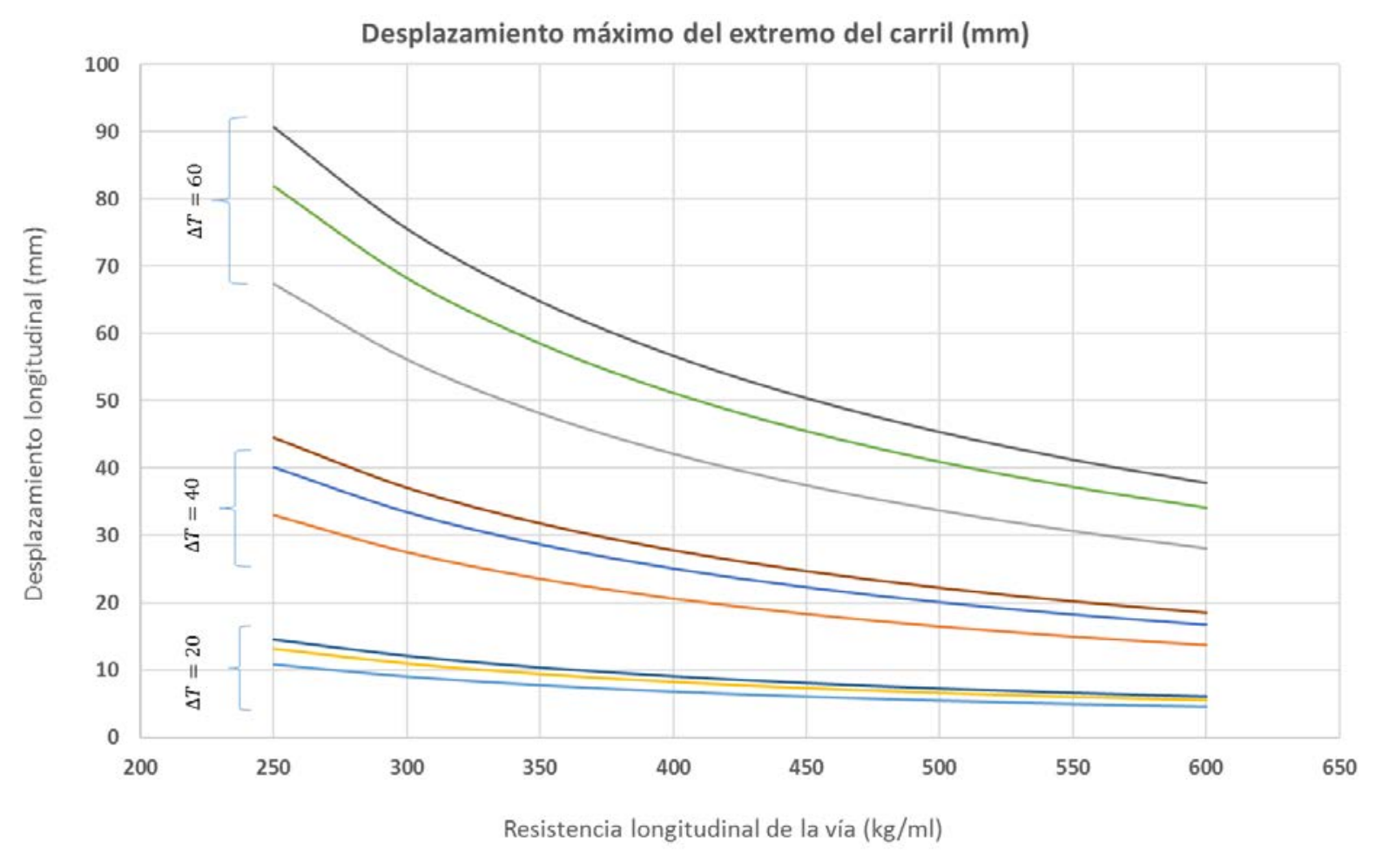

Figura 2.26: Valores del desplazamiento máximo del carril en los extremos. Fuente: Elaboración propia.

Como es posible observar, los desplazamientos máximos se sitúan alrededor de los $80 \mathrm{~mm}$, para incrementos máximos de temperatura de unos $50^{\circ} \mathrm{C}$. Estos desplazamientos deben ser tenidos en consideración en el diseño de los aparatos de dilatación presentes en los extremos (si bien depende del tipo de elemento al que se unan los carriles no siempre son necesarios).

Para finalizar, cabe mencionar que en el planteamiento realizado se ha considerado la resistencia longitudinal del balasto $(r)$ como un valor constante. Esta hipótesis no es totalmente cierta, pues en la realidad la resistencia longitudinal es función de del desplazamiento de las traviesas, creciendo hasta un valor límite. Bajo estas condiciones mucho más reales y con un planteamiento similar al realizado, se observaría que en la zona neutra se producen ciertos desplazamientos. Pese a ello, si se comparan los resultados obtenidos en ambos casos las diferencias son poco significativas, pudiendo considerar la resistencia longitudinal constante como una buena aproximación. 


\subsection{Causas del pandeo en vías}

Para poder analizar con precisión y poder minimizar el riesgo de pandeo es necesario identificar todas las causas que lo producen. Pese a que los factores que condicionan el fenómeno son bien conocidos e identificados desde el punto de vista teórico, la evaluación y cuantificación de cada uno de ellos no ha sido llevada a cabo uniformemente por las diversas administraciones ferroviarias, poniendo de manifiesto la dificultad del fenómeno a tratar. En cierta medida, este hecho es debido a que el comportamiento de la vía puede resultar muy variable según las condiciones en que se encuentre y los esfuerzos a los que esté sometida.

Si se analizan las zonas donde se produce más frecuentemente la experiencia obtenida muestra que las zonas más susceptibles de sufrir el pandeo son los tramos cercanos a estructuras, zonas con pendientes pronunciadas y las zonas de frenado. Además, un número importante de los pandeos se produce durante los días posteriores a las intervenciones de mantenimiento, por lo que se debe tener especialmente cuidado cuando se realiza cualquier intervención en la vía.

Tras estas consideraciones previas, cabe mencionar que la metodología utilizada para analizar el pandeo debe considerar el riesgo y la interacción de todos y cada una de los factores que influyen en el fenómeno, en tanto en cuanto cada uno de ellos modifica el estado tensodeformacional de la vía en mayor o menor medida. Bajo esta perspectiva, los factores que condicionan el pandeo son:

- Variaciones de temperatura.

- Cargas dinámicas, esfuerzos de frenado y arranque, transmitidos por las ruedas.

- Perdida de resistencia lateral de la vía (desconsolidación por bateo).

- Defectos en soldaduras.

- Defectos de alineación de la vía.

- Reducida resistencia transversal.

- Reducida temperatura de neutralización. 


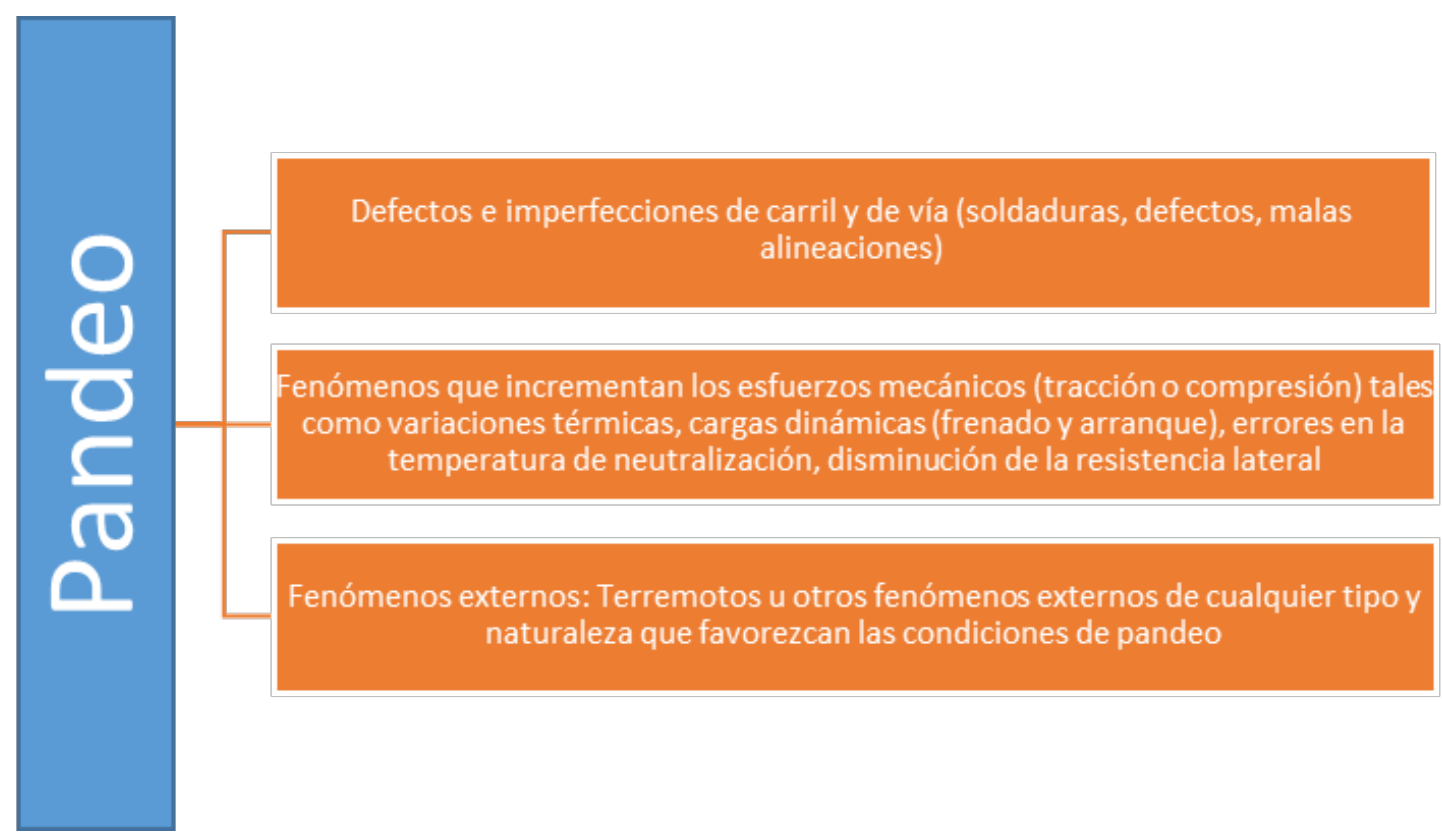

Figura 2.27: Esquema de factores que condicionan el pandeo. Fuente: Elaboración propia.

Pese a que todas las acciones citadas anteriormente contribuyen, en mayor o menor medida, a favorecer o contrarrestar el pandeo en vía el principal causante del pandeo es, sin lugar a dudas, el incremento de la temperatura en los carriles. Aunque no es el único factor sí es el más importante, siendo necesario tener limitados los esfuerzos que se pueden generar a través de la temperatura de neutralización. Como se ha visto en el apartado 2.4, cuando la temperatura de los carriles sobrepasa la temperatura de neutralización, se produce un esfuerzo axial proporcional a la diferencia de ambas temperatura. Si la temperatura de los carriles supera un cierto límite, es probable que los esfuerzos axiales desestabilicen la vía, dando como resultado deformaciones en el plano longitudinal.

Por este motivo, las administraciones y compañías ferroviarias de todo el mundo usan generalmente una política de restricción de velocidad cuando la temperatura atmosférica es superior a un determinado límite. Estas restricciones de velocidad se imponen para poder circular con un cierto margen de seguridad, si bien puede resultar muy conservador en algunos casos e inseguro en otros. Por ello, la política de restricción de velocidad obstaculiza la explotación de la infraestructura y aumentan el costo de operación del servicio. 

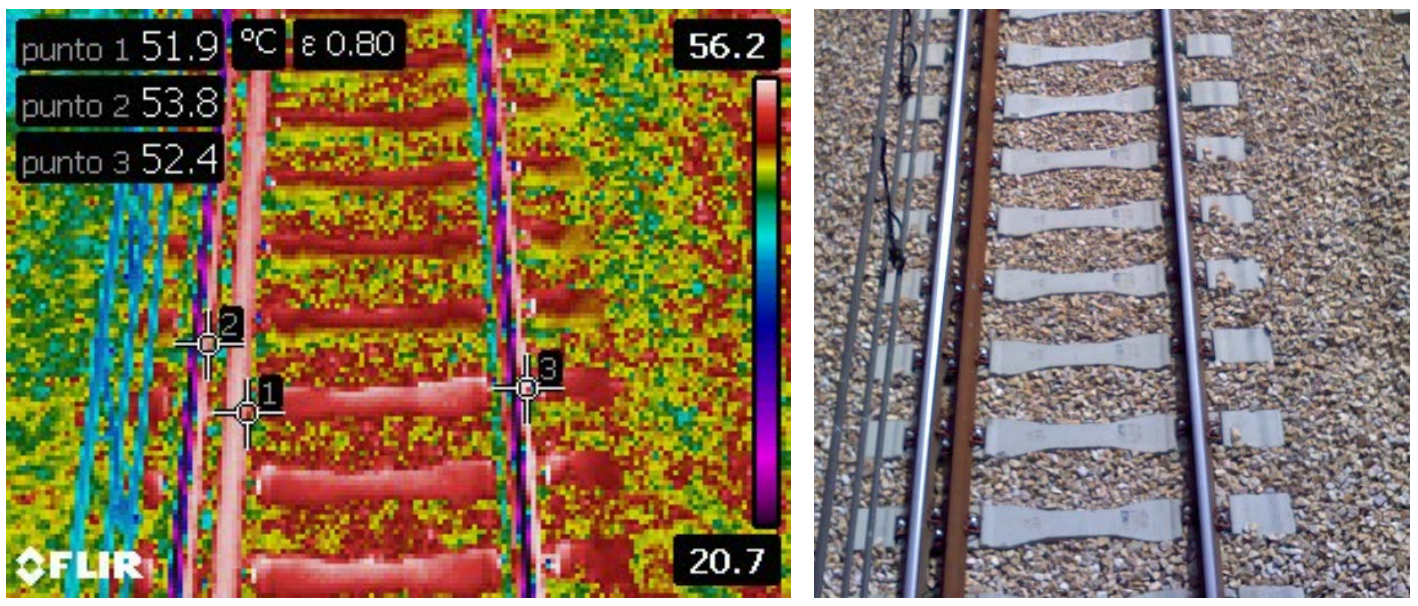

Figura 2.28: Medida de temperaturas en carriles. Fuente: Elaboración propia.

Además de la temperatura, un aspecto clave en el estudio del pandeo lo constituyen los defectos de alineación. Esto es debido a que el pandeo, para que pueda desencadenarse, requiere la presencia de imperfecciones iniciales en la vía, ya que estas imperfecciones proporcionan la excentricidad necesaria para que las fuerzas axiales puedan desplazar lateralmente la vía. En este sentido y desde el punto de vista teórico, una vía perfectamente recta no puede pandear, tal y como se verá en el capítulo III.

Si la clasificación atiende a los factores que favorecen o contrarrestan el fenómeno, una posible clasificación viene representada en la Figura 2.29.

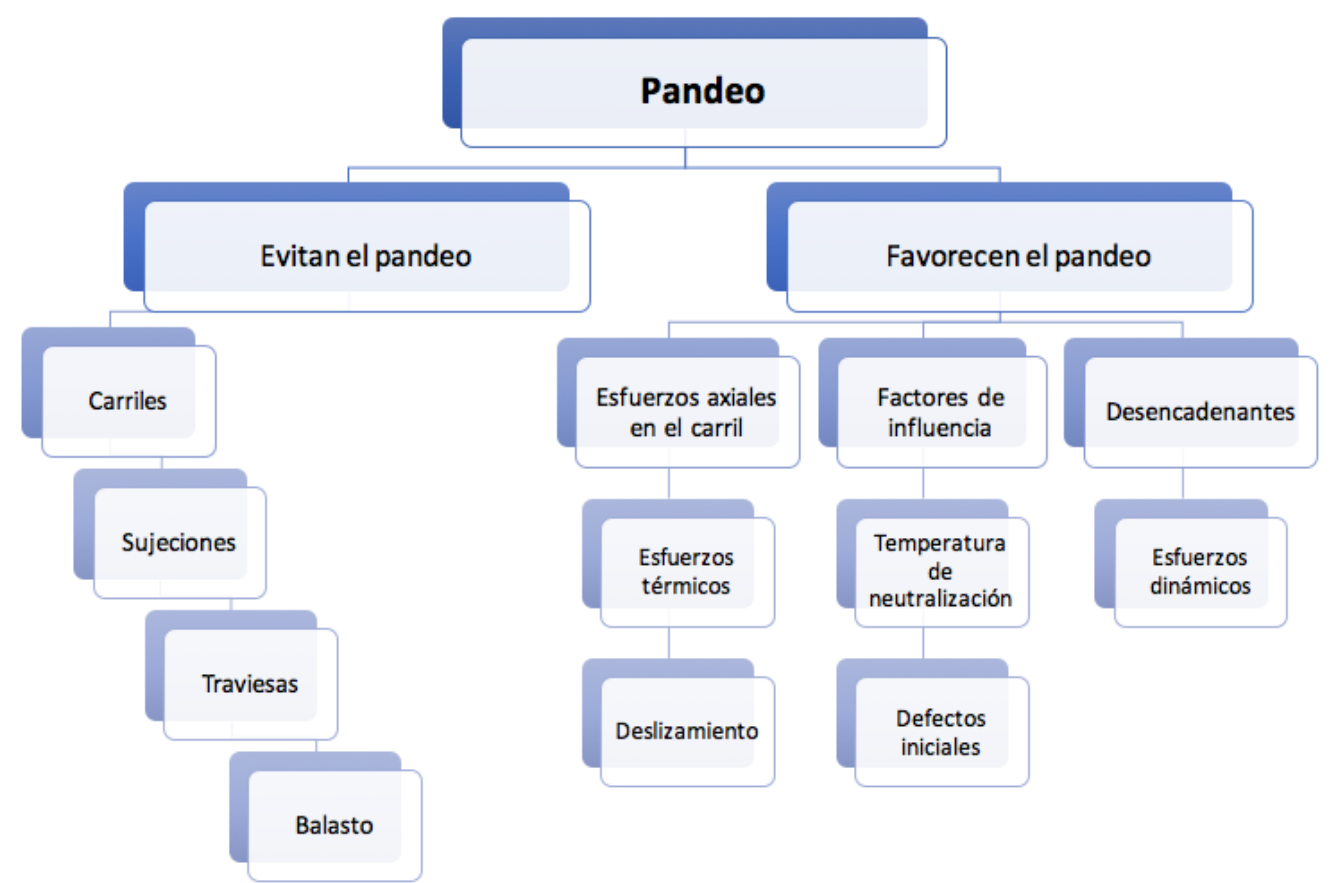

Figura 2.29: Esquema de factores que condicionan el pandeo. Fuente: Elaboración propia. 
En un lado, los factores que permiten mantener estable la vía se encuentran representados por los propios elementos que conforman la superestructura. Tanto la rigidez de los carriles, las sujeciones, las traviesas y el balasto son componentes que contribuyen a aumentar la resistencia transversal de la vía y, por lo tanto, a evitar que se produzca el pandeo.

Es fácil entender que cuanto mayor sea la inercia del carril, el par de apriete, el peso de la traviesa o la altura y la forma/compactación del balasto, mayor será la resistencia transversal de la vía. Ahora bien, dada una cierta configuración de la superestructura de la vía (carril, sujeciones, traviesa y balasto), la resistencia transversal de la misma alcanza un límite superior, por lo que si se supera la vía no será capaz de ofrecer una mayor resistencia.

En el lado opuesto encontramos los factores que favorecen el pandeo. De entre éstos el factor con más peso es, como ya se ha citado en varias ocasiones, el aumento de la temperatura. Más allá de este factor (será tratado en profundidad en los próximos capítulos), es posible observar como existen otros elementos que contribuyen a reducir la resistencia lateral de la vía. Entre estos factores destaca los esfuerzos longitudinales (debido a las acciones de frenado y/o aceleración), un valor inadecuado de la temperatura de neutralización o la presencia de defectos de alineación.

\subsubsection{Operaciones que modifican la respuesta de la vía}

Además de los factores citados, hay que tener presente que la vía debe ser periódicamente sometida a una serie de operaciones de mantenimiento o reparación que permiten asegurar su funcionalidad y estabilidad. Este tipo de operaciones puede ser muy variado y con diferentes frecuencias de intervención, pudiendo cambiar o modificar las condiciones iniciales en las que la vía había sido instalada y, por consiguiente, su respuesta frente al pandeo. De entre las múltiples operaciones de mantenimiento que pueden afectar al comportamiento de la vía, es posible destacar:

- Alineación de vía.

- Bateo de la capa de balasto.

- Amolado o reperfilado de carril.

- Renovación o sustitución de carriles/traviesas/sujeciones.

- Depuración o desguarnecido del balasto.

- Reparación de roturas de carril. 
Del mismo modo que sucede con los factores anteriormente citados, no se debe olvidar que una determinada vía, durante su vida útil, puede sufrir cambios importantes en su configuración para poder adaptarse a las necesidades de cada momento. Estos cambios comportan, en algunos casos, la sustitución parcial o total de los elementos que la componen, así como la creación o eliminación de determinados aparatos de vía, alterando la estructura inicial. Estas operaciones deben ser llevadas a cabo con especial atención pues, desde el punto de vista del pandeo, es posible que se reduzca la resistencia de la vía y se favorezca el pandeo.

De entre las múltiples intervenciones, es posible destacar las siguientes:

- Soldadura y/o creación de nuevas juntas.

- Construcción o supresión de desvíos.

- Cambio de la alineación de la vía.

- Reparación de descarrilos.

Para finalizar, es necesario destacar el efecto perjudicial que tienen los terremotos, pues si bien el incremento de esfuerzos axiales en los carriles producido por un terremoto no es muy elevado frente al esfuerzo generado por la temperatura (Arbabi y Khalighi, 2010), la reducción de la resistencia transversal y el aumento de las deformaciones laterales que produce puede llevar a que la vía acabe pandeando.

\subsection{Frecuencia y accidentalidad del pandeo}

Para conocer la frecuencia y severidad con la que el fenómeno se presenta en las vías europeas, es posible analizar la magnitud del problema a través de las estadísticas de seguridad ferroviaria.

Gracias a la nueva directiva sobre seguridad ferroviaria (2016/768 de 11 de mayo de 2016) se establece un marco común para llevar a cabo un seguimiento común de los datos de accidentes ferroviarios. Bajo este marco, se han definido unos indicadores de resultados que permitan el seguimiento y la gestión de la seguridad a escala de la UE. 
Por ello, la Agencia Ferroviaria de la Unión Europea (ERA), recoge en un informe bianual cuáles son las principales causas de los accidentes ferroviarios a través de los denominados "precursores de accidentes". Estos precursores de incidentes son indicadores de incidentes que, en otras circunstancias, podría haber llevado a un accidente mucho más serio.

Uno de los indicadores recogidos por la ERA es el denominado "track buckle". Este indicador aglutina todos los sucesos que tienen como causa principal un defecto geométrico de vía que requiere la reducción inmediata de la velocidad o la suspensión temporal del servicio. Si bien no recoge de forma estricta aquellos sucesos ocasionados por el pandeo, si puede proporcionar una idea de su importancia.

Dicho esto, para dar una idea de la frecuencia en la que se suceden eventos relacionados con el pandeo y los defectos de vía, cabe destacar que durante el período 2012-2014 (el año 2014 es el último del que se tienen datos), el pandeo y los defectos de vía son la segunda causa más frecuente, únicamente por detrás de la rotura de carriles (ver Figura 2.30).

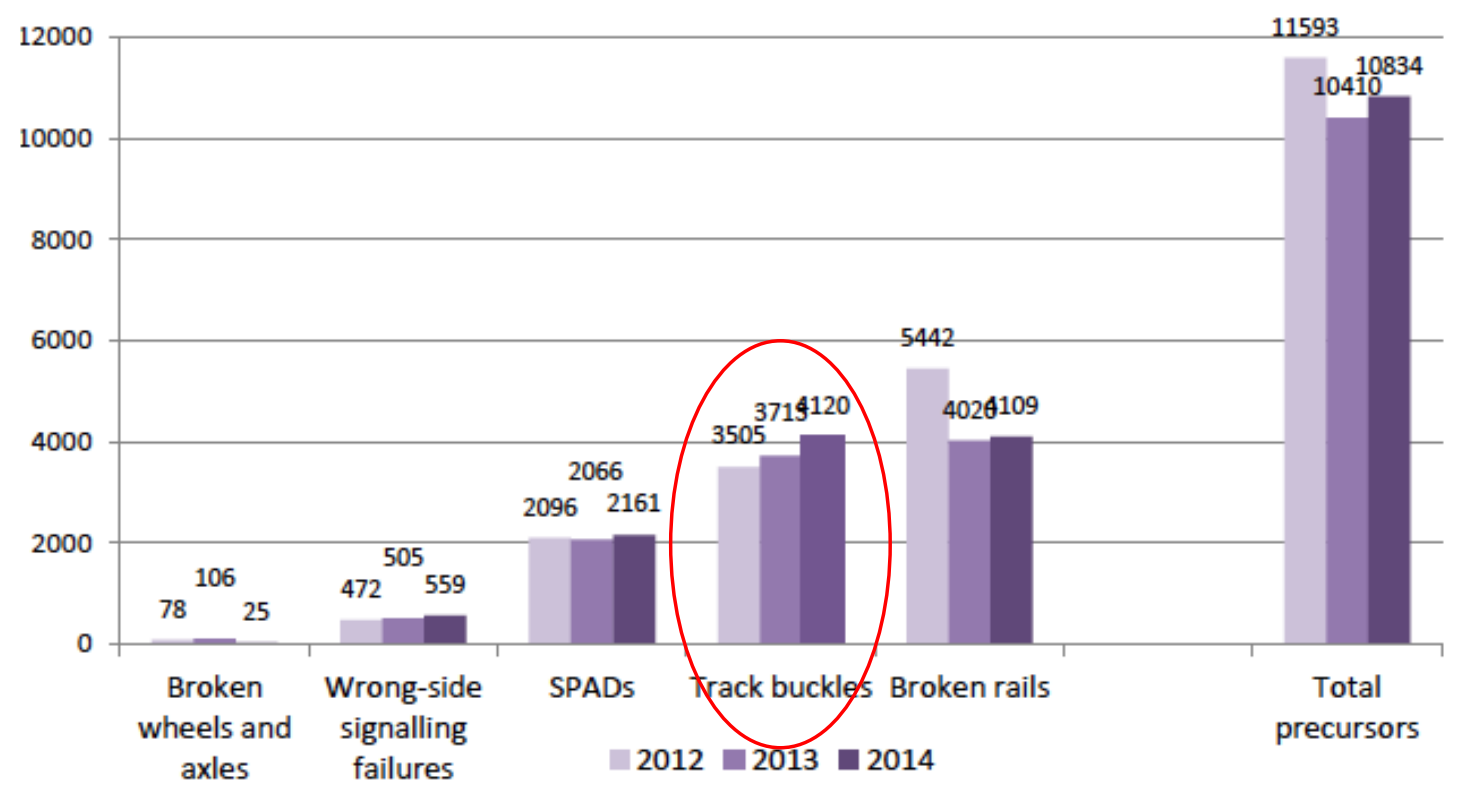

Figura 2.30: Causas principales de incidentes ferroviarios y numero de eventos registrados. Fuente: Railway safety performance in the European Union (2016), European Railway Agency (ERA). 
Si se analizan los datos para los 27 países de la Unión Europea, durante el período 20062014 se han producido un total de 29.500 incidentes donde el responsable principal es la geometría de vía, lo que supone una media de 3277 incidentes al año, con un crecimiento preocupante desde el año 2008 (ver Figura 2.31).

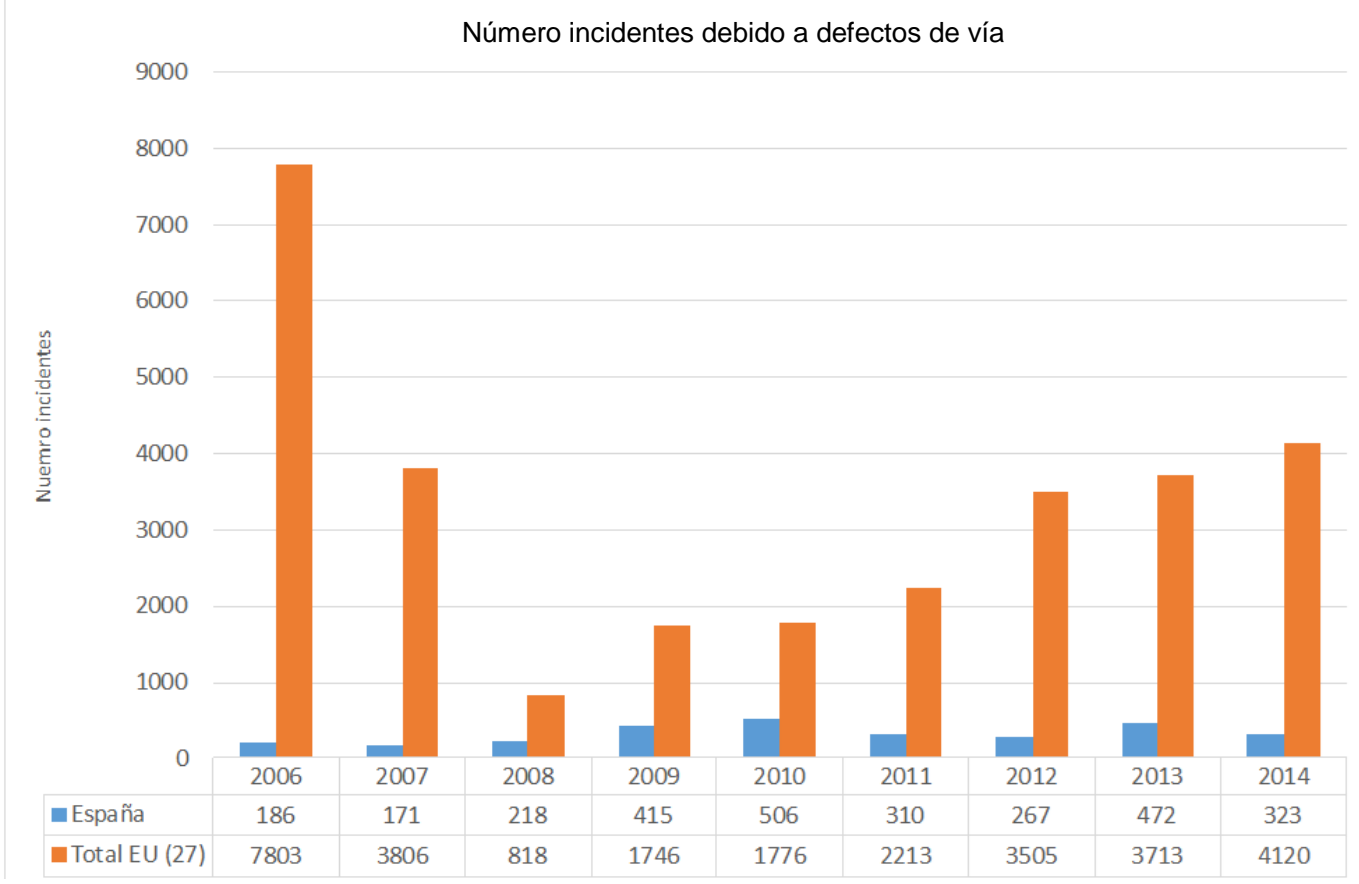

Figura 2.31: Número de incidentes debidos a defectos de vía. Fuente: European Railway Agency (ERA).

En cuanto a los eventos ocurridos en cada uno de los países, es posible afirmar que la mayoría de éstos se producen en los países localizados en la zona más al sur de Europa (España, Portugal, Italia). Este hecho pone de manifiesto la importancia que posee del clima en el fenómeno, pues los países donde se alcanzan mayores temperaturas son los que, en mayor medida, sufren este problema. 


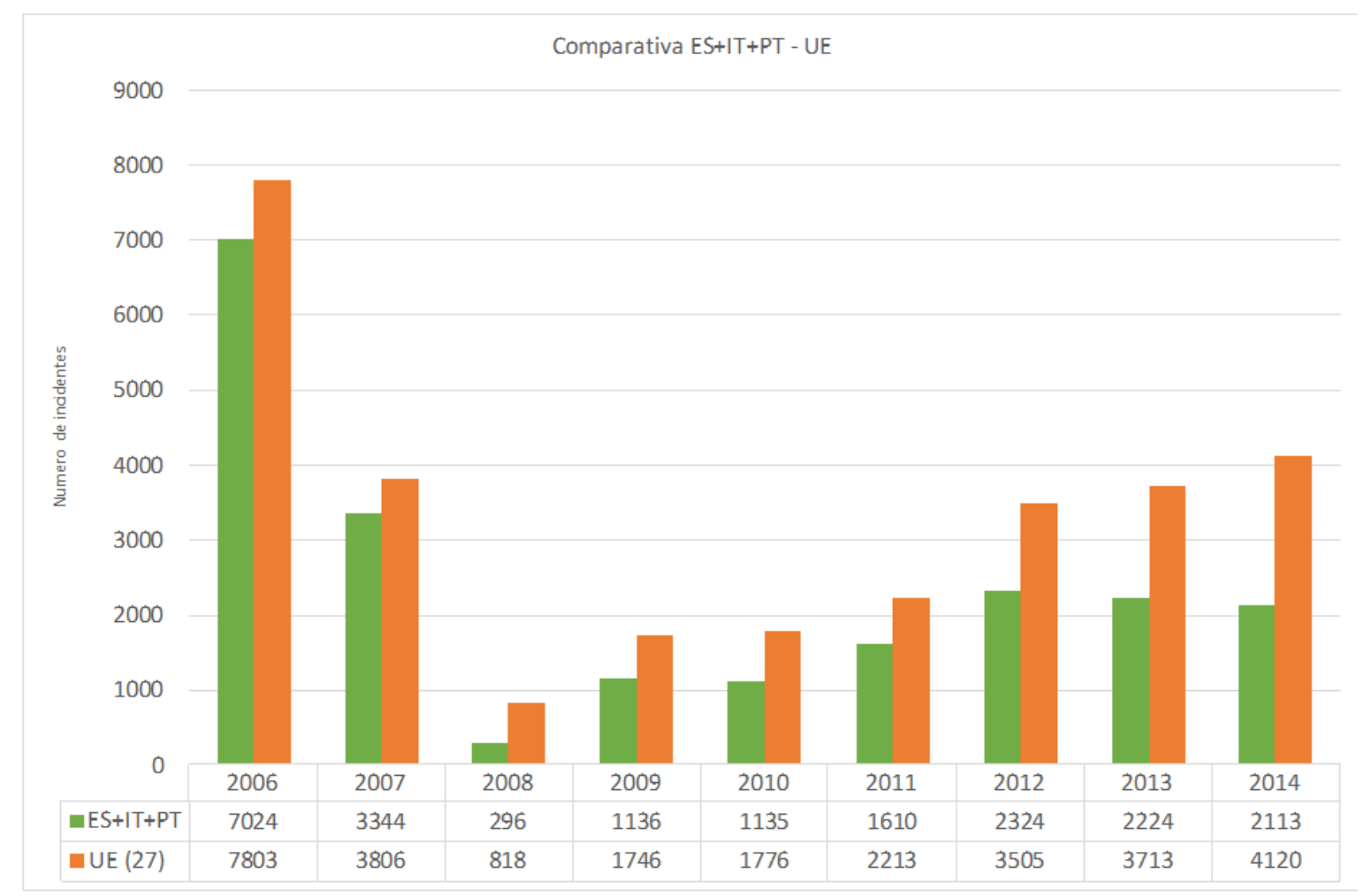

Figura 2.32: Número de incidentes debidos a defectos de vía. Fuente: European Railway Agency (ERA).

En el caso de España, la tendencia de los incidentes en los últimos años es algo confusa, si bien la media de eventos se sitúa en torno a los 320 incidentes al año. Por su parte, la Figura 2.33 muestra el número de incidentes y la temperatura media durante los meses de verano (generalmente de junio a agosto).

Es interesante observar como parece existir una cierta relación entre el número de incidencias por defectos de la vía y la temperatura media durante los meses de verano. En efecto, esta tendencia puede llevar a pensar que existe una clara relación entre la temperatura ambiente y la desestabilización de la vía.

No obstante, hay que tener presente que aspectos como el estado de conservación y el mantenimiento, entre otros factores, son especialmente importantes en la estabilidad de la vía y hacen que no sea posible afirmar claramente la existencia de relación causa-efecto entre la temperatura y el pandeo. 


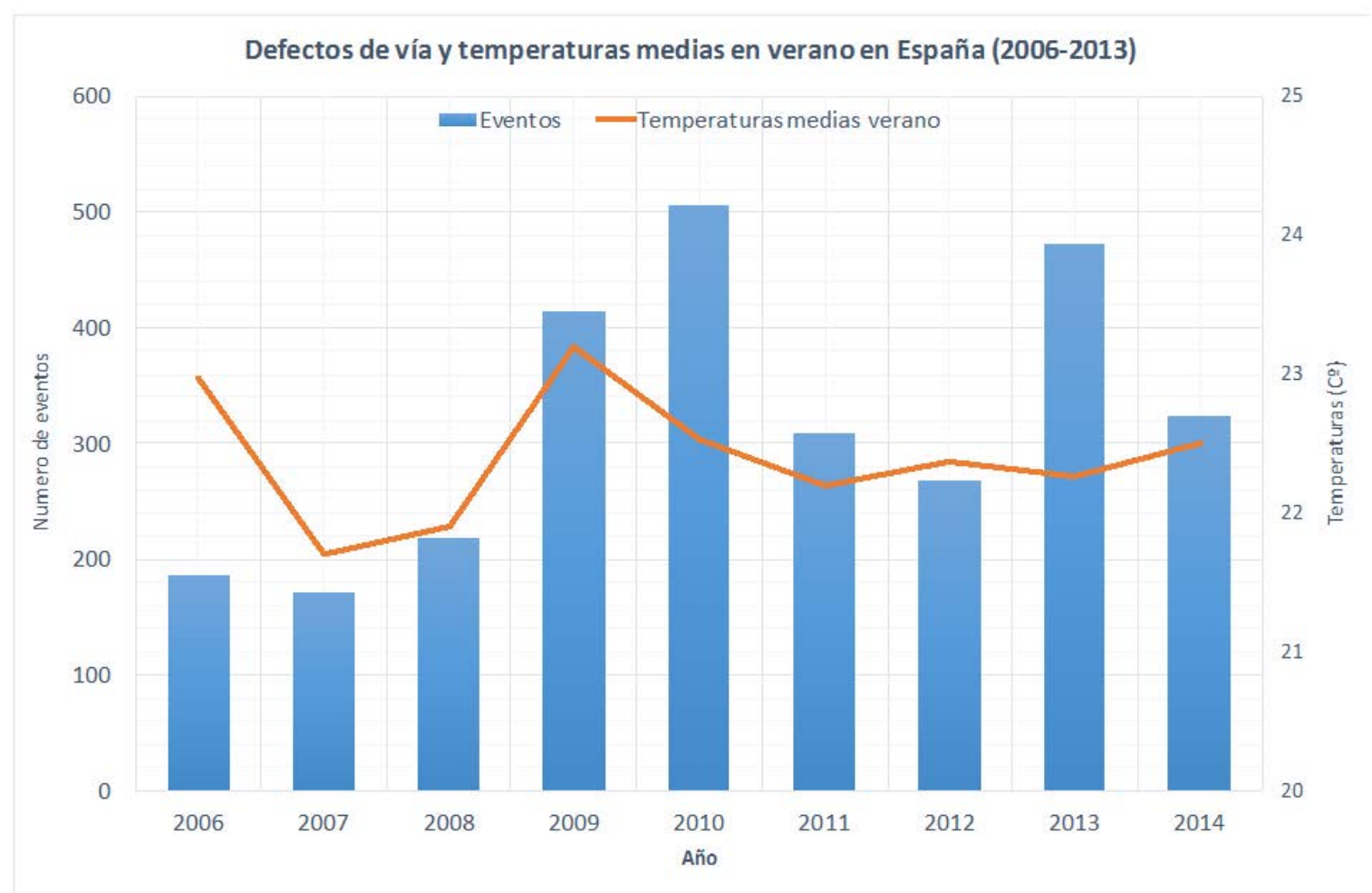

Figura 2.33: Número de incidentes debidos a defectos de vía en España y temperatura media de verano. Fuente: European Railway Agency (ERA). 


\section{La teoría de la estabilidad transversal}

En el capítulo anterior se ha abordado el estudio del pandeo en elementos aislados esbeltos como paso previo al estudio del pandeo en vías férreas. A lo largo del presente apartado se describe el estudio del pandeo de vías desde el punto de vista teórico.

En este tema también se introduce el concepto de energía de pandeo, así como una descripción detallada de la estabilidad transversal de la vía en el plano horizontal (el plano vertical no suele producirse el pandeo, tal y como se ha descrito en el capítulo anterior), introduciendo los aspectos generales y particulares que condicionan dicho fenómeno.

Tras esta breve introducción, en primer lugar, se estudiará el caso de una vía sin defectos de alineación y se determinará la carga teórica de pandeo. Posteriormente, se analizará el comportamiento de la vía frente al pandeo bajo diversos factores relacionados con la estabilidad transversal. Para facilitar el seguimiento, se hará uso de las curvas de pandeo y se analizará la influencia de cada factor en la respuesta de la vía.

\subsection{Introducción}

Tal y como se ha descrito previamente, el pandeo ocurre generalmente en climas calurosos debido al aumento considerable de la temperatura de los carriles y, por tanto, de los esfuerzos longitudinales. Frente a los esfuerzos generados por la temperatura, la vía es capaz de ofrecer una resistencia que se opone a la posible deformación, cuya magnitud y comportamiento es el resultado de la interacción de varios elementos. 
Pese a que las acciones que condicionan el fenómeno son bien conocidas, el planteamiento teórico del problema es enormemente complejo. Por ello, tradicionalmente, el estudio del pandeo se ha abordado mediante aproximaciones simplificadas, permitiendo encontrar una solución que pueda ser aplicada en la práctica.

Con estas premisas, la resistencia de la vía es el resultado de los esfuerzos comprendidos en el plano de vía (longitudinal, transversal y torsional) y una fuera de este plano (vertical). Las tres componentes del plano horizontal de vía, representadas por elementos tipo muelle, se muestran en la Figura 3.1.

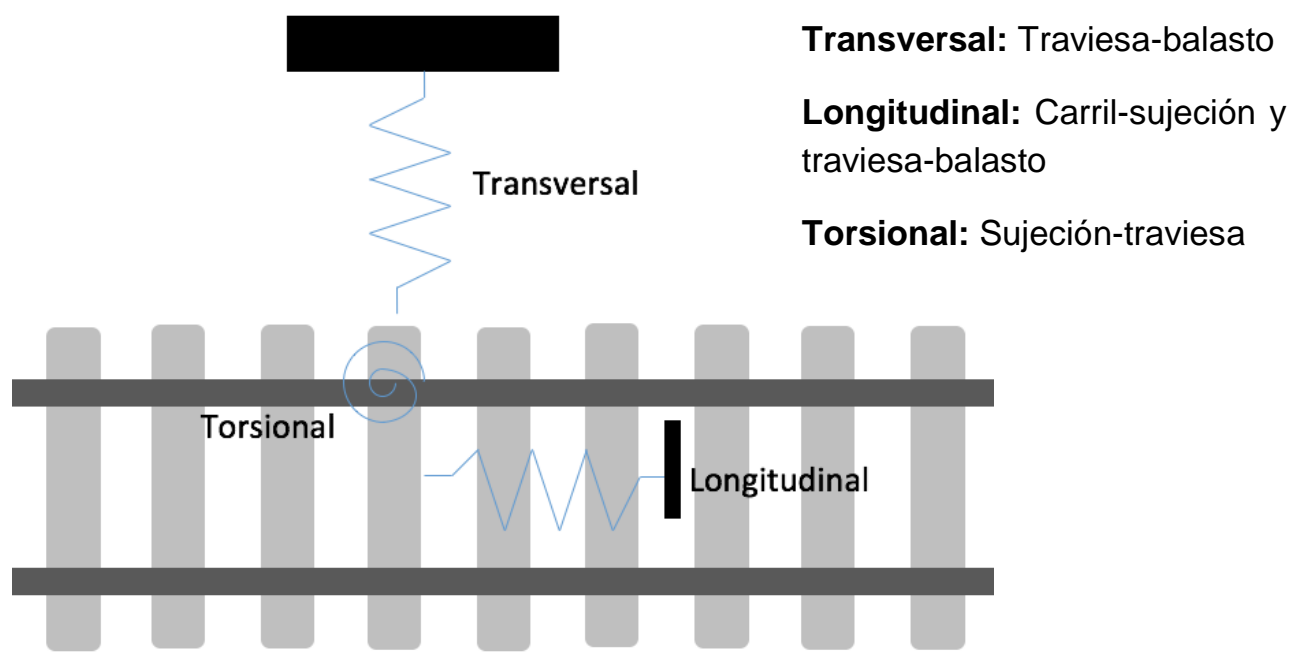

Figura 3.1: Resistencias en el plano de vía. Fuente: Elaboración propia.

La resistencia longitudinal de la vía es aquella proporcionada por las sujeciones y el contacto traviesa balasto es importante para prever el desplazamiento longitudinal del carril y limitar la posible rotura del carril. Por su parte, la resistencia torsional proporcionada por el apriete de las sujeciones contrarresta el posible giro del carril sobre la sujeción, aportando rigidez frente al pandeo.

La última de las resistencias en el plano horizontal, la resistencia transversal, es aquella proporcionada principalmente por la oposición del balasto a desplazarse lateralmente. Esta resistencia está influenciada por una multitud de factores y resulta fundamental en la estabilidad transversal de la vía frente al pandeo. Su origen resulta de la suma de los esfuerzos proporcionados por tres niveles elementos o niveles, que son: 


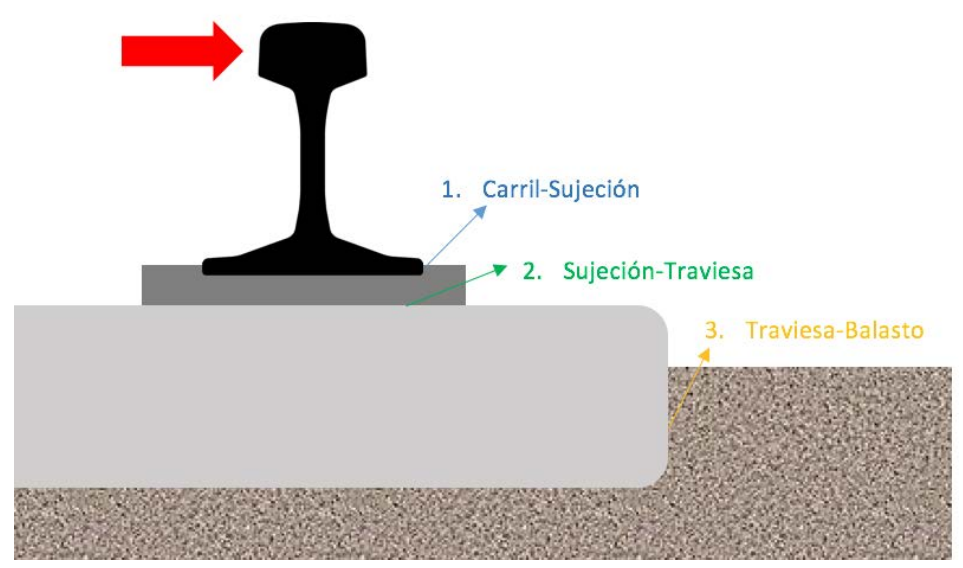

Figura 3.2: Niveles de resistencia longitudinal y transversal en la vía. Fuente: Elaboración propia.

En el primer nivel y segundo nivel, las sujeciones permiten resistir tanto esfuerzos longitudinales como transversales, debido a la fuerza de apriete y su anclaje a la traviesa. En el primer caso, la contribución a la resistencia transversal se sitúa en torno al 10\%. El segundo nivel, representado por las sujeciones, su contribución alcanza un 30\%. Estas sujeciones, formadas por una serie de elementos unidos entre sí, pueden ser elásticas o no elásticas, si bien las elásticas proporcionan una mayor resistencia a la torsión y una mayor la resistencia al pandeo.

En cuanto al tercer nivel, el que considera la interacción traviesa-balasto, cabe destacar que es la componente más importante en la estabilidad transversal, pues supone alrededor del $60 \%$ de la resistencia transversal. Su comportamiento viene determinado por múltiples factores como la sección de balasto, el estado y consolidación del mismo, el mantenimiento, el tipo y estado de la traviesa, así como por las cargas inducidas por los vehículos.

Una vez vistos los 3 niveles de resistencia, es lógico pensar que el pandeo se producirá en aquel más débil. En las vías modernas, gracias a la mejora en la fabricación de los carriles y de las sujeciones, el pandeo se produce en el tercer nivel (traviesa-balasto), cuando se supera la resistencia del balasto. Por ello, el estudio del pandeo centra su atención en la relación fuerza-desplazamiento lateral entre la traviesa y el balasto, pues resulta el parámetro crítico. Sin embargo, la multitud de factores que influyen en dicho valor condiciona notablemente su evaluación, siendo el objeto central de este apartado. 


\subsection{Vía sin defectos de alienación. Carga teórica de pandeo}

Como paso previo al estudio de las diferentes teorías de la estabilidad transversal y del cálculo de la carga de pandeo, se considera necesario justificar la razón por la cual estas metodologías consideran todas ellas la hipótesis de la existencia de defectos iniciales de alineación.

Para ello, en el presente apartado se describirá con la ayuda del modelo elaborado por López Pita (2006), quien analiza la carga de pandeo en una vía perfectamente recta (situación teórica sin defectos de alineación). Tal y como se expondrá a continuación, el resultado obtenido permite asegurar que, en caso de no existir defectos en la vía, no se produce el pandeo.

Para desarrollar el análisis, se considera como punto de partida un tramo de vía perfectamente recta, sometida a un esfuerzo axial de compresión debido al aumento de temperatura de los carriles.

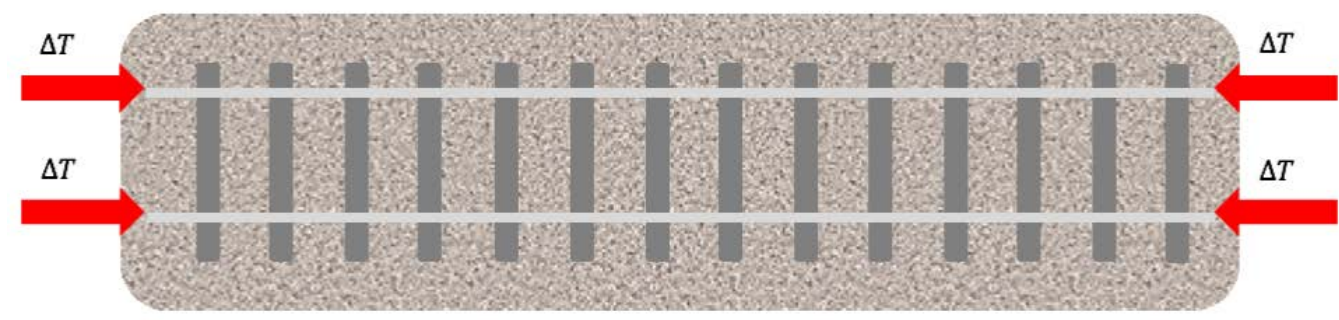

Figura 3.3: Vista de vía sin defectos de alineación. Fuente: Elaboración propia.

Bajo esta situación, aislando un elemento diferencial de longitud del carril, se tiene:

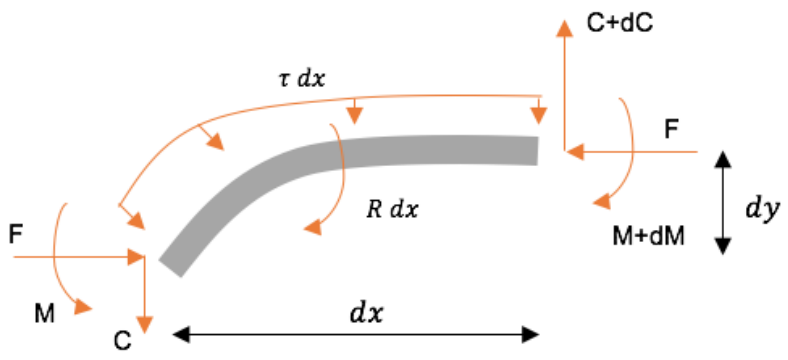

F: Esfuerzo axial de origen térmico

C: Esfuerzos contenidos en el plano de la vía M: Momentos flectores en los extremos

$\tau$ : Reacción, por unidad de longitud, del balasto

R: momento, por unidad longitud, debido a la unión carril-traviesa

Figura 3.4: Esquema de esfuerzos en elemento diferencial de vía. Fuente: Elaboración propia. 
Considerando el equilibrio del elemento anterior, es posible expresar las siguientes igualdades:

$$
\text { Eje } y: \quad C+\tau d x=C+d C \rightarrow d C=\tau d x
$$

Momentos: $\quad M-R d x+F d y+C d x=M+d M \quad \rightarrow \quad d M=F d y+C d x-R d x$

Si diferenciamos dos veces la ecuación 3.2 anterior y empleando la ecuación 3.1, tenemos:

$$
\frac{d^{2} M}{d x^{2}}=F \frac{d^{2} y}{d x^{2}}+\tau-\frac{R}{d x}
$$

Y considerando la ecuación diferencial de la elástica de una viga, donde el momento flector $M=-E I^{d^{2} y} / d x^{2}$, se tiene:

$$
E I \frac{d^{4} y}{d x^{4}}+F \frac{d^{2} y}{d x^{2}}+\tau-\frac{R}{d x}=0
$$

Asumiendo ahora que, para pequeñas rotaciones del carril respecto de la traviesa, la relación entre el giro y el momento puede ser considerada como proporcional, al igual que sucede con la reacción del balasto para pequeños desplazamientos transversales, se tiene que:

$$
\begin{gathered}
R \approx \Gamma \alpha_{\text {giro }} \\
\tau \approx \Psi y
\end{gathered}
$$

Por lo que finalmente, el esfuerzo de pandeo es:

$$
F_{\text {critico }}=2 \sqrt{E I \Psi}+K
$$

Si en la expresión anterior se introducen los valores habituales de los valores para un carril convencional (asumiendo un valor de $\Gamma=150 \mathrm{kN} / \mathrm{rad}$ y de $\Psi=20.000 \mathrm{kN} / \mathrm{m}^{2}$ ), es posible obtener un orden de magnitud aproximado del valor de la carga crítica de pandeo, siendo: 


$$
F_{\text {critico }} \approx 335 \text { toneladas }
$$

Este modelo descrito y desarrollado por López Pita se construye mediante un modelo teórico sencillo, mediante la determinación de las ecuaciones de equilibrio para la geometría deformada de la vía, bajo esfuerzos axiles de compresión.

Así pues, en el capítulo anterior se han obtenido los valores de la fuerza generada debido a un determinado incremento de temperatura, observándose que no se superan las $100 \mathrm{t}$ (ver Tabla 2.4). Por ello, según el desarrollo realizado por López Pita, en una vía sin defectos de alienación el pandeo no es posible, pues el esfuerzo necesario para desestabilizar la vía es muy superior a los que se alcanzan por efecto del aumento de la temperatura.

$$
F_{\text {critico }} \gg F_{\text {temperatura }} \rightarrow \text { No es posible el pandeo }
$$

\subsection{Comportamiento característico de la vía frente al pandeo}

Si bien se ha justificado el hecho de que una vía perfectamente recta no podría pandear, esta situación es puramente teórica pues en la realidad cualquier vía presenta ligeras desviaciones e imperfecciones que facilitan, en mayor o menor medida, el pandeo. Por ello, debido que si se consideraba una vía perfectamente recta no era posible que se produjera el pandeo, las investigaciones plantearon la necesidad de abordar el problema considerando la hipótesis de la existencia de defectos de alineación iniciales.

Este hecho resulta fundamental en el estudio del pandeo, pues casi todas las formulaciones desarrolladas asumen como hipótesis de partida la presencia de defectos iniciales de alineación. Estos defectos, al contrario de lo que podría pensarse, están ocasionados por un posicionamiento inadecuado de la vía, perdida de resistencia transversal, trabajos de vía mal ejecutados, deterioro debido al paso de los vehículos, etc.

Para llevar a cabo el estudio se considera un tramo recto de un CCS con un pequeño defecto de alineación. Respecto a la forma que adopta el defecto, en principio cabría pensar que la vía puede adoptando cualquier forma. No obstante, en la práctica, la posición deformada suele asimilarse a una sinusoide, definida por una amplitud $\delta_{0}$ y una longitud de onda de valor $2 L_{0}$. 


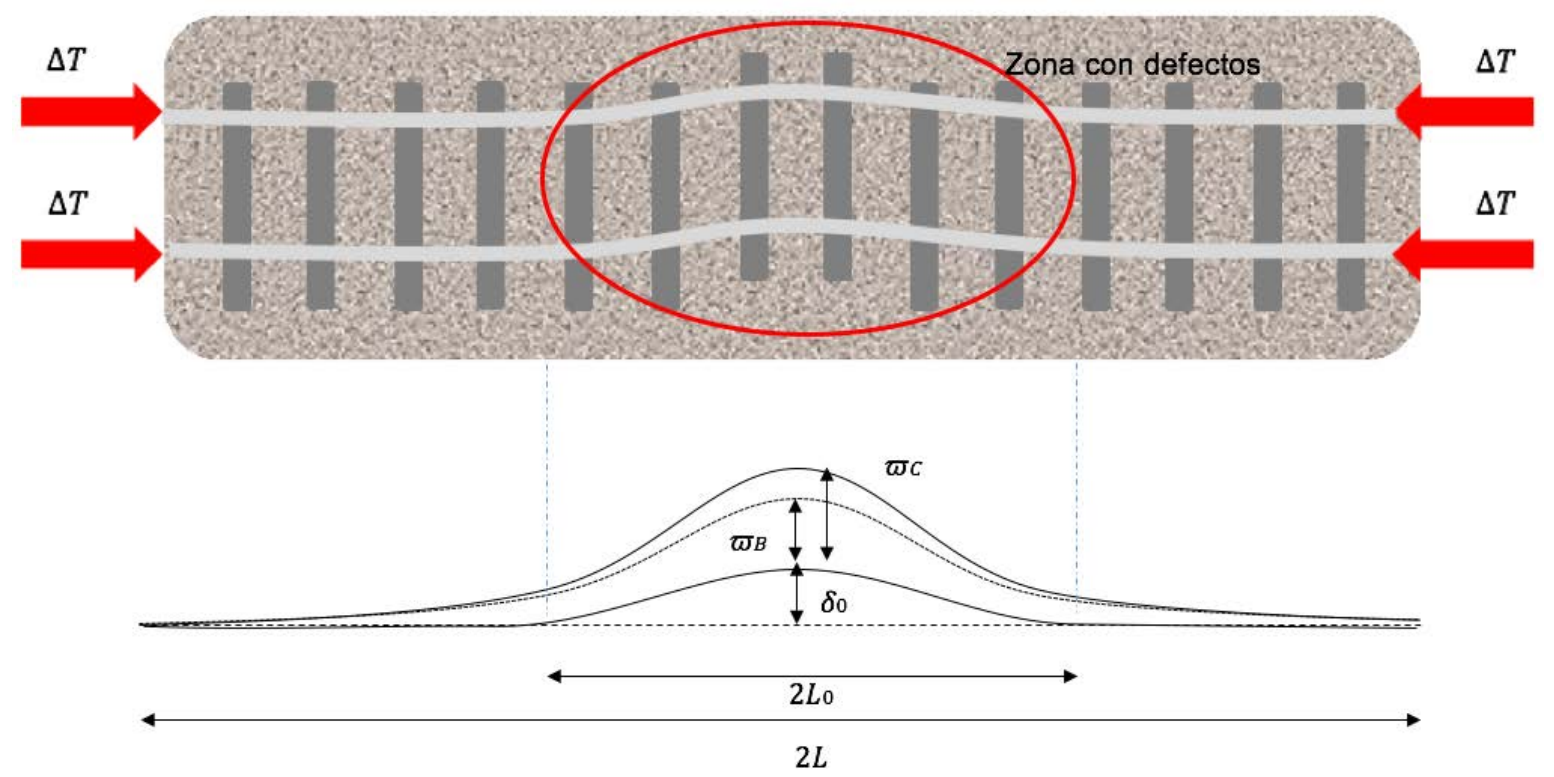

Figura 3.5: Vista de vía con defectos de alineación. Fuente: Elaboración propia.

Con el aumento de la temperatura en los carriles, el esfuerzo de compresión longitudinal aumenta proporcionalmente, lo que produce que el defecto inicial crezca hasta un valor de $\varpi_{B}$, interesando una mayor longitud de vía. Llegados a este punto, la vía se encuentra en un estado de inestabilidad, pues frente a un pequeño incremento de temperatura o esfuerzo externo no es capaz de ofrecer mayor resistencia, pudiendo producirse un desplazamiento importante bajo carga constante hasta alcanzar una posición deformada $\varpi_{C}$ con una longitud de $2 L$.

Los diferentes experimentos y observaciones llevadas a cabo muestran que las deformaciones laterales, cuando se supera la resistencia transversal de la vía, alcanzan valores del orden de $15-75 \mathrm{~cm}$, mientras que la longitud de onda es del orden de 8-24 m.

Para comprender mejor el comportamiento de una vía férrea frente al pandeo suele utilizarse una gráfica, donde se representan las deformaciones laterales de la vía (eje de abscisas) frente al incremento de temperatura respecto de la temperatura de neutralización de los carriles (eje de ordenadas). Este tipo de representación, tal y como se ha descrito previamente, se denomina curva de pandeo y resulta muy útil a la hora de estudiar el comportamiento de la vía.

En este tipo de gráficas, el pandeo se representa tal y como se muestra en la Figura 3.6. Partiendo del punto inicial A (la curva inicia con un valor de la deformación igual al defecto 
inicial $\delta_{0}$ ), existe una primera zona donde las deformaciones laterales son proporcionales al incremento de temperatura (zona A-B), encontrándose en un estado de equilibrio (equilibrio pre-pandeo). Este comportamiento se mantiene hasta llegar a una cierta temperatura límite (punto B) con una deformación $\varpi_{B}$ para la cual se ha alcanzado el límite de resistencia de la vía. En este estado de inestabilidad, cualquier pequeño incremento del esfuerzo produce la desestabilización y el pandeo de la vía (punto C), generando una importante deformación $\varpi_{C}$ en la vía. Alcanzada esta zona (equilibrio post-pandeo), ya no es posible recuperar la situación inicial, incluso si cesa totalmente la carga aplicada, por lo que las deformaciones serán permanentes.

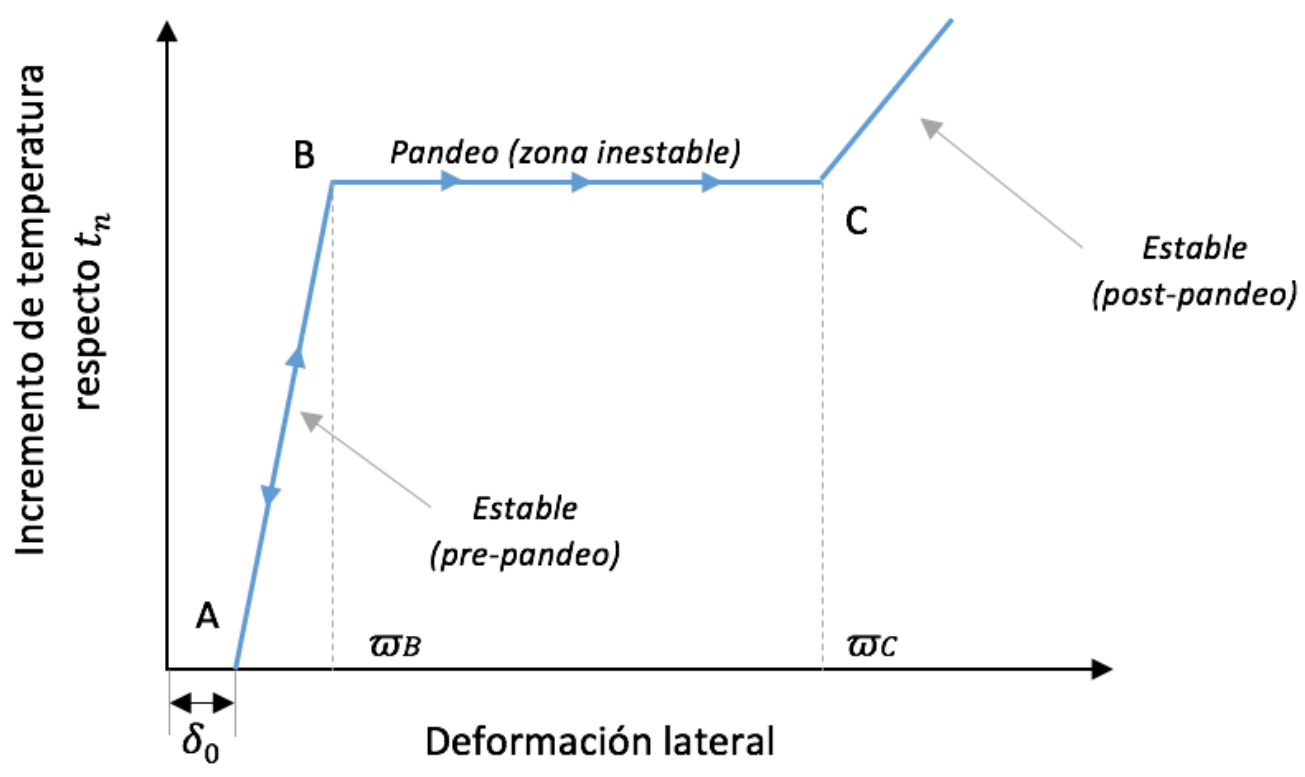

Figura 3.6: Representación del comportamiento frente a pandeo. Fuente: Elaboración propia.

El comportamiento apenas descrito representa la respuesta de la vía desde una aproximación puramente teórica. Por ello, el comportamiento real de la vía no viene definido por la curva trazada en la Figura 3.6.

Para poder representar el comportamiento real es necesario tener en consideración que la respuesta de la vía se encuentra muy influenciada por el tipo y elementos que conforman la superestructura, así como de la condición en la que se encuentran y las acciones a las que están sometidos. 
La Figura 3.7 muestra el comportamiento de la vía, considerando los múltiples puntos de equilibrio que la vía puede alcanzar una vez superada la zona estable inicial (rama discontinua B-C). El comportamiento viene caracterizado por una primera zona estable (zona A$B)$, al igual que en el caso anterior. Seguidamente aparece una zona, caracterizada por estar comprendida entre dos valores de temperatura $\Delta T_{\max }$ y $\Delta T_{\min }$, en la que existen multitud de puntos de equilibrio. Esta zona, atendiendo al equilibrio, está separada a su vez en dos zonas. En la primera zona (tramo B-D), la vía se encuentra en una posición de inestabilidad mientras que aumentando las deformaciones se pasa a una zona de estabilidad (tramo D-C).

Si bien desde el punto de vista teórico es posible obtener cualquier punto del tramo comprendido entre el equilibrio y el pandeo (tramo B-D-C), en la práctica la vía solo puede alcanzar posiciones estables, por lo que las situaciones reales únicamente se encuentran en una posición localizada en la zona estable (tramo D-C).

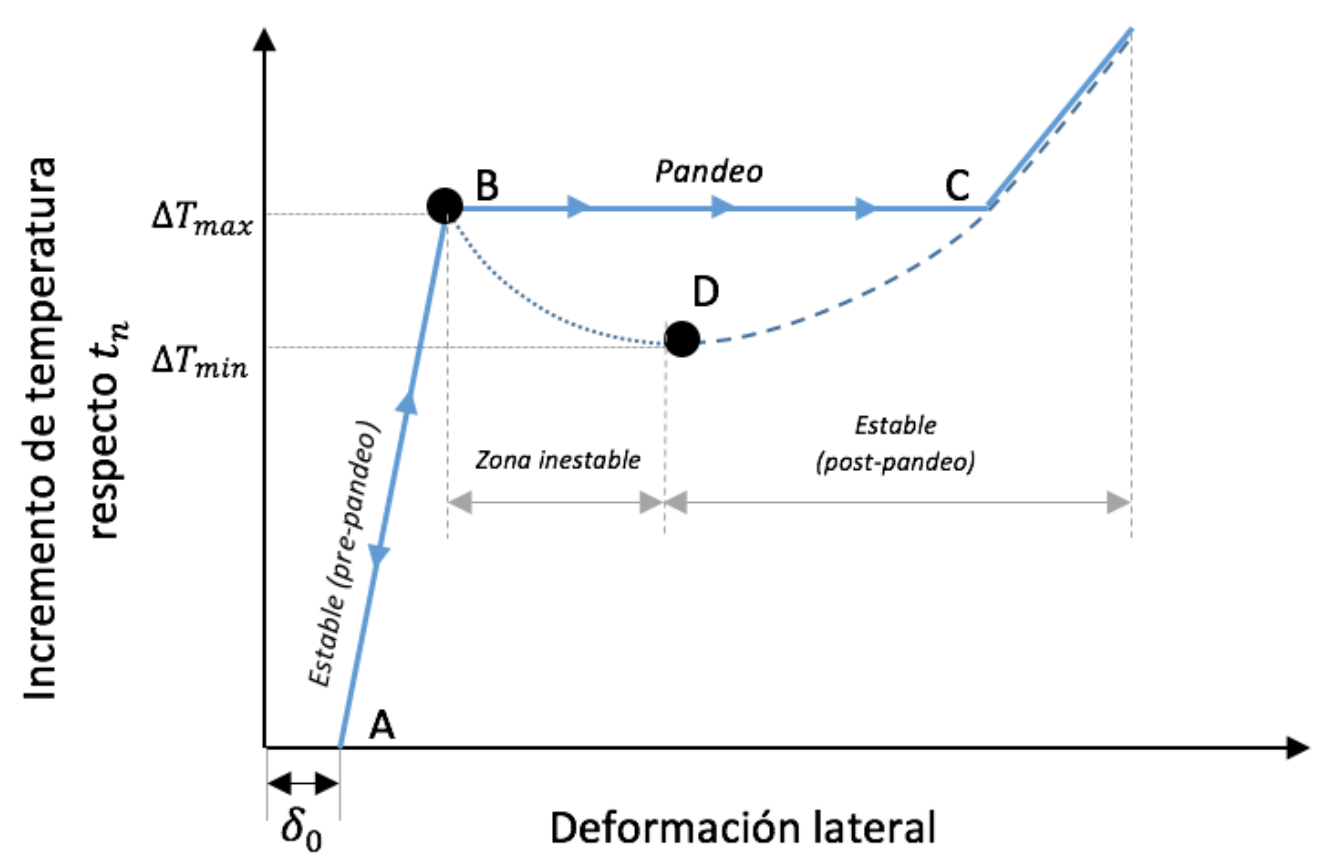

Figura 3.7: Representación del comportamiento frente a pandeo. Fuente: Elaboración propia.

Otro punto a destacar es el cambio de comportamiento que se produce en el punto $\mathrm{B}$, el cual separa la zona estable previa al pandeo de aquella inestable. Este punto suele denominarse como "estabilidad infinitesimal", por cuanto la vía puede repentinamente desestabilizarse y alcanzar el punto $C$. 
Desde el punto de vista de la seguridad frente al pandeo, el valor de $\Delta T_{\min }$ es aquel por debajo del cual no se producirá el pandeo, por lo que constituye un límite que no debe ser sobrepasado. Una vez superado este valor (zona comprendida entre $\Delta T_{\min }$ y $\Delta T_{\max }$ ) es posible que el efecto de los esfuerzos externos combinado con la acción de la temperatura desestabilice la vía.

Si bien lo expuesto hasta el momento puede representar de forma aproximada el pandeo, es necesario considerar en el estudio los efectos de las acciones externas, pues pueden modificar la respuesta de la vía.

En este sentido, si sobre una vía sometida a unos esfuerzos axiales de compresión se le aporta una determinada energía externa (por ejemplo, esfuerzos transmitidos por las ruedas de un vehículo), es posible que la vía cambie repentinamente de una posición estable previa al pandeo (punto 1) a una posición estable tras el pandeo (punto 3), pasando a través de la zona de inestabilidad, tal y como puede verse en la Figura 3.8. Hay que destacar que, en este caso, se alcanza la posición tras el pandeo si llegar a alcanzar la temperatura máxima $\Delta T_{\max }$. El rango de temperaturas en los que es posible que la vía, por efecto de alguna fuerza externa cambie repentinamente de configuración comprende el intervalo entre $\Delta T_{\min }$ y $\Delta T_{\max }$.

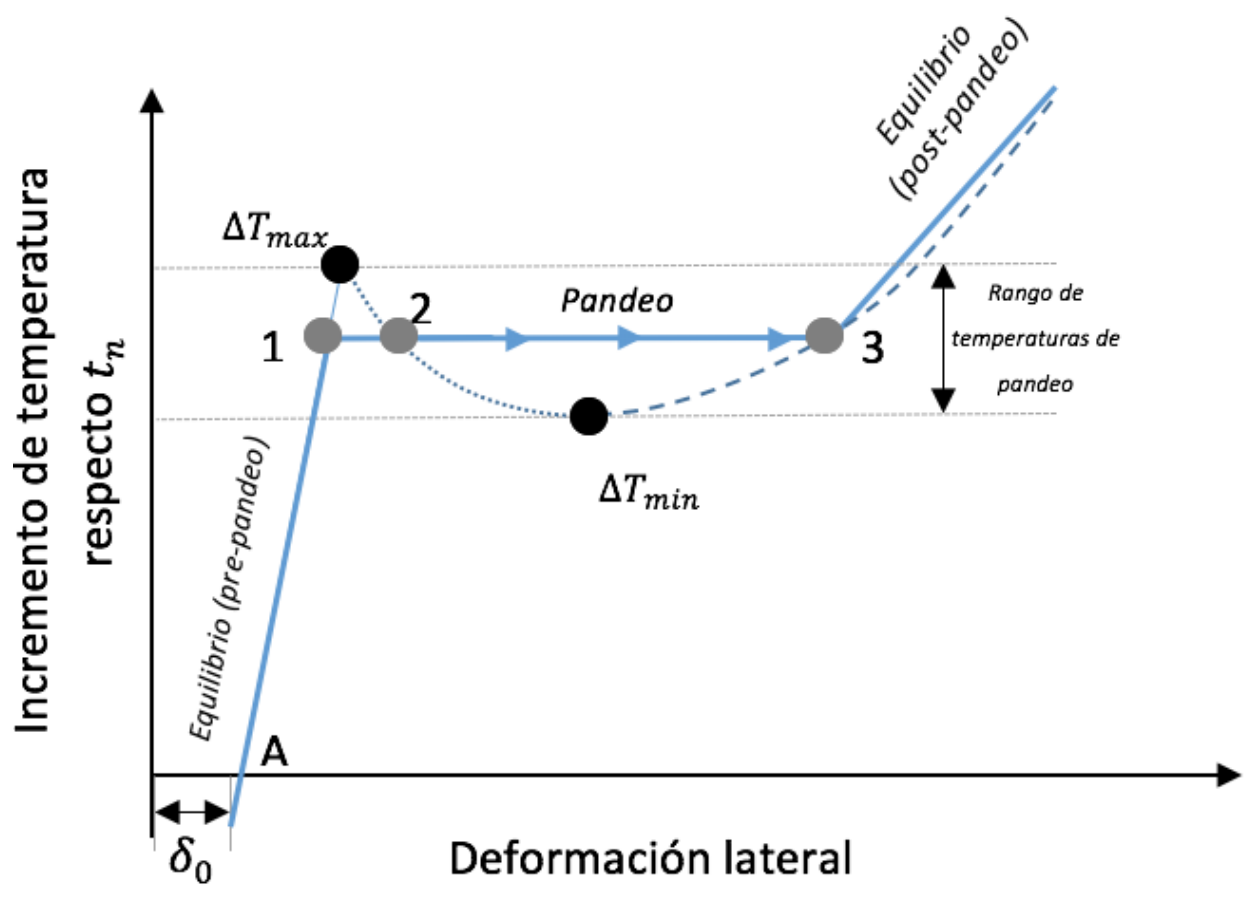

Figura 3.8: Representación del comportamiento frente a pandeo. Fuente: Elaboración propia. 
De lo descrito hasta el momento puede concluirse que, en ausencia de esfuerzos externos, la vía no pandeará hasta que el incremento de temperatura no alcance $\Delta T_{\max }$. No obstante, en presencia de esfuerzos externos, la vía puede pandear para temperaturas inferiores a la máxima, hasta un valor de $\Delta T_{\min }$ por debajo del cual la vía adquiere siempre una posición estable donde no es posible el pandeo (ver Figura 3.9). Este motivo justifica que, durante jornadas especialmente cálidas, es posible que existan restricciones en las velocidades máximas, con el fin de evitar que los vehículos generen mayores esfuerzos en la vía que puedan desestabilizarla.

Finalmente, es posible afirmar que el intervalo comprendido entre los valores $\Delta T_{\min }$ y $\Delta T_{\max }$ constituye el rango de temperaturas en las que el CCS puede pandear, siendo la probabilidad de pandeo más elevada cuanto más cerca nos encontremos del valor $\Delta T_{\max }$.

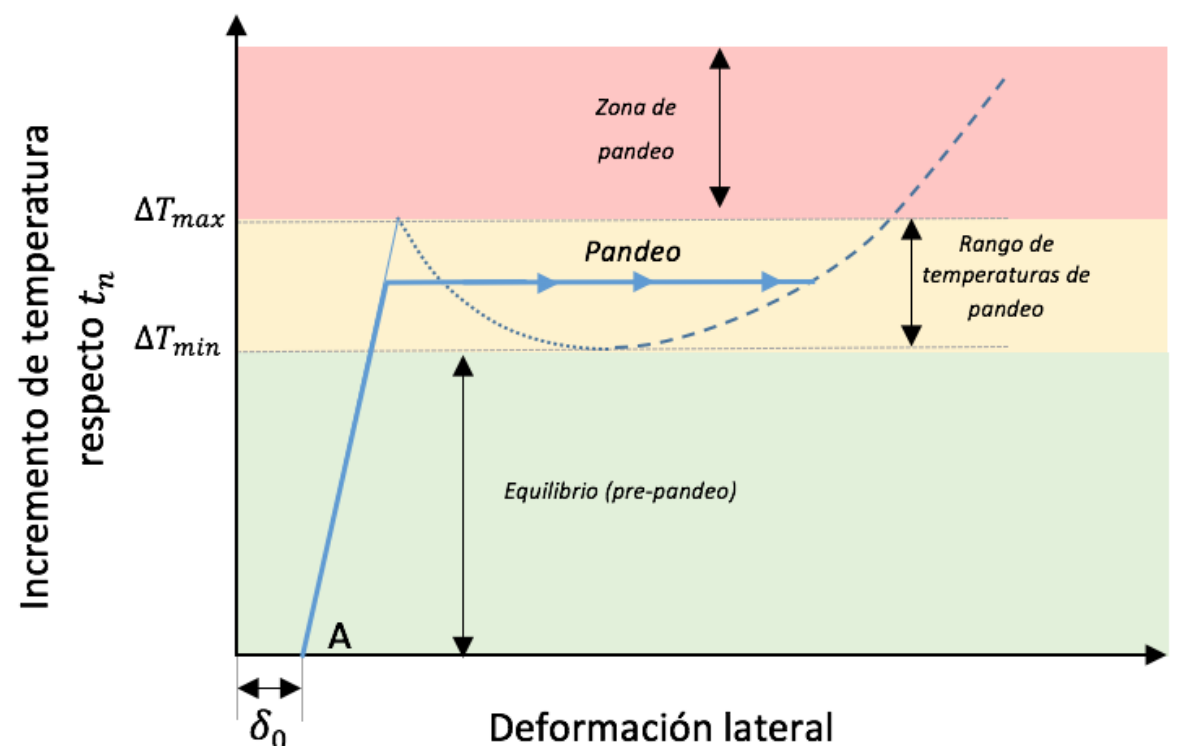

Figura 3.9: Zonas de riesgo de pandeo. Fuente: Elaboración propia.

\subsection{Resistencia transversal}

Una vez descrito el comportamiento mediante la curva de pandeo, es momento de analizar cuáles son los factores que influencian la respuesta descrita anteriormente.

Si bien existen múltiples factores que condicionan el comportamiento, el factor que más condiciona y en mayor medida considera todos los aspectos relacionados con el pandeo es la denominada resistencia transversal de la vía. A su vez, esta resistencia es función de 
otros muchos factores. Es por este motivo que muchas de las investigaciones llevadas a cabo se han centrado en estudiar y determinar su magnitud (Emdal, 2007; Kish, 2011; Koc, Wilk, Chrostowski y Grulkowski 2011; Koike, Nakamura, Hayano y Momoya, 2014; Esmaeili, Hosseini y Sharavi, 2016). La correlación e influencia de todos los parámetros que condicionan la resistencia transversal da como resultado un comportamiento no-lineal entre el esfuerzo y el desplazamiento lateral, tal y como se verá más adelante.

La tabla siguiente muestra, de forma cualitativa, cómo influyen los diferentes parámetros en la resistencia transversal: 


\section{Factores que condicionan la resistencia transversal}

\begin{tabular}{|c|c|c|c|c|c|}
\hline Influencia & $\begin{array}{c}\text { Muy } \\
\text { positiva }\end{array}$ & Positiva & No influye & Negativa & $\begin{array}{c}\text { Muy } \\
\text { negativa }\end{array}$ \\
\hline Momento inercia carriles & & $X$ & & & \\
\hline Peso de la traviesa & & $X$ & & & \\
\hline Ancho de la traviesa & & $X$ & & & \\
\hline Altura de la traviesa & $X$ & & & & \\
\hline Longitud de la traviesa & & $X$ & & & \\
\hline Traviesas bi-bloque & $x$ & & & & \\
\hline $\begin{array}{l}\text { Disminución distancia entre travie- } \\
\text { sas }\end{array}$ & & $X$ & & & \\
\hline $\begin{array}{c}\text { Fricción en la superficie inferior de } \\
\text { la traviesa }\end{array}$ & X & $X$ & & & \\
\hline Anclajes de seguridad & $X$ & & & & \\
\hline $\begin{array}{l}\text { Aumento del tamaño de las partícu- } \\
\text { las de balasto }\end{array}$ & & $x$ & & & \\
\hline Balasto con aditivos & & & $x$ & & \\
\hline $\begin{array}{l}\text { Amento lateral de la hombrera de } \\
\text { balasto }\end{array}$ & & & $x$ & & \\
\hline $\begin{array}{c}\text { Aumento del ancho de la hombrera } \\
\text { de balasto }\end{array}$ & & X & & & \\
\hline Espesor de balasto bajo traviesa & & & & $X$ & \\
\hline $\begin{array}{l}\text { Aumento de la altura de balasto en } \\
\text { el cajón de vía }\end{array}$ & $X$ & & & & \\
\hline Resistencia a torsión emparrillado & & & $X$ & & \\
\hline Levante de la vía & & & & & $x$ \\
\hline Soplado del balasto & & & & & $x$ \\
\hline Bateo & & & & $x$ & \\
\hline Estabilizador dinámico & $x$ & & & & \\
\hline Velocidad de los trenes & & & $x$ & & \\
\hline Aumento cargas por eje & & $x$ & & & \\
\hline Temperatura & & & $x$ & & \\
\hline
\end{tabular}

Tabla 3.1: Factores que condicionan la resistencia transversal. Fuente: Lichtberger, B: Manual de vía, Hamburg, Eurailpress (2011). 
Uno de los parámetros más influyentes que engloba un grupo de factores en la resistencia es la denominada calidad. En función de dicha calidad, el balasto presenta una primera fase aproximadamente lineal, hasta alcanzar un valor pico o máximo más allá del cual la vía no puede ofrecer una mayor resistencia. Tras superar este máximo, se produce un cambio en el comportamiento, con una disminución progresiva de la resistencia a media que aumentan los desplazamientos, hasta alcanzar un valor límite de resistencia residual, cuando los desplazamientos son ya importantes (de algunos centímetros).

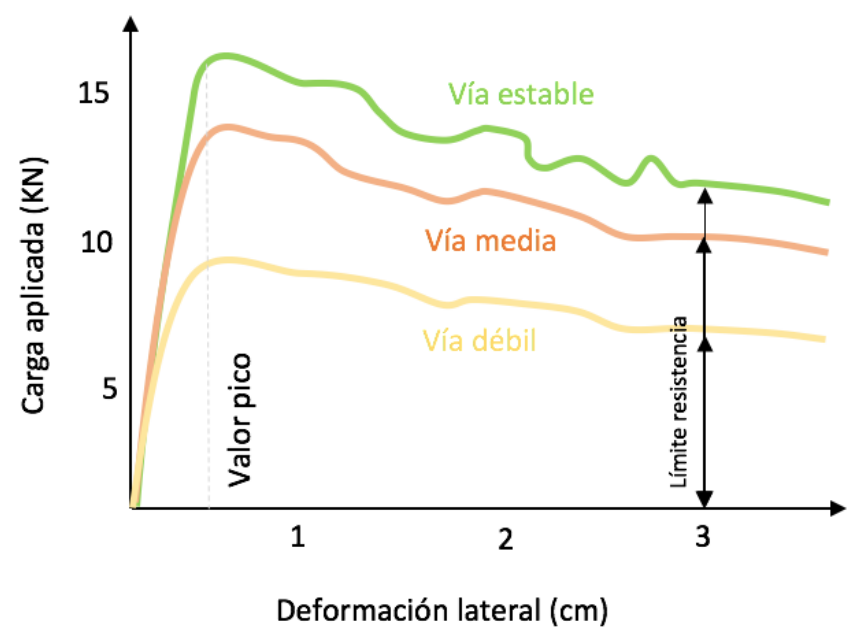

Figura 3.10: Resistencia transversal en función de la calidad de vía. Fuente: Elaboración propia.

Debido a que la respuesta transversal de la vía es bastante compleja, generalmente para su modelización se utilizan simplificaciones. Una aproximación al comportamiento real mostrado viene representado en la Figura 3.11.

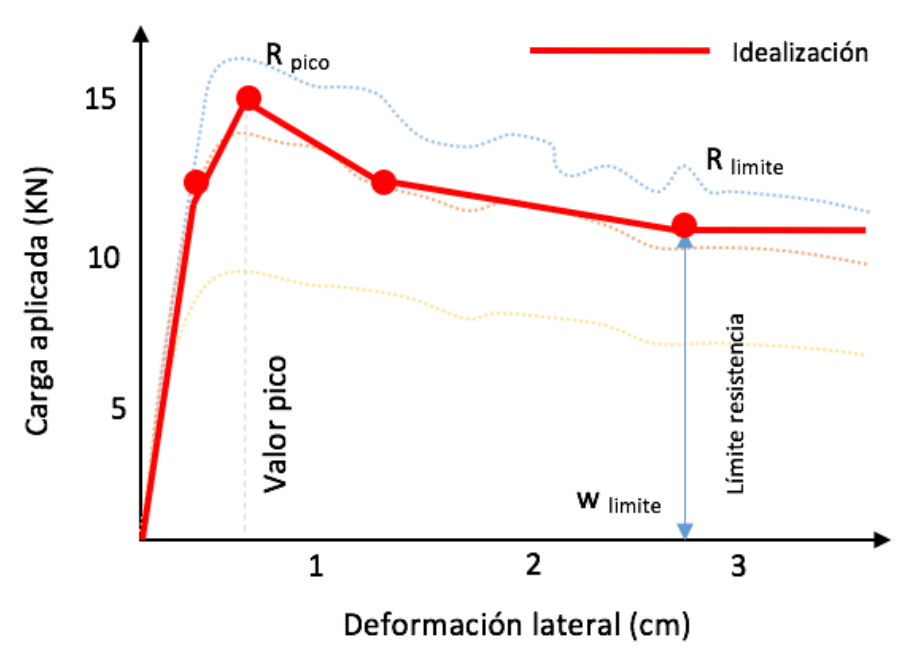

Figura 3.11: Idealización del comportamiento de la vía. Fuente: Elaboración propia. 
La influencia de la resistencia transversal en el pandeo es crucial, pues el valor pico de resistencia $\left(R_{\text {pico }}\right)$ condiciona el incremento máximo de temperatura $\left(\Delta T_{\max }\right)$ que puede resistir una vía, mientras que la resistencia límite $\left(\mathrm{R}_{\text {limite }}\right)$ determina notablemente el incremento de temperatura mínimo, o lo que es lo mismo, el máximo incremento de temperatura admitido para evitar que la vía pueda pandear $\left(\Delta T_{\min }\right)$, tal y como puede apreciarse en la Figura 3.12.

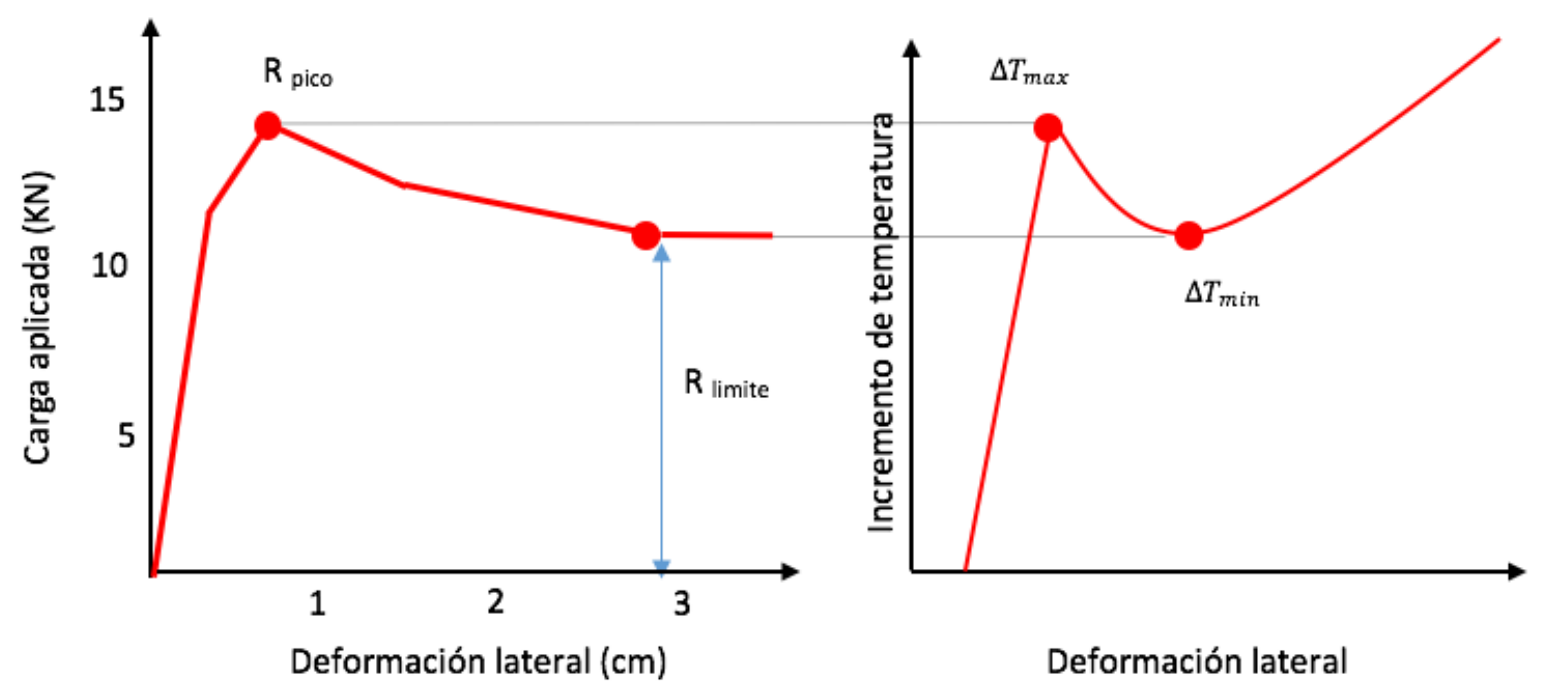

Figura 3.12: Relación entre la resistencia transversal (izquierda) y la curva de pandeo (derecha). Fuente: Elaboración propia.

Una vez visto el comportamiento de la vía es momento de analizar el origen de dicha resistencia. La resistencia transversal está formada por tres componentes principales, que son:

- Resistencia debida al rozamiento de la base de la traviesa: Es la resistencia proporcionada por el rozamiento que se desarrolla entre la base de la traviesa y el balasto, siendo la más importante.

- Resistencia de punta: Es la resistencia ofrecida por el balasto a ser desplazado lateralmente, debido al empuje de la pared lateral de la traviesa.

- Resistencia debida al rozamiento de las paredes laterales de la traviesa: Es la resistencia que se desarrolla en las paredes laterales de la traviesa debido al rozamiento con el lecho de balasto. 
$\mathrm{F}_{\mathrm{r}}$ : Fuerza debida al rozamiento de la base

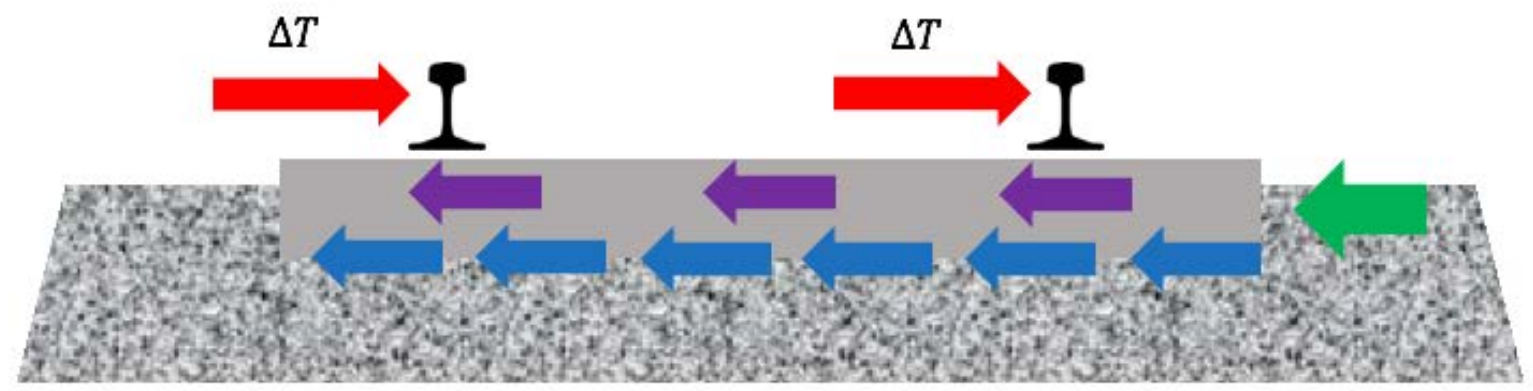

Figura 3.13: Componentes de la resistencia transversal. Fuente: Elaboración propia.

La componente principal de la resistencia movilizada entre la traviesa y el balasto la proporciona el rozamiento de la base, así como la cara lateral, mientras que el rozamiento con las paredes laterales tiene una menor importancia. No obstante, estos valores pueden cambiar sustancialmente para diferentes tipos de traviesa y balasto, así como bajo determinadas circunstancias, por lo que los pesos de cada una de las tres componentes deben ser considerados como valores orientativos.

Por ejemplo, bajo una carga vertical elevada, en las traviesas contiguas a la carga se produce una pequeña elevación de las traviesas, cosa que reduce notablemente la resistencia de la base. Bajo dichas condiciones, la resistencia proporcionada por la hombrera y los laterales de la traviesa adquiere mucha más relevancia.

Tras el estudio de la resistencia transversal y para profundizar en el tema, a continuación se analizarán algunos de los principales factores que alteran dicho comportamiento y que, por tanto, influyen en la capacidad resistente de la vía y en el pandeo.

\subsubsection{Influencia de la calidad de vía}

Tal y como se ha citado, existen una gran cantidad de factores que condicionan la resistencia transversal. Uno de los factores más determinantes y que representa, en cierta medida, al resto de factores lo constituye la calidad de la vía. 
La calidad de vía, entendida como la mayor o menor presencia de irregularidades y defectos geométricos respecto de un trazado teórico, es evaluada regularmente por las administraciones ferroviarias, pues permite conocer el estado en el que se encuentra y observar su evolución en el tiempo.

En cuanto a su influencia en el pandeo, es posible observar como aquellas vías que poseen una elevada calidad poseen una mayor diferencia entre el valor de la mínima temperatura de pandeo $\Delta T_{\min }$ y la máxima $\Delta T_{\max }$, respecto a una misma vía que posee una calidad inferior. El caso extremo (para una vía con una reducida calidad), la diferencia entre ambas temperaturas es prácticamente nula $\left(\Delta T_{\min }=\mathrm{a} \Delta T_{\max }\right)$.

Desde el punto de vista de la seguridad frente al pandeo y con estas consideraciones, en vías con una calidad elevada o media, el valor límite determinado por el incremento de temperatura mínimo que puede producir el pandeo $\Delta T_{\min }$ suele ser de $\Delta T_{\min } \approx 35^{\circ} \mathrm{C}-$ $60^{\circ} \mathrm{C}$, mientras que en vías con una baja calidad dicho valor es sustancialmente menor, con valores de $\Delta T_{\text {min }} \approx 20^{\circ} \mathrm{C}$. 


\section{Calidad de vía elevada}

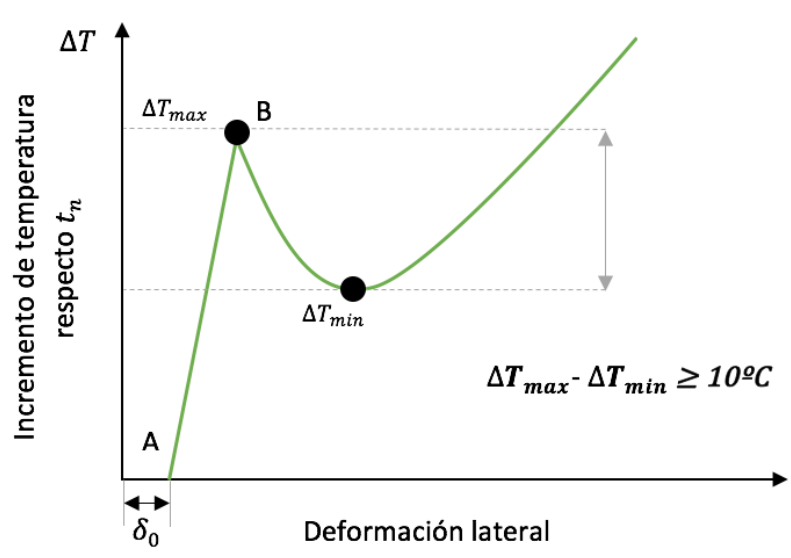

\section{Calidad de vía media}

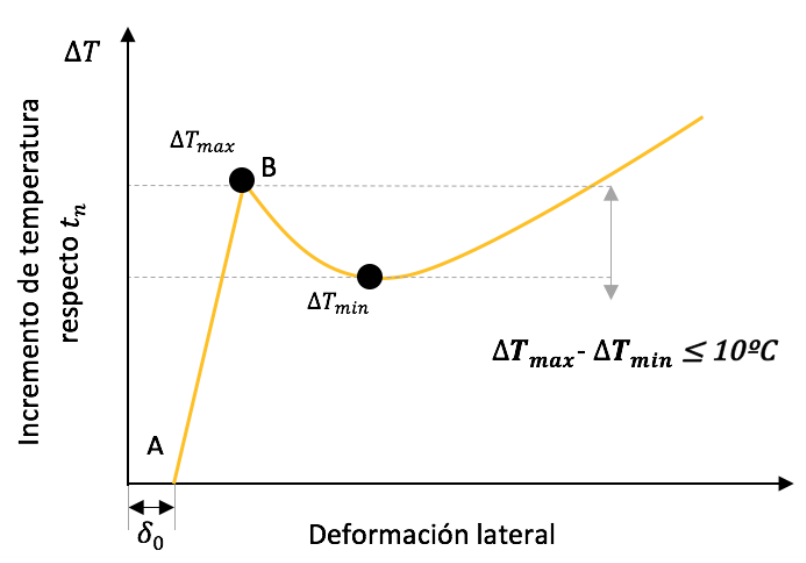

\section{Calidad de vía reducida}
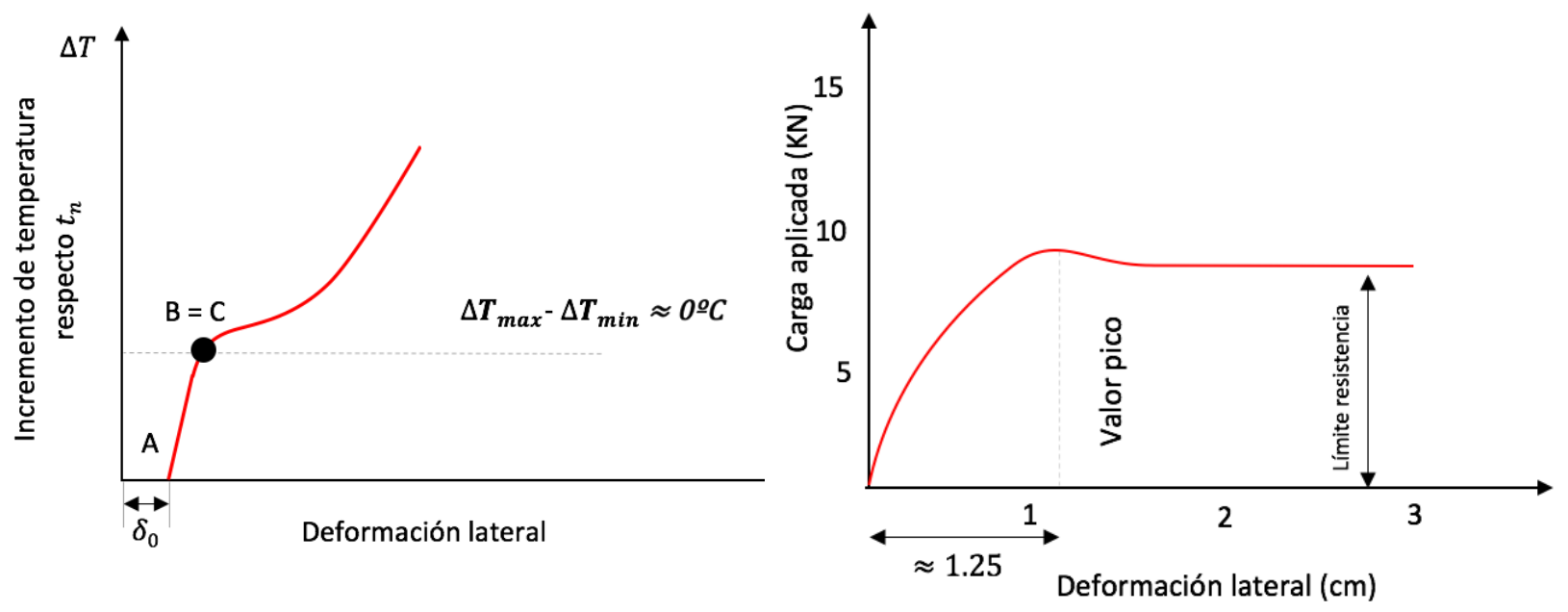

Figura 3.14: Comportamiento frente al pandeo en función de la calidad de vía y resistencia lateral. Fuente: Elaboración propia.
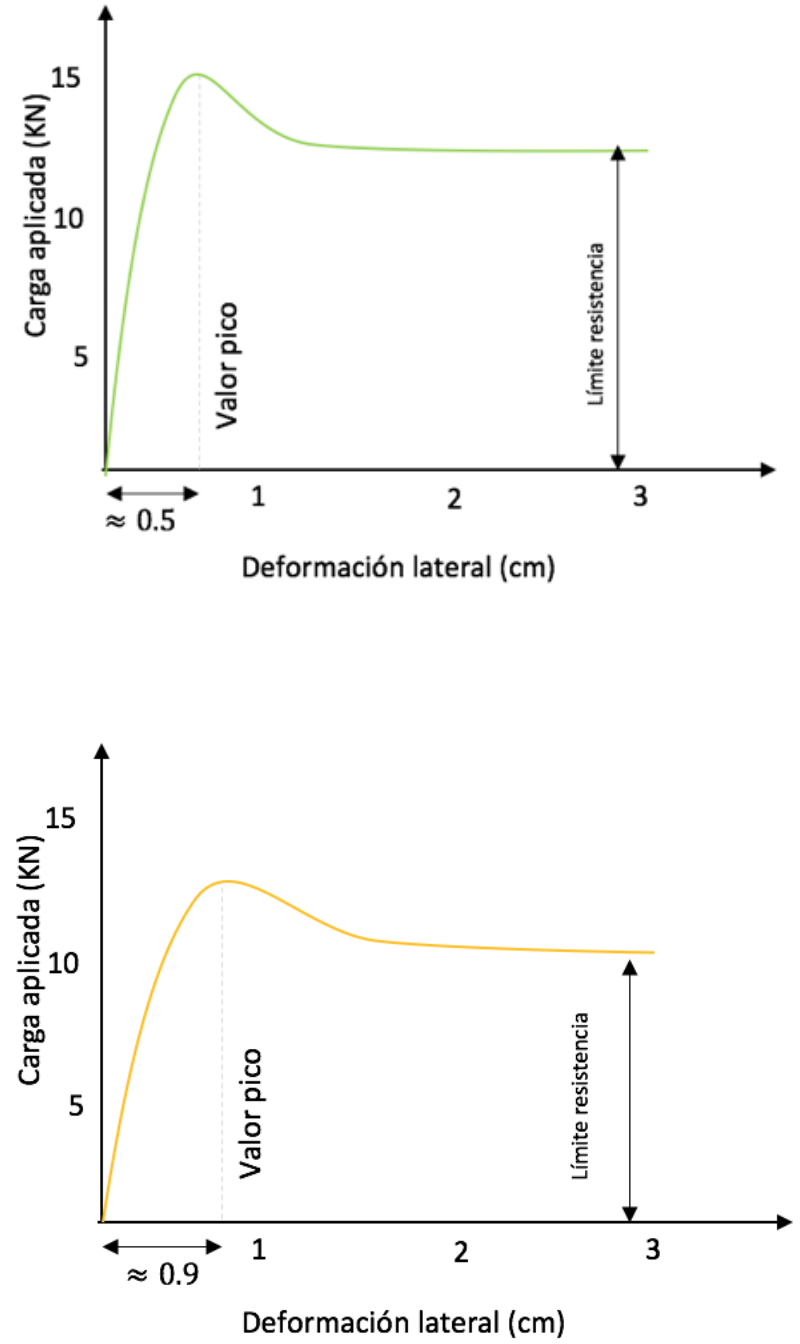
Tal y como puede observarse, la calidad de vía determina notablemente la forma en la que se comporta la vía y, por lo tanto, la curva de pandeo. A medida que se aumenta la calidad, mayor es el esfuerzo que es capaz de desarrollar, así como el incremento de temperatura necesario para hacerla pandear. Esto es de suma importancia, pues la mayoría de los criterios de seguridad frente a pandeo consideran el incremento de temperatura $\Delta T_{\min }$ como el valor máximo que puede alcanzarse en la vía.

\subsubsection{Influencia de las cargas verticales}

Uno de los factores externos que condiciona la respuesta de la vía es la aplicación de cargas externas verticales. Teniendo en consideración este efecto, surge la denominada resistencia lateral dinámica, la cual considera el incremento o disminución de la resistencia lateral debido al efecto de las cargas verticales aplicadas en la vía.

Cuando una rueda se sitúa sobre una traviesa, la carga debida al peso del vehículo se transmite desde el carril al balasto a través de la sujeción y la traviesa. Debido al esfuerzo aplicado, el rozamiento entre la traviesa y el balasto aumenta. Sin embargo, se produce un efecto contrario sobre las traviesas adyacentes, puesto que la deformación que experimenta el carril tiende a desplazarlo verticalmente y, por tanto, separar la traviesa del balasto.

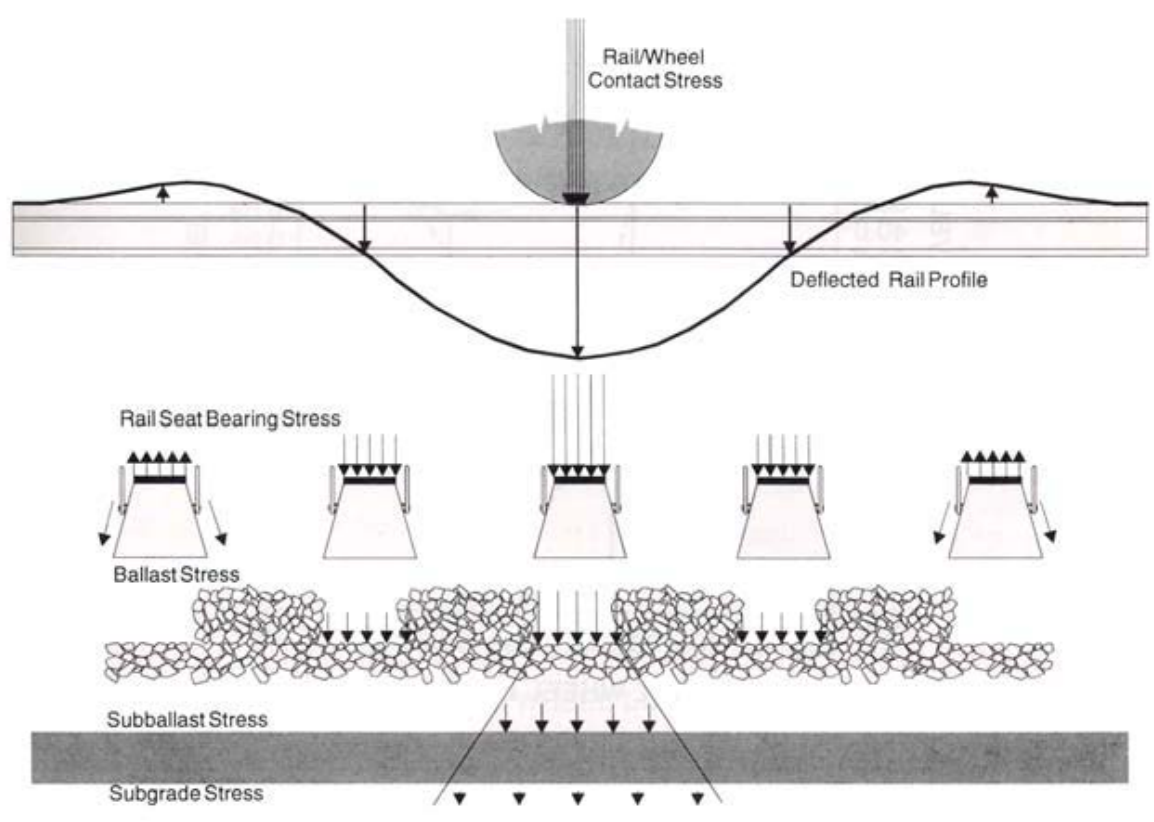

Figura 3.15: Onda de levante debido a cargas verticales. Fuente: Lim, W.H.(2004). Mechanics of Railway Ballast Behaviour. 
Este efecto de levante produce una reducción del rozamiento entre la base de las traviesas contiguas y el propio balasto, lo que se traduce en una disminución del coeficiente de fricción $\mu$ y, con ello, de la resistencia transversal total.

Tal y como puede verse en la Figura 3.16, la carga vertical manifiesta un efecto positivo cuando se aumenta la presión sobre una determinada traviesa y un efecto negativo, por el efecto del levante en las traviesas contiguas. Por lo tanto, el efecto global de la presencia de una o varias cargas debe ser evaluado teniendo en consideración estas consideraciones.

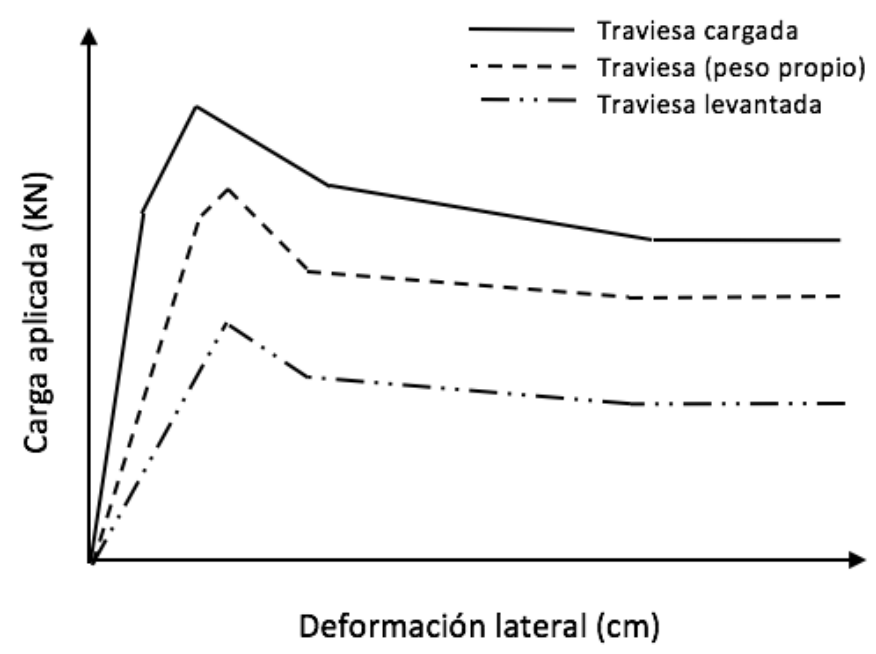

Figura 3.16: Influencia de la carga vertical en la resistencia transversal. Fuente: Elaboración propia.

Otro aspecto interesante es el de analizar cómo cambia la relevancia o peso de cada una de las tres componentes (base, caras laterales y punta) de la resistencia cuando se carga una traviesa. De acuerdo con unos test realizados (Zakeri and Bakhtiary, 2014), para una vía cargada, alrededor del 90\% de la resistencia total viene proporcionada por el rozamiento entre la base y el balasto, mientras que la resistencia de las paredes laterales y de la punta es casi despreciable. 


\begin{tabular}{|c|c|c|}
\hline \multicolumn{2}{|c|}{ Influencia de la carga en las componentes de la resistencia (\%) } \\
\hline Componente & Vía no cargada & Vía cargada \\
\hline Base & $35-40$ & $90-95$ \\
\hline Laterales & $20-25$ & $0-5$ \\
\hline Punta & $30-35$ & $0-5$ \\
\hline
\end{tabular}

Tabla 3.2: Efecto de las componentes de la resistencia transversal. Fuente: Elaboración propia a partir de Zakeri and Bakhtiary (2014).

Además, es también reseñable la influencia de las vibraciones inducidas por la circulación de vehículos. Debido a que el efecto de las vibraciones en la resistencia transversal es difícil de evaluar, la British Rail llevó a cabo algunos test dentro del proyecto ERRI/D202 (Hunt, D and Z. Yu, 1998), observando disminuciones de la resistencia lateral entorno al 20-25\%, dependiendo de los niveles de vibración generados.

\subsubsection{Influencia de la banqueta de balasto}

Tal y como se ha visto anteriormente, alrededor del 30-35\% de la resistencia movilizada entre la traviesa y el balasto se genera en el contacto de la cara lateral de la traviesa con la capa de balasto. Por este motivo, la parte del balasto localizada entre el lateral de la traviesa y el final de la banqueta, denominada hombrera, tiene una función importante en la resistencia transversal.

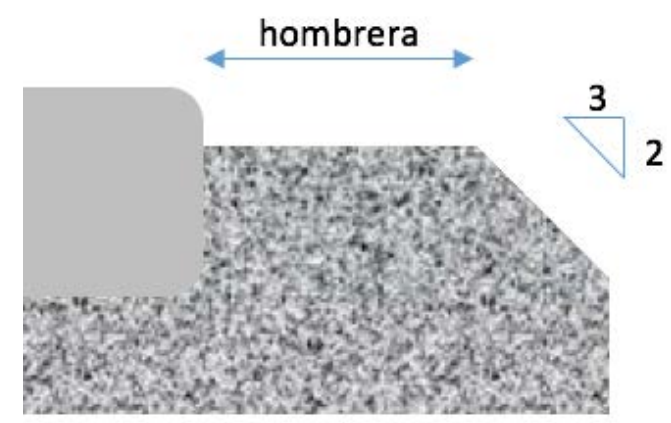

Figura 3.17: Esquema de la hombrera de balasto. Fuente: Elaboración propia.

Una forma posible de aumentar la resistencia transversal es aquella de aumentar la dimensión de la banqueta de balasto, pues con ello se minimiza el desplazamiento de las partículas de balasto desde la base de la traviesa a zonas menos comprimidas y se aumenta su resistencia lateral. 
Sin embargo, pese a que es posible pensar que a medida que se aumenta la dimensión de la banqueta aumentará la resistencia, hay que tener en consideración que ésta relación es no es lineal, ya que se ha observado que a partir de $65-70 \mathrm{~cm}$, un incremento apenas aporta resistencia transversal. A su vez, la granulometría del balasto también tiene una influencia importante, por cuanto se ha observado que una granulometría con tamaños entre los 25$60 \mathrm{~cm}$ aporta una mayor resistencia respecto al mismo balasto con unos tamaños entre los $40-60 \mathrm{~cm}$.

Por otro lado, también es posible pensar en aumentar el espesor que recubre la traviesa, pues cuanto mayor superficie de contacto traviesa-balasto exista, mayor debe ser la resistencia proporcionada. No obstante, el aumento del recubrimiento conlleva la dificultad en poder controlar el estado de las sujeciones a la vez que genera problemas de aislamiento entre los carriles (en alta velocidad existe el fenómeno del vuelo del balasto).

Algunos recientes estudios (Le Pen, 2014) han verificado experimentalmente la influencia de la dimensión de la banqueta en cuanto al aumento de la resistencia lateral, demostrando de forma experimental un hecho consabido (ver Figura 3.18). Generalmente, la dimensión recomendada por las administraciones ferroviarias es de unos $50 \mathrm{~cm}$, si bien su valor se suele adaptar a las necesidades y condiciones de servicio de la línea.

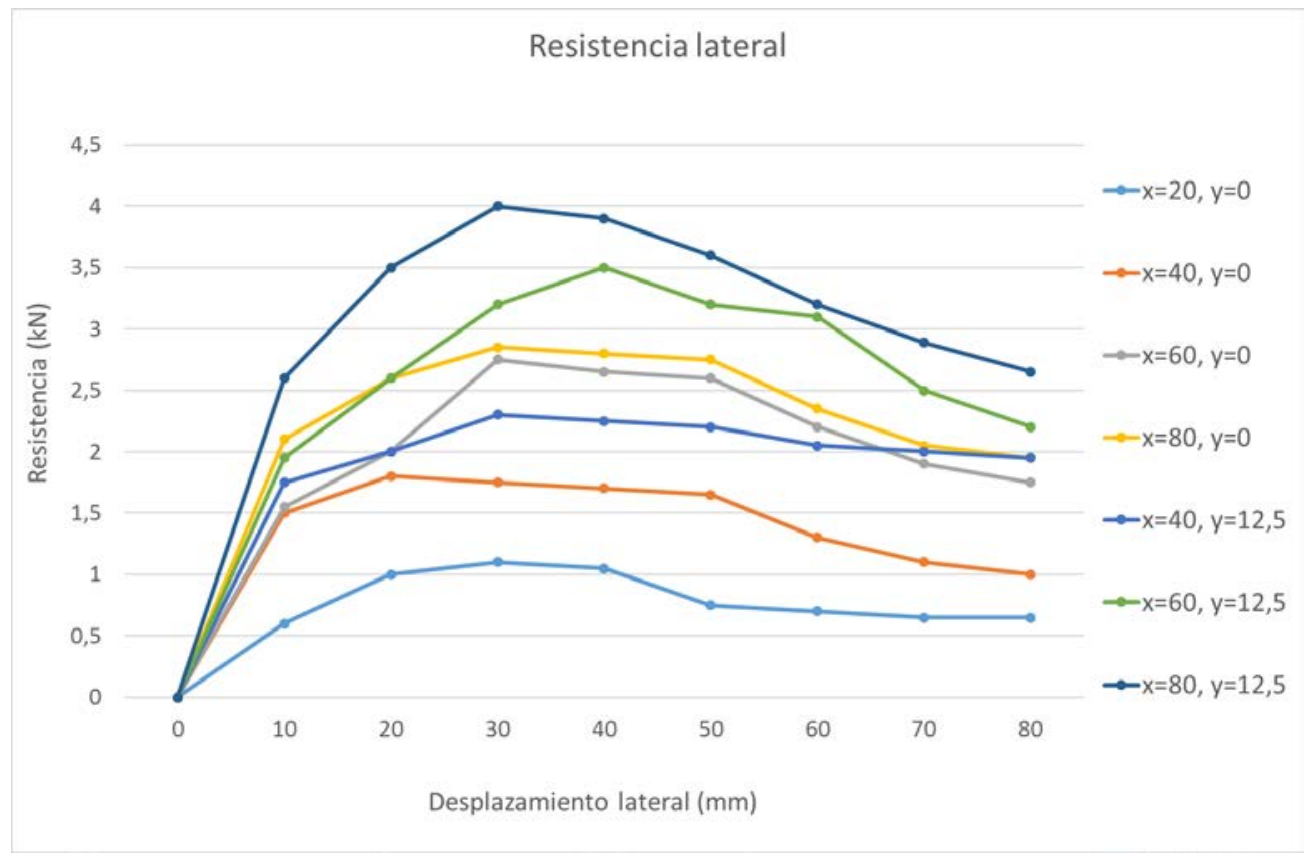

Figura 3.18: Influencia de la hombrera de balasto en la resistencia transversal. Fuente: Recuperado de Le Pen et al. 2014. 


\subsubsection{Influencia de la operación de bateo}

Para poder corregir los defectos geométricos de nivelación y alineación de la vía, periódicamente se lleva a cabo una operación de bateo mediante una maquinaria de vía (bateadora), la cual está dotada de bates vibrantes que se introducen en la capa de balasto y lo vibran enérgicamente, permitiendo recuperar la geometría original de la vía.

Esta operación, necesaria para corregir los defectos, tiene un efecto negativo sobre la resistencia lateral pues produce una desconsolidación del balasto, dando como resultado que una buena parte de las partículas de no se encuentran en una posición estable.

Para consolidar el balasto y minimizar la perdida de consolidación se introdujo en los años 70 los estabilizadores de vía, los cuales usan vibradores con masas excéntricas que generan una vibración horizontal en dirección transversal a la vía, provocando que las piedras de balasto se reordenen en una estructura más compacta. El efecto introducido por los estabilizadores es similar al del paso continuado de los vehículos, por lo que permiten alcanzar rápidamente la consolidación que, de lo contrario, se obtendría tras el paso de un determinado número de ejes tras un tiempo bastante prolongado.

Pese a las precauciones en la operación y el uso de la estabilización dinámica, el bateo produce una importante pérdida de resistencia lateral, cuyo efecto negativo se va minimizando con el tiempo. Así pues, la estabilización produce un valor de pico inicial de resistencia similar al que se obtiene previo al bateo, pero el comportamiento es mucho más inestable y aleatorio, si bien la mayor rigidez y resistencia alcanzada es compatible con la idea que la estabilización permite densificar y consolidar el balasto.

La pérdida de resistencia tras el bateo y la recuperación que se produce tras la estabilización depende de factores como la granulometría, forma y angulosidad de las partículas de balasto y la rugosidad de las paredes de la traviesa, entre otros. La pérdida habitual tras el bateo puede alcanzar en algunos casos el 60\% de la resistencia lateral mientras que con la operación de estabilización es posible llegar a recuperar hasta un 30\% de la misma. 


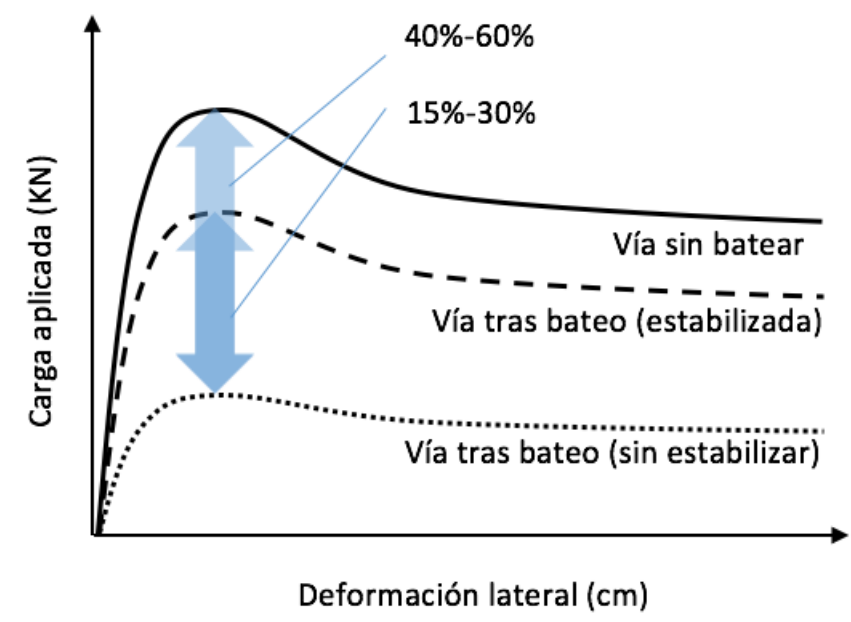

Figura 3.19: Influencia del bateo en la resistencia transversal. Fuente: Elaboración propia.

Uno de los trabajos más destacados en este ámbito son las investigaciones llevadas a cabo por Amtrak, la Federal Railroad Administration y el instituto Volpe Center (Kish et al. 2003) en los EE.UU. Durante las investigaciones se analizó la resistencia lateral previo y post bateo en una vía de balasto con traviesas monobloque de hormigón, evaluando que la pérdida de resistencia lateral (en una vía sobre balasto con traviesa de hormigón) tras el bateo alcanzaba el 45\% mientras que la estabilización producía una recuperación alrededor del $20 \%$ de la resistencia previo al bateo, confirmando la importante pérdida de resistencia producida tras el bateo y la recuperación de parte de la misma con la estabilización (ver Figura 3.20).

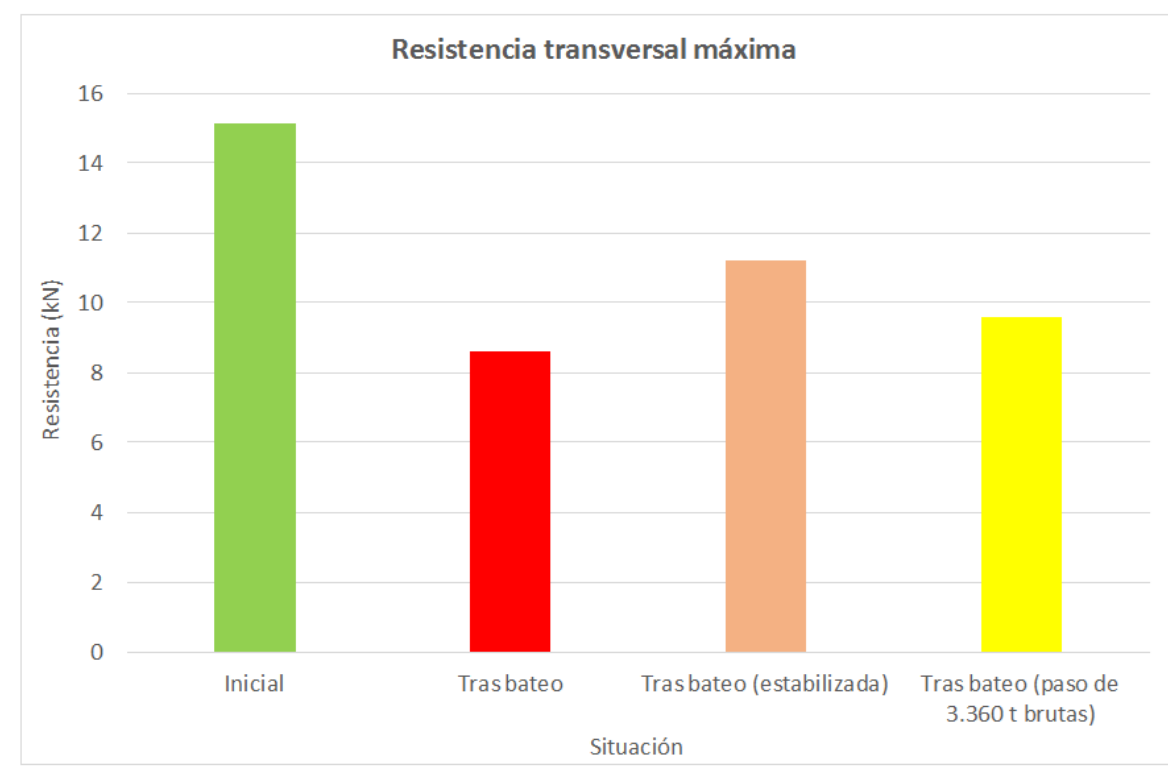

Figura 3.20: Influencia del bateo en la resistencia transversal. Fuente: Recuperado de Kish et al. 2003. 


\subsubsection{Influencia del tipo de traviesas}

Una de las funciones principales de las traviesas es la de mantener la estabilidad lateral de la vía. En cuanto a sus características y considerando las tipologías más comunes, es posible llevar a cabo una clasificación en función del material con el que están fabricadas o en función de su forma.

Desde el punto de vista del material, existen traviesas de madera, acero y hormigón (algunos desarrollos recientes han utilizado plástico), mientras que en el segundo caso es posible distinguir principalmente entre traviesas monobloque y bi-bloque (existiendo algunos otros tipos más complejos, que no son objeto de estudio).

Desde el punto de vista de la resistencia al desplazamiento longitudinal (aquella que aparece ante la tendencia al desplazamiento en el eje de la vía), para un lecho de balasto limpio y no compactado, se tienen los siguientes valores:

- $50 \mathrm{~N} / \mathrm{cm}$, para traviesa de hormigón.

- $40 \mathrm{~N} / \mathrm{cm}$, para traviesa de madera.

- $70 \mathrm{~N} / \mathrm{cm}$, para traviesa de acero.

Al igual que sucede con la resistencia longitudinal, cada tipología de traviesa ofrece una resistencia transversal claramente diferenciada. Tal y como se ha descrito, esta resistencia es fundamental para evitar pandeos y depende de múltiples factores como la forma, peso, espaciamiento, etc.

Con ello, las traviesas de hormigón bi-bloque son las que ofrecen una mayor resistencia lateral, mientras que las traviesas de madera son las que menor resistencia poseen, especialmente por su reducido peso.

En la Figura 3.21 es posible observar la pérdida de resistencia transversal pico, tomando como referencia la resistencia proporcionada por una traviesa bi-bloque de hormigón y bajo las mismas condiciones de vía. 


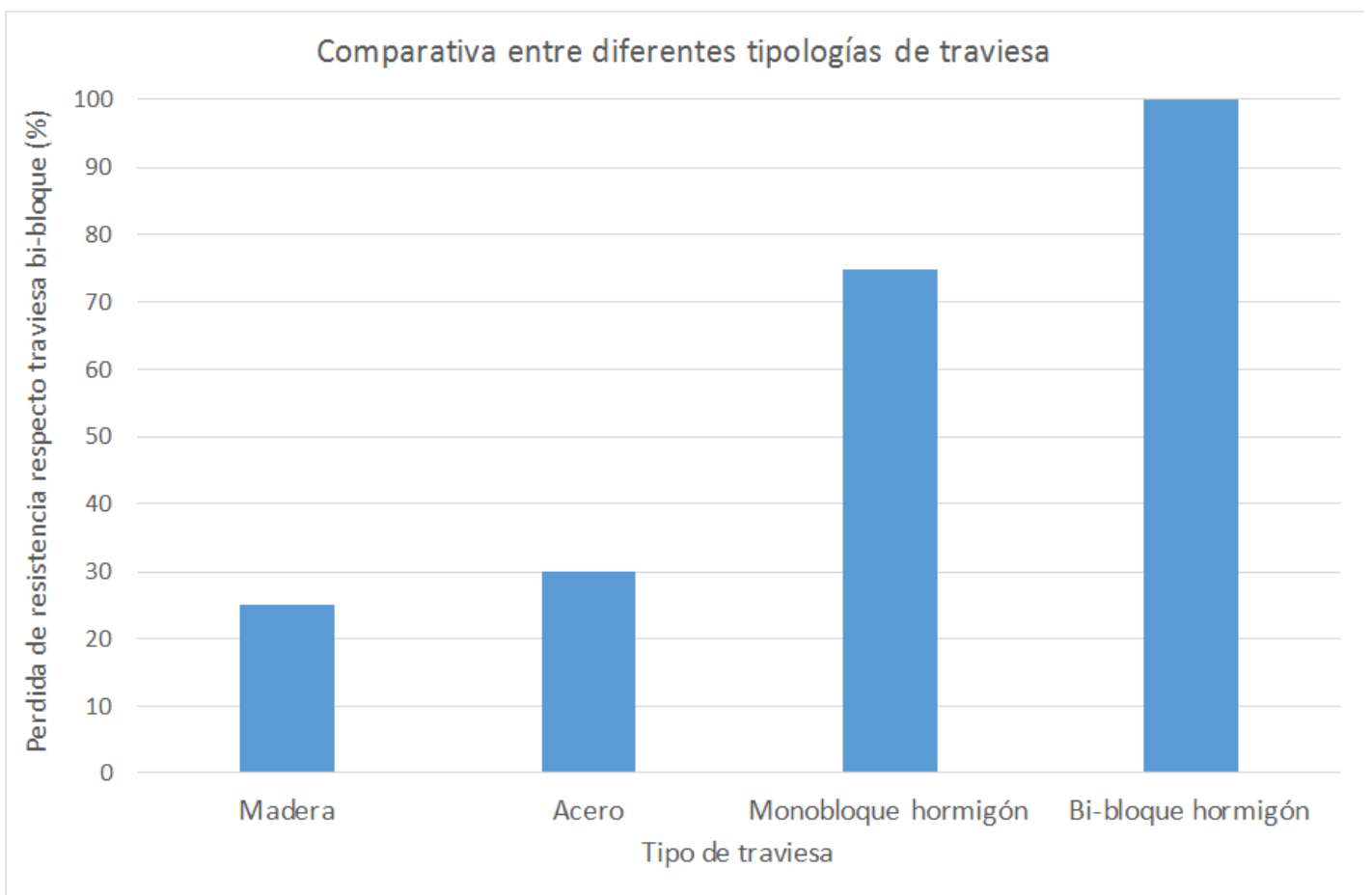

Figura 3.21: Tipo de traviesa y resistencia transversal. Fuente: López Pita, A. 2006.

Una posible intervención a realizar sobre las traviesas y que permite aumentar la resistencia transversal es la instalación de elementos de anclaje. Estos elementos, generalmente metálicos, aumentan el área de transferencia de esfuerzos entre la traviesa y el balasto, por lo que permiten generar un mayor esfuerzo resistente. Su uso se aplica en tramos singulares, donde es necesario aumentar la resistencia lateral para evitar problemas.
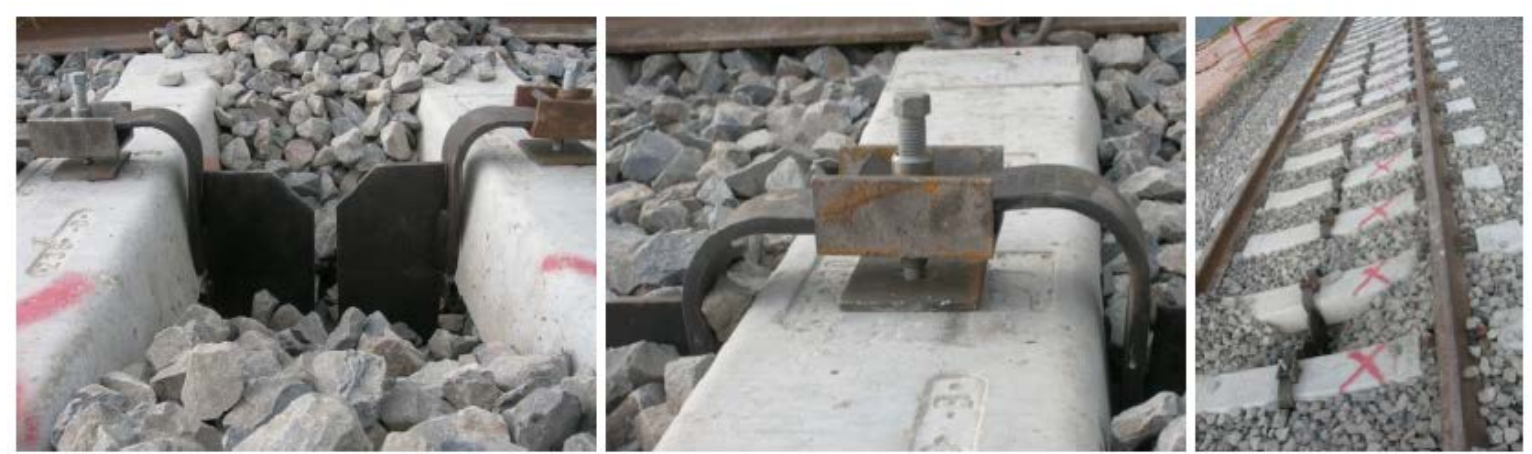

Figura 3.22: Elementos de anclaje en traviesas. Fuente: De Iorio, Pucillo \& Alii, (2014). 


\subsubsection{Influencia del coeficiente de rozamiento traviesa-balasto}

Debido a que una parte importante de la resistencia transversal se desarrolla gracias a la interacción entre la traviesa y el balasto, es fácil comprender que el coeficiente de rozamiento entre ambos elementos posee un rol importante. Con ello, para una determinada vía, cuanto mayor sea el rozamiento, mayor será la resistencia transversal y, por lo tanto, el incremento de temperatura necesario para desestabilizarla.

Puesto que en el rozamiento esta implicados tanto la traviesa como el balasto, éstos dos elementos contribuyen en mayor o menor grado a determinar el rozamiento. Respecto del balasto, el rozamiento viene determinado por el tipo y estado en el que se encuentre, pudiendo definir los siguientes valores orientativos, respecto de un balasto normal machacado:

- Grava sin machacar

- Grava machacada

- Balasto fino $(10 \times 30)$

- Balasto grueso $(80 \times 150)$ reducción del 30\% - 35\%

sin reducción

reducción de 5\% - 10\%

aumento del $20 \%$

En cuanto al coeficiente de rozamiento, éste viene definido como el cociente entre la fuerza de rozamiento en la base de la traviesa y el peso propio de la misma.

$$
\mu=\frac{\text { F.rozamiento }}{\text { Peso traviesa }}
$$

Bajo esta definición, el coeficiente de rozamiento balasto-traviesa descrito no debe ser confundido con coeficiente de rozamiento de Coulomb para dos cuerpos en contacto directo, donde el coeficiente de rozamiento es la constante de proporcionalidad entre la fuerza máxima de rozamiento y el valor de la fuerza normal.

Si bien el coeficiente de rozamiento es un factor fundamental, su evaluación es sumamente compleja. Algunos estudios (Zand y Moraal, 1997) han tratado de evaluar este coeficiente, comparando la variación de la resistencia lateral frente a la carga vertical (peso de la traviesa), obteniendo un valor del coeficiente igual a 0,7247 (con un rango de variación entre $0,66$ y 0,80$)$. 


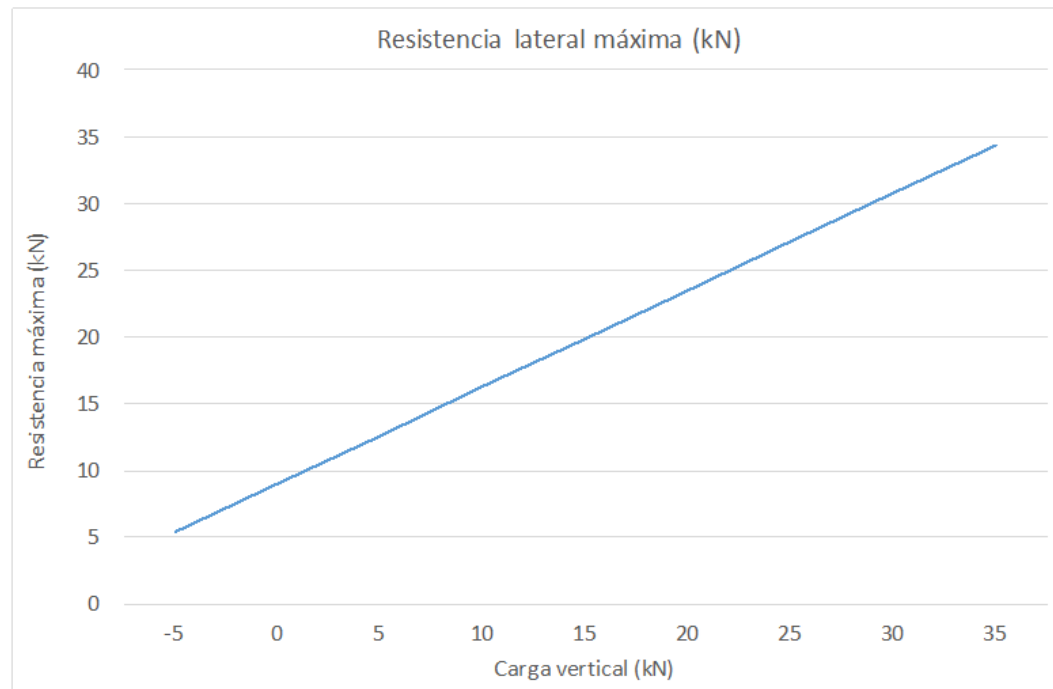

Figura 3.23: Resistencia transversal pico frente a carga vertical. Fuente: Recuperado de Zand y Moraal, 1997.

\subsection{Metodologías para la evaluación de la resistencia transversal}

Dada la gran complejidad que presenta la evaluación teórica de la resistencia lateral de una vía, muchos han sido los experimentos y pruebas llevadas a cabo con el objetivo de medir y evaluar su magnitud. El valor de la resistencia, tal y como se ha descrito previamente, está influenciado por múltiples factores como: tipo, peso y dimensiones de la traviesa, tipo y condición del balasto, dimensiones de la banqueta, estado de consolidación, calidad de la vía, ciclos de carga aplicados, mantenimiento, etc.

La experiencia adquirida y la práctica muestran que la resistencia pico de una vía tipo se sitúa en torno a los 9-11 kN/traviesa para vías con una baja resistencia y alcanza valores de 14-16 kN/traviesa para vías con elevada resistencia.

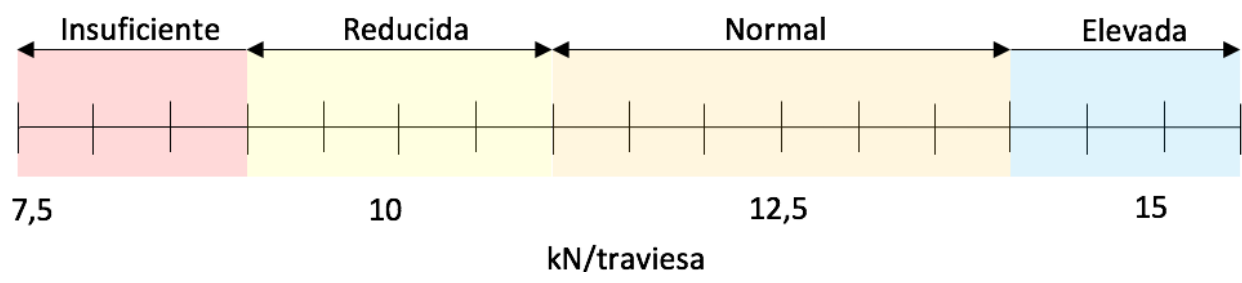

Figura 3.24: Resistencia transversal pico y tipo de vía. Fuente: Elaboración propia.

Para llegar a determinar la capacidad resistente de una vía se hace uso, generalmente, de ensayos y test donde se analiza y mide tanto la fuerza aplicada como los desplazamientos 
que se producen. De entre las múltiples técnicas disponibles, es posible distinguir los siguientes métodos principales:

- Ensayo de empuje de una traviesa (denominado STPT).

- Ensayo de desplazamiento de un panel o grupo de traviesas.

- Ensayo mecánico de desplazamiento.

- Método del vagón descarrilador.

- Medida dinámica continua de la resistencia lateral.

En el primer caso, el ensayo STPT es el más utilizado y consiste en desplazar lateralmente una traviesa cualquiera, registrando la fuerza y el desplazamiento de la traviesa. Para llevar a cabo el ensayo, es necesario eliminar las 4 sujeciones que fijan la traviesa a los carriles, para posteriormente aplicar la fuerza lateral sobre la traviesa mediante un gato hidráulico. Una vez libre de las sujeciones, sobre la traviesa se aplica un esfuerzo lateral, registrando tanto la fuerza como el desplazamiento lateral, cosa que permite obtener la curva esfuerzodeformación característica.
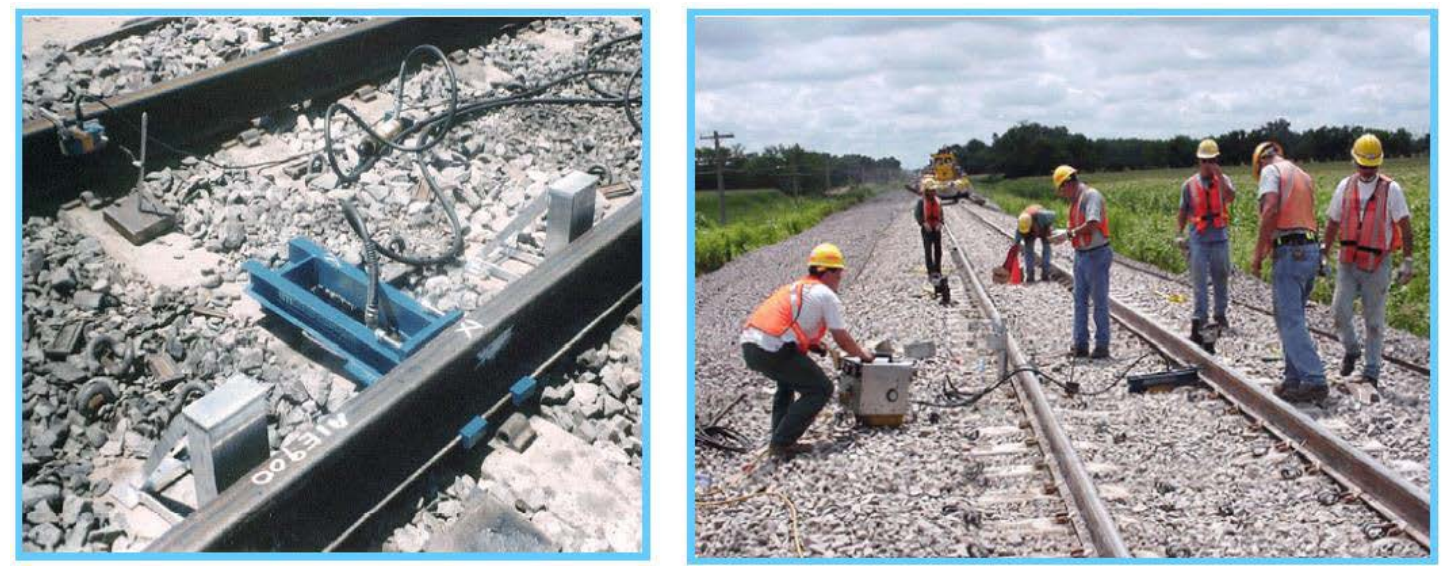

Figura 3.25: Ensayo STPT. Fuente: Recuperado de Kish, On the Fundamentals of Track Lateral Resistance, 2011.

Con este ensayo se obtiene un comportamiento no-lineal característico de la resistencia lateral, si bien los desplazamientos obtenidos son reducidos, por lo que la parte de la curva tras la carga máxima o resistencia pico no puede ser determinada. Las ventajas proporcionadas por el ensayo STPT frente al resto son:

- Obtención de un valor característico de la vía.

- Facilidad de portabilidad del equipamiento, montaje y ensayo. 
- Ensayo no destructivo, con lo que la vía mantiene su integridad.

Sin embargo, pese a las ventajas descritas, el problema principal del STPT es la gran variabilidad de resultados que se obtiene traviesa a traviesa. Por ello, se suele tener en consideración un valor medio para un conjunto de varias traviesas ensayadas, lo que permite obtener un valor representativo del tramo analizado.

En cuanto al segundo método relativo al desplazamiento de un grupo de traviesas, en este caso se aplica una fuerza a un tramo de al menos 4 traviesas, registrando su desplazamiento. En este caso, la resistencia lateral obtenida es una combinación de la rigidez de los carriles, la resistencia longitudinal y la resistencia transversal de un grupo de traviesa. Por ello, el valor obtenido en este tipo de ensayos no es directamente aplicable en los métodos de cálculo, pues generalmente se requiere la resistencia por metro de vía o por unidad de traviesa. Además, el ensayo requiere que una zona de la vía sea seccionada (corte de los carriles) mientras que el desplazamiento aplicado produce deformaciones importantes, por lo que el uso práctico de este tipo de método es muy limitado.

Para el ensayo mecánico de desplazamiento se utilizan generalmente bateadoras adaptadas, cuyos cilindros de ripado permiten aplicar una fuerza transversal, registrándose el desplazamiento con los transmisores de alineación.

Respecto del método del vagón descarrilador, se requiere tanto un vehículo de ensayos especial como dispositivos de medición en vía, cosa que dificulta su aplicabilidad.

Para finalizar los ensayos dinámicos continuos son métodos donde el comportamiento de la vía es analizado considerando la rigidez de flexión de los carriles y la rigidez de torsión de los sistemas de sujeción, por lo que es prácticamente imposible determinar con precisión la resistencia lateral.

Todos los métodos anteriormente descritos tienen asociado una gran dificultad técnica y operativa, así como la necesidad de disponer de equipos y personal capaz de llevar a cabo dichos trabajos. Estos inconvenientes hacen que en la práctica se realicen únicamente en situaciones especiales y para unos pocos puntos de una línea, lo que dificulta conocer con precisión la resistencia transversal real de un determinado tramo de vía. 


\section{Estudios previos y mode- lización del pandeo de vía}

\subsection{Introducción}

Con la introducción de la barra larga soldada en el ámbito ferroviario surge la necesidad de considerar el fenómeno del pandeo y evaluar el riesgo de que se produzca. Debido a ello $y$, en paralelo a la mejora de las técnicas computacionales, son muchos los autores que desde la década de 1960 han puesto especial interés en su estudio.

En su evolución confluyen diversos factores, si bien la mejora en el conocimiento de la resistencia de materiales, así como la evolución de la capacidad computacional ha condicionado la interacción entre el problema físico real y la aproximación teórica.

Como paso previo al estudio del pandeo, es importante conocer el método de diseño de una vía con carril continuo soldado. Si bien en el punto anterior se han descrito los mecanismos y factores que condicionan la estabilidad de la vía, desde el punto de vista del diseño se parte de la hipótesis que para cualquier punto de la vía la resistencia supera a los esfuerzos que puedan originarse.

Tal y como se ha descrito, las tensiones longitudinales pueden generarse por efecto de la temperatura, de las operaciones de mantenimiento, por el frenado o aceleración de los vehículos, así como otros factores adicionales. Además de los mencionados esfuerzos y para estar del lado de la seguridad, es necesario disponer de un cierto margen de resistencia, pues cualquier esfuerzo externo no previsto podría ocasionar graves consecuencias. Con ello, la Figura 4.1 muestra un esquema para el diseño, considerado los aspectos citados. 


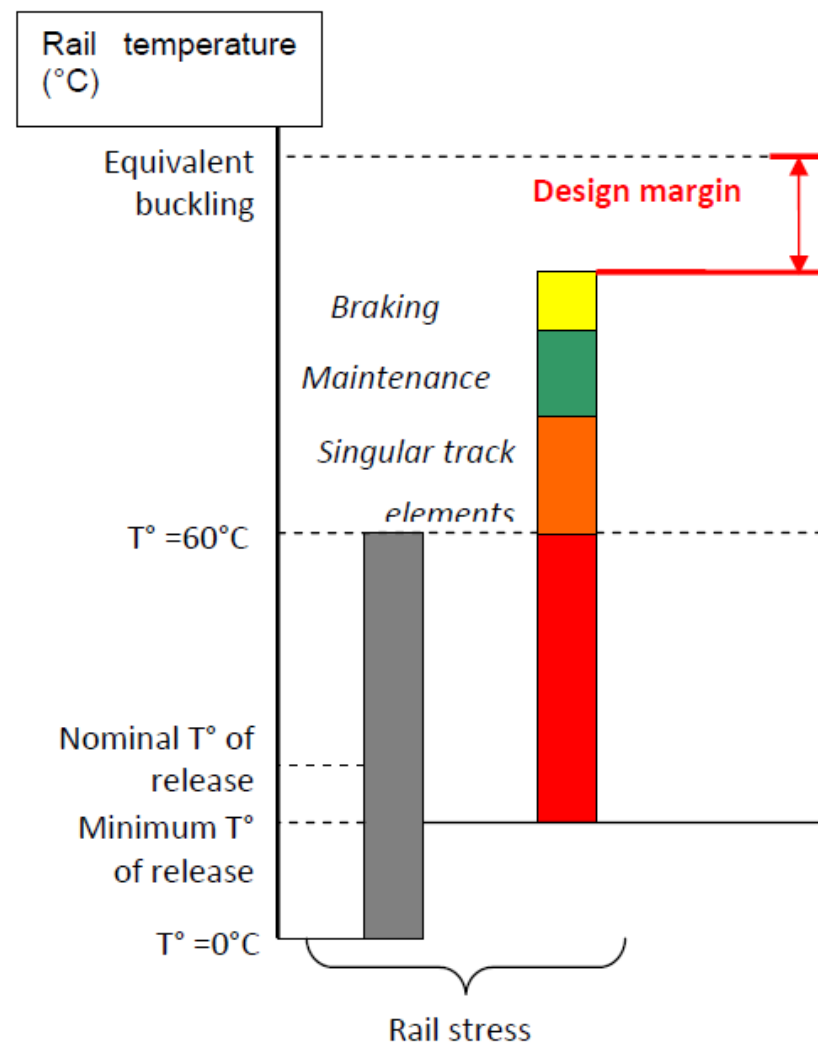

Figura 4.1: Esquemas de modelos de vía. Fuente: Eddy Current Brake Compatibility Project.

Por lo que respecta a la resolución del problema de pandeo, se busca determinar la relación entre la variación de temperatura y el desplazamiento lateral de la vía, bajo unas ciertas condiciones de contorno. Para ello, el estudio y determinación del pandeo ferroviario ha tratado de considerar los diferentes factores y condicionantes que intervienen en el fenómeno: comportamiento del balasto, presencia de defectos de vía, cargas aplicadas, etc.

El estudio en este campo aún continúa desarrollándose, con el objetivo de desarrollar métodos más precisos y que sean capaces de considerar todas las variables del problema.

Tradicionalmente el pandeo ha sido analizado mediante métodos analíticos. En este tipo de modelos, la resolución del problema se aborda mediante expresiones simplificadas con objeto de alcanzar, de modo efectivo, soluciones analíticas al problema.

Más recientemente han sido desarrollados modelos numéricos, especialmente con el desarrollo del método de los elementos finitos (MEF), donde es posible considerar un mayor número de variables y bajo comportamientos más complejos y no lineales, cosa que no es 
posible con los modelos analíticos. En este tipo de modelos, la solución se alcanza mediante la resolución de una serie de ecuaciones algebraicas simultaneas, donde los elementos de la vía son simulados con un comportamiento caracterizado por expresiones programadas y definidas por el usuario, en función de la mayor o menor complejidad alcanzada.

Como paso previo al modelo desarrollado en la presentes Tesis, en este capítulo se realiza un análisis del problema de pandeo en el ámbito ferroviario y se describen de forma sintética los procedimientos usados por los autores presentes en la bibliografía.

Finalmente, se dedicará un último apartado en cuanto al uso de software específico en el estudio del pandeo, aplicado al ámbito ferroviario.

\subsection{Modelos para la determinación de la carga de pandeo}

En la actualidad, se considera que el fenómeno del pandeo está asociado a una compleja interacción entre la resistencia vertical, lateral y torsional de la vía. Esto se debe a que la estabilidad de la vía es el resultado de las resistencias proporcionadas por conjunto de factores, gran parte de los cuales se encuentran interrelacionados entre sí. En la literatura es posible encontrar un gran número de estudios, con diferentes grados de complejidad. Tradicionalmente, es posible caracterizar la respuesta de la vía frente al pandeo mediante tres valores de temperatura: la de neutralización $\left(t_{n}\right)$, la de seguridad o temperatura mínima de pandeo $\left(\Delta T_{\min }\right)$ y, por último, la temperatura de pandeo o temperatura máxima $\left(\Delta T_{\max }\right)$.

No obstante, para poder abordar el estudio con eficacia, los investigadores han utilizado simplificaciones que permiten resolver el problema, dando como resultado la existencia de numerosas metodologías resolutivas. La complejidad resolutiva se debe tanto al número de factores que forman parte del problema como a la interacción y variabilidad que presentan muchos de ellos. Con ello, la determinación de la curva de pandeo depende, fundamentalmente, del modelo e hipótesis consideradas en su resolución.

De forma global, los modelos pueden ser clasificados en dos grandes bloques: modelos viga y modelos carril-traviesa. 


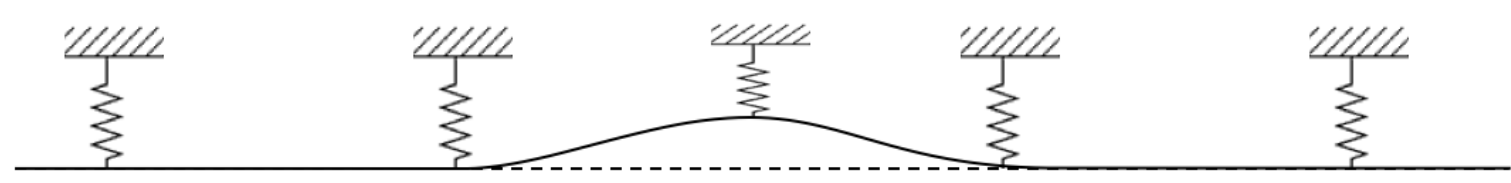

a) Modelo tipo viga

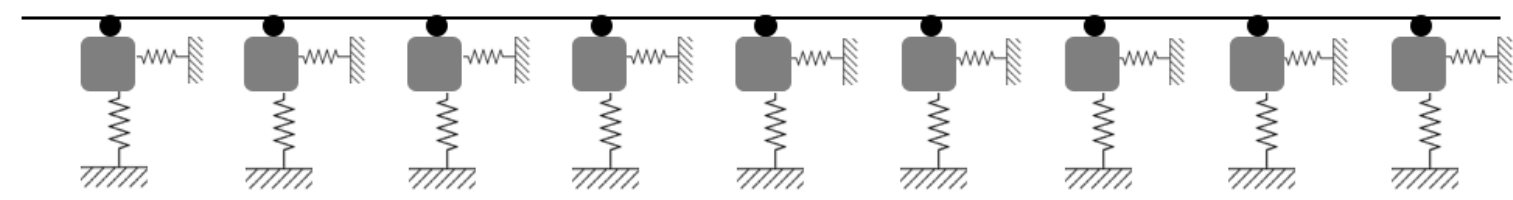

b) Modelo tipo carril-traviesa

Figura 4.2: Esquemas de modelos de vía. Fuente: Elaboración propia.

En los modelos viga, los carriles son representados por un único elemento tipo viga de una cierta longitud, cuyas propiedades (área e inercia) representan las características resistentes de la vía analizada. A su vez, las sujeciones y las traviesas son sustituidas por elementos tipo muelle, cuya rigidez caracteriza el comportamiento de estos elementos, mientras que la interacción entre el balasto y la traviesa es representada por elementos tipo muelle con diferentes posibles comportamientos.

Con este esquema simplificado de vía, las primeras contribuciones científicas se atribuyen a Bijl (1964), quien ya en los años 50 y 60 abordó por primera vez mediante una formulación bastante simple el problema del pandeo en vías. En estos primeros modelos la solución era obtenida mediante una aproximación energética, donde los esfuerzos axiales eran representados por fuerzas de compresión. El mayor problema de este tipo de modelos radica en el hecho de que no se considera la reducción de la resistencia lateral que se produce una vez alcanzado el valor pico. Por este motivo, la curva de pandeo obtenida se sobreestima la resistencia de la vía y, en consecuencia, se obtienen valores de temperatura de pandeo no por encima de los que se obtenían en la práctica.

Tras los primeros estudios, no tardaron en surgir nuevas investigaciones, tratando de comprender los mecanismos que condicionan el pandeo. Las investigaciones realizadas por Kerr $(1976 ; 1978 ; 1980)$ en los años 70 utilizó definieron, por primera vez, el concepto de 
región o zona de pandeo. Bajo esta aproximación el tramo de estudio era dividido en dos regiones con comportamiento claramente diferenciados: una zona central donde se producían grandes desplazamientos y, otra, formada por las zonas adyacentes, caracterizada por una deformación únicamente axial.

El análisis teórico desarrollado por Kerr sirvió como base para realizar numerosas investigaciones relacionadas con la inestabilidad lateral de vías. Paralelamente, se seguían realizando importantes trabajos de campo para tratar de respaldar los resultados obtenidos. No obstante, aún se estaba lejos de obtener un modelo preciso, pues factores como la desconsolidación de la vía por el bateo o irregularidades en las sujeciones y traviesas todavía no habían sido considerados.

Haciendo uso de un modelo de viga, en (Tvergaard y Needleman, 1981) se enfocaba el estudio del pandeo asumiendo diferentes imperfecciones laterales periódicas y no periódicas, obteniendo en todos los casos las curvas de pandeo con la temperatura máxima, correspondiente al cambio de comportamiento de la vía.

Desde el 1979 hasta el 1993, los investigadores Kish (1982; 1985) y Samavedam (1979; 1983; 1993) publican una serie de artículos con un planteamiento mucho más experimental, donde se realizan y comparan los valores obtenidos en los modelos analíticos con datos de pruebas realizadas en vías reales, tanto para tramos rectos como en curvas de gran radio. En estas investigaciones se introduce, como gran novedad, el efecto dinámico que tiene lugar cuando una o varias cargas puntuales circulan sobre la vía, y la posible reducción de la temperatura de pandeo debido a su efecto. Estos trabajos también permitieron confirmar de forma experimental la importancia que poseen en el control del pandeo tanto los defectos iniciales como la resistencia lateral.

A raíz de los problemas de inestabilidad lateral detectados en tramos curvos, algunos autores (Donley y Kerr, 1987) centraron sus investigaciones en la determinación de la carga de pandeo en curvas. Para ello, fueron consideradas explícitamente las deformaciones previas, además de una respuesta no lineal característica de la resistencia axial. Los resultados obtenidos evidencian que el incremento de temperatura admisible o temperatura de seguridad se reduce a medida que el radio de la curva disminuye. 
Por su parte, Esveld y Hengstum (1988) utilizaron el MEF para la resolución del pandeo en tramos curvos. El cálculo era llevado a cabo mediante un modelo de viga, mientras que otros investigadores (El-Ghazaly, Sherbourne y Arbabi, 1991) profundizaron en dicho análisis utilizando un modelo 3D de la vía representado por una viga de perfil hueco apoyada sobre un lecho elástico, donde el valor de la carga vertical y la rigidez del terreno eran obtenidas bajo una aproximación estadística. Para poder alcanzar una solución, era necesario considerar la resistencia del balasto y de las sujeciones como constante.

Ya en el año 1996, Samavedam, Blader y Thomson (1996) establecieron en sus trabajos desarrollados para el Department of Transportation de los EE.UU. un método en la resolución numérica del pandeo basado en el equilibrio de la deformada de la vía. La construcción del método se realizaba mediante la resolución de dos modelos: el primero de ellos para el cálculo de los esfuerzos laterales debido al paso de los vehículos, mientras que el segundo permitía llevar a cabo el cálculo del pandeo. En este segundo modelo, la resolución se obtenía a través del uso de las series de Fourier, siendo necesarias varias iteraciones. La mayor limitación que presenta este tipo de solución es que únicamente puede ser resuelto el problema para pequeños desplazamientos (se fija como máximo un desplazamiento de $6,4 \mathrm{~mm}$ ), rango donde la resistencia lateral de la vía es aproximadamente proporcional al desplazamiento.

Junto con las referencias clásicas citadas previamente, en la actualidad se siguen realizando nuevas soluciones analíticas al problema. Digno de mención son los estudios llevados a cabo por Esveld (2001), donde se discute ampliamente sobre la relación no lineal existente entre la resistencia lateral y las cargas verticales. El modelo utilizado viene representado por una viga elástica en 3D, mientras que la resistencia lateral está caracterizada por un comportamiento bilineal. La resolución se obtiene mediante criterios energéticos considerando que, tras el pandeo, la vía adopta la misma forma que el defecto inicial y que dicho defecto es senoidal, por lo que se vinculan desde el inicio ambos factores.

Así pues, recientemente López Pita (2006) presenta un modelo basado resolver las ecuaciones para la posición deformada de la vía para un elemento diferencial de vía. El modelo permite considerar diferentes factores, si bien como sucede en otros modelos la resolución requiere algunas simplificaciones, pues de lo contrario la ecuación diferencial puede resultar irresoluble. Además, la presencia de defectos iniciales complica notablemente la resolución de la ecuación diferencial. 
Durante ese mismo año y partiendo de los modelos elaborados por el propio Kerr a finales de los años 70, Grisson y Kerr (2006) derivan las ecuaciones de secciones tipo con las que introducen de forma explícita algunas variables como el ancho de vía, la resistencia a torsión de las sujeciones y la rigidez a flexión de las traviesas. Los autores abordan el problema diferenciando dos regiones: una central donde se produce deformaciones laterales y otra, constituida por las zonas adyacentes, donde no existe ningún tipo de desplazamiento lateral. El modelo considera una resistencia lateral constante y no se consideran los efectos de las cargas verticales ni los defectos de alineación.

Por su parte, Choi y $\mathrm{Na}$ (2010) estudian el pandeo mediante un modelo de un tramo en curva sometido a cargas verticales y longitudinales, determinando que la temperatura máxima de pandeo está estrechamente relacionada con la pérdida de resistencia lateral de la traviesa debido al efecto producido por el paso de un vehículo.

Recientemente Navarro, Villalba, Martínez e Insa (2015) han utilizado un modelo, resolviendo para ello las ecuaciones potenciales en una posición de equilibrio deformada, lo cual proporciona la carga de pandeo y, con ello, la temperatura de los carriles. Pese a que se considera la influencia de las cargas verticales, el tipo de traviesas y carriles, la amplitud de los defectos y la desconsolidación por bateo, no es considerada la no linealidad de la resistencia lateral ni la perdida de resistencia por efecto de las cargas aplicadas por los vehículos.

Un planteamiento diverso es el seguido por Zhu y Attard (2015), los cuales utilizan un modelo tipo sándwich para representar la estructura carril-traviesa bajo un comportamiento hiperelástico. Por último, cabe destacar los trabajos de Yang y Bradford (2016). Estos autores han publicado la resolución del pandeo considerando el principio de la energía potencial mínima, con el que se han derivado las ecuaciones diferenciales pre y post pandeo, obteniéndose soluciones simétricas y anti simétricas de la deformada de la vía.

Pese a los esfuerzos realizados y las continuas evoluciones desarrolladas, los modelos basados en la representación de la vía como una viga continua sobre apoyos discontinuos requieren la necesidad de asumir simplificaciones matemáticas que permiten resolver el problema. Por ello, el grado de precisión alcanzado mediante los modelos descritos está estrechamente relacionado con las diferentes simplificaciones realizadas.

Algunos de los aspectos más importantes que condicionan las soluciones son: 
- La homogeneidad en las propiedades mecánicas y geométricas de los elementos del modelo.

- La necesidad de asumir, a priori, la forma de la posición deformada que debe alcanzar la vía tras el pandeo.

- Debido a la simplificación de la vía a una viga, se asume la misma temperatura de neutralización y de pandeo para ambos carriles.

Para evitar parte de los problemas descritos previamente y gracias al desarrollo de las computadoras y los métodos de cálculo, desde finales de los años 70 se empiezan a utilizar modelos numéricos, generalmente basados en el MEF, como alternativa a los modelos analíticos.

De entre los primeros autores que hizo uso de este método resolutivo para el cálculo del pandeo de vía destacan los trabajos realizados por So y Martin (1978) así como So y Yang (1978), donde se planteaba un modelo de vía en dos dimensiones, considerando las cargas verticales, la curvatura de la vía, la rigidez de las sujeciones, así como algunos posibles defectos de vía.

Es ya durante la década de los años 80 cuando el uso de los modelos numéricos empieza a tener una mayor relevancia. Mediante el uso de "superelementos", Jackson, Bauld y Ramesh $(1986 ; 1988)$, construyeron un modelo bidimensional carril-traviesa de un tramo del emparrillado, el cual representa una longitud igual al espaciamiento entre traviesas. Los resultados obtenidos muestran una buena aproximación entre los valores calculados y los obtenidos en pruebas experimentales. A su vez, es posible calcular la posición final de la vía tras el pandeo sin necesidad de forzar el problema, como sí sucedía en los modelos tipo viga. No obstante, pese a las ventajas que ofrecía el MEF, los estudios planteados hasta ese momento eran basados en aproximaciones bidimensionales, donde no se tiene en consideración explícitamente el efecto de la rigidez vertical del balasto ni la resistencia longitudinal de la vía.

El uso del MEF bajo un entorno tridimensional tiene la capacidad de representar de forma detallada los elementos y materiales que componen la vía en sus diferentes ejes, necesarios para llegar a una solución precisa. En este tipo de modelos las acciones (efectos térmicos y las cargas de los vehículos) se establecen mediante algoritmos e interacción de los contactos entre los diferentes elementos. Otro aspecto interesante es la posibilidad de 
considerar variaciones espaciales de las características físicas y geomecánicas de los materiales.

Con estas premisas, son muchos los autores que recientemente han utilizado el MEF, tratando de obtener de forma más precisa la curva de pandeo, bajo unas condiciones predefinidas.

De entre los más relevantes destacan las publicaciones realizadas por Lim (2003; 2004; 2008). En los trabajos de Lim se consideran los dos carriles por separado, la rigidez de las sujeciones, la no linealidad de la resistencia del balasto y los defectos de vía, por lo que permite analizar una gran variedad de condiciones. Un aspecto fundamental de estos estudios reside en la necesidad de establecer un criterio para la seguridad, pues el modelo estima la temperatura de pandeo para cada combinación de factores asociada a un determinado riesgo de que se produzca el fenómeno. Una de las conclusiones alcanzadas por Lim es la necesidad de que el pandeo debe estudiarse desde una perspectiva tridimensional, pues los modelos en dos dimensiones tienden a subestimar la temperatura de pandeo.

A su vez, la extensión del cálculo del pandeo a tramos curvos ha concentrado los esfuerzos de recientes investigaciones. Destacan las contribuciones realizadas por Feng, Zong y Lei (2005), donde construyen un modelo para curvas de radio reducido, permitiendo determinar la relación entre la temperatura de los carriles y el desplazamiento lateral en la curva. No obstante, en estos estudios no se considera la influencia de las cargas dinámicas inducidas por el paso de los vehículos.

Durante ese mismo año, otros autores como Sung, Shih, Lin y Go (2005) han analizado la inestabilidad lateral empleando el método de las diferencias finitas. Los resultados obtenidos han sido aplicados para el cálculo del pandeo, considerando la presencia de cargas axiales debidas a la aceleración y deceleración ejercidas por un vehículo. El análisis revela que el caso más desfavorable se produce en presencia de cargas debidas a la deceleración (y que comprimen los carriles), reduciéndose en esos casos la temperatura máxima de pandeo.

En comparación con las investigaciones basadas en vías clásicas o con un solo ancho, son muy escasas las referencias bibliográficas en las que se analiza el pandeo de vía con tres carriles. En Cuadrado et al. (2008), los investigadores han llevado a cabo un estudio mediante el MEF compuesto por dos sub-modelos para el estudio del pandeo en vías con 
doble ancho. El primer sub-modelo permite simular el efecto de las cargas verticales mientras que el segundo sub-modelo considera el comportamiento horizontal, únicamente bajo la presencia de cargas térmicas. Los resultados han sido comparados con un modelo similar para vías convencionales (un único ancho), destacando que en vías con 3 carriles la temperatura de pandeo es inferior $y$, por lo tanto, existe un mayor riesgo de pandeo, especialmente en curvas de radio reducido. No obstante, el uso de un modelo tipo viga no tiene en consideración la asimetría generada por la presencia del tercer carril.

Siguiendo con el estudio en curva, algunos otros autores (Yaping, Xu, Wu y Jianzhong, 2010), han utilizado el MEF para la determinación del efecto de la introducción de un refuerzo en curvas con reducida estabilidad transversal. Los resultados obtenidos muestran el efecto positivo que se obtienen tras llevar a cabo un refuerzo (mediante elementos de anclaje al terreno) en curvas con poca resistencia lateral.

Ya recientemente es posible destacar el trabajo realizado por Pio Pucillo (2016). El autor utiliza un MEF en 3D para realizar análisis de sensibilidad, determinando las variables más significativas. En la misma línea que otros autores, los resultados obtenidos muestran que la resistencia longitudinal de la vía condiciona la temperatura mínima de pandeo, los defectos iniciales la temperatura máxima de pandeo, mientras que la curvatura y la resistencia lateral condiciona ambas temperaturas.

A diferencia de la mayoría de los trabajos desarrollados hasta el momento, en la presente Tesis se realiza la simulación precisa de una vía con doble ancho, cuyo estudio en profundidad no ha sido abordado hasta este momento. 


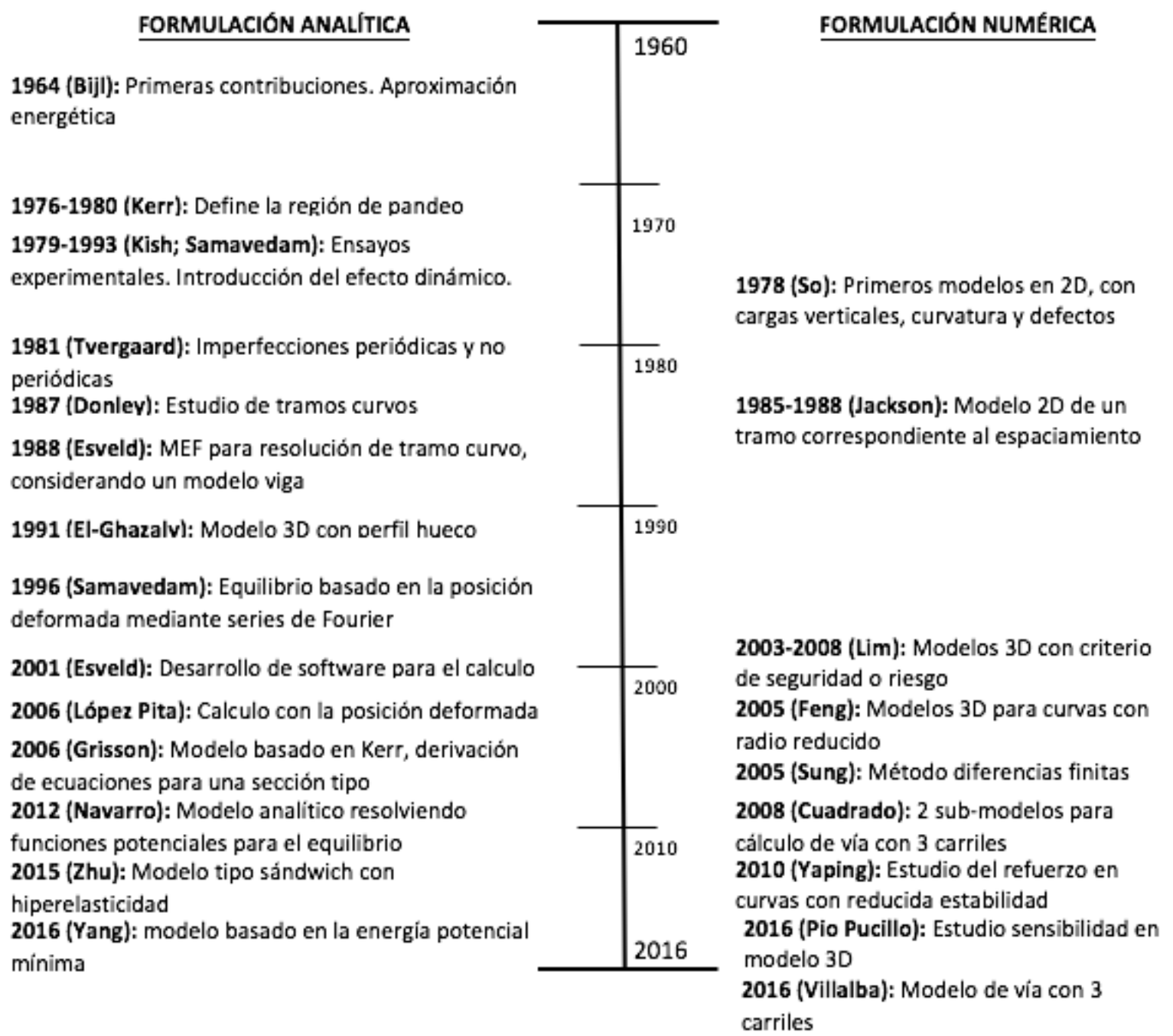

Figura 4.3: Cronograma con las principales contribuciones científicas en el campo del pandeo de vía. Fuente: Elaboración propia.

\subsection{Software para el cálculo del pandeo}

Ante la falta de una metodología comúnmente aceptada y las dificultades que plantea el problema del pandeo, durante los años 1992-1999 la Unión Internacional de Ferrocarriles (UIC) supervisó un estudio desarrollado por el Instituto Europeo de Investigación Ferroviaria (ERRI). Para ello se creó un comité de expertos, el ERRI-D202, con el fin de ampliar y mejorar el conocimiento sobre la barra larga soldada y poder actualizar la ficha UIC-720, en la que se establecen los procedimientos generales para la construcción y mantenimiento de vías con carril continuo soldado. 
Como resultado de los trabajos realizados, en la nueva ficha UIC-720 publicada en el año 2005 se recoge gran parte de los avances alcanzados, así como diversos casos de estudios del pandeo, mediante el uso de dos aplicaciones informáticas diferentes: el CWERRI (actualmente denominado y combinado con LONGIN) utilizado por el ERRI y el CWRSAFE, usado por la Administración Federal de Ferrocarriles (FRA) de los EE.UU.

A continuación, se analizará cada uno de ellos por separado, destacando sus principales características.

\subsubsection{CWERRI}

EI CWERRI es un software para el diseño y análisis de vías con carril continuo soldado basado en un programa de elementos discretos desarrollado en los años 90. Este software, desarrollado por la Technical University of Delft en un entorno Windows, posee las siguientes características:

- Obtención de fuerzas y desplazamientos en 3D: longitudinales, laterales y verticales.

- Comportamiento pre y post pandeo.

- Análisis de tramos en recta y curva.

- Introducción de cargas de un tren completo.

- Compatibilidad con elementos singulares como puentes y estructuras.

- Introducción de fuerzas mecánicas y térmicas.

- Análisis estático y dinámico.

El modelo utilizado por el CWERRI consiste en una viga Timoshenko apoyada sobre soportes elásticos, mientras que la resistencia lateral se representa mediante elementos con un criterio de rotura de Mohr-Coulomb. Los datos necesarios para poder llevar a cabo el cálculo son: radio de curvatura, resistencia lateral máxima y residual, deformación máxima y residual, rigidez longitudinal y torsional, así como la amplitud y longitud de onda del defecto analizado. Para poder analizar el comportamiento tras el pandeo, se ha implementado el método del "arc-length", con el que se resuelve el problema de las cargas térmicas.

Los resultados obtenidos tras el cálculo son expresados en términos de temperatura, respecto de la temperatura de neutralización. Las conclusiones más interesantes obtenidas mediante el uso de este software son: 
- No resulta seguro considerar como criterio de seguridad la temperatura máxima de pandeo $\left(\Delta \mathrm{T}_{\max }\right)$

- Resulta un criterio demasiado conservador tomar como temperatura límite la temperatura mínima de pandeo $\left(\Delta \mathrm{T}_{\min }\right)$.

- Un criterio razonable es aquel de adoptar como temperatura máxima permisible en los carriles: $\Delta T_{\text {admisible }}=\Delta \mathrm{T}_{\min }+0.25\left(\Delta \mathrm{T}_{\max }-\Delta \mathrm{T}_{\min }\right)$

Haciendo uso de este software, cabe destacar los trabajos realizados por Van (1997). El autor realizó un estudio de sensibilidad, proponiendo desacoplar y representar por separado la resistencia longitudinal y lateral del balasto.

De su estudió se concluye que la temperatura máxima de pandeo está influenciada por la resistencia lateral y los defectos de vía, mientras que la temperatura mínima de pandeo viene condicionada por el radio de curvatura y la rigidez de la capa de balasto, así como por la resistencia a torsión de las sujeciones.

\subsubsection{CWR-SAFE}

Al igual que el ERRI, la FRA de los EE.UU. desarrollo durante los años 90 un software de cálculo del pandeo. Gracias a la estructura de este programa, es posible introducir gran parte de los parámetros necesarios para realizar el cálculo.

El programa CWR-SAFE está compuesto por tres módulos, combinados entre sí: CWRBUCKLE, CWR-INDY y CWR-RISK.

El primero de ellos, el CWR-BUCKLE es un módulo para el cálculo del pandeo calibrado con valores experimentales llevados a cabo en diferentes líneas de los EE.UU., el cual permite obtener los siguientes resultados:

- Calculo del pandeo, en términos de incremento de temperatura máxima y mí$\operatorname{nima}\left(\Delta \mathrm{T}_{\text {max }}, \Delta \mathrm{T}_{\min }\right)$.

- Cálculo de la energía de pandeo para una determinada temperatura.

- Cálculo de fuerzas en carriles pre y post pandeo.

- Determinación de la temperatura segura, asociada a un riego y mantenimiento.

Los datos necesarios para el cálculo son: 
- Tipo de carril, traviesa y balasto.

- Peso de la traviesa y espaciamiento.

- Curvatura de la vía.

- Coeficiente de fricción balasto-traviesa.

- Resistencia a torsión de las sujeciones.

- Rigidez longitudinal y vertical de la vía.

- Valor pico de resistencia lateral.

- Amplitud y longitud de onda del defecto.

- Temperatura máxima y de neutralización.

Una vez introducidos todos los datos necesarios, el módulo puede ser ejecutado, obteniéndose tanto el gráfico temperatura-deformación característico, así como una tabla con todos los resultados.
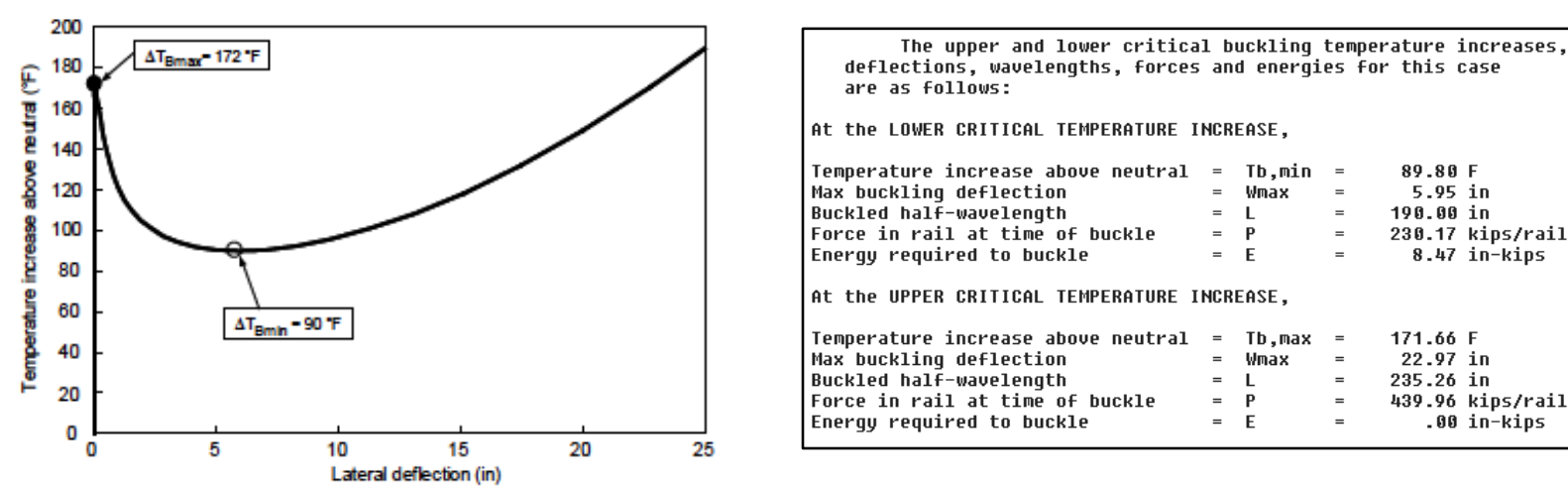

Figura 4.4: Salida de datos del módulo CWR-BUCKLE. Fuente: Track Buckling Prevention: Theory, Safety Concepts, and Applications (FRA, 2013).

Pese al gran potencial que posee este módulo, el problema fundamental reside en la complejidad que existe para conocer con precisión dichos valores.

Como alternativa al módulo anterior, el CWR-INDY fue desarrollado para llevar a cabo estudios simples, introduciendo únicamente unos pocos datos cualitativos y cuantitativos (tipo de vía y balasto, altura del lecho de balasto y toneladas que han circulado sobre la vía), mientras que para el resto de factores son determinados por el módulo asumiendo unos valores medios representativos. La solución con este módulo se obtiene mediante fórmulas empíricas, basadas en la experimentación llevada a cabo. 
Finalmente, el módulo CWR-RISK permite llevar a cabo un cálculo bajo una aproximación probabilística. Mientras que en los dos módulos anteriores la resolución se lleva a cabo bajo un entorno determinístico, en este caso los valores de los parámetros son obtenidos mediante funciones de probabilidad, las cuales permiten transformar los datos estadísticos recogidos en campo en valores probabilísticos, asociados a un determinado riesgo.

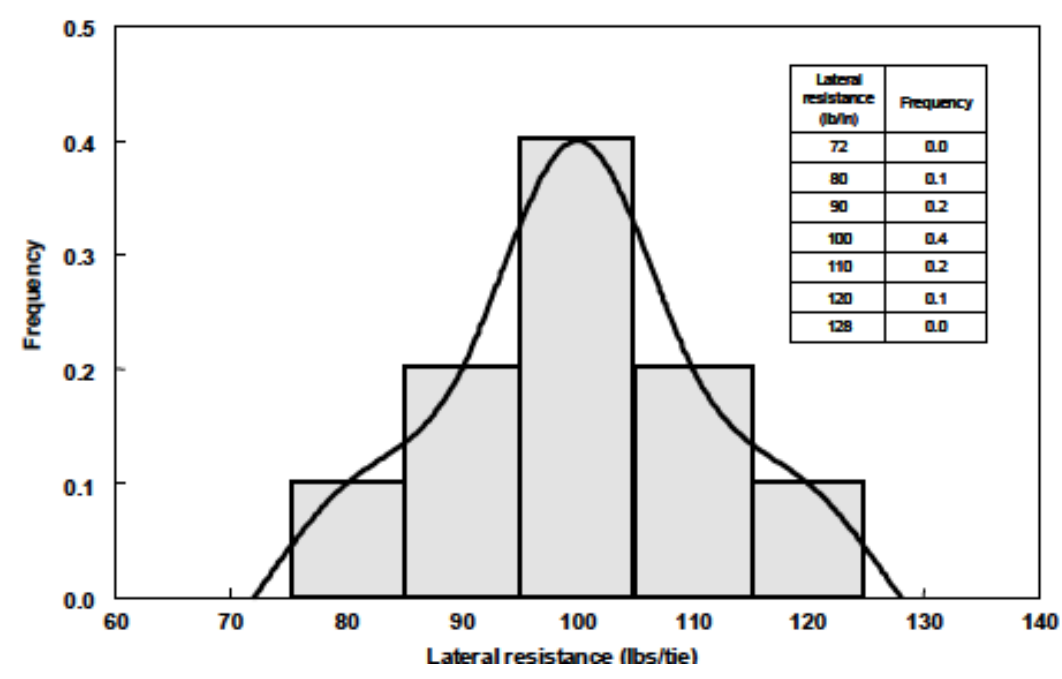

Figura 4.5: Distribución estadística para la resistencia lateral considerada en CWR-RISK. Fuente: Track Buckling Prevention: Theory, Safety Concepts, and Applications (FRA, 2013).

Esta metodología probabilística proporciona una mayor flexibilidad y su aplicabilidad al mantenimiento de vías, por cuanto considera el riesgo asociado a unas determinadas condiciones, pudiendo planificar y determinar las intervenciones a realizar.

\subsection{Conclusiones}

Tras la revisión de algunos de los trabajos más importantes en materia de cálculo de pandeo en vías, es posible plantear las siguientes conclusiones:

- Con la introducción del carril continuo soldado, el fenómeno del pandeo de vía ha suscitado un gran interés en investigadores, técnicos y administraciones ferroviarias. Esto se ha traducido en la producción de un gran número de estudios, en los que se aborda el pandeo mediante diferentes perspectivas. A la vez que se aumentaban las velocidades de circulación y con la mejora de las técnicas de construcción y mantenimiento de vía, el estudio del pandeo ha ido evolucionando hacia modelos 
cada vez más complejos, tratando de determinar las temperaturas admisibles en los carriles de forma precisa, con el objetivo de evaluar el riesgo de pandeo.

- Gran parte de los estudios realizados se emplean para predecir de forma teórica la temperatura a la que una vía se desestabiliza, mientras que son pocos los que se utilizan para contrastar datos experimentales obtenidos a través de ensayos más o menos complejos realizados en vía.

- En un enfoque analítico, la resolución del pandeo se obtiene a través de expresiones que representan el comportamiento de las diferentes variables que condicionan el problema. Estos modelos poseen ciertas limitaciones inherentes a la metodología utilizada, cosa que condiciona los resultados obtenidos. Se han estudiado aspectos relacionados con la desconsolidación producida por el bateo, la influencia de la curvatura, la influencia de las cargas aplicadas por los vehículos, utilizando modelos simplificados de la vía, generalmente modelos de vigas.

- Con la mejora de la capacidad computacional, la tendencia ha sido la de resolver el pandeo mediante modelos numéricos que permiten considerar la tridimensionalidad del problema. Con este tipo de aproximación es posible considerar la resistencia longitudinal, vertical y transversal por separado, aspecto fundamental para poder analizar de forma precisa la respuesta de la vía.

- Pese a las diferentes soluciones alcanzadas, existe un consenso general respecto a los factores que influencian en mayor grado el pandeo, siendo: la resistencia lateral, los defectos de vía y las cargas derivadas del paso de los vehículos.

- El uso de software para el cálculo del pandeo es una buena herramienta para estimar el riesgo. No obstante, el principal problema reside en la necesidad de conocer con precisión los valores de las variables utilizadas para llevar a cabo el cálculo.

- La gran mayoría de los trabajos analizados se centran en el estudio de vías tradicionales, es decir, compuesta por dos carriles que forman un único ancho. Son pues muy pocos los investigadores que han analizado el pandeo en vías con 3 carriles. En las contribuciones que tratan este tipo de vías, se obtienen conclusiones parciales como resultado del estudio de unos pocos casos discretos, por lo que se considera necesario llevar a cabo un estudio mucho más amplio. 
Para finalizar, cabe destacar que el trabajo desarrollado en esta Tesis se basa en parte de los estudios realizados en Navarro, Villalba, Martinez e Insa (2015) así como por Villalba, Insa, Salvador y Martínez (2017), en los que se ha abordado el cálculo del pandeo en vías convencionales y en vías de doble ancho mediante un modelo analítico y numérico, respectivamente. 


\section{Capítulo III}

\section{La vía de doble ancho}

\subsection{Introducción}

Tal y como se ha comentado previamente, la existencia en el territorio español de un ancho de vía diferente al resto de Europa ha supuesto un grave problema de conexión. Para acabar con estas fronteras ferroviarias, a lo largo de las últimas décadas se han utilizado diferentes acciones encaminadas a resolver el problema, pudiéndose clasificar en tres grandes bloques:

- Transbordo de un tipo de vehículo a otro: Esta solución tradicional utilizada supone el traslado de la mercancía y de los viajeros desde un vehículo a otro, permitiendo salvar los problemas de interconectividad. No obstante, el tiempo necesario para realizar la operación y los costes adicionales de manipulación, riesgos de pérdidas y daños, así como retrasos en la entrega hacen que sea una solución poco adecuada en la actualidad.

- Cambio de ancho. Se trata de una maniobra más o menos automática que permite cambiar el ancho de un vehículo ferroviario. Entre estos sistemas hay tres variantes: intercambio de ejes de los vagones, Intercambio de los bogies completos y, por último, el cambio automático de ancho de vía.

- Vías de doble ancho (o ancho mixto). Esta solución suele emplearse en corredores en los que es difícil ampliar el número de vías, disponiendo sobre la misma vía 
varios anchos, lo que permite circular a diferentes vehículos por la misma infraestructura.

Centrando la atención en la última solución propuesta, los escenarios en los que el uso de la vía de doble ancho es especialmente interesante se definen como:

- Tramos o líneas donde la circulación de trenes con dos anchos diferentes no permite justificar la construcción de vías independientes para cada ancho, generalmente debido a la baja densidad de tráfico u otras condiciones (económicas, ambientales, etc.).

- Tramos o líneas con densidad de tráfico elevada, donde la vía de doble ancho ofrece una mayor capacidad respecto al uso de dos vías, cada una con un ancho. Generalmente, para optimizar este tipo de explotación se banaliza la vía, cosa que permite circular en ambos sentidos de la marcha sobre una misma vía.

- Tramos ferroviarios en los que, por espacio o disponibilidad funcional, no admiten un mayor número de vías.

- Zonas especiales de longitud reducida (zonas de maniobras, talleres y estaciones, etc.).

Es pues bajo estas condiciones particulares donde la construcción de tramos con doble ancho tiene su aplicación. A continuación, se analizarán más en detalle los elementos particulares que componen la vía de doble ancho, por ser el tipo de vía objeto de estudio de la presente Tesis doctoral.

\subsection{Superestructura de vía de doble ancho}

Desde el punto de vista teórico, una vía de doble ancho es aquella que permite la circulación sobre la misma de trenes con, al menos, dos anchos de vía diferentes. Bajo esta definición, es posible identificar y clasificar tres tipos diferentes de vías:

- Vía estuchada: Se trata de una vía con cuatro carriles, simétricamente dispuestos respecto a su eje, apta para la circulación de trenes con dos anchos de vía diferentes. 
- Vía imbricada: Existen 4 carriles, dos para cada ancho, aunque a diferencia de la vía estuchada no están centrados en un mismo eje, sino que se alternan, situando un carril del otro ancho entre cada dos del mismo ancho.

- Triple carril: Cuando la diferencia de ancho entre los dos anchos de vía es reducida y no es posible disponer una configuración de vías estuchada, puede emplearse la configuración de triple carril. Para que sea posible esta configuración, la diferencia entre ambos anchos debe ser, al menos, igual o superior al ancho del patín del carril (para un carril UIC-60 el ancho del patín es igual a $150 \mathrm{~mm}$ ). En este tipo de vía, ambos anchos comparten uno de los carriles, existiendo en el lado opuesto dos carriles, cada uno de ellos para uno de los dos anchos.
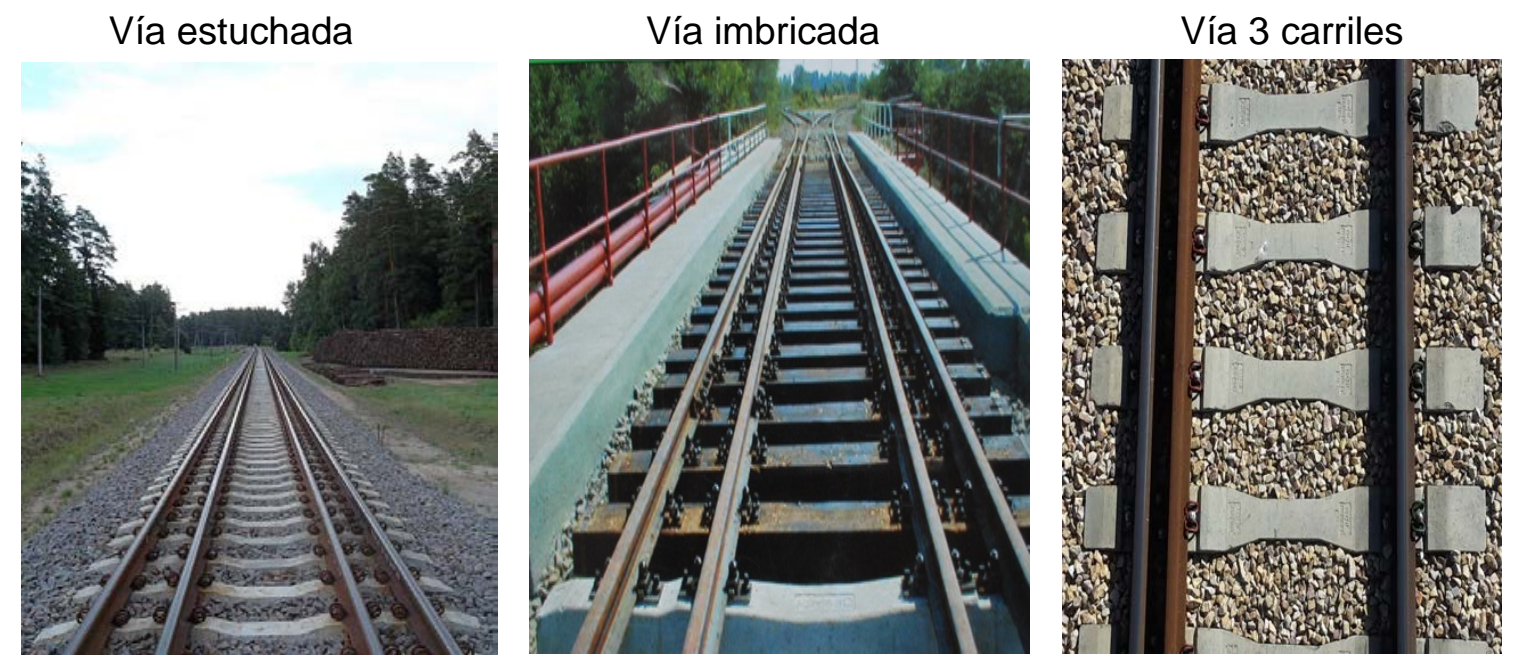

Figura 5.1: Imágenes de las diferentes tipologías de vías de doble ancho. Fuente: Elaboración propia a partir de imágenes.

Ante las diferentes posibilidades planteadas, el uso o adopción de una determinada solución depende, principalmente, de la diferencia existente entre los anchos, así como del tipo de explotación de la línea. Con estos requisitos, cuando la diferencia entre los dos anchos es grande es posible realizar una vía estuchada, disponiendo 4 carriles. Si la diferencia es más reducida, no es posible colocar todos los carriles, por lo que se utiliza la configuración de tercer carril. Finalmente, si la diferencia entre anchos es muy reducida (inferior al ancho del patín del carril), no existe espacio para fiar el tercer carril, por lo que se hace necesaria la utilización de la vía imbricada, cuyos ejes no son coincidentes.

En el caso español, ante la coexistencia de dos tipos principales de ancho de vía (1.435 mm y $1.668 \mathrm{~mm}$ ), el Ministerio de Fomento ha optado como solución global la implantación de vías con tres carriles (la diferencia entre ambos, de $233 \mathrm{~mm}$, es superior a los $150 \mathrm{~mm}$ del 
patín). Dicha solución todavía no ha sido usada hasta el momento en tramos largos o corredores importantes. De hecho, las especificaciones técnicas de interoperabilidad (ETI's) recogen el uso del tercer carril como un caso muy específico sin apenas desarrollo.

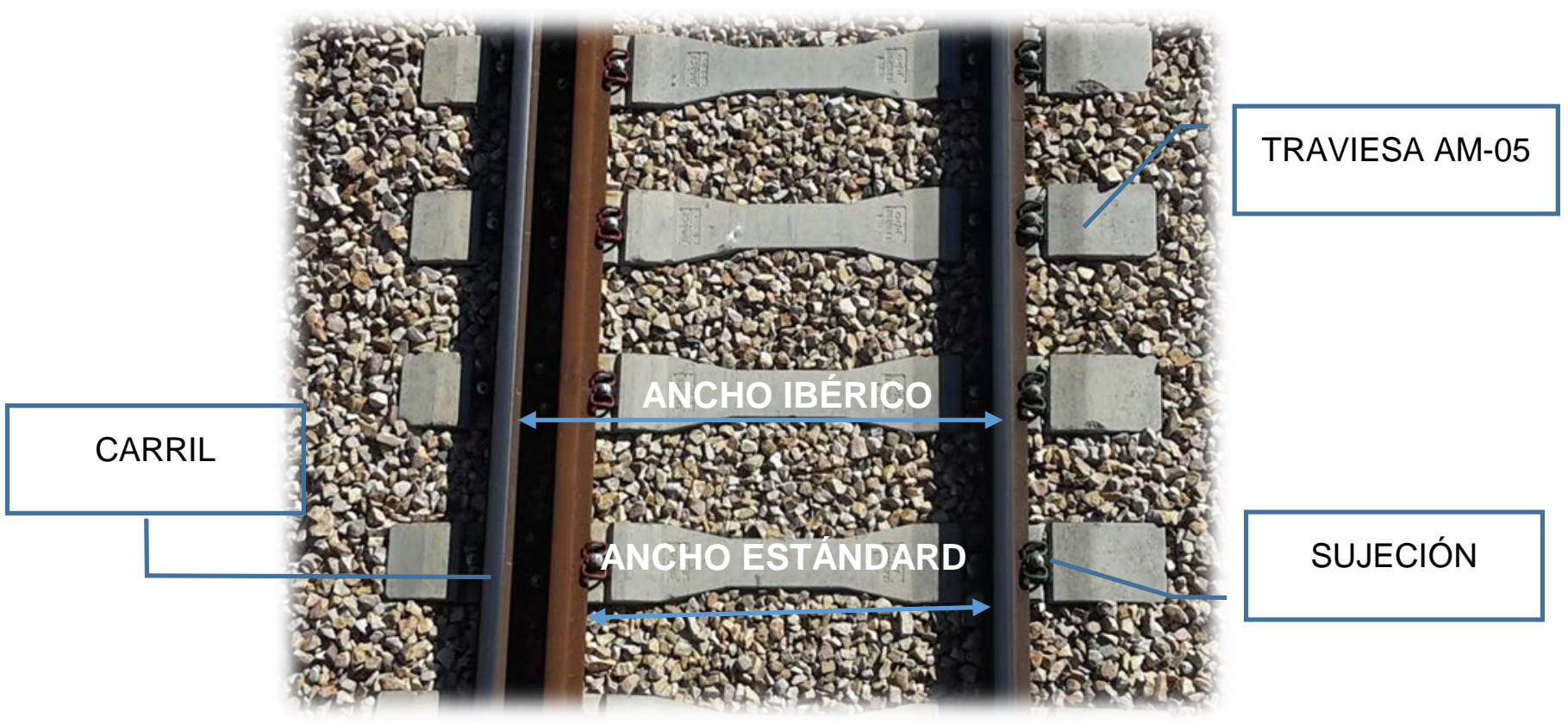

Figura 5.2: Elementos de una vía de doble ancho. Fuente: Elaboración propia.

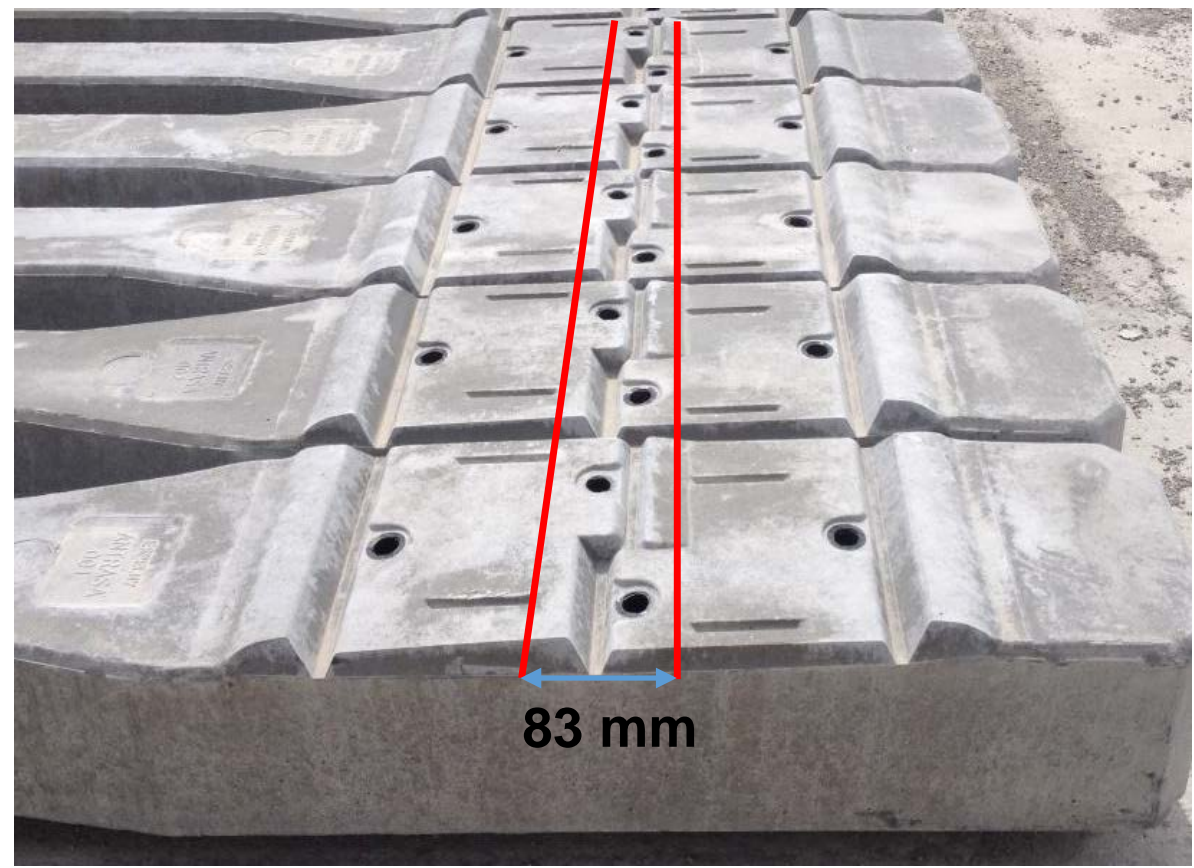

Figura 5.3: Detalle de zona que aloja los dos carriles, para traviesa AM-05 Fuente: Antrasa S.A.. 


\subsection{Desvíos y aparatos de vía}

Al igual que en cualquier tipo de vía, en vías de doble ancho son necesarios elementos que permitan el cambio de dirección y de vías, mediante el desdoblamiento de los carriles, denominados aparatos de vía.

En este tipo de vías, estos elementos son mucho más complejos, pues a las piezas habituales que poseen es necesario añadir nuevos componentes debido a la presencia del tercer carril. Estos nuevos elementos suponen un mayor coste económico y de mantenimiento, estando asociados a una mayor probabilidad de fallo.
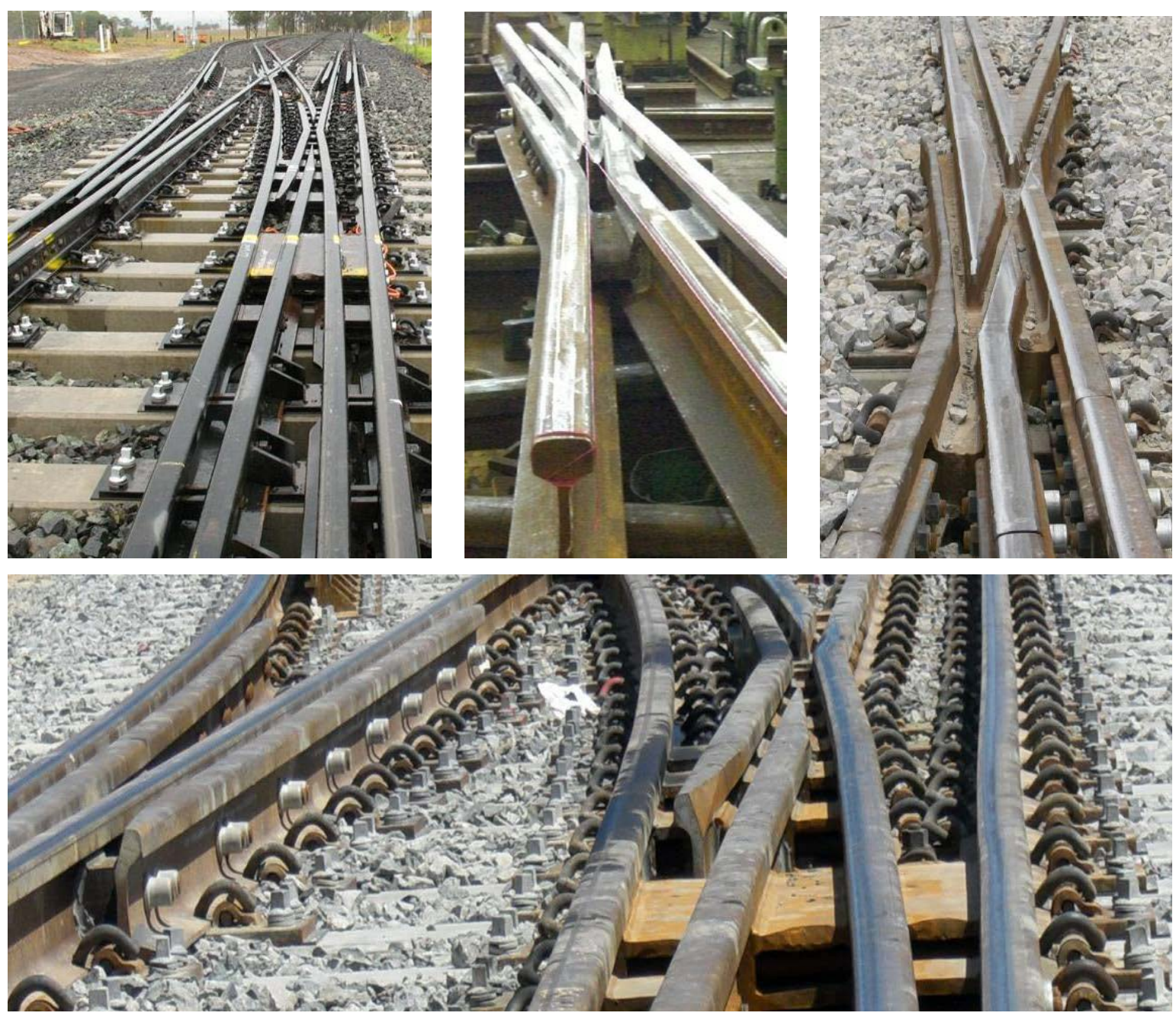

Figura 5.4: Imágenes de desvíos de 3 carriles. Fuente: Vossloh Cogifer Australia.

En el caso español se ha debido desarrollar una nueva tipología de desvíos, a la que se ha designado con una nomenclatura que los identifica, siendo los más comunes los desvíos DMI-D, DMI-I, DMR-D y DMR-I (ver Tabla 5.1 y Tabla 5.2). 


\begin{tabular}{|c|c|c|c|}
\hline \multirow{2}{*}{ Tipo de elemento } & $\begin{array}{c}\text { Vía directa a la } \\
\text { salida del desvío }\end{array}$ & Vía desviada & $\begin{array}{c}\text { Situación del } \\
\text { tercer carril }\end{array}$ \\
\hline \multirow{2}{*}{$\mathrm{D}$ (desvío) } & $\mathrm{M}$ (mixta) & $\mathrm{M}$ (mixta) & $\mathrm{D}$ (derecha) \\
\cline { 2 - 4 } & $\mathrm{R}$ (renfe) & $\mathrm{R}$ (renfe) & $\mathrm{I}$ (izquierda) \\
\cline { 2 - 4 } & $\mathrm{I}$ (internacional) & $\mathrm{I}$ (internacional) & \\
\hline
\end{tabular}

Tabla 5.1: Nomenclatura de desvíos de 3 carriles. Fuente: Elaboración propia.

\begin{tabular}{|c|c|c|c|c|c|c|c|}
\hline & & & Veloci & $\operatorname{dad} M$ & áxima & $\mathrm{km} / \mathrm{h}$ & \\
\hline & & DENOMINACIÓN & dire & & dest & iada & OBSERVACIONES \\
\hline & & & 1668 & 1435 & 1668 & 1435 & \\
\hline DMRIH & $-G \circ P$ & $250-0,11-\mathrm{CC}-\mathrm{TC}-1$ & 200 & 200 & 45 & - & \\
\hline DMRDH & $-G \circ P$ & $60-250-0,11-C C-T C-D$ & 200 & 200 & 45 & - & Simétrico al anterior \\
\hline DMIIH & $-G \circ P$ & $60-250-0,11-C C-T C-D$ & 200 & 200 & - & 45 & \\
\hline $\mathrm{DMIDH}$ & $-G \circ P$ & $60-250-0,11-C C-T C-1$ & 200 & 200 & - & 45 & Simétrico al anterior \\
\hline$\overline{\mathrm{DRIDH}}$ & $-G \circ P$ & $60-250-0,11-\mathrm{CC}-\mathrm{TC}-\mathrm{I}$ & 200 & - & - & 45 & \\
\hline DRIIH & $-G \circ P$ & $60-250-0,11-C C-T C-D$ & 200 & - & - & 45 & Simétrico al anterior \\
\hline DMRIH & $-G \circ P$ & $60-1500-0,042-C R-T C-I$ & 200 & 200 & 100 & - & También llamado 3HA \\
\hline DMRDH & $-G \circ P$ & $60-1500-0,042-C R-T C-D$ & 200 & 200 & 100 & - & Simétrico al anterior \\
\hline DMIIH & $-G \circ P$ & $60-1500-0,042-C R-T C-D$ & 200 & 200 & - & 100 & También llamado 3HB \\
\hline $\mathrm{DMIDH}$ & $-G \circ P$ & $60-1500-0,042-C R-T C-1$ & 200 & 200 & - & 100 & Simétrico al anterior \\
\hline CAMH & $-G \circ P$ & $60-1500$ & 200 & 100 & - & - & \\
\hline CAMHD & $-G \circ P$ & $60-1500$ & 200 & 100 & - & - & Simétrico al anterior \\
\hline
\end{tabular}

Tabla 5.2: Nomenclatura de desvíos de 3 carriles. Fuente: ADIF.

Una importante peculiaridad que poseen los desvíos de doble ancho (con ancho ibérico y ancho estándar) es el hecho de que, cuando se quiere circular a velocidades elevadas, es necesario que cada ancho solo se pueda desviar hacia un lado (el ancho ibérico de desvía hacia el lado de los dos carriles, mientras que el ancho estándar se desvía hacia el lado del carril común) puesto que, de lo contrario, el espadín del desvío interferiría con la rueda del vehículo. Este problema se da para las vías con poco espacio entre anchos, como el caso de los anchos ibérico-estándar, siendo posible los desvíos hacia ambos lados en vías con una mayor diferencia entre anchos. 


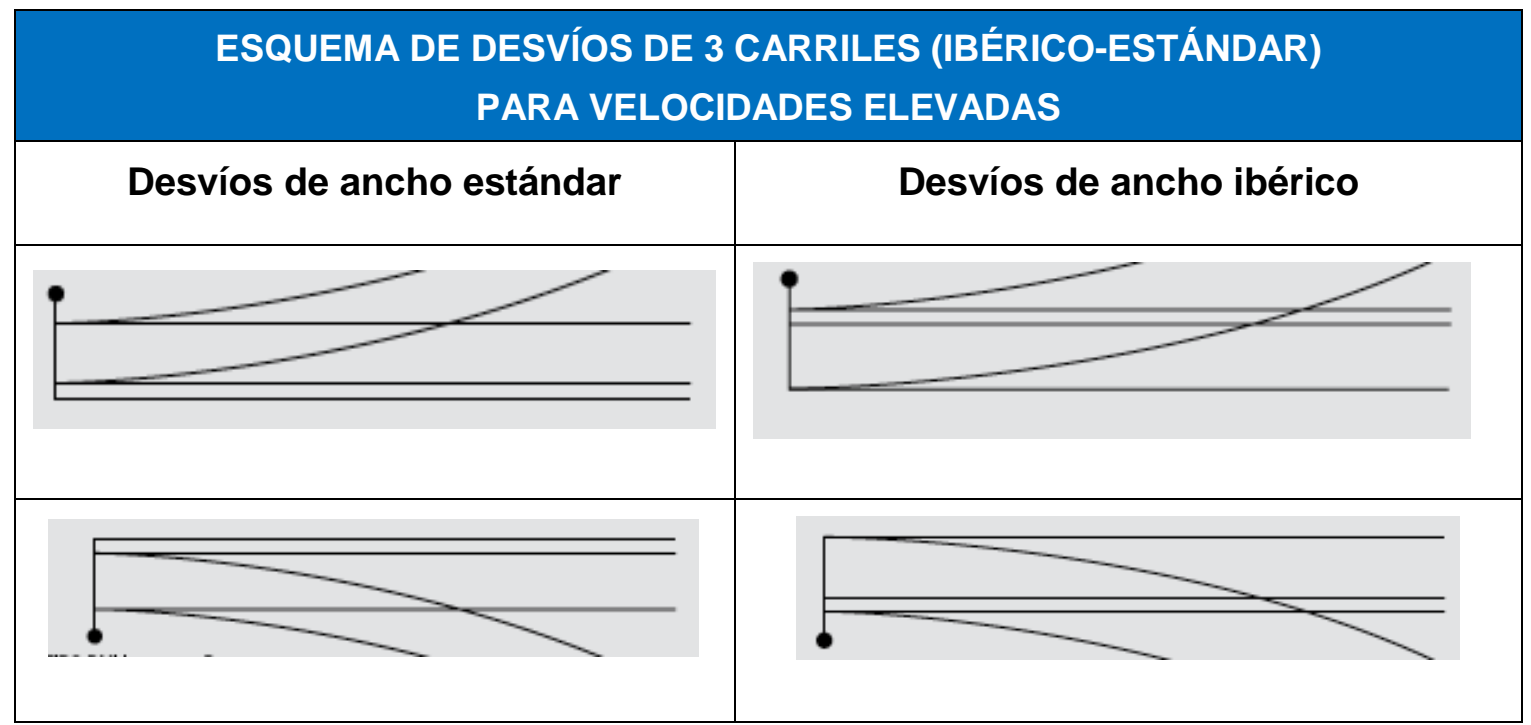

Tabla 5.3: Esquemas de desvíos de 3 carriles. Fuente: Elaboración propia.

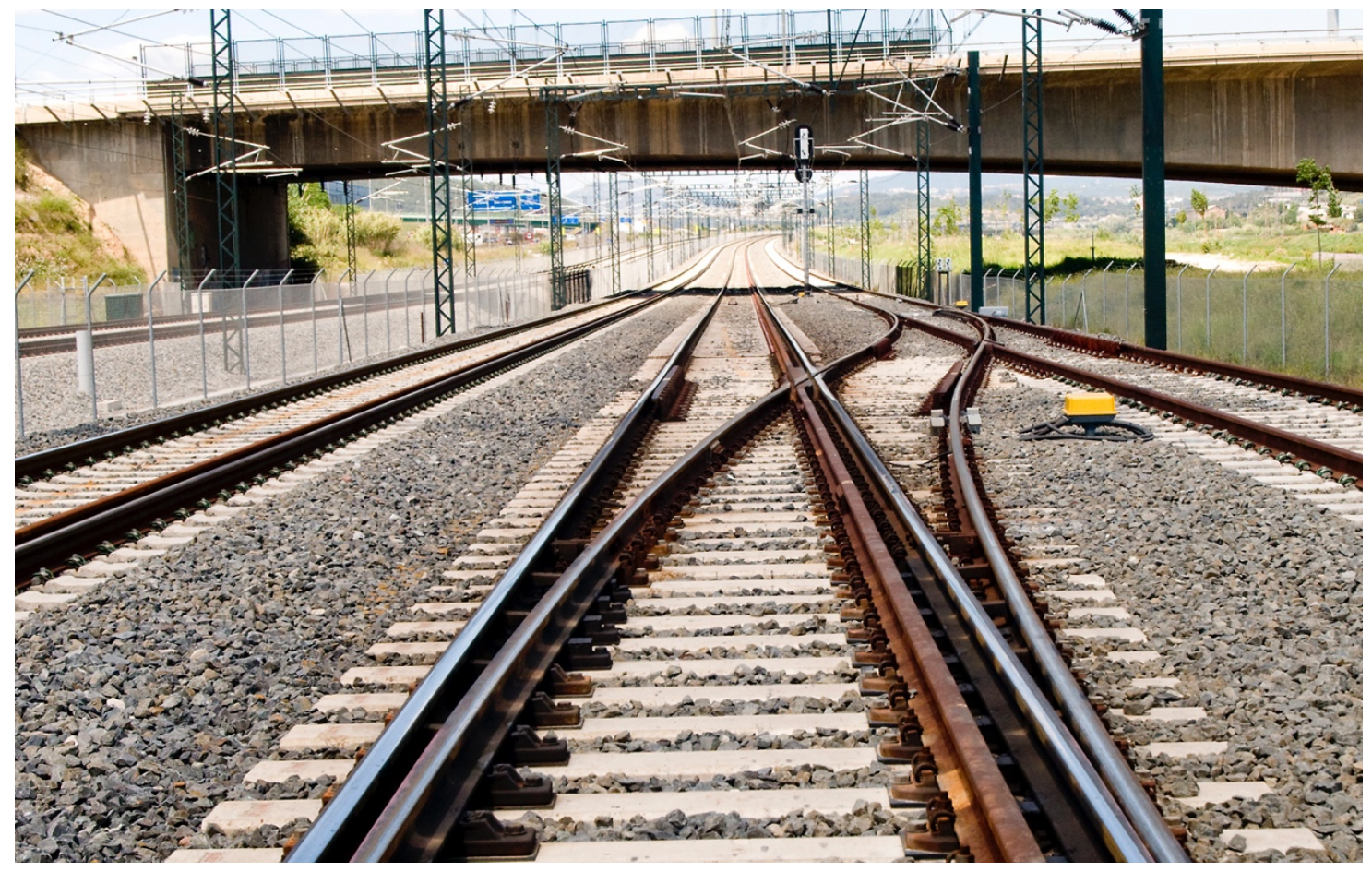

Figura 5.5: Imágenes de desvío en vía de 3 carriles, para el ancho ibérico, sobre el lado de los 2 carriles. Fuente: ADIF.

Este inconveniente técnico complica mucho la explotación de vías de doble ancho de este tipo, siendo necesario incorporar un nuevo elemento en la vía, denominado cambiador de hilo. 


\subsubsection{Cambiadores de hilo}

El cambiador de hilo es un aparato de vía que permite pasar la circulación del ancho más reducido de un lado al otro en la propia vía.

En el caso de una vía mixta ibérico-estándar, cuando se encuentra en posición "normal", el cambiador de hilo permite la circulación de trenes de ancho ibérico mientras que en posición "invertida" permiten que los trenes de ancho estándar cambien de hilo, pasando a situarse a la derecha o izquierda de la vía, en función del lado donde se encuentre instalado el tercer hilo y en el sentido de la marcha en el que se circule.
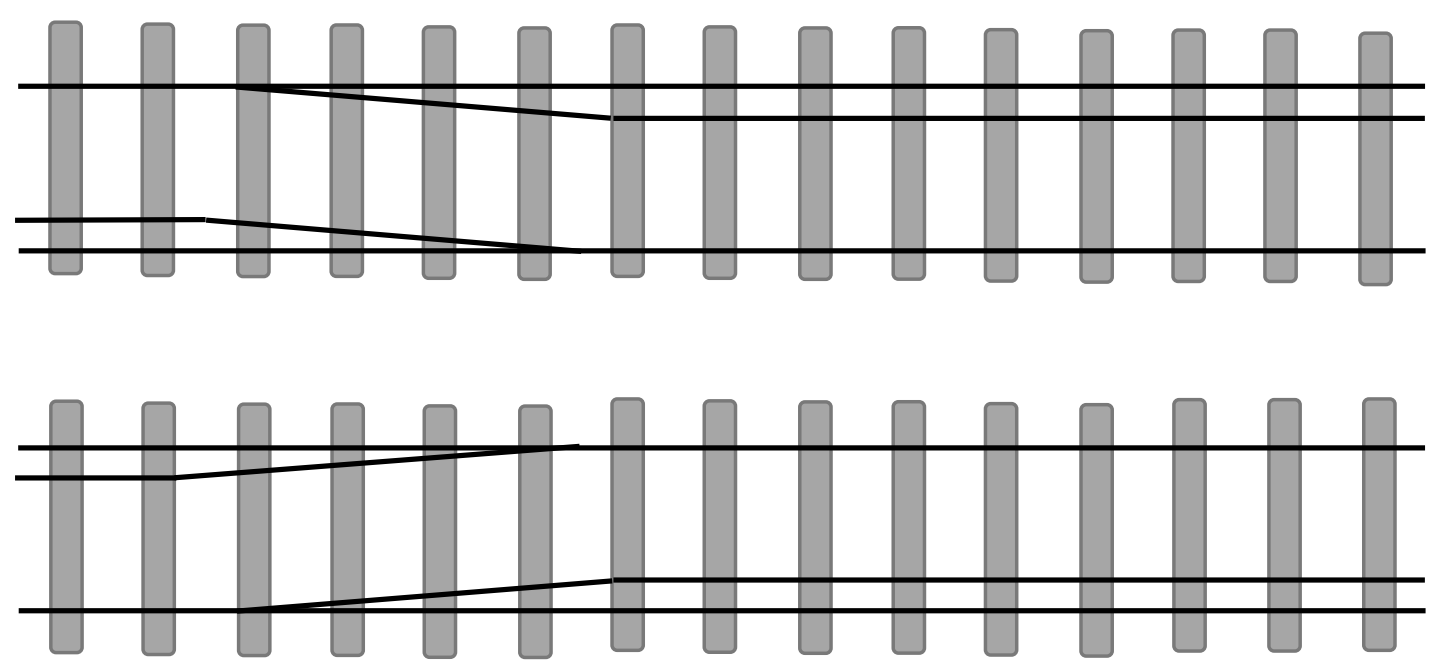

Figura 5.6: Esquema de cambiador de hilo. Fuente: Elaboración propia.

En general, estos nuevos cambiadores de hilo tienen un elevado coste, debido a los 8 motores que son necesarios para su funcionamiento. Así pues, existen dos tipos de cambiadores de hilo, uno para hilo derecho denominado CAMHD-G60-1500-TC y otro para hilo izquierdo, denominado CAMHI -G60-1500-TC.

También merece especial atención las velocidades que se pueden desarrollar en el ancho más estrecho, pues existen ciertas limitaciones que impiden circular a grandes velocidades. 


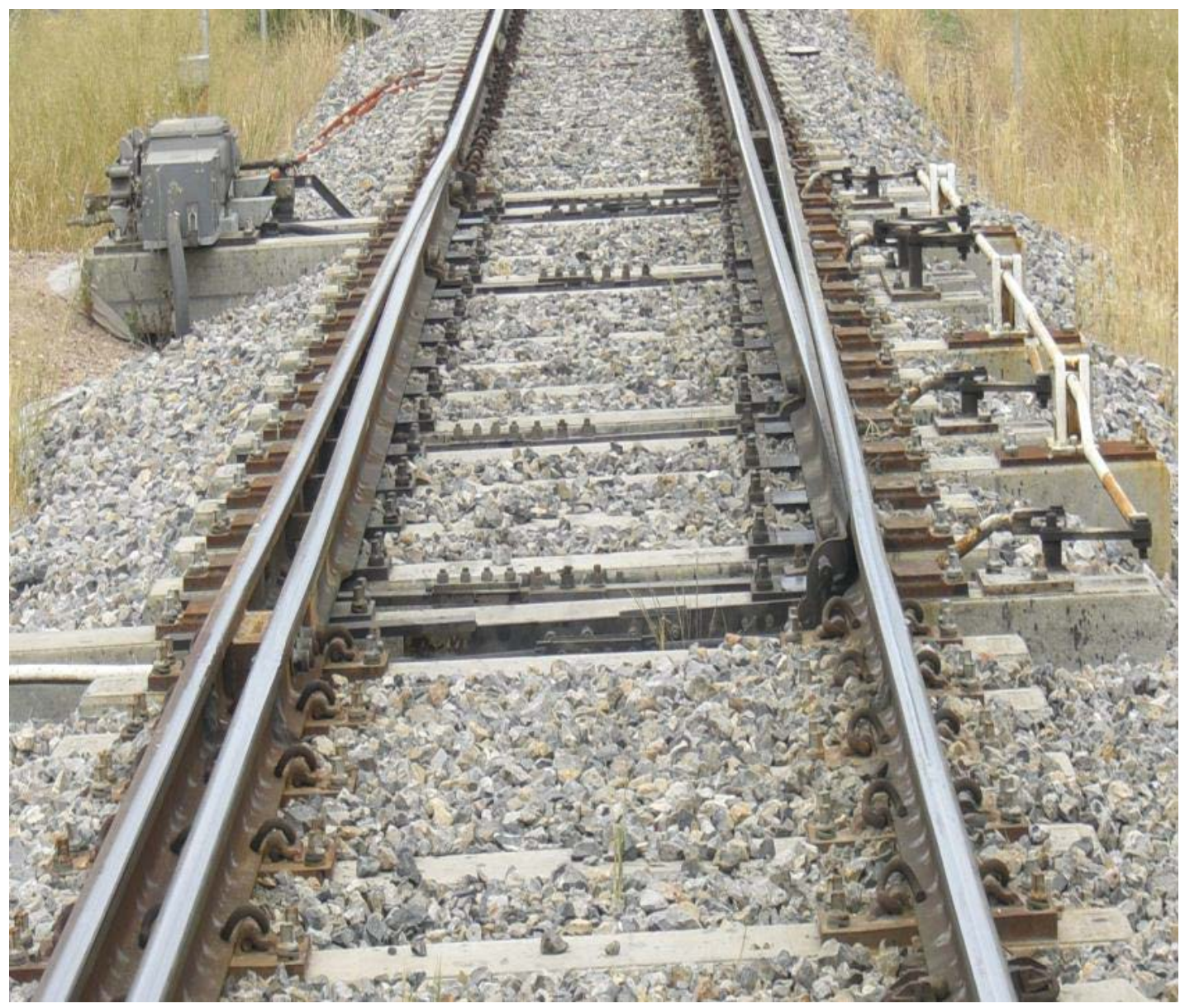

Figura 5.7: Imágen de cambiador de hilo. Fuente: Vossloh Cogifer Australia.

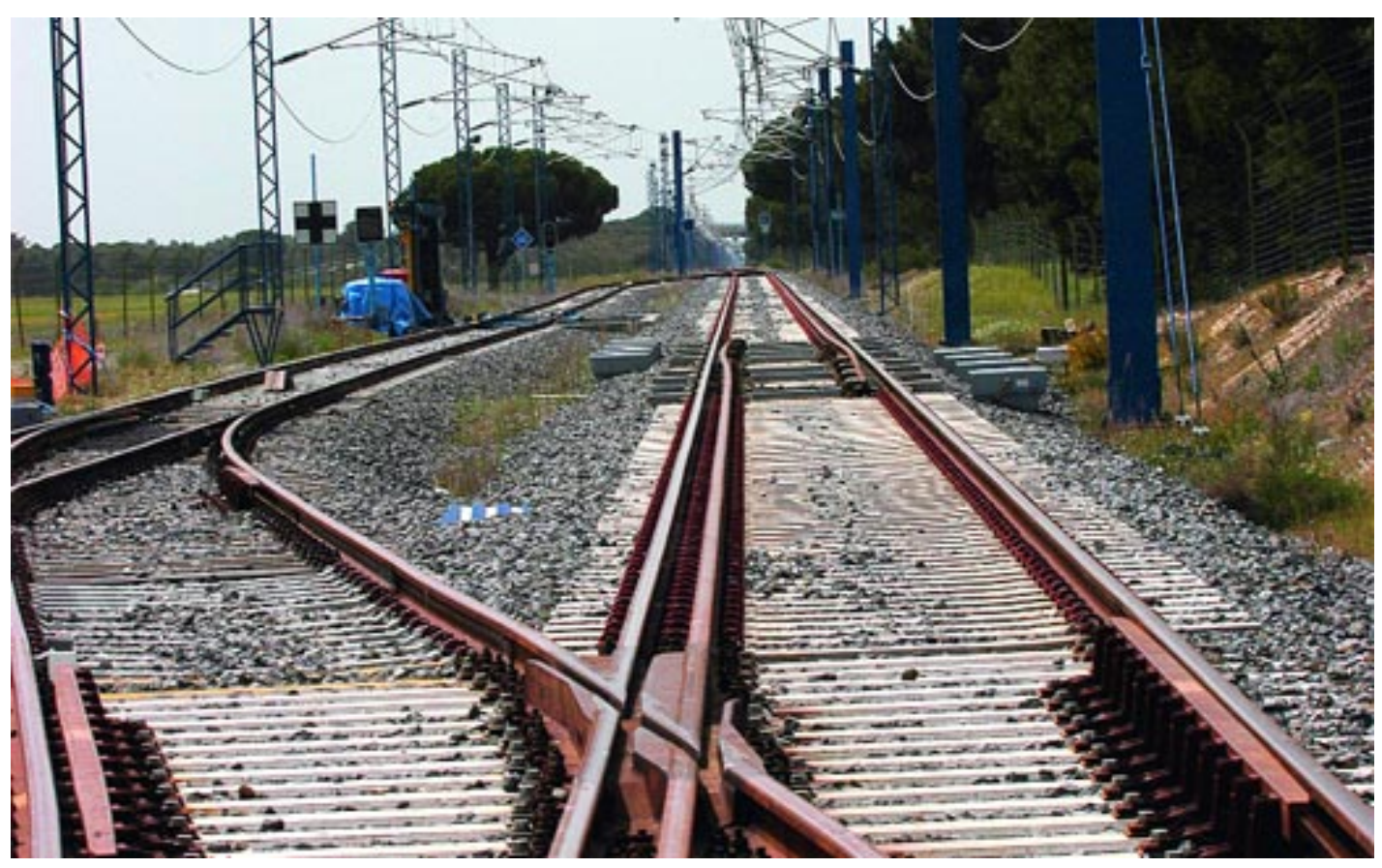

Figura 5.8: Imagen de desvío y cambiador de hilo. Fuente: ADIF. 


\section{Capítulo IV \\ 6. Modelo analítico}

Tras la descripción del problema de pandeo y la definición de las vías de doble ancho, en el presente capítulo se llevará a cabo el planteamiento de dos modelos, uno analítico y otro numérico, tal que permitan calcular la temperatura de pandeo en vías de doble ancho con carril continuo soldado sometidas a esfuerzos térmicos.

Estos dos modelos constituyen la herramienta básica de cálculo de pandeo, permitiendo integrar los aspectos particulares de las vías con 3 carriles que no han sido considerados previamente. El desarrollo planteado pretende obtener expresiones analíticas y numéricas que proporcionen el valor de la temperatura de pandeo, bajo una serie de hipótesis y simplificaciones necesarias.

La estructura en este capítulo pretende facilitar el entendimiento por parte del lector, exponiéndose en cada punto los aspectos que se consideran más relevantes. La descripción se inicia con el planteamiento del modelo, las hipótesis y simplificaciones realizadas y, por último, la descripción de los valores de entrada y salida que proporciona el modelo.

Tras la descripción de los modelos, en los capítulos posteriores se analizarán los resultados obtenidos, así como las conclusiones finales alcanzadas.

\subsection{Descripción del modelo}

En este apartado se describe de forma global el modelo analítico propuesto para el cálculo de la carga de pandeo en vías férreas de doble ancho con carril continuo soldado. Este 
método es especialmente útil si se implementa sobre un software de cálculo matemático, utilizándose en esta Tesis el software Mathematica ${ }^{\circledR}$ (Wolfram Languaje).

El modelo se fundamenta en los desarrollos realizados por Esveld (2001), utilizando un planteamiento de criterios energéticos, en el que se tiene en consideración los factores y variables principales que condicionan el fenómeno y que han sido descritos a lo largo del capítulo II.

Para llevar a cabo el desarrollo se asume que el objeto de estudio es una viga elástica con un sistema conservativo, lo que permite aplicar el principio del valor estacionario de la energía potencial total, el cual determina los extremos de la función de energía potencial total del sistema.

A su vez y para tener consideración la existencia de defectos iniciales, el estudio del pandeo se basa en la teoría de la divergencia del equilibrio. Bajo este principio, sobre una determinada viga o columna y debido a los defectos iniciales que presenta, las cargas axiales aplicadas actúan desde el inicio con una pequeña excentricidad, lo que produce deformaciones no lineales y momentos flectores. Tras una primera zona aproximadamente lineal, el elemento alcanza un punto a partir del cual se pasa de un equilibrio estable a uno inestable.

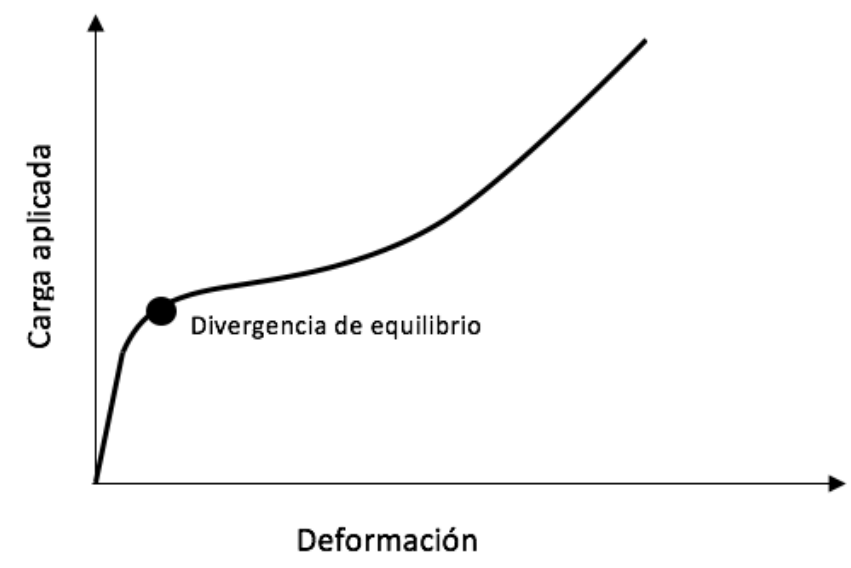

Figura 6.1: Esquema de la divergencia del equilibrio. Fuente: Elaboración propia.

Con estas consideraciones previas, la formulación del modelo parte de la consideración de un tramo recto de vía comprimido por una carga de valor P. Esta carga representa pues 
los esfuerzos generados por el aumento de temperatura en los carriles, los cuales se consideran constantes a lo largo de todo el tramo de estudio y durante el proceso de pandeo.
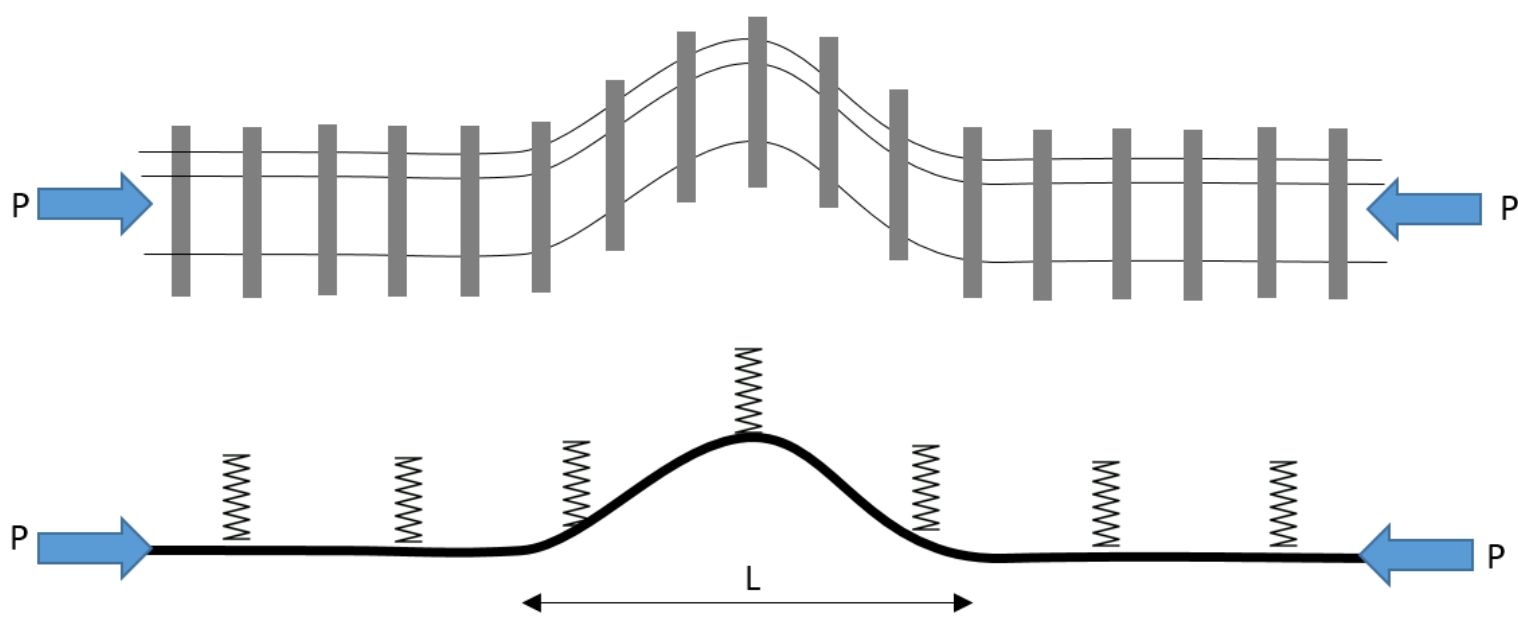

Figura 6.2: Forma de los defectos considerados. Fuente: Elaboración propia.

Además de la carga, el modelo considera que sobre la vía existe un cierto defecto inicial. La forma del defecto, al igual que han determinado otros autores (Kerr, 1978; Esveld, 2001), viene representada por una onda senoidal (con amplitud $f_{0}$ y longitud de onda $L_{d e f}$ ) y cuya forma puede ser igual a media senoide o una senoide completa.

Forma del defecto $\begin{cases}\text { Caso } 1: & f=f_{0} \sin \left(\frac{\pi x}{L_{\text {def }}}\right) \\ \text { Caso } 2: & f=f_{0} \sin \left(\frac{2 \pi x}{L_{\text {def }}}\right)\end{cases}$

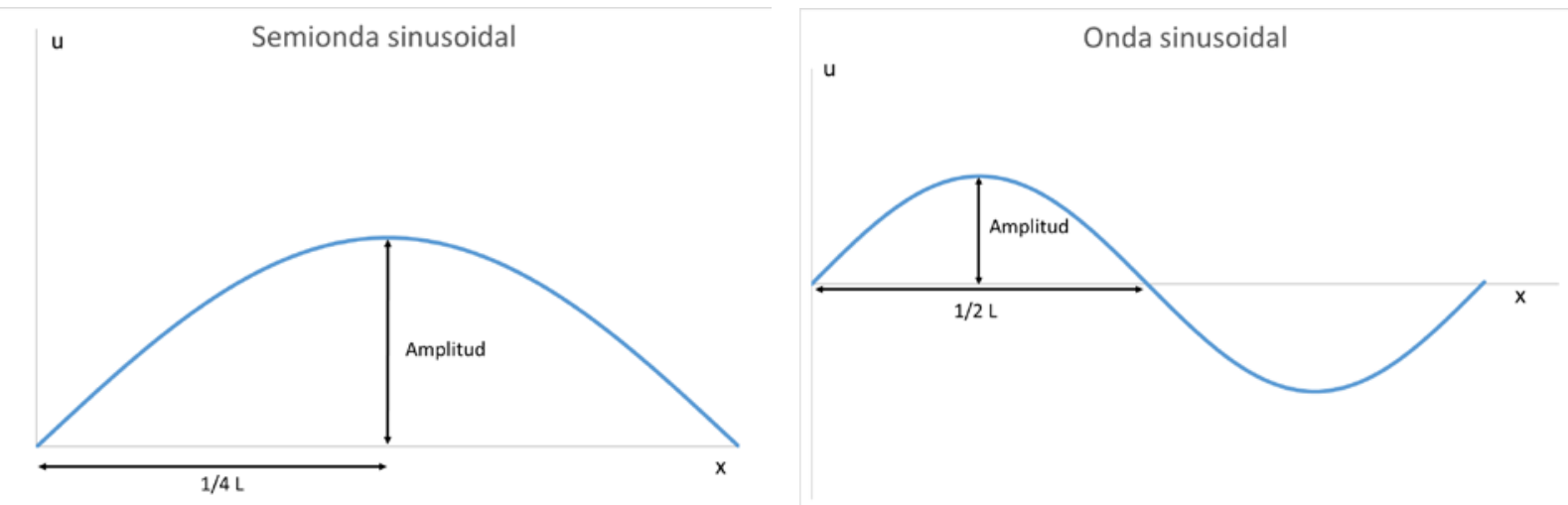

Figura 6.3: Forma de los defectos considerados. Fuente: Elaboración propia. 
Con este escenario, se asume implícitamente que la deformada de la vía, en cada instante, mantiene una forma semejante a la del defecto inicial y cuya longitud afectada no se extiende más allá del tramo considerado inicialmente. Con ello, la amplitud del defecto aumentará a media que se aplique una mayor carga, hasta alcanzar a un valor máximo donde se produce la inestabilidad. La posición final de la vía, por tanto, puede ser obtenida con una fórmula similar a la ecuación 6.1 anterior.

Pese a que las hipótesis previamente descritas condicionan el resultado y la respuesta de la vía, se considera que el error cometido es reducido y, por lo tanto, la solución es una buena aproximación al problema, permitiendo resolver las ecuaciones analíticas planteadas.

Descritas las hipótesis sobre las que se construye el modelo, es posible plantear el modelo mediante las expresiones analíticas. Para ello, se parte del principio del valor estacionario de la energía potencial para un sistema elástico, donde la energía potencial total puede ser expresada como la diferencia entre la energía potencial de los esfuerzos internos y aquella de las fuerzas externas.

$$
V(y)=U(y)+\Omega(y)
$$

donde $V(y)$ es la energía potencial total, $U(y)$ la energía potencial de los esfuerzos internos y $\Omega(y)$ la energía potencial de las fuerzas externas.

En el problema de pandeo y para el tramo de vía considerado, la energía potencial de los esfuerzos internos viene definida por:

$$
U(y)=U_{\text {flexion }}+U_{\text {balasto }}
$$

En cuanto a la energía de flexión $\left(U_{\text {flexion }}\right)$, ésta adquiere la siguiente expresión:

$$
U_{\text {flexion }}\left(y_{0}, L\right)=\int_{V} \sigma_{i j} \varepsilon_{i j} d V=\frac{1}{2} \int_{0}^{L} E I_{h} y^{\prime \prime 2} d x
$$

donde $E I_{h}$ representa la rigidez de los carriles en el plano horizontal, mientras que $y^{\prime \prime}$ es la segunda derivada de la deformada en el plano horizontal respecto de la dirección longitudinal. 
Por lo que respecta a la energía de deformación del balasto $\left(U_{\text {balasto }}\right)$, ésta es función de la resistencia lateral y, por lo tanto, dependiente de la curva esfuerzo-desplazamiento que se asuma en el cálculo. Según se ha visto el capítulo anterior, la respuesta lateral de la vía depende, entre otros factores, del estado de conservación, operaciones de mantenimiento realizadas, etc. De forma genérica, es posible expresar la energía como:

$$
U_{\text {balasto }}\left(y_{0}, L\right)=\int_{0}^{L} \varphi(y) y d x
$$

donde $\varphi(y)$ es una función que representa la resistencia transversal de la vía, por unidad de longitud de vía.

Tal y como se ha descrito en el apartado 3.4, la resistencia transversal generada entre la traviesa y el balasto es el resultado de la suma de tres componentes diferentes: resistencia de la base, de los laterales y de la punta. Por ello, la expresión de la resistencia lateral puede ser descompuesta en cada uno de estos tres términos, siendo:

$$
\varphi(y, h)=\varphi_{\text {base }}(y)+\varphi_{\text {laterales }}(y, h)+\varphi_{\text {punta }}(y, h)
$$

donde la resistencia lateral y de la punta dependen de la altura de la banqueta de balasto sobre la traviesa $(h)$.

Con ello, la energía potencial de los esfuerzos internos tiene la siguiente expresión:

$$
U\left(y_{0}, L, h\right)=\frac{1}{2} \int_{0}^{L} E I_{h} y^{\prime \prime 2} d x+\int_{0}^{L}\left(\varphi_{\text {base }}+\varphi_{\text {laterales }}+\varphi_{\text {punta }}\right) y d x
$$

Por último, considerando que la única fuerza externa aplicada es la debida al incremento de temperatura en los carriles (expresada mediante una compresión de valor P), y asumiendo que en la dirección del desplazamiento (eje longitudinal de la vía) es posible considerar la carga como constante para un intervalo diferencial $d x$, se puede expresar el trabajo total como:

$$
d \Omega=P d u \rightarrow \Omega=\int d \Omega \quad \Rightarrow \quad \Omega=\int_{\text {p.inicial }}^{p . \text { final }} P d u
$$


Para poder desarrollar, es necesario apoyarse en el siguiente esquema, donde se muestra un elemento diferencial de vía, sometido a una carga axial de compresión de valor $\mathrm{P}$, donde df expresa el defecto inicial, u la traslación horizontal y v la traslación vertical.

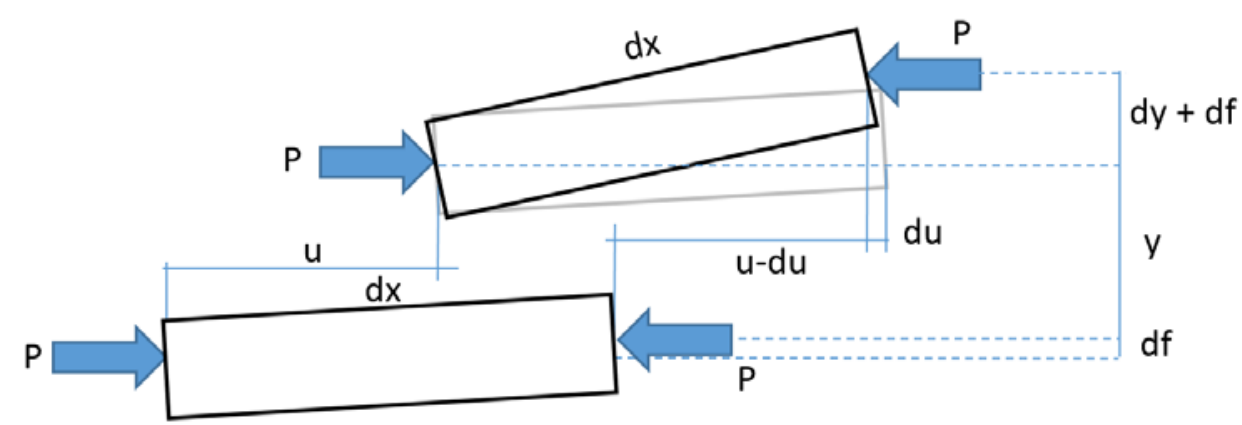

Figura 6.4: Elemento diferencial de vía. Fuente: Elaboración propia.

Analizando el elemento diferencial, es posible obtener la siguiente igualdad:

$$
d u=\sqrt{d x^{2}-d f^{2}}-\sqrt{d x^{2}-(d y+d f)^{2}}=d x\left(\sqrt{1-f^{\prime 2}}-\sqrt{1-\left(y^{\prime}+f^{\prime}\right)^{2}}\right)
$$

Si se linealiza la ecuación anterior, es posible expresar el diferencial como:

$$
d u=d x\left(1-\frac{1}{2} f^{\prime 2}-1+\frac{1}{2}\left(y^{\prime}+f^{\prime}\right)^{2}\right)=d x \frac{1}{2}\left(\left(y^{\prime}+f^{\prime}\right)^{2}-f^{\prime 2}\right)
$$

Finalmente, la energía potencial puede expresarse como:

$$
\Omega\left(y_{0}, L, P\right)=\int_{0}^{L} P d u=\frac{1}{2} \int_{0}^{L} P\left[\left(y^{\prime}+f^{\prime}\right)^{2}-f^{\prime 2}\right] d x
$$

Una vez definidas las expresiones de las energías potenciales y considerando que el sentido de aplicación de la fuerza externa $\mathrm{P}$ y el de la deformación que produce son el mismo (esto implica que el potencial asociado a la fuerza de compresión disminuye).es posible expresar el potencial total del sistema como:

$$
V\left(y_{0}, L, P\right)=\frac{1}{2} \int_{0}^{L}\left[\left(E I_{h} y^{\prime \prime 2}\right)+\left(\varphi_{\text {base }}+\varphi_{\text {laterales }}+\varphi_{\text {punta }}\right) y-P\left[\left(y^{\prime}+f^{\prime}\right)^{2}-f^{\prime 2}\right]\right] d x
$$


Con el potencial total y considerando como coordenadas generalizadas del sistema la amplitud de la deformación inicial $\left(y_{0}\right)$ y la longitud del tramo afectado por el pandeo $(L)$, y bajo el teorema de los trabajos virtuales, si el sistema está en equilibrio se cumplen las siguientes condiciones:

$$
\begin{aligned}
& \frac{\partial V\left(y_{0}, L, P\right)}{\partial y_{0}}=0 \\
& \frac{\partial V\left(y_{0}, L, P\right)}{\partial L}=0
\end{aligned}
$$

Las condiciones de equilibrio anteriores constituyen un sistema de dos ecuaciones y tres incógnitas, siendo por tanto necesario plantear una tercera ecuación que permite resolver el problema.

Para poder platear la tercera ecuación hace falta apoyarse en el criterio de inestabilidad elástica enunciado por el científico alemán Trefftz (1933), derivado del principio de la energía mínima potencial.

$$
\delta V=0
$$

De acuerdo con este principio, cuando sobre un sistema se aplica una determinada fuerza $F<F_{\text {crit }}$ la energía potencial es un mínimo relativo debido a que el sistema se encuentra en una posición estable. En esta situación, cualquier pequeña alteración que se produzca en el sistema resulta en un incremento de la energía potencial, con lo que $\delta^{2} V>0$, encontrándose en un estado de pre-pandeo. En el caso opuesto, si la carga aplicada $F>F_{c r i t}$ es sistema resulta inestable, pues existe al menos una acción que produce una disminución del potencial $\delta^{2} V<0$. Bajo estas condiciones, el cambio de comportamiento se produce en el momento en que $F=F_{\text {crit }}$, verificándose que la segunda derivada del potencial es nula $\left(\delta^{2} V=0\right)$.

El planteamiento descrito permite determinar la inestabilidad del sistema cuando la matriz hessiana (matriz cuadrada de segundas derivadas parciales) es nula. 


$$
\left[\begin{array}{ll}
\frac{\partial^{2} V\left(y_{0}, L, P\right)}{\partial y_{0}{ }^{2}} & \frac{\partial^{2} V\left(y_{0}, L, P\right)}{\partial y_{0} \partial L} \\
\frac{\partial^{2} V\left(y_{0}, L, P\right)}{\partial L \partial y_{0}} & \frac{\partial^{2} V\left(y_{0}, L, P\right)}{\partial L^{2}}
\end{array}\right]=0
$$

Es importante destacar que pese a que la función del potencial total $V\left(y_{0}, L, P\right)$ depende de tres variables, sólo se consideran como coordenadas generalizadas del sistema la deformación inicial y la longitud del tramo de pandeo, motivo por el cual la matriz hessiana consideran únicamente las derivadas respecto a estas variables.

Finalmente, con esta tercera ecuación es posible resolver el problema, pues se dispone de un sistema de tres ecuaciones con tres incógnitas (ecuación 5.15).

$$
\begin{gathered}
\frac{\partial V\left(y_{0}, L, P\right)}{\partial y_{0}}=0 \\
\frac{\partial V\left(y_{0}, L, P\right)}{\partial L}=0 \\
{\left[\begin{array}{cc}
\frac{\partial^{2} V\left(y_{0}, L, P\right)}{\partial y_{0}^{2}} & \frac{\partial^{2} V\left(y_{0}, L, P\right)}{\partial y_{0} \partial L} \\
\frac{\partial^{2} V\left(y_{0}, L, P\right)}{\partial L \partial y_{0}} & \frac{\partial^{2} V\left(y_{0}, L, P\right)}{\partial L^{2}}
\end{array}\right]=0}
\end{gathered}
$$

La solución del sistema proporciona los valores del desplazamiento lateral, así como la longitud y carga de pandeo $\left(y_{0}, L, P\right)$.

El modelo aquí planteado permite obtener el valor de la longitud $L$ del defecto (es una de las variables a resolver), asociado a la carga de pandeo más reducida. Cualquier otro valor de longitud resulta en una carga de pandeo mayor de la obtenida en la solución. Este aspecto representa una importante ventaja frente a otros modelos analíticos, en los que la longitud de pandeo se obtiene tras un proceso iterativo complejo. 


\subsection{Formulación e hipótesis realizadas}

La implementación de un modelo de pandeo realista conlleva, generalmente, un coste computacional elevado. Para facilitar la resolución y tras la descripción del modelo analítico, en esta Tesis se han considerado una serie de hipótesis y técnicas, las cuales permiten abordar la resolución del problema de pandeo eficazmente. Para ello, se ha estudiado el modelo completo, simplificando aquellos aspectos de mayor complejidad resolutiva.

En primer lugar, se asume que, durante el proceso de deformación, no existen momentos resistentes en los extremos del tramo analizado. Esta hipótesis supone que en los puntos de unión entre el tramo de vía con el defecto de alineación y los tramos de vía adyacentes existen rótulas, por lo que los momentos en los extremos son nulos.

En cuanto a la resistencia transversal de la vía, factor fundamental en el pandeo, es especialmente necesario simplificar las expresiones que definen la curva esfuerzo-desplazamiento. Para facilitar el cálculo y puesto que la gran mayoría de las formulaciones propuestas tienen un carácter no lineal (lo que complica la resolución), algunos autores han recurrido al uso de relaciones lineales entre los esfuerzos y desplazamientos (Lopez Pita, 2006), mientras que otros autores utilizan valores constantes (Kerr, 1978; Esveld, 2001).

En los cálculos y considerando la magnitud de los desplazamientos en el instante de pandeo (suele situarse en la rama plástica de la curva), se ha optado por considerar la resistencia lateral constante y de valor igual a la resistencia residual ( $\left.\mathrm{R}_{\text {limite }}\right)$ de la curva esfuerzodesplazamiento.

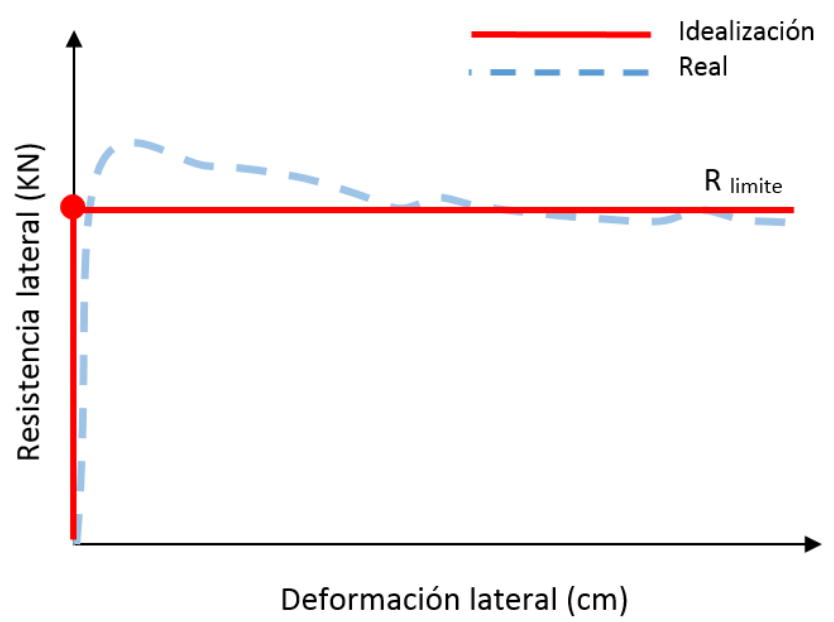

Figura 6.5: Esquema para la resistencia lateral considerada, en el modelo analítico. Fuente: Elaboración propia. 
Para permitir la posibilidad de considerar algunos aspectos referentes a las traviesas y el balasto, se ha planteado una segunda alternativa para el cálculo de la resistencia lateral. Para ello y tal y como se ha visto en el capítulo anterior, la resistencia transversal puede considerarse como la suma de 3 resistencias diferenciadas (base, laterales y punta). La determinación precisa de cada una de estas componentes es sumamente compleja, pues entran en juego diversos factores interrelacionados entre sí. Si además se considera que la vía objeto de estudio está compuesta por 3 carriles con traviesas especiales, la información disponible es prácticamente nula.

Ante la falta de datos bibliográficos y valores reales, se ha optado por utilizar las expresiones proporcionadas por Le Pen y Powrie (2011), cuyas investigaciones proporcionan por separado la contribución de cada una de las tres componentes. Es importante destacar que, en este caso, se asume que no existe ninguna carga vertical, pues de lo contrario las contribuciones de cada una de las componentes pueden variar sustancialmente. Con ello, la resistencia de la base puede aproximarse mediante un valor constante, mientras que las otras dos resistencias se obtienen como:

$$
\begin{gathered}
\varphi_{\text {laterales }}(y, h)=K_{0} h^{2} \gamma^{\prime} a \tan (\mu) \\
\varphi_{\text {punta }}(y, h)=\frac{1}{2}\left(K_{p} \gamma^{\prime}+2 c^{\prime} \sqrt{K_{p}}\right) h^{2} b \\
\varphi_{\text {base }}(y) \approx 2 \mathrm{kN} / \text { traviesa }(\text { monobloque }) \\
\approx 1,75 \mathrm{kN} / \text { traviesa (bibloque })
\end{gathered}
$$

donde:

$K_{0} \quad$ es el coeficiente de empuje al reposo del balasto;

$K_{p} \quad$ es el coeficiente de empuje pasivo del balasto;

$\gamma^{\prime} \quad$ es el peso específico del balasto;

$a, b \quad$ son la longitud y el ancho de la traviesa, respectivamente;

$h \quad$ es la altura de la banqueta de balasto sobre la base de la traviesa;

$c^{\prime} \quad$ es la cohesión del balasto;

$\mu \quad$ es el coeficiente de rozamiento traviesa - balasto

Bajo este planteamiento, una vez definidos los parámetros de los que dependen las expresiones $\left(K_{0}, K_{p}, \gamma^{\prime}, a, b, h, c^{\prime}\right)$, se obtiene un valor de resistencia lateral que únicamente 
depende de la altura de balasto por lo que, para cada valor de $h$ se obtiene un valor de resistencia lateral, pudiendo resolverse el modelo.

En cuanto a la consideración de cargas verticales, se ha determinado que el balasto responde al criterio de rotura de Mohr-Coulomb. Bajo este comportamiento, el esfuerzo cortante máximo que es capaz de resistir un suelo depende, linealmente, del esfuerzo normal aplicado en cada punto. Con ello, la resistencia máxima que posee el balasto, cuando se aplica una carga vertical, viene modificada por la siguiente expresión:

$$
R_{\text {carga }}=R+N \tan \varphi_{\text {roz.balasto }}
$$

donde $\varphi_{\text {roz.balasto }}$ es el ángulo de rozamiento interno del balasto.

\subsubsection{Consideraciones adicionales}

Analizando el sistema de ecuaciones propuesto en el modelo (ecuación 6.15) se observa que en las expresiones propuestas aparecen unas ciertas incógnitas, cuyo valor se obtiene mediante la resolución del sistema de ecuaciones. Este aspecto complica notablemente la resolución, pudiendo siendo probable que no exista una solución al sistema.

Para evitar estos problemas, uno de los aspectos que se ha considerado para su simplificación es la deflexión vertical de la vía, la cual interviene en la energía de deformación $\left(U_{\text {balasto }}\right)$. Esta deflexión puede obtenerse mediante el método de Zimmermann, para una vía dispuesta sobre un medio elástico (representa la reacción de la viga carril-larguero reposando sobre un medio elástico definido por el coeficiente de balasto $c$ ). Según ésta formulación, la deformación vertical puede expresarse mediante la siguiente ecuación:

$$
z(x)=\frac{Q}{2 b c} \frac{1}{L_{z i m m}} e^{-x / L_{z i m m}}\left[\cos \frac{x}{L_{\text {zimm }}}+\sin \frac{x}{L_{\text {zimm }}}\right]
$$

donde Q es la carga vertical, $L_{\text {zimm }}$ es la longitud elástica expresada como $L_{\text {zimm }}=$ $\sqrt[4]{\frac{4 E I}{b c}}, b$ el ancho del larguero $(\mathrm{mm})$ y $c$ el coeficiente de balasto $\left(\mathrm{N} / \mathrm{mm}^{3}\right)$.

Con el objetivo de simplificar la fórmula anterior, se ha utilizado una expresión aproximada, haciendo uso del método de mínimos cuadrados. Se observa que, a partir de un grado 15, el polinomio de aproximación presenta un error suficientemente reducido. 
Por otro lado, cabe recordar que tanto el defecto inicial como la deformada final están representadas por funciones senoidales, definidas a priori. Para facilitar la resolución, se ha optado por considerar dichas funciones mediante una aproximación polinómica, siendo:

Para media senoide:

Defecto de alineación: $f(x, L)=f_{0} \sin \left(\frac{\pi x}{L}\right) \approx 4 \frac{f_{0}}{L} x-4 \frac{f_{0}}{L^{2}} x^{2}$

Deformada de la vía: $y(x, L)=y_{0} \sin \left(\frac{\pi x}{L}\right) \approx 4 \frac{y_{0}}{L} x-4 \frac{y_{0}}{L^{2}} x^{2}$

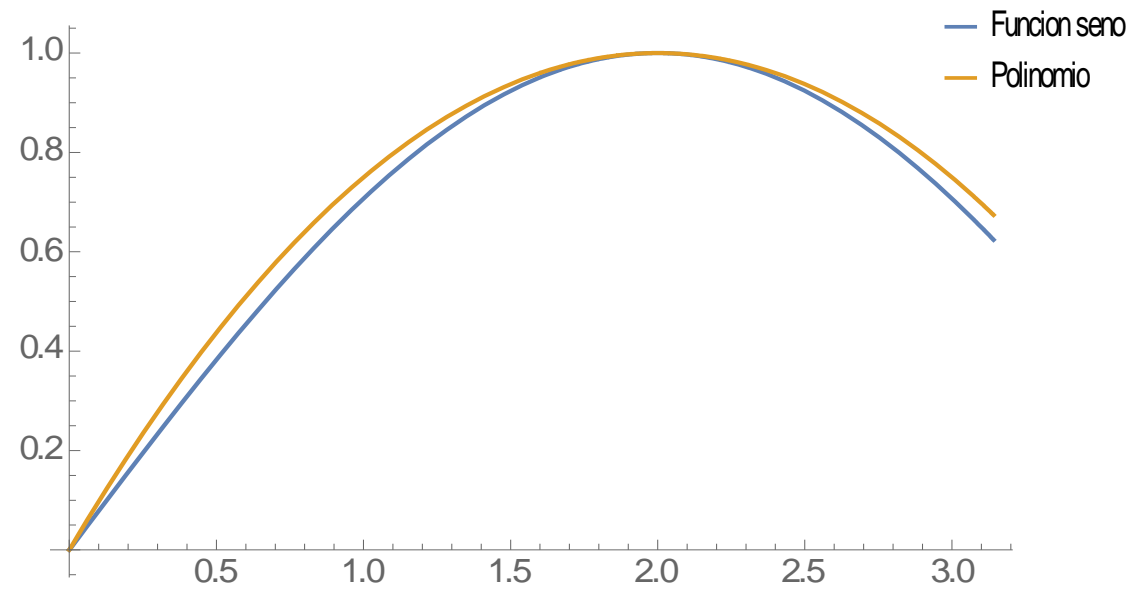

Figura 6.6: Comparativa de expresiones, para media senoide. Fuente: Elaboración propia.

Para senoide completa:

Defecto de alineación: $f(x, L)=f_{0} \sin \left(\frac{2 \pi x}{L}\right) \approx 32 \frac{f_{0}}{3 L} x-32 \frac{f_{0}}{L^{2}} x^{2}+64 \frac{f_{0}}{3 L^{3}} x^{3}$

Deformada de la vía: $y(x, L)=y_{0} \sin \left(\frac{2 \pi x}{L}\right) \approx 32 \frac{y_{0}}{3 L} x-32 \frac{y_{0}}{L^{2}} x^{2}+64 \frac{y_{0}}{3 L^{3}} x^{3}$ 


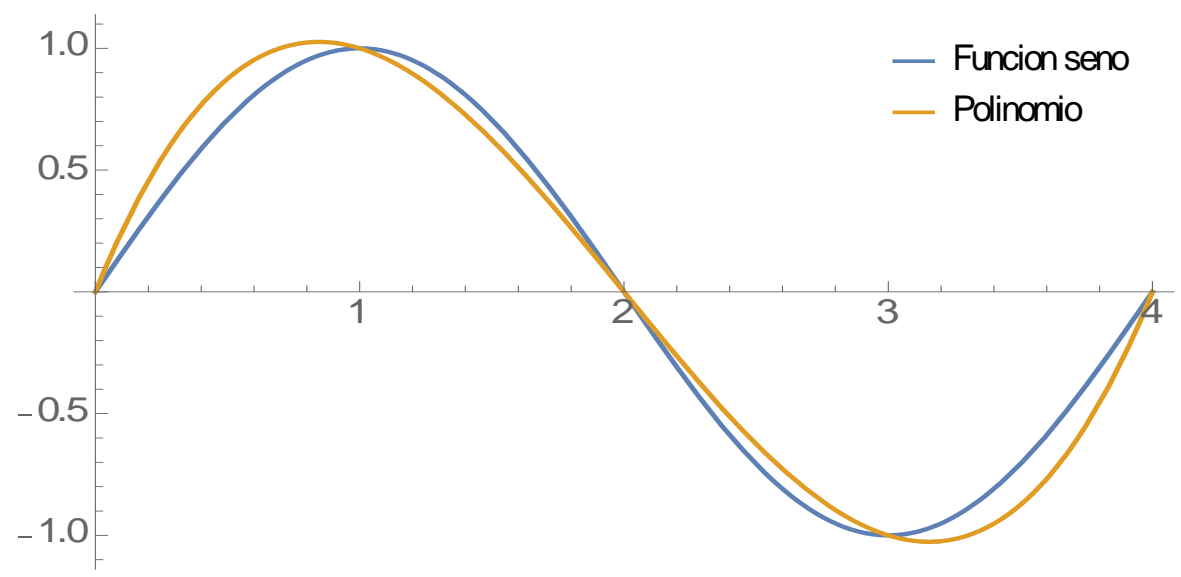

Figura 6.7: Comparativa de expresiones, para un ejemplo con senoide. Fuente: Elaboración propia.

\subsection{Valores de entrada}

Tras la construcción del modelo y para poder resolver el modelo es necesario definir todas las variables y sus valores. El objetivo de las simulaciones es el de estudiar la influencia de los diferentes parámetros en el pandeo de vía.

En la Tabla 6.1 se recogen los valores definidos para las diferentes variables del modelo y que serán analizadas en el siguiente capítulo. 


\begin{tabular}{|c|c|c|c|c|c|c|c|c|}
\hline \multicolumn{9}{|c|}{ Valores de entrada en el modelo analítico } \\
\hline Parámetro & \multicolumn{8}{|c|}{ Valores } \\
\hline \multirow{4}{*}{ Carriles } & Tipo & & rea $\left(m^{2}\right)$ & $\begin{array}{c}\text { Inercia } \\
\text { hor. }\left(m^{4}\right)\end{array}$ & \multicolumn{2}{|c|}{$\begin{array}{c}\text { Inercia } \\
\text { vert. }\left(m^{4}\right)\end{array}$} & $\begin{array}{c}\text { Peso } \\
\text { esp. } \\
\left(\mathrm{kN} / \mathrm{m}^{3}\right)\end{array}$ & $\begin{array}{c}\text { Peso } \\
(\mathrm{kN} / \mathrm{m})\end{array}$ \\
\hline & UIC 54 & \multicolumn{2}{|c|}{0,006934} & $4,18^{\star} 10^{-6}$ & \multicolumn{2}{|c|}{$2,35^{\star} 10^{-5}$} & 78,5 & 0,5443 \\
\hline & UIC 60 & \multicolumn{2}{|c|}{0,007686} & $5,13^{\star} 10^{-6}$ & \multicolumn{2}{|c|}{$3,06 * 10^{-5}$} & 78,5 & 0,6034 \\
\hline & UIC 71 & \multicolumn{2}{|c|}{0,009079} & $7,35 * 10^{-6}$ & \multicolumn{2}{|c|}{$4,15^{\star} 10^{-5}$} & 78,5 & 0,7127 \\
\hline \multirow{3}{*}{ Traviesas } & Tipo & \multicolumn{3}{|c|}{$\begin{array}{c}\text { Dimensiones } \\
(\mathrm{m})\end{array}$} & $\begin{array}{l}\text { Peso } \\
\text { esp. } \\
\left(\mathrm{kN} / \mathrm{m}^{3}\right)\end{array}$ & \multicolumn{2}{|c|}{$\begin{array}{l}\text { Separa- } \\
\text { ción }(\mathbf{c m})\end{array}$} & Peso (kN) \\
\hline & Monobloque & \multicolumn{3}{|c|}{$0,25 \times 0,3 \times 2,6$} & 25 & \multicolumn{2}{|c|}{60} & 4,875 \\
\hline & Bi-bloqu & \multicolumn{3}{|c|}{$0,25 \times 0,3 \times 0,72$} & 25 & \multicolumn{2}{|c|}{60} & 2,7 \\
\hline \multirow{3}{*}{$\begin{array}{c}\text { Resistencia } \\
\text { lateral de la } \\
\text { vía }\end{array}$} & \multicolumn{3}{|c|}{ Tipo } & \multicolumn{5}{|c|}{ Valor de la resistencia $(\mathrm{kN} / \mathrm{m})$} \\
\hline & \multicolumn{3}{|c|}{ Valor residual } & \multicolumn{5}{|c|}{$3-5-7-9-11-13-15$} \\
\hline & \multicolumn{3}{|c|}{3 Componentes } & \multicolumn{5}{|c|}{ Función de parámetros traviesa/balasto } \\
\hline \multirow{2}{*}{$\begin{array}{l}\text { Defecto de } \\
\text { alineación }\end{array}$} & \multicolumn{4}{|c|}{ Amplitud (cm) } & & & Forma & \\
\hline & & -1 & $-2-3$ & $4-5$ & & dia & enoide/Se & hoide \\
\hline $\begin{array}{l}\text { Característi- } \\
\text { cas del ba- }\end{array}$ & $\begin{array}{l}\text { Rigidez } \\
(\mathrm{kN} / \mathrm{m} / \mathrm{m})\end{array}$ & & $\begin{array}{l}\text { ngulo } \\
\text { z. ba- } \\
\text { sto (o) }\end{array}$ & $\begin{array}{l}\text { Angulo ro } \\
\text { zamiento. } \\
\text { trav-bal }\end{array}$ & $\begin{array}{r}\text { Coh } \\
\text { (kN }\end{array}$ & & $\begin{array}{c}\mathrm{K} . \\
\text { pasivo }\end{array}$ & $\begin{array}{l}\mathrm{K} . \\
\text { reposo }\end{array}$ \\
\hline & 70.000 & & 55 & 24 & 0 & & 10,059 & 4,25 \\
\hline Carca & Tip & & & Cars & por ej & & & $\begin{array}{l}\text { Numero } \\
\text { ejes }\end{array}$ \\
\hline verticales & & & & Sin & arga & & & \\
\hline & Con cé & & & & $17-22$ & & & $1-2$ \\
\hline
\end{tabular}

Tabla 6.1: Valores de los diferentes factores considerados. Fuente: Elaboración propia.

El modelo se ha construido para alcanzar una elevada eficiencia computacional, a la vez que se obtenga una estimación suficientemente aproximada de la carga de pandeo. Se considera útil mostrar, de forma resumida, los pasos principales que constituyen el método de cálculo utilizado, siendo el siguiente:

1. Inicialización de las variables asociadas a las condiciones de cálculo seleccionadas

1.1 Selección del tipo de carril 


\subsection{Selección del tipo de traviesa}

1.3 Selección del tipo de defecto considerado

1.4 Selección de la amplitud del defecto

1.5 Selección de la altura de la capa de balasto

1.6 Determinación de la presencia o no de cargas verticales

a. En caso de existir cargas, determinación del tipo de carga considerada (tren convencional o mercancías) y distancia entre ejes.

2. Resolución del sistema de tres ecuaciones y obtención de la amplitud y longitud del defecto, así como de la carga de pandeo.

Una vez resulto el sistema de ecuaciones, se obtiene la temperatura de pandeo en los carriles mediante la fórmula de dilatación térmica.

\subsection{Conclusiones}

A lo largo del presente apartado se ha descrito o el modelo analítico para el cálculo de pandeo en vías de doble ancho que será utilizado para para estimar la temperatura de pandeo. El modelo se basa en criterios energéticos, a partir de un sistema conservativo, donde se aplica el principio del valor estacionario de la energía potencial total.

La vía se representa por medio de un modelo de viga continua, en el que el estudio del pandeo de una vía infinita se limita a un tramo de vía de una determinada longitud.

Para construir el modelo se han desarrollado las ecuaciones de la energía de deformación y potencial del sistema. Asimismo, se han descrito las hipótesis utilizadas para llegar a dichas expresiones y los valores de las diferentes variables, los cuales permitirán realizar un estudio del fenómeno.

Pese a que el modelo planteado no es especialmente complejo en su naturaleza, éste requiere de la evaluación de una serie de derivadas cuya solución no es inmediata. Para poder obtener una solución se plantea tanto la condición de equilibrio (sistema de dos ecuaciones) como la condición de equilibrio neutro (matriz hessiana), lo que proporciona un sistema de tres ecuaciones con tres incógnitas (amplitud del defecto, longitud del defecto y carga crítica de pandeo). Para concluir y en cuanto a la temperatura de pandeo, se 
determina mediante la expresión 2.30, la cual permite determinar el incremento de temperatura para un determinado esfuerzo. El tiempo de ejecución para obtener una solución es de, aproximadamente, 1 min.

Cabe destacar que en el análisis y puesto que muchas de las variables tienen un rango continuo de valores, se han determinado unos ciertos valores discretos, de manera que se analicen únicamente combinaciones representativas de dichas variables, dentro de los límites habituales o rango de posibles valores reales de dichas variables. 


\section{Modelo numérico}

Tras la descripción del modelo analítico, el presente capítulo se completará con la descripción del modelo numérico. En el ámbito ferroviario son bien conocidos los problemas mecánicos, siendo común realizar ensayos en vía para conocer su comportamiento. No obstante, los problemas térmicos han sido tradicionalmente menos estudiados, siendo complejo el poder llevar a cabo ensayos y estudios de laboratorio.

Debido a que no es objeto de esta Tesis exponer la teoría y estructura del método de cálculo, en este apartado se llevará a cabo una descripción práctica del modelo de elementos finitos propuesto para el análisis de la inestabilidad en el plano horizontal de vías de doble ancho.

El objetivo de la construcción de un modelo numérico es el de poder comparar y analizar la validez de la metodología y las expresiones analíticas desarrolladas previamente, así como estudiar la influencia de cada uno de los factores que condicionan el problema. Esta labor de análisis será llevada a cabo en el capítulo IV, dedicado al estudio de resultados.

El modelo representa una idealización matemática de la vía real, donde los nodos, elementos y condiciones de contorno permiten representar su comportamiento. Este método es especialmente interesante en problemas con geometrías complejas y comportamientos no lineales. Además, otra de las ventajas que proporciona el MEF es su facilidad de implementación en un programa informático, utilizándose en esta Tesis el software ANSYS ${ }^{\circledR}$.

En primer lugar, se llevará a cabo una descripción de la geometría general, así como las características de los elementos considerados. Posteriormente, se describirán las hipótesis 
y simplificaciones realizadas para llevar a cabo el cálculo para, finalmente, describir los valores de entrada y los resultados que proporciona el modelo.

\subsection{Descripción del modelo}

Tal y como se ha descrito previamente, el MEF utiliza una resolución numérica matricial que permite resolver problemas complejos. Así pues, el modelo numérico propuesto pretende simular, de la forma más precisa, el fenómeno del pandeo. Para ello, se ha considerado necesario construir un modelo de elementos finitos en 3D, donde se representan todos los elementos que condicionan el problema: carriles, sujeciones, traviesa y balasto.

Si bien no es objeto de la tesis la descripción teórica del método de elementos finitos, si cabe destacar que mediante este método es posible analizar el comportamiento un objeto o cuerpo a través de la división del entorno de estudio en un determinado número de elementos, donde se resuelven las ecuaciones. Mediante esta técnica es posible obtener, en general, las tensiones, deformaciones, deflexiones, etc. de un cuerpo sujeto a una serie de acciones y bajo las restricciones impuestas por las condiciones de contorno.

Previo a la construcción de cualquier modelo de elementos finitos, es necesario considerar algunos principios básicos que permiten resolver adecuadamente el problema:

- Deben ser consideradas todas las simetrías presentes en el problema (geométricas, condiciones de contorno, solicitaciones) con el objetivo de reducir el entorno de estudio y, por tanto, el tamaño del modelo.

- El tamaño de los elementos debe adecuarse a la precisión de los resultados, por lo que debe ser suficientemente fino en las zonas más solicitadas, mientras que puede ser mayor en las zonas menos comprometidas.

- El tamaño de los elementos debe ser tal que la razón entre la mayor dimensión y la menor sea cercana a la unidad.

- En los modelos tridimensionales se debe tener en cuenta el número de elementos utilizados, pues el tamaño de los sistemas matriciales puede aumentar considerablemente y repercutir sobre el tiempo de cálculo. 
Con estas premisas, lo primero que cabe plantearse pues es la magnitud del modelo a considerar. El tramo de vía considerado debe tener una longitud tal que los resultados obtenidos no estén condicionados por la longitud de estudio, escogiéndose la menor posible. Dicha longitud será determinada posteriormente, cuando se aborde la aplicación práctica del modelo.

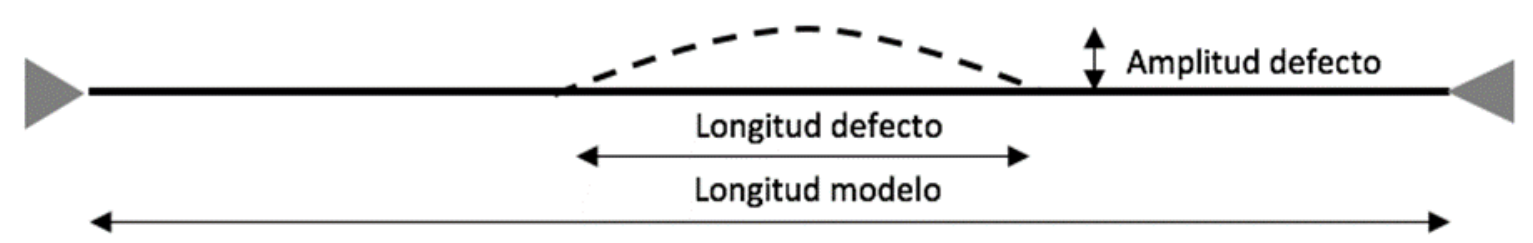

Figura 7.1: Vista esquemática del modelo considerado. Fuente: Elaboración propia.

Definido al ámbito de estudio, resulta importante escoger el tipo de elemento a utilizar, puesto que debe ser el apropiado para resolver el problema: térmico, estructural, etc. El modelo propuesto emplea dos tipos de elementos. En primer lugar, los elementos tipo viga (BEAM), los cuales permiten representar unidimensionalmente elementos tridimensionales, con un buen comportamiento frente a problemas no lineales con grandes deformaciones y rotaciones. En segundo lugar, se encuentran los elementos tipo muelle (COMBIN), con esfuerzos longitudinales y torsionales en una, dos o tres dimensiones y con la capacidad de representar comportamientos complejos mediante curvas fuerza-deformación introducidas por el usuario.

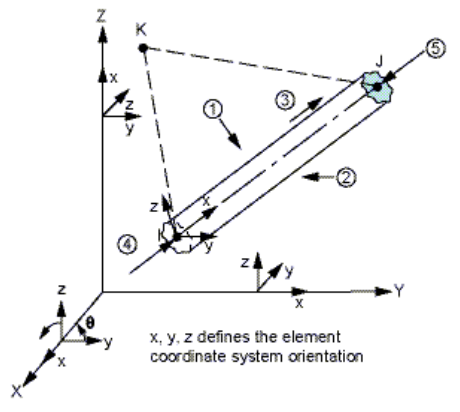

a)

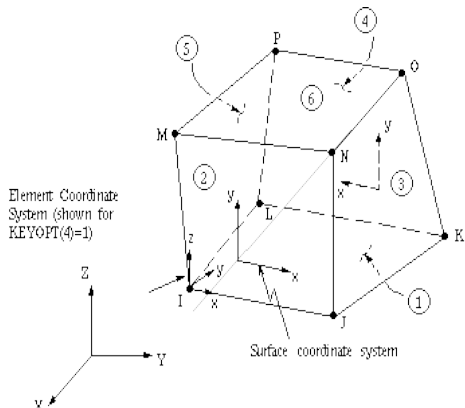

b)
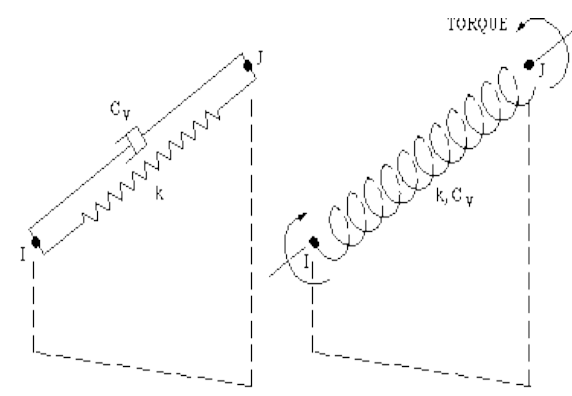

c)

Figura 7.2: Vista de elementos utilizados. a) BEAM b) SOLID c) COMIBN. Fuente: Manual Ansys. 
Por otro lado, en cuanto a las características de los materiales, la propiedad más importante es la relación entre la tensión y la deformación (Módulo de Young). En problemas tridimensionales dinámicos, el comportamiento de los materiales se determina mediante la relación tensión-deformación, para la cual son necesarias dos magnitudes independientes (módulo de Young y coeficiente de Poisson), además de la densidad del material. Si se considera un análisis térmico, como es el caso, es necesario definir los coeficientes de dilatación térmica en aquellos materiales sometidos a cargas térmicas.

Tras esta introducción, a continuación se describen en términos generales los aspectos más relevantes de los elementos de la vía considerados en la construcción del modelo.

\subsubsection{Carriles}

El carril es uno de los elementos principales del problema estudiado, pues se trata del elemento sobre el que se aplican las cargas térmicas y cuyos esfuerzos deben ser transmitidos al resto de la estructura de vía. Puesto que la sección transversal de los carriles reales (generalmente perfiles derivados del carril tipo Vignole) están compuestos por un conjunto de curvas y acuerdos enlazados entre sí, resulta complejo representar dicha geometría, especialmente cuando no se analiza en detalle el propio carril.

Generalmente, en la modelización se recurre a secciones más simplificadas, que permiten representar el comportamiento del carril evitando la complejidad geométrica y mecánica que presenta. En el modelo planeado, la representación de los carriles se ha realizado utilizando elementos tipo viga, cuyas propiedades son las que presenta el carril real.

Así, los carriles son representados por una viga con apoyos discretos (en coincidencia con las traviesas), en los que se consideran 6 grados de libertad por nodo (traslaciones y rotaciones en ejes $x, y, z)$.

Por otro lado, hay que considerar que las magnitudes del peso por unidad de longitud, el módulo de Young y el coeficiente de expansión térmica es la misma, mientras que se debe introducir para el cálculo el momento de inercia vertical. 

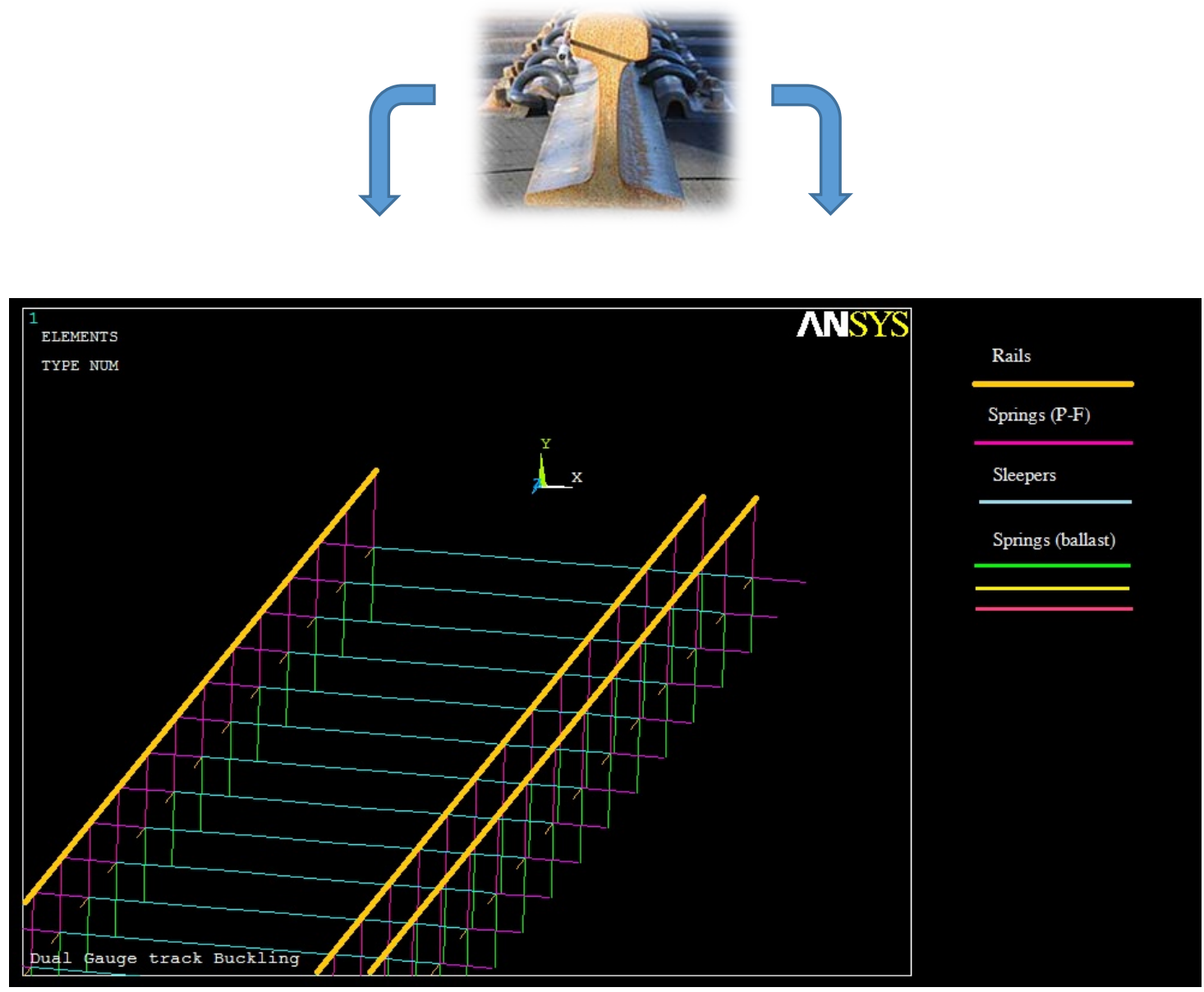

Figura 7.3: Vista de carril real y modelos utilizados. Fuente: Villalba et al. (2017).

\subsubsection{Sujeciones}

Para representar las sujeciones, se ha optado por introducir un conjunto de elementos tipo muelle que representan el vínculo existente entre el carril y las traviesas. Estos elementos permiten simular de forma adecuada el comportamiento real de las sujeciones ante las cargas aplicadas.

Las sujeciones están diseñadas para vincular los movimientos horizontales y transversales entre el carril y la traviesa, así como para ofrecer una determinada resistencia al posible giro entre carril y traviesa. Por lo tanto, se ha generado tres elementos tipo muelle que consideran la resistencia en el plano horizontal y vertical, así como un cuarto muelle que considera la rigidez a la torsión. Con esto, cada sujeción viene representada por un grupo de 4 elementos tipo muelle. 

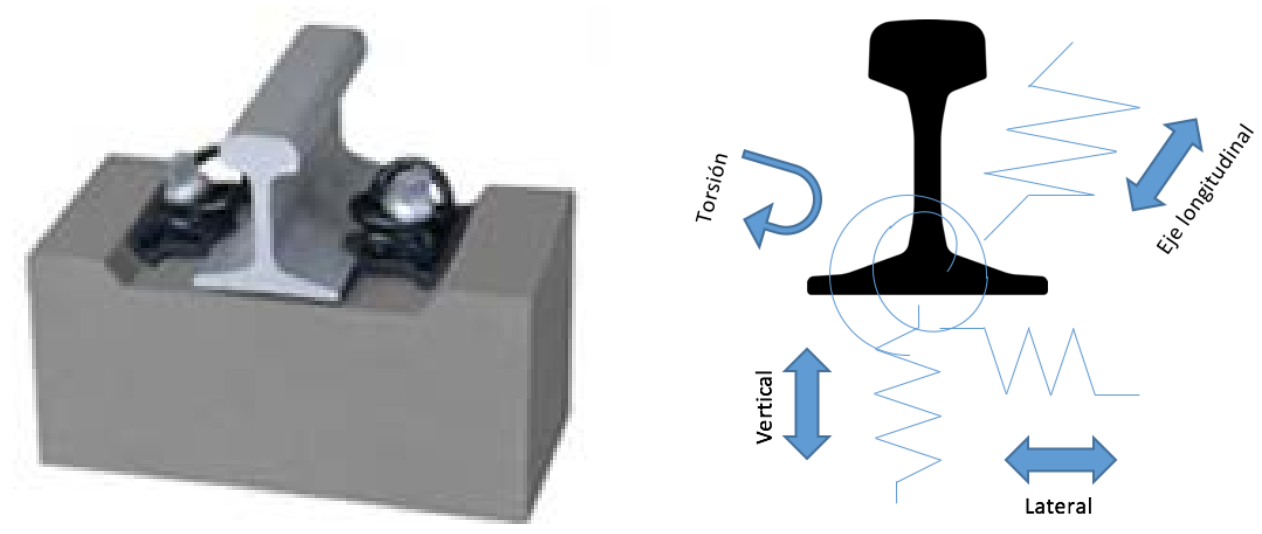

Figura 7.4: Vista real y esquema representativo de la sujeción. Fuente: Elaboración propia.

\subsubsection{Traviesas}

En cuanto a las traviesas, las vías con tres carriles disponen generalmente de traviesas de hormigón monobloque AM-05 (surge como evolución de la primera traviesa de tres carriles, la AM-00) con unas dimensiones principales igual a $275 \times 30 \times 24 \mathrm{~cm}$. Debido a su forma de paralelepípedo, se han representado mediante elementos tipo viga, cuyo módulo de elasticidad y área son iguales a las de una traviesa real.

En el modelo, además de la traviesa de hormigón monobloque, en el estudio se ha considerado la posibilidad de que existan traviesas bi-bloque, con el objetivo de comparar ambas tipologías y validar los datos del modelo analítico.

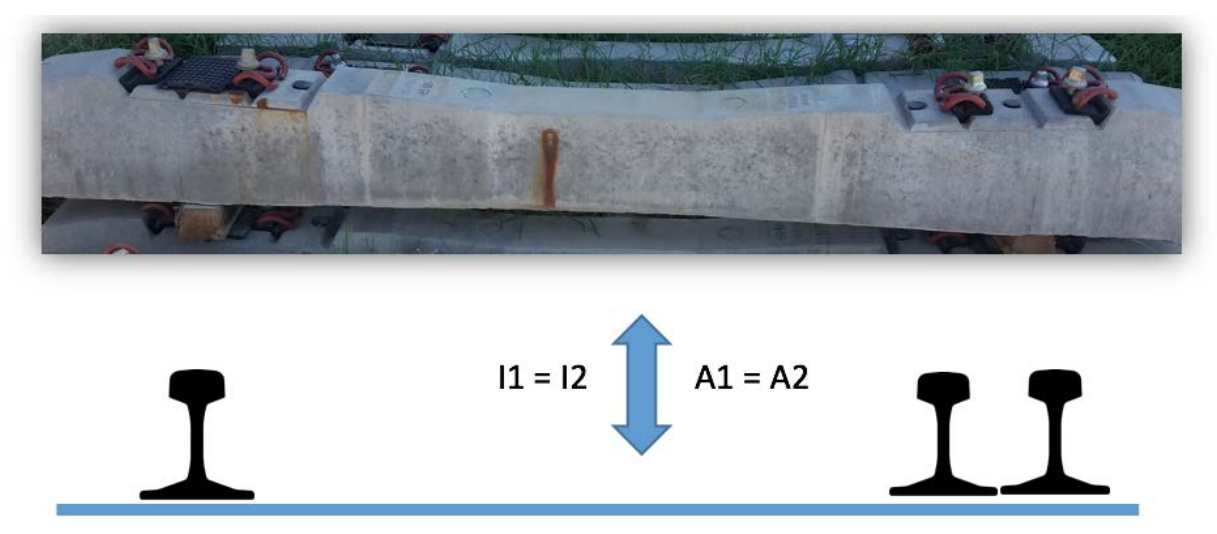

Figura 7.5: Vista y esquema representativo de la traviesa AM-05. Fuente: Elaboración propia. 


\subsubsection{Balasto}

La resistencia ofrecida por la capa de balasto es uno de los aspectos fundamentales frente al problema de pandeo. Su comportamiento depende del tipo, tamaño, forma y estado del balasto, así como de otros muchos factores descritos previamente.

La resistencia ofrecida por el balasto se modeliza mediante una distribución de resortes, en cada una de los tres ejes, conectados tanto a los nodos de las traviesas como a la base rígida de la vía, cuyos comportamientos viene caracterizados por la curva esfuerzo-deformación establecida, tal y como se verá más adelante.
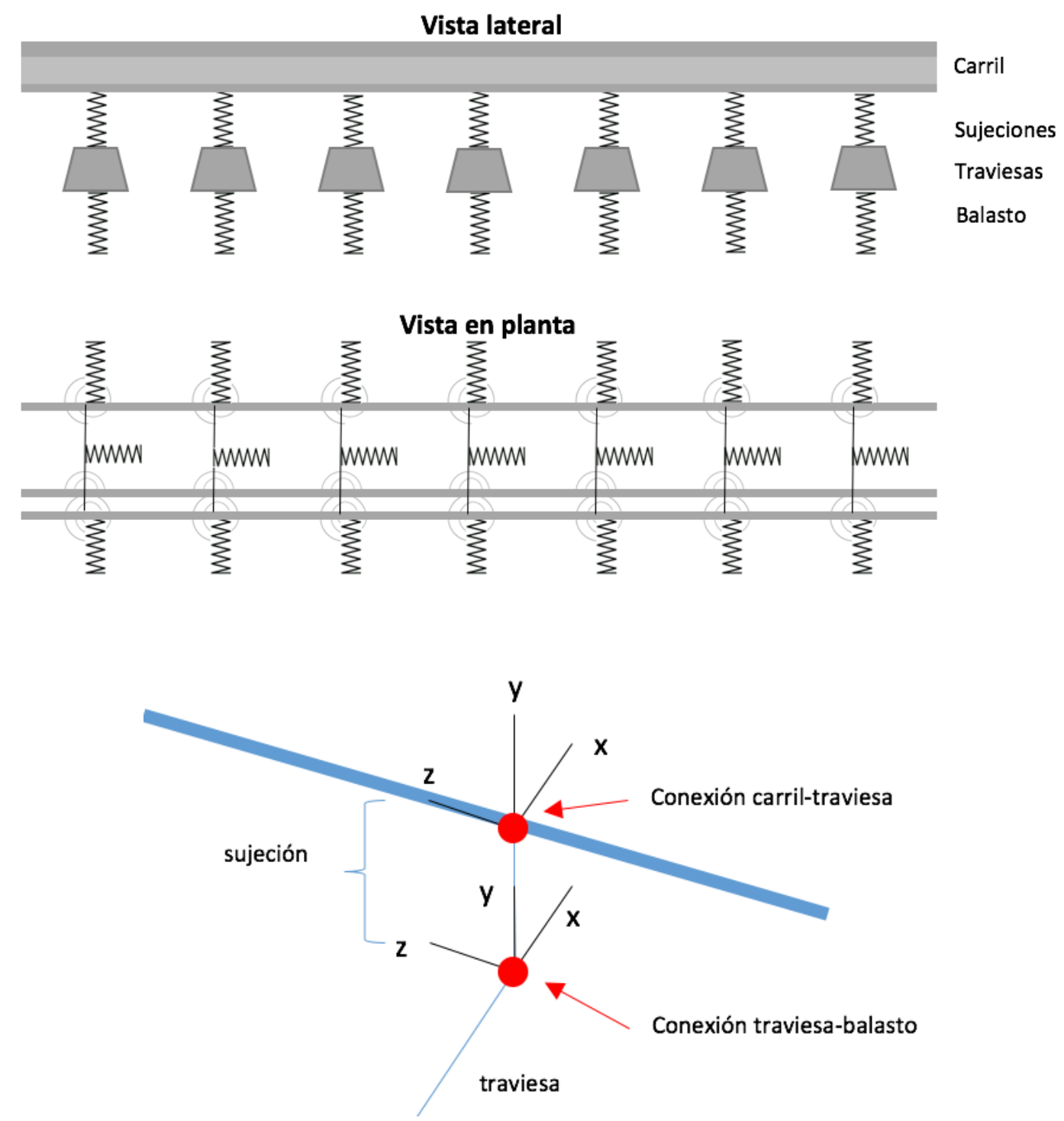

Figura 7.6: Esquema representativo del modelo numérico. Fuente: Elaboración propia. 


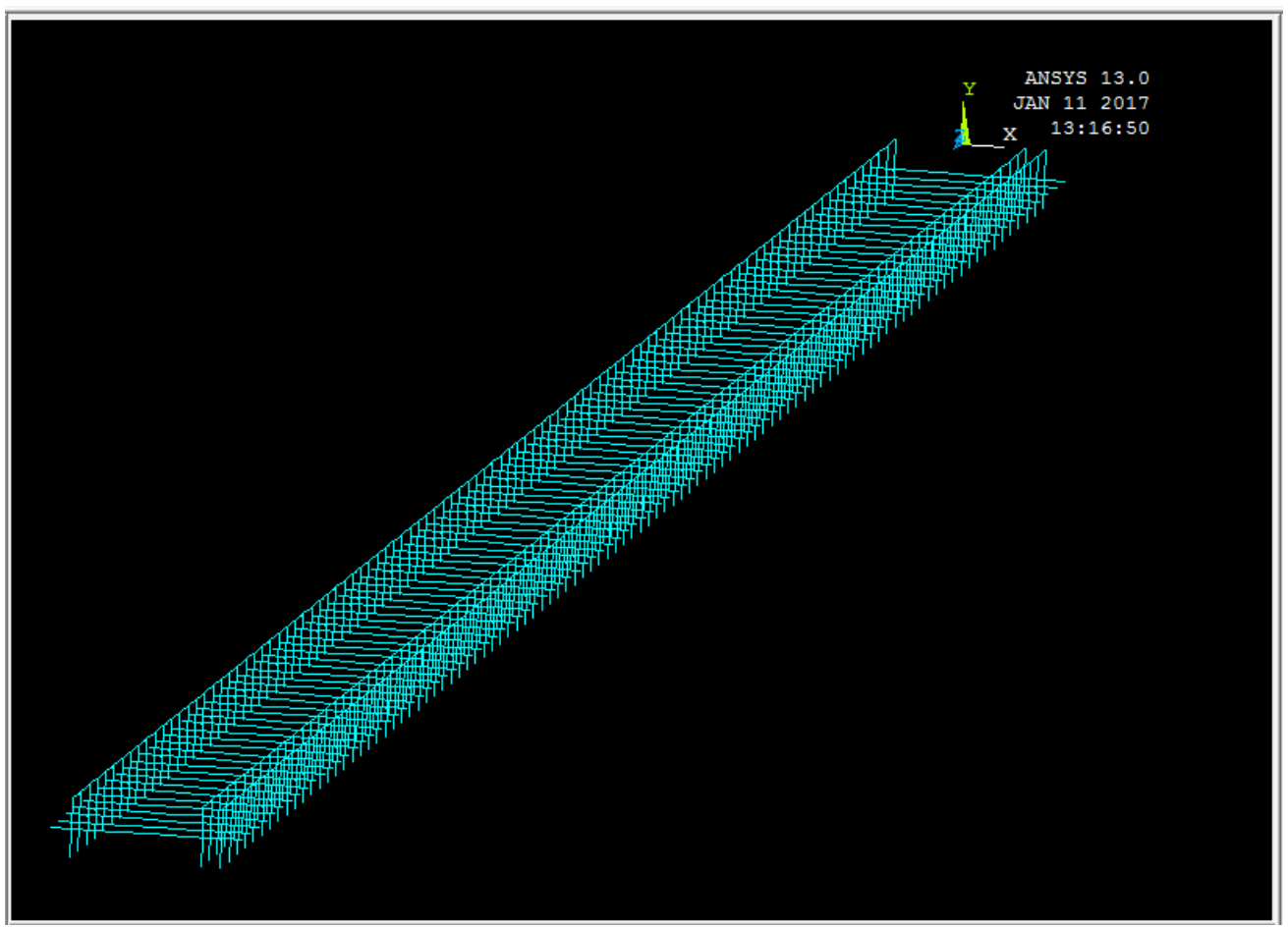

Figura 7.7: Vista general del modelo numérico. Fuente: Elaboración propia.

\subsection{Metodología e hipótesis consideradas}

Un aspecto fundamental en la definición del modelo son sus condiciones de contorno. En los modelos de elementos finitos, las condiciones de contorno se aplican restringiendo los movimientos en uno o más nodos, áreas, líneas, etc. junto con la determinación del conjunto de cargas a las que va a estar sometida la estructura.

Para evitar problemas de contorno, la dimensión longitudinal del modelo ha sido determinada comprobando que las reacciones laterales en el empotramiento son despreciables en el momento en que la vía se desestabiliza. Con este criterio se ha determinado la longitud mínima a considerar igual a $50 \mathrm{~m}$. Pese a que se trata de una condición no real, puesto que el tramo de vía sometido a esfuerzos térmicos puede ser mayor a un kilómetro, se ha comprobado que esta longitud es suficiente para que, en el estudio del pandeo lateral, las condiciones de contorno sean similares a las de un tramo de vía infinitamente largo.

En cuanto a los carriles, se considera un comportamiento lineal e isótropo, para las cargas a las que están sometidos. Esta hipótesis es adecuada cuando sobre los carriles se aplican cargas habituales de servicio. No obstante, durante el proceso de pandeo es posible que se desarrollen compresiones importantes que podrían llegar a la zona plástica del material. Sin embargo, para evitar complicaciones en la resolución, en el análisis se tendrán en 
cuenta un comportamiento lineal, el cual permite resolver el problema sin aumentar considerablemente el coste computacional.

Respecto a las sujeciones, la rigidez a torsión viene considerada mediante elementos tipo muelle comportamiento ortótropo, de manera que la rigidez al giro sea similar a la que ofrecen las sujeciones reales en vía, a la vez que permite vincular los movimientos laterales del carril y la traviesa. En cuanto al tipo de comportamiento, la mayoría de los investigadores considera modelos elástico lineales, cuyo valor de rigidez depende del tipo de sujeción considerada. A su vez, esta rigidez no depende únicamente de la propia sujeción, sino que viene influenciada también por el tipo de carril y traviesa. Según el comité ERRI D202-RP12 (1999), se proponen valores entre los $150 \mathrm{kNm} / \mathrm{rad}$ y los $250 \mathrm{kNm} / \mathrm{rad}$, por metro de vía.

Para introducir la resistencia del balasto se utilizan una serie de muelles, uno para cada uno de los 3 ejes (longitudinal, vertical y transversal). En cuanto al comportamiento vertical, se ha considerado una respuesta lineal, asumiendo que los movimientos en estas direcciones son relativamente pequeños y, por tanto, se encuentran dentro de la zona de comportamiento elástico. Por su parte, la resistencia longitudinal viene representada por muelles con comportamiento elastoplastico, lo que supone una respuesta lineal hasta alcanzar un valor máximo, a partir del cual el balasto no ofrece mayor resistencia pese al aumento de las deformaciones.

Considerando la resistencia lateral y para lograr una simulación más realista del comportamiento transversal de la vía el modelo tiene en consideración el cambio de comportamiento producido por la presencia de cargas verticales aplicadas sobre la vía. Para ello, se consideran curvas fuerza-desplazamiento en función de la carga vertical aplicada, siendo necesario definir tres valores: valor y desplazamiento pico $\left(R_{\text {pico }} / \delta_{\text {pico }}\right)$ y resistencia residual $\left(R_{\text {limite }}\right)$, relacionados a través de la siguiente formulación:

$$
\begin{array}{ll}
F=\xi \delta & \text { si } \delta<\delta_{\text {pico }} \\
F=R_{\text {limite }} & \text { si } \delta \geq \delta_{\text {pico }}
\end{array}
$$




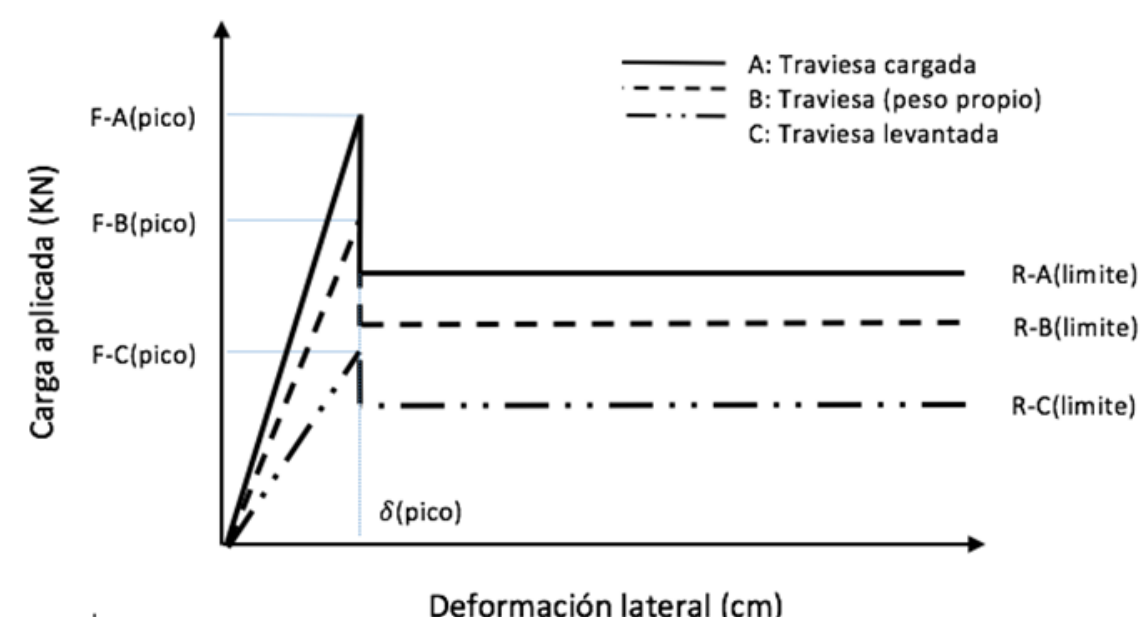

Figura 7.8: Comportamiento lateral del balasto. Fuente: Elaboración propia.

\begin{tabular}{|c|c|}
\hline \multicolumn{2}{|c|}{ Comportamiento de los muelles traviesa-balasto } \\
\hline Dirección & Tipo \\
\hline Longitudinal & lineal \\
\hline Vertical & lineal \\
\hline Transversal & Curva de comportamiento característica \\
\hline
\end{tabular}

Tabla 7.1: Comportamiento del balasto considerado, para cada dirección. Fuente: Elaboración propia.

\subsubsection{Condiciones de contorno y cargas}

Para poder llevar a cabo el cálculo y junto con la necesidad de obtener un tiempo de cálculo razonable, en las simulaciones es fundamental establecer ciertas consideraciones relacionadas con el grado de complejidad del modelo tridimensional desarrollado. Además, las restricciones determinadas deben ser compatibles con la respuesta de la vía que se quiere obtener.

Así pues, considerando que la dimensión longitudinal es suficientemente grande, en los extremos los carriles tienen impedidos los desplazamientos longitudinales, así como la rotación, permitiendo el libre desplazamiento lateral. 


\begin{tabular}{|c|c|}
\hline \multicolumn{2}{|c|}{ Condición de contorno en los extremos del modelo } \\
\hline Condición & Valor \\
\hline$u_{z=0}$ & 0 \\
\hline$u_{z=L}$ & 0 \\
\hline$\theta_{y=0}$ & 0 \\
\hline$\theta_{y=L}$ & 0 \\
\hline
\end{tabular}

Tabla 7.2: Condiciones de contorno para el modelo numérico. Fuente: Elaboración propia.

En cuanto a las cargas aplicadas, se consideran tanto las cargas térmicas debidas a la temperatura como las cargas debidas a la presencia de un vehículo, todas ellas aplicadas sobre los carriles. La simulación del tránsito ferroviario se realiza mediante una expresión de amplificación de cargas de cargas (fórmula de Eisenmann), según el cual, cada eje de trasmite una fuerza puntual de valor superior al estático en función de la velocidad a la que viaja el tren.

\subsubsection{Proceso de cálculo}

La resolución de un problema no lineal mediante el MEF consiste, generalmente, en un proceso de cálculo iterativo, donde la solución se obtiene en el instante en el que se verifican las condiciones de convergencia impuestas por el usuario. La solución obtenida proporciona los valores de los desplazamientos nodales que equilibran el sistema de fuerzas consideradas.

Para obtener la solución es posible hacer uso de diferentes métodos matemáticos, en función del problema estudiado. En la resolución de problemas no lineales, es posible utilizar dos métodos iterativos diferentes: el método de Newton - Raphson y el método del arco (Arc - Length).

En el primer caso, el método de Newton - Raphson es un método de iteración por defecto en la integración implícita. De forma gráfica, este método calcula rectas tangentes a la curva esfuerzo-deformación del problema, hasta que se alcanza el nivel de esfuerzo aplicado, para posteriormente descender hasta alcanzar el equilibrio interno. La solución final se obtiene cuando la diferencia entre la fuerza externa e interna es menor al error establecido. 


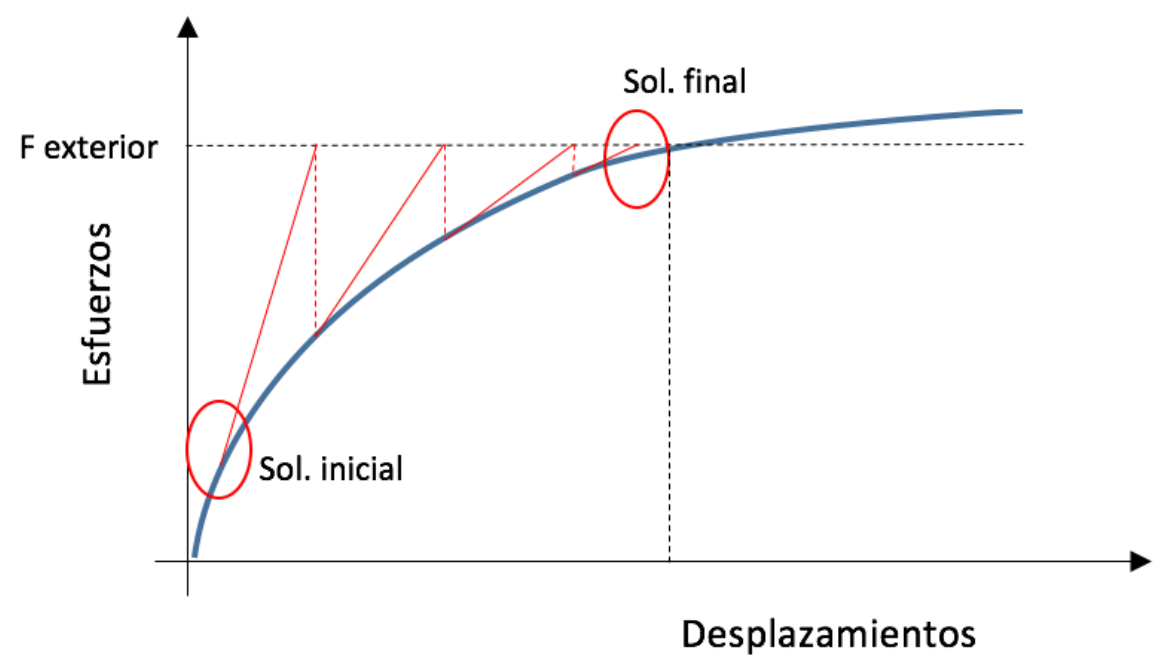

Figura 7.9: Representación de convergencia en el método Newton-Raphson. Fuente: Elaboración propia.

Para alcanzar la solución es necesario establecer un punto de inicio razonablemente cercano a la raíz buscada, cuyo valor depende del problema estudiado. En análisis no lineales, el método garantiza la convergencia si y solo si en cada paso iterativo la solución obtenida se encuentra cercana a la solución exacta. Además, hay que considerar que la matriz de rigidez tangente se debe recalcular en cada iteración, por lo que presenta problemas numéricos cuando la matriz se acerca a cero, como sucede en los puntos límite de cambio de comportamiento.

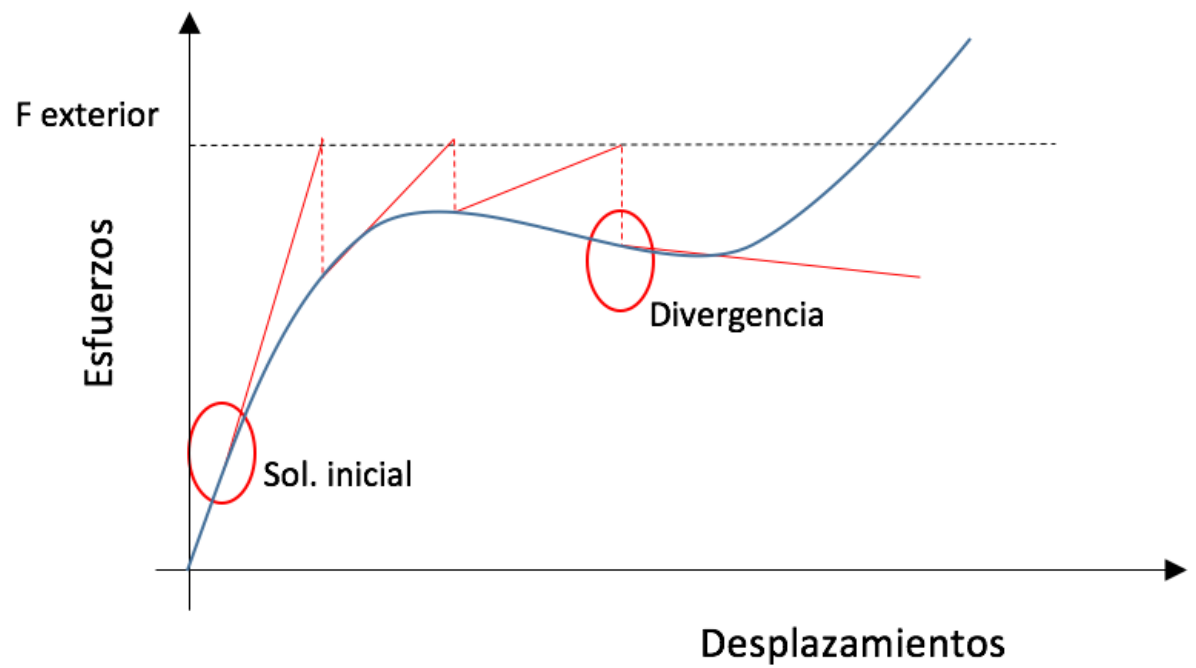

Figura 7.10: Ejemplo de divergencia en el método Newton-Raphson. Fuente: Elaboración propia. 
En cuanto al método del Arc - Length, utiliza iteraciones esféricas explícitas, manteniendo la ortogonalidad entre el radio y las propias direcciones ortogonales. La carga se aplica a la estructura de forma incremental, en cada paso de carga. Esta metodología de resolución es adecuada para representar la respuesta de sistemas con comportamientos complejos, y obtener la solución no lineal mediante la determinación de los puntos límites. Este método es mucho más costoso en términos computacionales, pero permite resolver problemas con grandes desplazamientos y pérdidas de rigidez, como sucede en el pandeo de vías. Requiere pues de una cierta pericia y experiencia por parte del usuario para llegar a compromiso entre el tiempo de cálculo y la precisión de la solución.

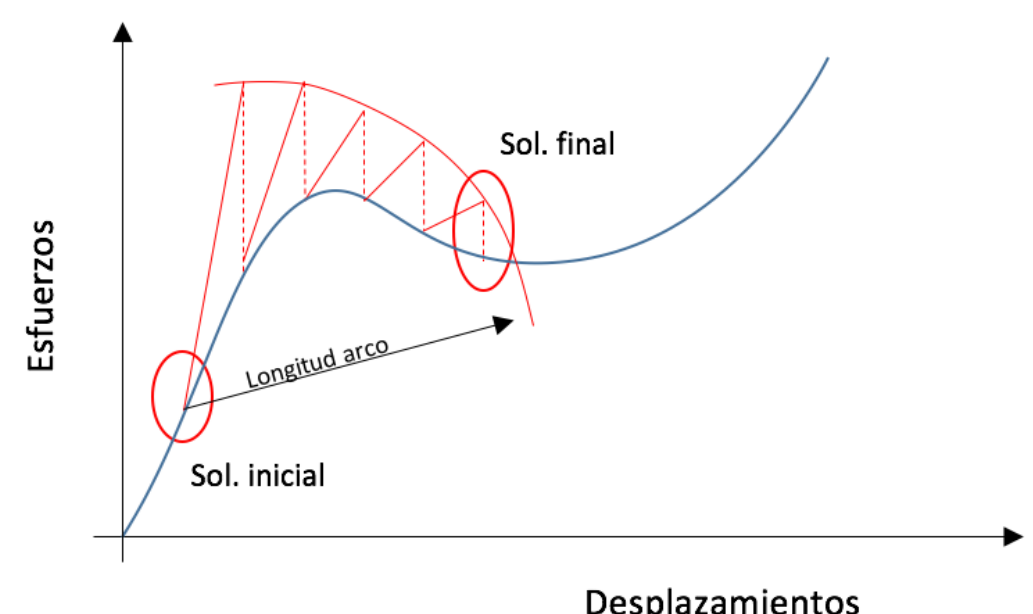

Figura 7.11: Ejemplo de convergencia en el método Arc-length. Fuente: Elaboración propia.

Además del proceso de convergencia descrito, la diferencia principal entre ambos métodos es que el método Arc - Length considera la fuerza exterior como una variable, mientras que en el método Newton - Raphson es considerada constante.

Con ello, el método escogido para resolver el pandeo no lineal es el Arc - Length. Como consecuencia, las cargas térmicas aplicadas al modelo deben ser superiores a la carga que, a priori, debe producir el pandeo. Los resultados obtenidos se obtienen a través del estudio de las curvas fuerza - desplazamiento, en aquellos puntos de interés. Finalmente, la carga de pandeo se obtiene como aquel valor tal que, tras un pequeño incremento de carga, produce un aumento considerable de los desplazamientos laterales, pues representa el instante en el que se pasa de un equilibrio estable a un equilibrio inestable, característico del fenómeno de pandeo. 


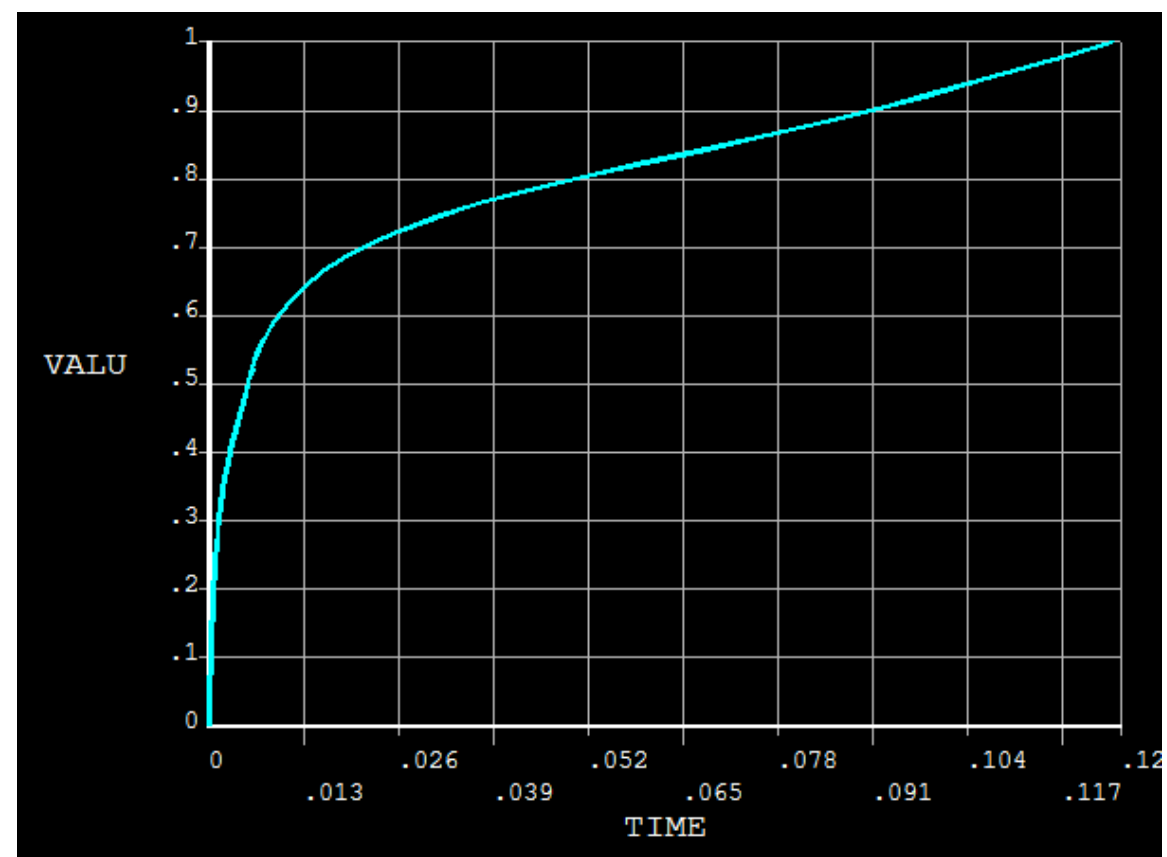

Figura 7.12: Ejemplo de curva temperatura-desplazamiento, para el cálculo de pandeo. Fuente: Elaboración propia.

\subsection{Valores de entrada}

Para la resolución en el MEF se utiliza el procedimiento habitual de resolución, el cual se divide en tres etapas: pre-procesado, resolución y post-procesado. En la primera fase de pre-procesado es donde se introducen las características físicas y geométricas del modelo, así como todos los valores de las variables y factores considerados. El modelo creado es, por tanto, un conjunto de elementos ensamblados entre sí, cuyos vínculos definen la relación y el comportamiento del modelo.

Dado que lo que se pretende es comprobar la adecuación de los modelos desarrollados en el cálculo del pandeo térmico en vías de doble ancho y ante la falta de datos experimentales se considerarán los mismos valores utilizados en el modelo anterior, a efectos de comparar los resultados de ambos modelos.

En la Tabla 7.3 se recogen los parámetros de vía considerados en el estudio y los valores característicos. 
Valores de entrada en el modelo analítico

\begin{tabular}{|c|c|c|c|c|c|c|c|}
\hline Parámetro & \multicolumn{7}{|c|}{ Valores } \\
\hline \multirow{4}{*}{ Carriles } & \multicolumn{3}{|c|}{$\begin{array}{l}\text { Área } \\
\left(\mathrm{m}^{2}\right)\end{array}$} & $\begin{array}{l}\text { Inercia } \\
\text { hor. }\left(\mathrm{m}^{4}\right)\end{array}$ & $\begin{array}{c}\text { Inercia } \\
\text { vert. }\left(m^{4}\right)\end{array}$ & $\begin{array}{l}\text { Peso esp. } \\
\left(\mathrm{kN} / \mathrm{m}^{3}\right)\end{array}$ & $\begin{array}{l}\text { Peso } \\
(\mathrm{kN} / \mathrm{m})\end{array}$ \\
\hline & UIC 54 & \multicolumn{2}{|c|}{0,006934} & $4,18 * 10^{-6}$ & $2,35^{\star} 10^{-5}$ & 78,5 & 5,443 \\
\hline & UIC 60 & \multicolumn{2}{|c|}{0,007686} & $5,13^{*} 10^{-6}$ & $3,06 * 10^{-5}$ & 78,5 & 6,034 \\
\hline & UIC 71 & \multicolumn{2}{|c|}{0,009079} & $7,35 * 10^{-6}$ & $4,15^{\star} 10^{-5}$ & 78,5 & 0,7127 \\
\hline \multirow{3}{*}{ Traviesas } & \multicolumn{2}{|l|}{ Tipo } & \multicolumn{2}{|c|}{$\begin{array}{c}\text { Dimensiones } \\
\text { (m) }\end{array}$} & $\begin{array}{l}\text { Peso esp. } \\
\left(\mathrm{kN} / \mathrm{m}^{3}\right)\end{array}$ & $\begin{array}{c}\text { Separación } \\
\text { (cm) }\end{array}$ & $\begin{array}{l}\text { Peso } \\
(\mathrm{kN})\end{array}$ \\
\hline & \multicolumn{2}{|c|}{ Monobloque } & \multicolumn{2}{|c|}{$, 232 \times 0,3 \times 2,75$} & 25 & 60 & 4,785 \\
\hline & \multicolumn{2}{|l|}{ Bi-bloque } & \multicolumn{2}{|c|}{$0,232 \times 0,3 \times 0,8$} & 25 & 60 & 2,78 \\
\hline \multirow{2}{*}{$\begin{array}{l}\text { Resistencia tor- } \\
\text { sional (sujecio- } \\
\text { nes) }\end{array}$} & \multicolumn{7}{|c|}{ Valores de la resistencia a torsión (kNm/rad) } \\
\hline & \multicolumn{7}{|c|}{100} \\
\hline \multirow{2}{*}{$\begin{array}{c}\text { Resistencia } \\
\text { lateral de la vía }\end{array}$} & \multicolumn{3}{|c|}{ Estado } & \multicolumn{4}{|c|}{ Valor de la resistencia residual (kN/m) } \\
\hline & \multicolumn{3}{|c|}{ Baja - Alta } & \multicolumn{4}{|c|}{$3-5-7-9-11-13-15$} \\
\hline \multirow{2}{*}{$\begin{array}{l}\text { Defecto de } \\
\text { alineación }\end{array}$} & \multicolumn{7}{|c|}{ Amplitud (cm) } \\
\hline & \multicolumn{7}{|c|}{$0,5-1-2-3-4-5$} \\
\hline \multirow{2}{*}{$\begin{array}{c}\text { Características } \\
\text { del balasto }\end{array}$} & \multicolumn{4}{|c|}{ Rigidez longitudinal (kN/m/m) } & \multicolumn{3}{|c|}{ Rigidez vertical (kN/mm) } \\
\hline & \multicolumn{4}{|c|}{70.000} & \multicolumn{3}{|c|}{100} \\
\hline & Tipo & & & Carg & por eje (t) & $\mathbf{N}$ & nero ejes \\
\hline Cargas & & & & & carga & & \\
\hline & Con cars & & & & $7-22$ & & $1-2$ \\
\hline
\end{tabular}

Tabla 7.3: Variables y valores utilizados en el modelo numérico. Fuente: Elaboración propia. 


\subsection{Conclusiones}

En el presente apartado se ha desarrollado un modelo numérico para el estudio del comportamiento frente a pandeo en el caso de vías de doble ancho que, por su naturaleza, no puede ser abordado mediante los modelos tradicionales aplicados a vías convencionales. Para ello, se ha hecho uso del método de los elementos finitos, cuya versatilidad permite el modelado de la superestructura de vía, especialmente por las ventas que ofrece frente a la representación de geometrías complejas.

A la hora de realizar un modelo numérico como el que aquí se plantea, hay que tener en cuenta que el dominio de estudio debe ser discretizado en elementos que deben estar vinculados entre sí. Bajo esta aproximación y con el fin de determinar los parámetros fundamentales de los que depende su respuesta de la vía frente a pandeo, se ha empleado un modelo de vía basado en elementos tipo vigas, unidos a través de un conjunto de muelles y resortes los cuales representan los diferentes elementos del emparrillado y de la capa de balasto.

Además, también se han definido las dimensiones del dominio, los materiales a introducir y la forma más adecuada para simular el comportamiento de cada elemento, tanto desde una perspectiva geométrica como mecánica. Por ejemplo, siendo conocedores que uno de los elementos que provoca no linealidad en la respuesta lateral frente a cargas longitudinales se debe a la resistencia lateral del balasto, el modelo considera dicho comportamiento mediante el uso de elementos tipo muelle, cuya respuesta se asimila a la de la vía real.

En cuanto a las acciones, en el modelo numérico se distingue entre la carga cuasi-estática producida por el paso de los vehículos y la carga térmica de los carriles, la cual se aplica de forma incremental sobre los carriles, tal que los esfuerzos generados desestabilizan el conjunto analizado cuando se supera un cierto valor, al que se denomina como temperatura de pandeo.

Con todo ello, la resolución se obtiene haciendo uso del método del arco. Esto permite estudiar diferentes aspectos del comportamiento frente a pandeo de vías de doble ancho que, hasta el momento, no han sido analizados con esta metodología. Para poder llevar a cabo el cálculo, el modelo planteado ha sido implementado haciendo uso de la herramienta de software Ansys ${ }^{\circledR}$. 


\section{Capítulo V \\ 8. Estudio de resultados y riesgo de pandeo}

En el capítulo anterior se han desarrollado dos modelos, uno analítico y otro numérico, para el cálculo de la temperatura de pandeo en el caso de vías de doble ancho. Haciendo uso de estos modelos y de acuerdo con la estructura planteada, el objetivo ahora es llevar a cabo un análisis del pandeo, comparando casos teóricos representativos que permitan analizar el rango de la variación de los resultados.

Tal y como se ha visto previamente, el estudio del pandeo se considera un problema de gran importancia ya que condiciona fuertemente la seguridad ferroviaria. Además, este tipo de problema se considera como un fenómeno físico no lineal, cuya resolución es altamente compleja. Por esto motivos, se hace necesario comprender los factores que condicionan la estabilidad de la vía.

Para ello, la determinación de la carga o temperatura de pandeo en el entorno ferroviario exige el manejo de herramientas y modelos específicos que consideren de forma explícita todas aquellas características particulares de este problema.

Pese a que el estudio del pandeo en vías nace y se desarrolla ya en la década de los años 50 y 60 a medida que aumenta el uso de los carriles continuos soldados, en el caso de vías con doble ancho existe una falta de conocimiento, plasmada en una escasa bibliografía y de experiencias previas, favorecida por el uso anecdótico y de poca entidad de este tipo de infraestructura. 
Sin embargo, con el nuevo escenario planteado por el Corredor Mediterráneo de mercancías y la situación presente en la red ferroviaria española, se plantea una nueva situación en la que el uso de vías de doble ancho de forma extensa plantea la necesidad de estudiar y analizar en profundidad este tipo de infraestructura.

Con estas premisas, en la primera parte se analiza el comportamiento frente a pandeo en vías de doble ancho mediante la formulación desarrollada en el capítulo anterior, obteniendo como resultado la temperatura de pandeo en diferentes escenarios y condiciones de vía.

En la segunda parte, se comparan los cálculos con valores obtenidos para vías convencionales, de tal forma que permita de manera a reflexionar sobre la estabilidad de las vías de doble ancho y comparar su comportamiento.

Para finalizar, se desarrolla una metodología probabilística, con el objetivo de determinar el riesgo frente a pandeo a través de las distribuciones de probabilidad de las variables fundamentales del problema.

\subsection{Metodología de estudio y variables estudiadas}

En este primer punto y como paso previo al estudio y análisis de los resultados, se considera oportuno definir la metodología aplicada y su justificación.

El estudio global de la estabilidad de la vía se aborda, generalmente, no como un único problema concreto sino como un conjunto de escenarios y situaciones a través de las cuales es posible comprender el fenómeno en sí. En este sentido, el pandeo se debe, no solo a los esfuerzos debidos a los incrementos de temperatura sino a la combinación de unas condiciones de vía degradadas o debilitadas.

Por estos motivos, los estudios teóricos de pandeo abordan el problema mediante el estudio de diversas de las variables que controlan la estabilidad lateral, lo que implica que los efectos de interacción entre las diferentes variables se valoren desde una perspectiva amplia.

Sin embargo, pese a la importancia del problema que aquí se aborda, no existe ningún método común y normalizado para el cálculo de la temperatura de pandeo. La construcción 
de modelos como los elaborados en esta Tesis posibilita el estudio de diversas variables relacionadas con los elementos de la vía, dimensiones, materiales, resistencias, cargas, etc.

Por otro lado, también es necesario tener presente la existencia de importantes limitaciones prácticas a la hora de comparar y realizar una validación de modelos teóricos. Esta limitación es, en gran medida, razonable, pues la realización de pruebas reales conlleva elevados costes económicos y el control de las variables es, en muchos casos, realmente complejo. Como ejemplo, cabe mencionar los métodos experimentales desarrollados para determinar la resistencia lateral de la vía, los cuales determinan la resistencia a partir de la medida de magnitudes asociadas a una o un grupo aislado de traviesas. Incluso cuando se dispone de mediciones reales de algunas de las diferentes variables que influyen en el modelo, existen ciertas interrelaciones y otros efectos de segundo orden que complican y distorsionan una eventual comparación y validación.

Pese a las limitaciones descritas, las aportaciones realizadas por diversos autores (Van, 1997; Lim et al. 2003, 2008; Choi y Na, 2010; Kish y Samavedam, 2013; Pucillo, 2016; Yang y Bradford, 2016) ponen de manifiesto la gran influencia que posee dos aspectos claves en la estabilidad transversal: la resistencia lateral y la amplitud del defecto. Ante estas evidencias, se plantea la selección de estos dos factores como variables fundamentales, con el objetivo de llevar a cabo un exhaustivo análisis que permita analizar y predecir las temperaturas de pandeo en vías de doble ancho.

En efecto, cuando se analizan la estabilidad transversal, la resistencia transversal y la amplitud del defecto resultan aspectos fundamentales, dado que:

- La resistencia transversal condiciona directamente la capacidad resistente de la vía, y a su vez,

- La amplitud del defecto inicial determina el valor del esfuerzo necesario para desestabilizar la vía y, en consecuencia, la temperatura de pandeo.

Naturalmente, la influencia de la resistencia transversal y de la amplitud del defecto dependerá de la combinación del resto de factores implicados en el fenómeno y que condicionan el pandeo. Así, por ejemplo, el estado de consolidación del balasto está estrechamente relacionado con la resistencia transversal, pues a medida que circulan cargas sobre la vía las partículas del balasto se ajustan, proporcionando una mayor resistencia. 
No obstante, el estudio de pandeo no trata de resolver un único problema, sino un conjunto de escenarios, pues existen otras relaciones no tan evidentes y que conviene estudiar. Para ello es útil el uso de modelos de simulación, especialmente en la toma de decisiones prácticas. Con ello se pretende, a su vez, comparar los resultados obtenidos y analizar las similitudes y diferencias entre el modelo numérico y analítico planteado

Para llevar a cabo este estudio, los parámetros secundarios utilizados en el estudio son: tipo de carril, tipo de traviesa, tipo de defecto y su posición respecto de la vía, la altura de la capa de balasto y cargas verticales. Para ello, una vez fijados todos los factores, se reflexionará sobre la influencia que posee la variación de uno de ellos en un rango real, en función de las dos variables principales consideradas. Al tomar valores fijos, se tiene un valor determinado de cada variable, lo cual elimina la posibilidad de analizar la influencia que variaciones de dicho parámetro tienen sobre la respuesta.

Cabe destacar que los resultados de temperatura obtenidos, en todos los casos, están expresados respecto de la temperatura de neutralización. Así, por ejemplo, el valor 0 no indica una temperatura absoluta de $0^{\circ} \mathrm{C}$, sino un incremento nulo respecto de la temperatura de neutralización de los carriles.

Bajo esta metodología, a lo largo del presente apartado se analiza la respuesta de la vía para las diferentes variables, en función de los dos parámetros fundamentales descritos.

Es importante destacar que los valores de referencia empleados para las diferentes variables no corresponden a datos reales de vía, sino que se utilizan valores representativos de las variables consideradas. Esto es debido a la falta de información en las diferentes normativas o especificaciones técnicas respecto a las vías de doble ancho, por ser un tipo de vía especial y del que existe muy poca información disponible. Con ello, el objetivo no es tanto validar los modelos sino analizar el comportamiento global en función de las características consideradas.

En consecuencia, la precisión de los resultados obtenidos queda supeditada a las hipótesis adoptadas, así como su validación con datos experimentales. Dicha tarea queda pendiente para futuros trabajos. 


\subsection{Análisis del pandeo en función de la resistencia lateral}

Una vez descrita la metodología de estudio, es momento de extender la aplicación de los modelos a la evaluación del comportamiento frente a pandeo de vías con doble ancho, objeto principal de estudio en esta Tesis.

Como paso previo al análisis de los resultados, es importante describir de forma concreta los escenarios de estudio. Para ello, se ha definido una configuración de referencia que permite analizar el comportamiento general del fenómeno.

En la Tabla 8.1 se recogen los valores y condiciones de referencia considerados en el cálculo. El ámbito de estudio es el de las estructuras habituales en líneas férreas, adoptando un emparrillado habitual con carriles UIC-60 y traviesas monobloque de hormigón separadas $60 \mathrm{~cm}$.

\begin{tabular}{|c|c|}
\hline \multicolumn{2}{|c|}{ Condiciones de referencia } \\
\hline Condición & Valor \\
\hline Carril & UIC-60 \\
\hline Traviesa & Monobloque \\
\hline Tipo defecto & Media Senoide / lado 2 carriles \\
\hline Amplitud defecto & Sin carga \\
\hline Carga vertical & Recto \\
\hline Tramo de vía & \\
\hline
\end{tabular}

Tabla 8.1: Condiciones de referencia utilizadas en el cálculo, en función de la resistencia lateral. Fuente: Elaboración propia.

Con esto, cabe aclarar que los valores mostrados en el presente apartado representan la tendencia general que presenta la vía de doble ancho, en función de diversos factores y frente al valor de la resistencia lateral.

Como se ha visto en capítulos anteriores, obtener valores reales de la resistencia transversal implica llevar a cabo ensayos en diferentes circunstancias, lo cual no es sencillo a causa de la amplia variedad de factores que intervienen. Un planteamiento que puede proporcionar una buena aproximación se basa en el hecho de considerar valores de resistencia lateral entre los 3 y $15 \mathrm{kN} /$ traviesa, lo que constituye un rango suficientemente representativo de los valores reales en vía. 


\subsubsection{Variación del tipo de carril}

Con el objeto de determinar qué tipo de carril presenta un mejor comportamiento frente a pandeo, en este primer punto se analiza la respuesta de la vía en función de dicho factor, para diferentes valores de la resistencia lateral.

La comparativa considera los carriles utilizados en líneas férreas del tipo UIC 54, UIC 60 y UIC 71, cuyas propiedades vienen definidas en la Tabla 6.1 y la Tabla 7.3. Es importante destacar que la elección de un determinado carril determina el valor de la sección transversal, el peso, así como los momentos de inercia (vertical y horizontal), lo que influye en la respuesta de la vía.

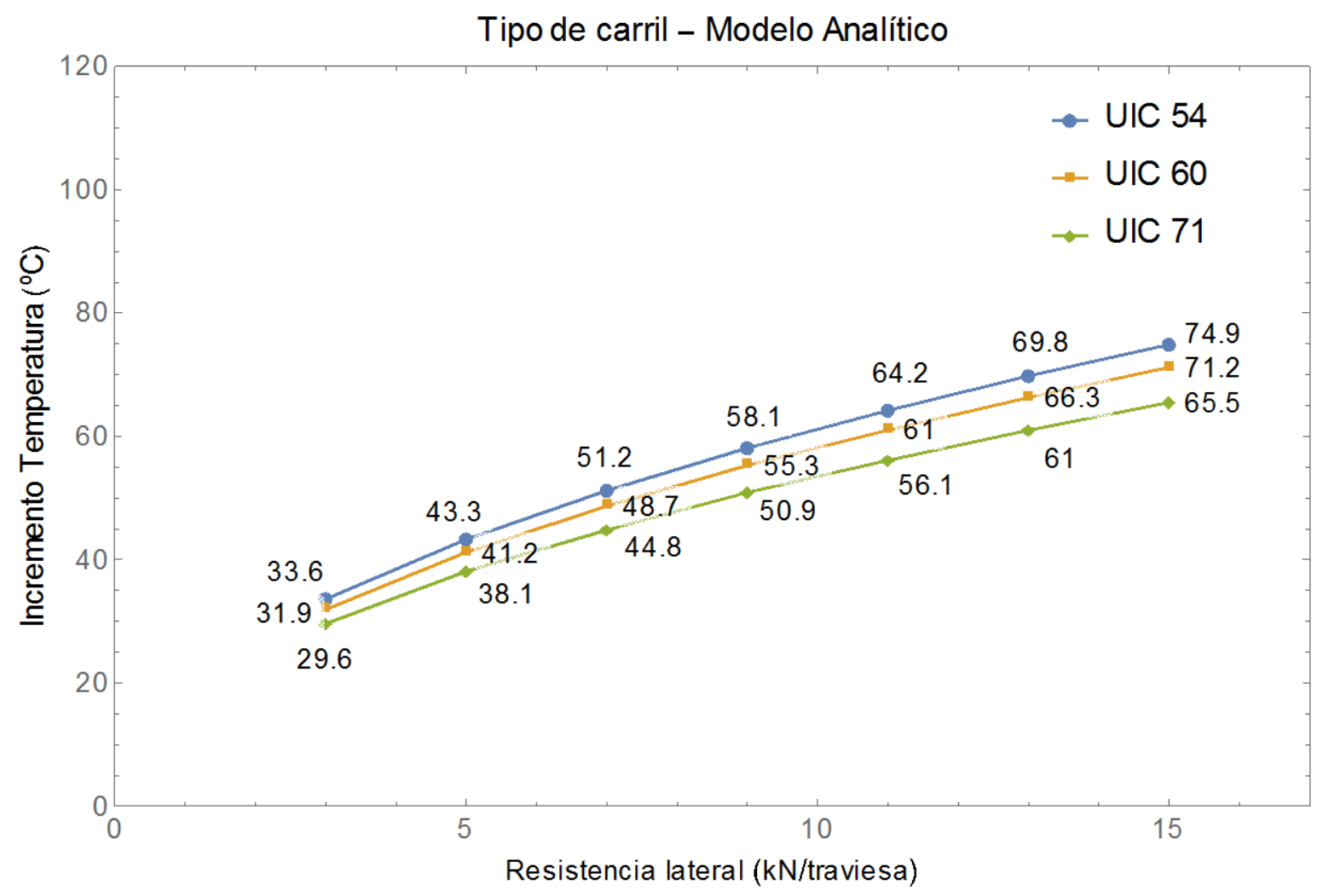

Figura 8.1: Temperatura de pandeo según el tipo de carril y de la resistencia lateral. Fuente: Elaboración propia 


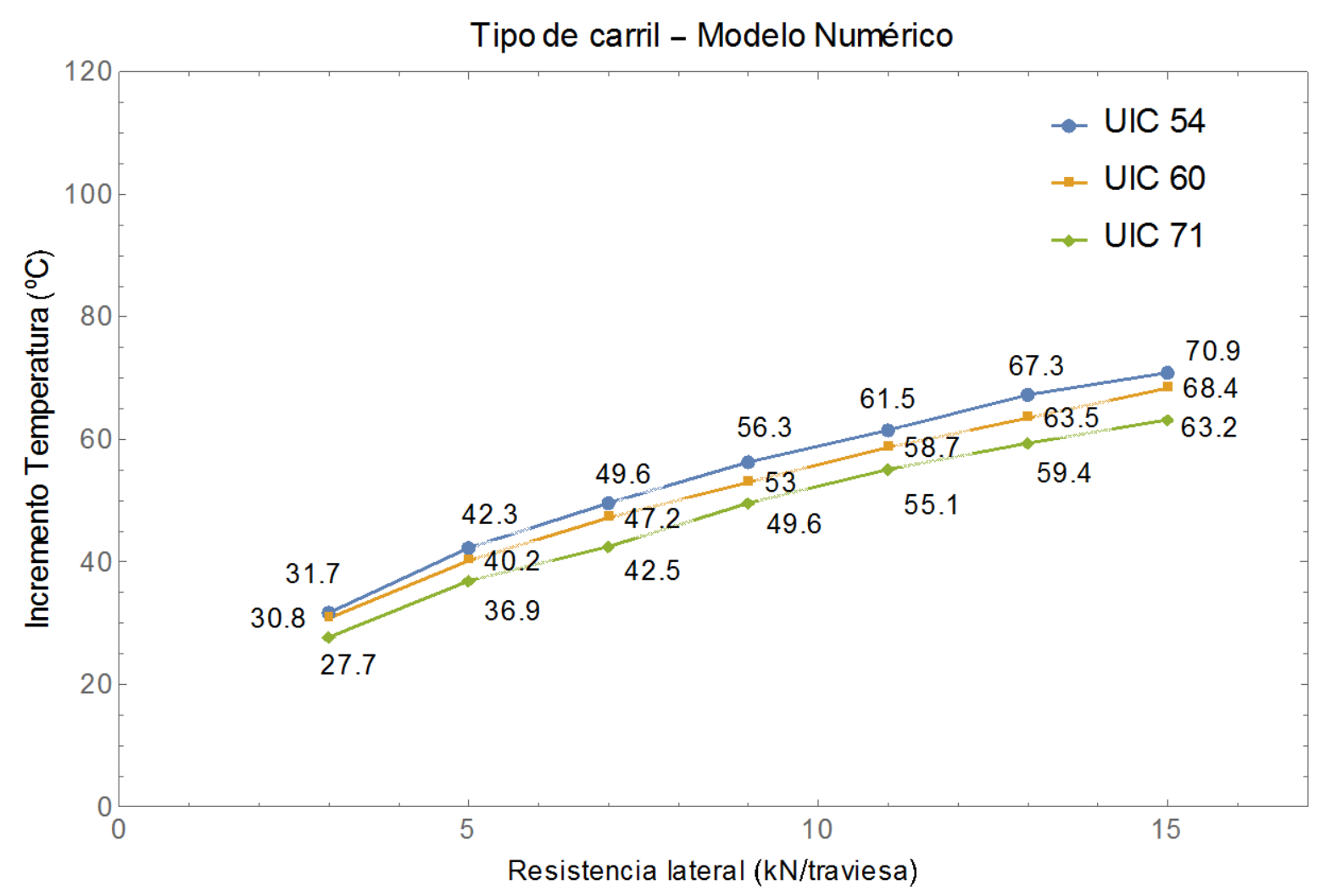

Figura 8.2: Temperatura de pandeo según el tipo de carril y de la resistencia lateral. Fuente: Elaboración propia.

En primer lugar y en cuanto al comportamiento observado en la Figura 8.1 y Figura 8.2, es posible comprobar como la curva que representa las temperaturas de pandeo sigue una tendencia creciente, a medida que aumenta la resistencia lateral. Este resultado, a priori esperable, se debe a que gran parte de la resistencia que se opone a la desestabilización de la vía se debe a la resistencia que ofrece el balasto a través de la traviesa. La mejora de la resistencia lateral conlleva, necesariamente, mayores temperaturas de pandeo.

En cuanto al tipo de carril, se observa como el UIC 54, correspondiente al de menor dimensiones de los tres, es el que proporciona una mejor respuesta. En consecuencia, las curvas de temperatura obtenidas se desplazan en sentido decreciente, respecto del eje vertical, a medida que se considera un carril con mayor sección.

El motivo de este particular comportamiento está estrechamente relacionado con las características mecánicas y resistentes del mismo. En concreto, los carriles con secciones más reducidas, como el caso del UIC 54, tiene una sección transversal más reducida, a la vez que un menor peso e inercia. Esta menor superficie produce que los esfuerzos de 
compresión generados por un determinado incremento de temperatura sean menores respecto de un carril de mayor sección (recuérdese que el esfuerzo térmico en un carril es directamente proporcional al área del mismo), siendo necesario un mayor incremento de temperatura a igualdad de esfuerzo.

La tendencia aquí observada es coherente con resultados obtenidos previamente por otros investigadores (Tew et al. 1991; Choi \& Na, 2010; Kish \& Samavedam, 2013), cuyos resultados muestran un comportamiento semejante al obtenido.

Ante esta situación, es posible pensar que en el diseño de una infraestructura ferroviaria los carriles con menor sección son los más adecuados. Sin embargo, el razonamiento adecuado no debe hacerse únicamente desde su respuesta frente al pandeo, pues es necesario considerar que los carriles están sometidos a tensiones muy importantes y con carácter cíclico, lo que puede llevar a la fatiga del material si no poseen las dimensiones adecuadas. Asimismo, las diferencias de temperatura de pandeo observadas entre los diferentes carriles no son suficientemente significativas como para decantarse claramente por un determinado tipo de carril, por lo que no es conviene el uso de carriles de dimensiones reducidas.

Finalmente, atendiendo a los resultados obtenidos en cada uno de los dos modelos, se aprecia que, en todos los casos, las temperaturas obtenidas con el modelo analítico son ligeramente superiores a las obtenidas con el modelo numérico. Puede observarse que, para los carriles tipo UIC 54, UIC 60 y UIC 71 las diferencias son del 6\%, 14\% y 7\% respectivamente, por lo que ambos modelos representan un comportamiento similar del fenómeno.

\subsubsection{Variación del tipo de traviesa}

Se analiza en este caso la influencia del tipo de traviesa. Las traviesas consideradas en el estudio son de hormigón monobloque y bibloque, excluyéndose la tradicional traviesa de madera ya que su resistencia transversal es, generalmente, muy inferior a la proporcionada por las traviesas de hormigón.

La comparativa se realiza mediante el uso del modelo analítico, donde es posible representar la resistencia transversal a través de cada una de las tres componentes resistentes 
del contacto traviesa-balasto. Para ello, en este caso concreto las temperaturas de pandeo se evalúan en base a las características y propiedades para cada tipo de traviesa.

La resistencia transversal queda definida, en este caso, a partir de ocho parámetros. Así pues, se consideran unas dimensiones de traviesa igual a 0,3 m de ancho y 0,232 $\mathrm{m}$ de altura, mientras que la longitud es de $2,7 \mathrm{~m}$ para las traviesas monobloque y de $0,8 \mathrm{~m}$ para las bibloque. Junto con las dimensiones geométricas, el valor de la resistencia viene caracterizado por el ángulo de rozamiento del balasto $\emptyset=55^{\circ}$, lo que proporciona valores del coeficiente de empuje al reposo máximo de $K_{0}=10,05$ y mínimo de $K_{0}=0,8$. Además, se han determinado el coeficiente de empuje pasivo $K_{p}=10,059$, la cohesión del balasto $c^{\prime}=$ 0,1 y el coeficiente de rozamiento traviesa-balasto $\mu=24^{\circ}$.

Con estos valores, la resistencia lateral total obtenida para cada tipo de traviesa se muestra en la Figura 8.3, en función del valor del coeficiente de empuje al reposo.

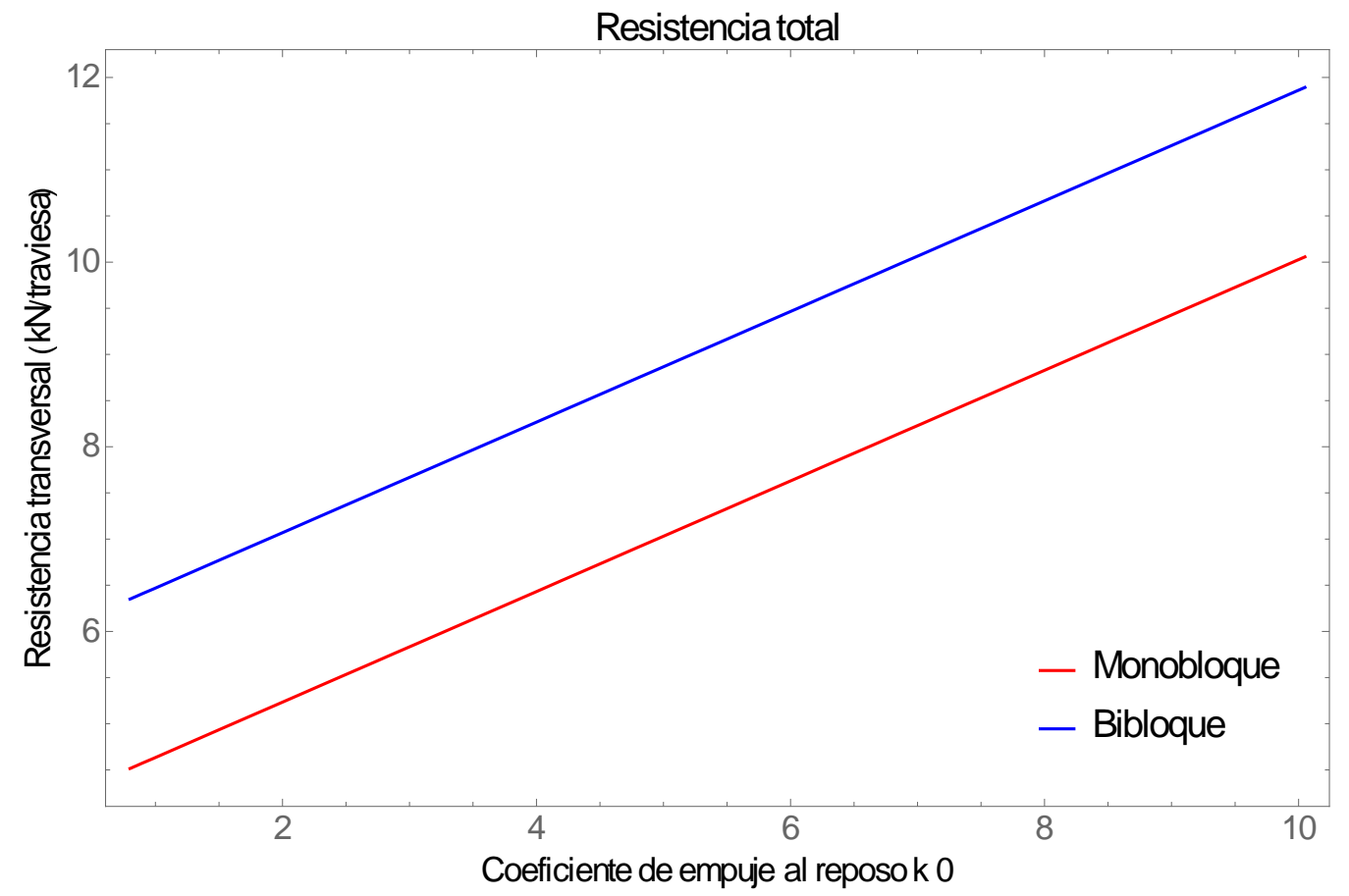

Figura 8.3: Resistencia lateral, para cada uno de los tipo de traviesa considerados. Fuente: Elaboración propia. 
Los resultados correspondientes a la temperatura de pandeo, para cada tipo de traviesa, se representa en la Figura 8.4, donde cada curva se ha obtenido para los valores del coeficiente de empuje al reposo $k 0$.

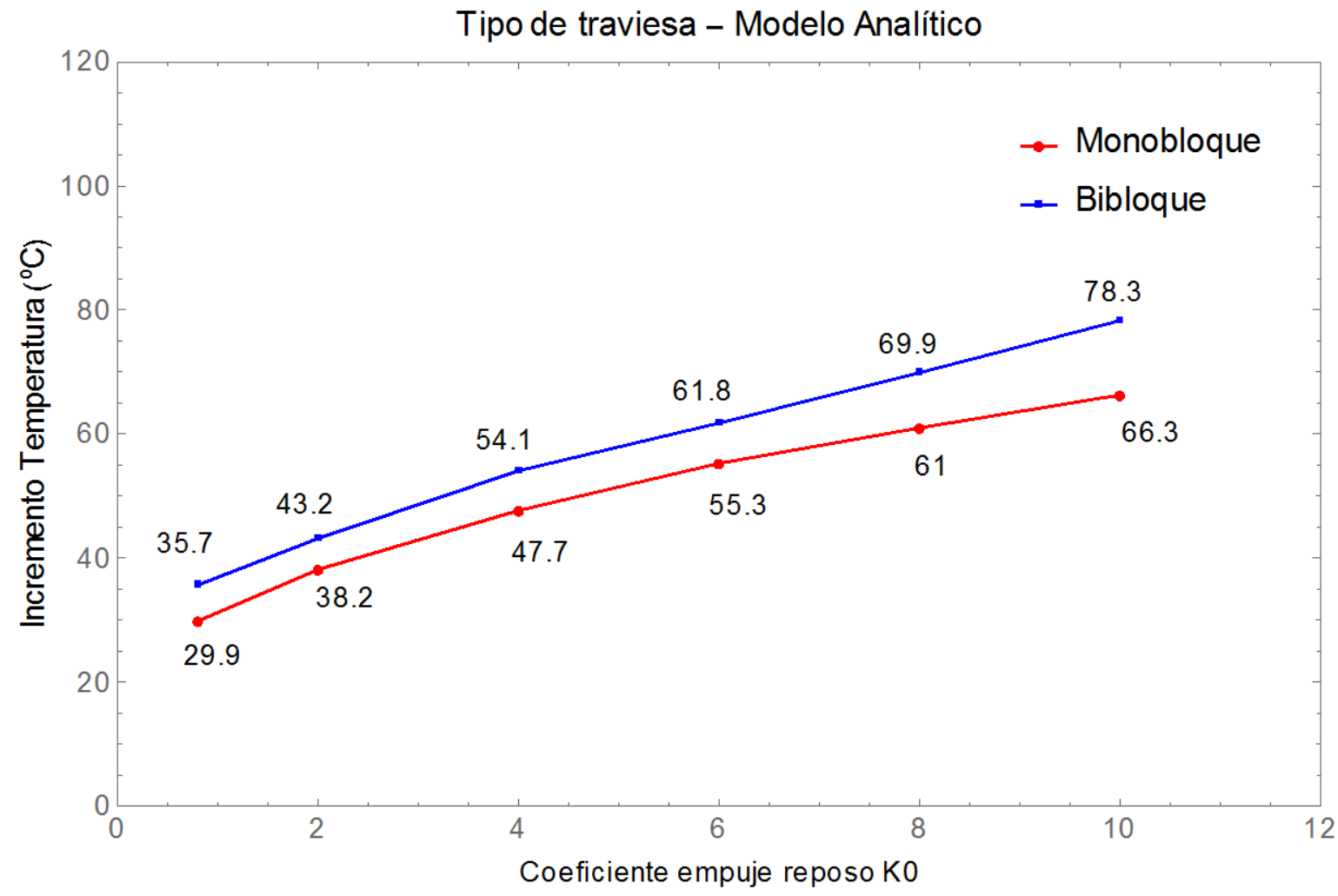

Figura 8.4: Temperatura de pandeo según el tipo de traviesa y dl coeficiente de empuje al reposo k0. Fuente: Elaboración propia.

Tal y como se observa, las traviesas bibloque proporcionan valores de temperatura de pandeo superiores, siendo este comportamiento coherente con las mayores resistencias laterales de este tipo de traviesa descrito en el apartado 3.4.5. El efecto beneficioso de la mayor resistencia se debe mayoritariamente a la existencia de dos caras laterales, con lo que la resistencia por punta es el doble de la proporcionada por una traviesa monobloque.

De la observación de los resultados puede observarse como la temperatura de pandeo oscila entre los $35,7^{\circ} \mathrm{C}$ y los $78,3^{\circ} \mathrm{C}$ para el caso de traviesa bibloque y entre los $29,9^{\circ} \mathrm{C}$ y $66,3^{\circ} \mathrm{C}$ para la monobloque. Además, en la zona correspondiente al rango de valores más bajos de resistencia lateral, las diferencias entre ambos tipos de traviesa son ligeramente inferiores. 


\subsubsection{Variación de tipo de defecto}

De acuerdo con los condicionantes estudiados en el capítulo 2, las irregularidades geométricas de la vía constituyen una fuente importante de inestabilidad lateral y suponen importantes alteraciones de la respuesta estructural. En este sentido, es interesante estudiar con mayor detalle la influencia del tipo de defecto en la respuesta de la vía.

En el caso del modelo analítico se emplean relaciones entre el defecto inicial y la deformada final. Por ello, el estudio de este parámetro se realiza a partir de las ecuaciones derivadas de este modelo, ya que no resulta sencillo implementar esta condición inicial en un modelo numérico como el desarrollado en la presente Tesis.

Así pues, en la Figura 8.5 se muestran los valores de la temperatura de pandeo obtenidas, para cada tipo de defecto (media senoide o senoide).

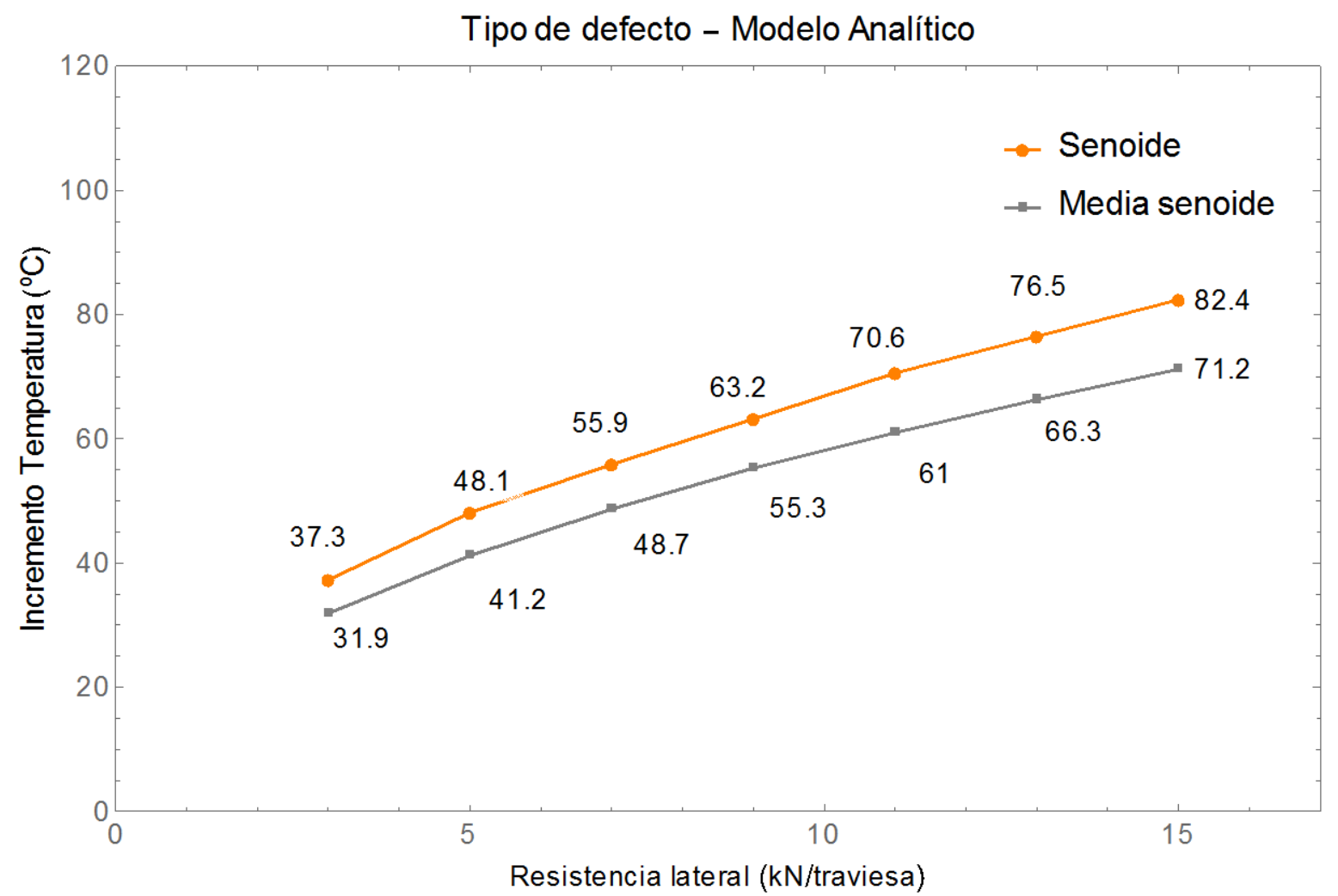

Figura 8.5: Temperatura de pandeo según el tipo de defecto y de la resistencia lateral. Fuente: Elaboración propia. 
La gráfica anterior pone de manifiesto la sensibilidad del modelo analítico respecto del tipo de defecto considerado en el cálculo. En efecto, se observa como para el caso de defectos con forma de media senoide, las temperaturas resultantes son inferiores respecto de las obtenidas para defectos senoidales. En particular, la reducción obtenida es aproximadamente del $16 \%$.

Desde un punto de vista teórico, el comportamiento observado anteriormente está relacionado con la formulación de Euler, pues el primer modo de pandeo y con mayor probabilidad de ocurrencia (menor temperatura de pandeo) se obtiene para defectos en forma de semionda senoidal (ver apartado 2.2).

Este hecho se confirma en la bibliografía, pues tendencia habitual en la formulación es la de considerar los defectos iniciales con forma de media senoide (Kish et al. 1982; Lim et al., 2008; Choi et al., 2010). Desde un punto de vista teórico, este factor está relacionado con la formulación de Euler, pues el primer modo de pandeo y con mayor probabilidad de ocurrencia (menor temperatura de pandeo) se obtiene para un defecto en forma de semionda senoidal.

En los resultados mostrados hasta el momento no se ha tenido en cuenta el efecto de la posición del defecto respecto de los carriles. No obstante, cuando se analizan vías de doble ancho y debido a la asimetría que presenta la incorporación de un tercer carril, cabe plantearse la influencia de la posición del tercer carril respecto del defecto considerado. Esta asimetría, no presente en las vías de un solo ancho, es una situación muy particular que no ha sido analizada hasta el momento.

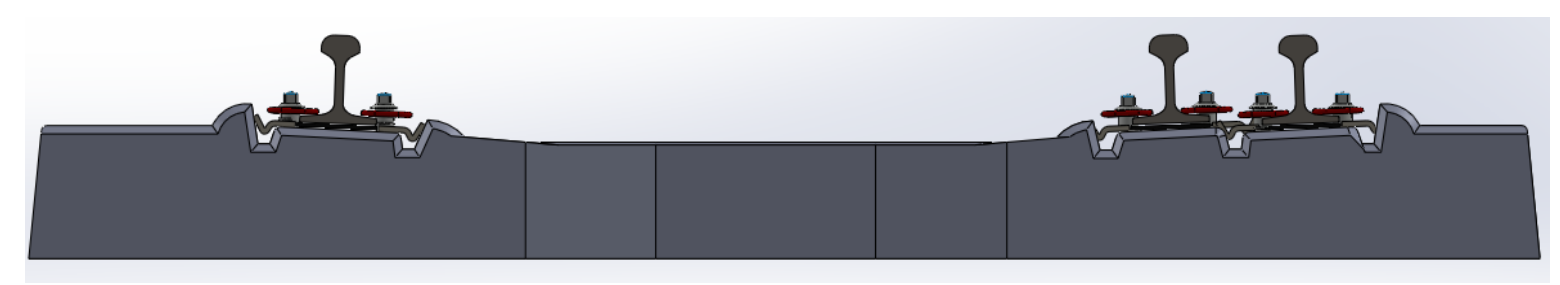

Figura 8.6: Imagen de vía con 3 carriles, representativa de la asimetría. Fuente: Elaboración propia. 
Es por ello que se diferencian dos situaciones de cálculo:

- Defecto de alineación hacia el lado del carril común.

- Defecto de alienación hacia el lado de los dos carriles.
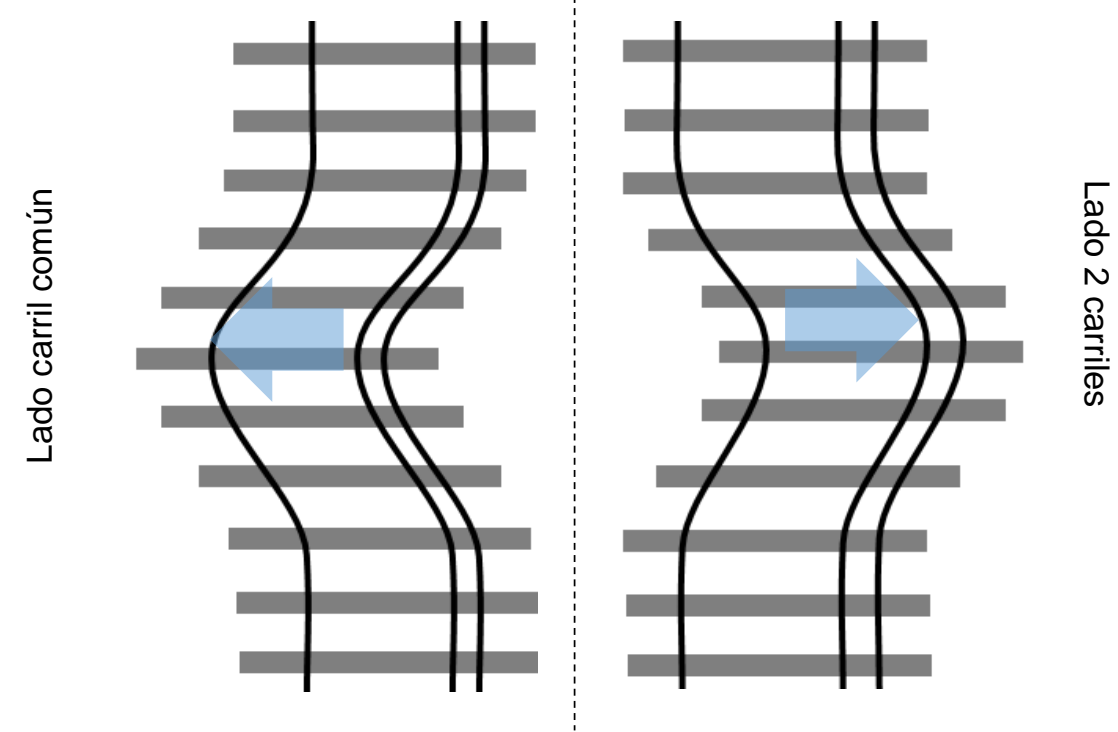

Figura 8.7: Esquemas representativos del tipo de defecto considerado. Fuente: Elaboración propia.

Para llevar a cabo este análisis se ha hecho uso del modelo numérico. Se recuerda que este modelo tiene en consideración la posición relativa de los carriles, pues representa cada uno de ellos en su posición real. Las ventajas del modelo en este caso son evidentes, pues permite analizar el lado hacia el que crecen las deformaciones, mientras que en las soluciones analíticas sería imposible.

Para ello, la simulación inicial llevada a cabo en este escenario se obtiene como resultado de asumir un determinado defecto inicial, tras el cual se aplica un incremento temperatura en los carriles, analizando los desplazamientos laterales resultantes. 

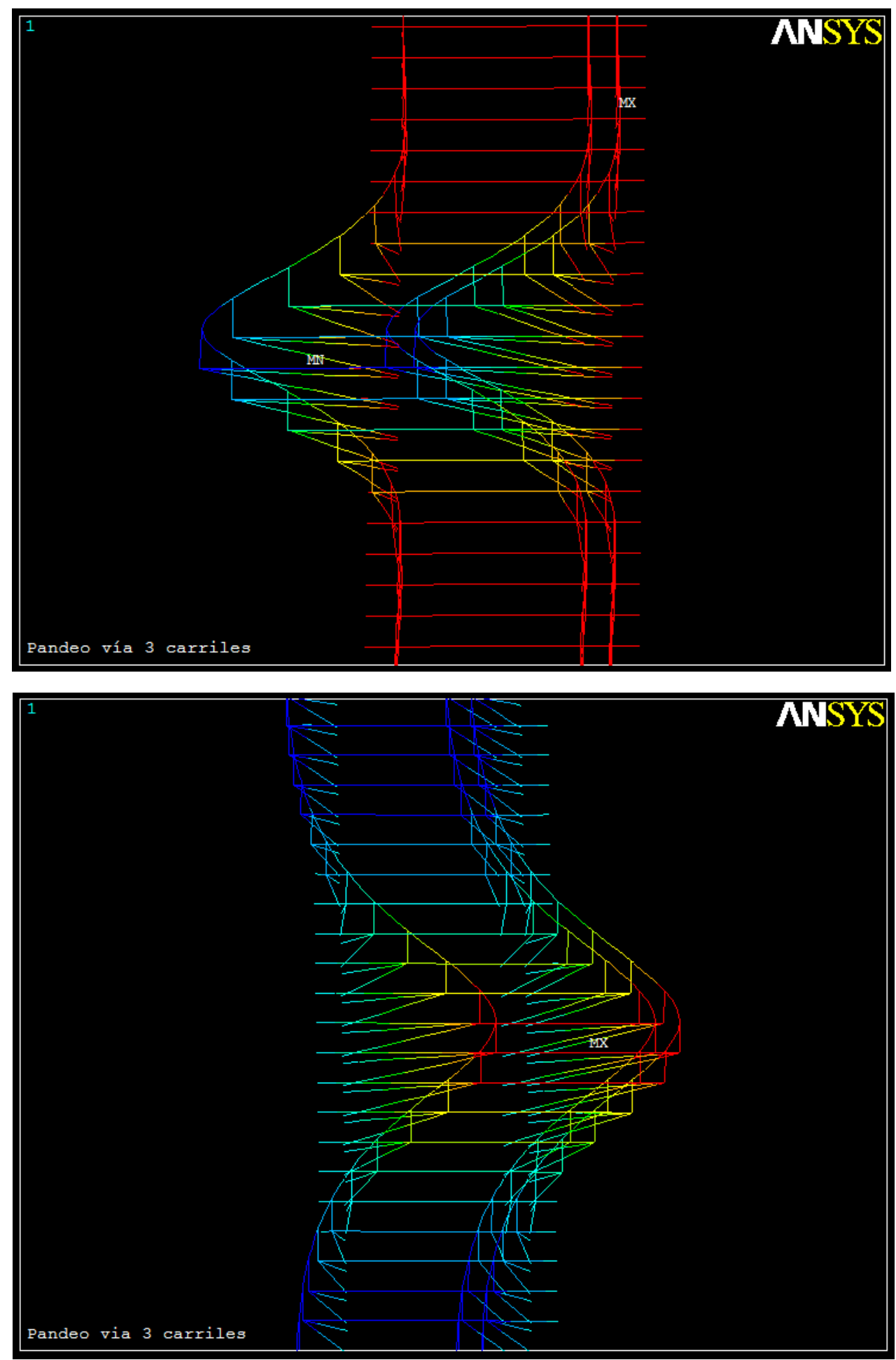

Figura 8.8: Vista del modelo numérico de 3 carriles con el defecto inicial, en cada caso (escala 50:1). Fuente: Elaboración propia. 


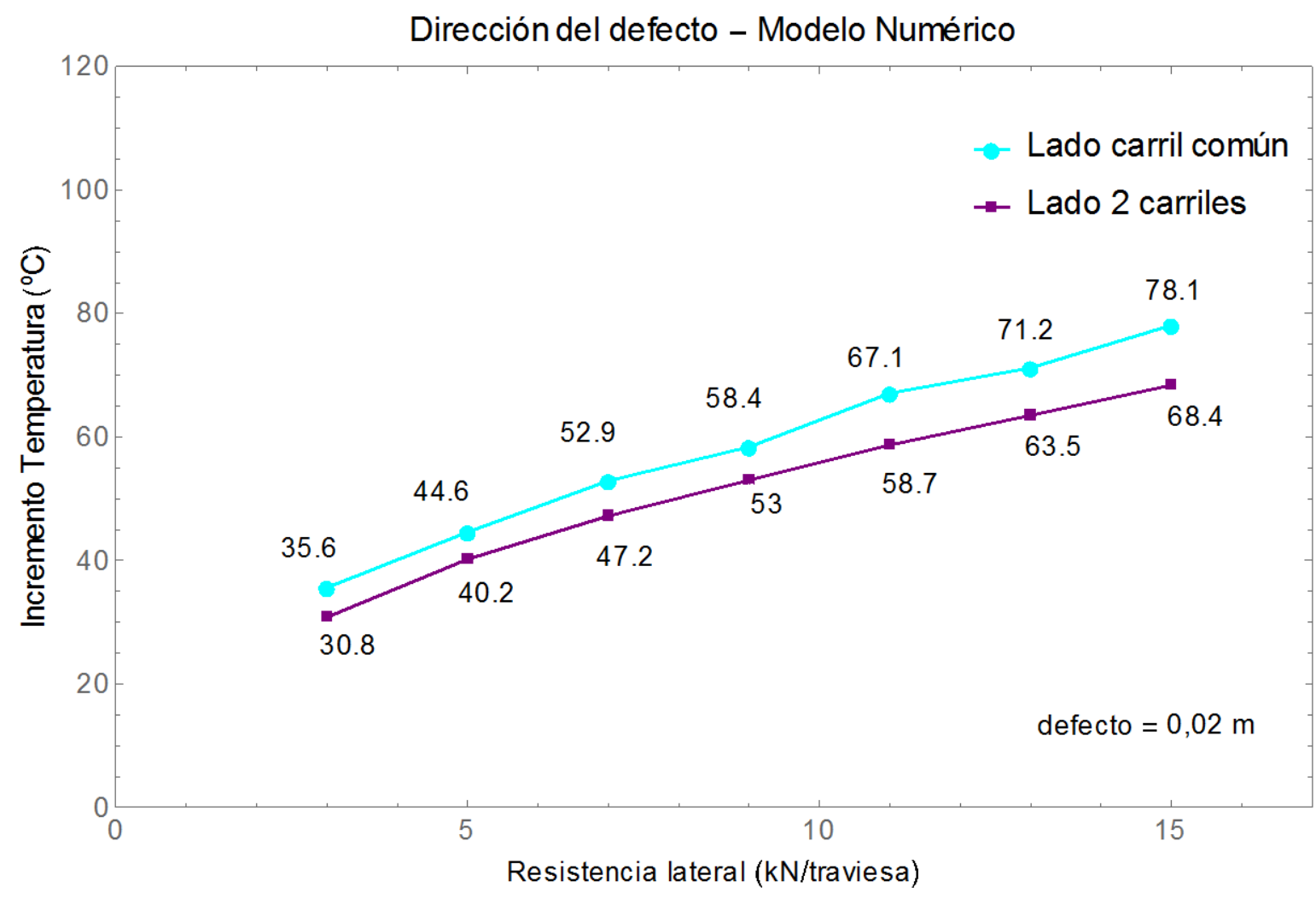

Figura 8.9: Temperatura de pandeo en función del lado del defecto, según la resistencia transversal. Fuente: Elaboración propia.

Como se puede observar tanto en la Figura 8.9, el mejor comportamiento en cuanto a pandeo se obtiene cuando el defecto se localiza sobre el lado del carril común, pues las temperaturas resultantes son relativamente superiores a las que se obtienen cuando el defecto se localiza en el lado donde se sitúan los 2 carriles.

Por ello, los resultados obtenidos muestran que la falta de alineación puede dar origen a problemas cuya gravedad se establece en función del lado donde se localicen, siendo un nuevo factor hasta el momento no considerado en el estudio y mantenimiento de vías férreas.

Este comportamiento se puede deber al mayor momento resultante de las cargas cuando la vía se desplaza hacia el lado donde se encuentran los dos carriles, pues el desplazamiento hacia este extremo produce una mayor excentricidad. No obstante, este comportamiento particular calculado no permite extraer conclusiones definitivas, pues la tendencia observada no ha sido comprobada ni analizada todavía experimentalmente. Sin embargo, los resultados obtenidos ponen de manifiesto la necesidad de considerar en el cálculo la 
asimetría del emparrillado, lo que plantea nuevos retos en cuanto a la instalación y mantenimiento de este tipo de vías.

\subsubsection{Variación de la altura del balasto}

Otro de los factores considerado en la modelización analítica (de forma indirecta podría introducirse en el modelo analítico a través de la resistencia lateral considerada) es la altura de la capa de balasto, relacionada directamente con la resistencia transversal. Para analizar su influencia se utiliza, como en el caso anterior, la modelización analítica, donde se formula la resistencia lateral en función de dicha variable.

De esta forma, para el caso de una traviesa monobloque y de acuerdo con los valores de la Tabla 6.1, se obtiene la siguiente expresión:

$$
\varphi(y, h)=2+165.53 h^{2}
$$

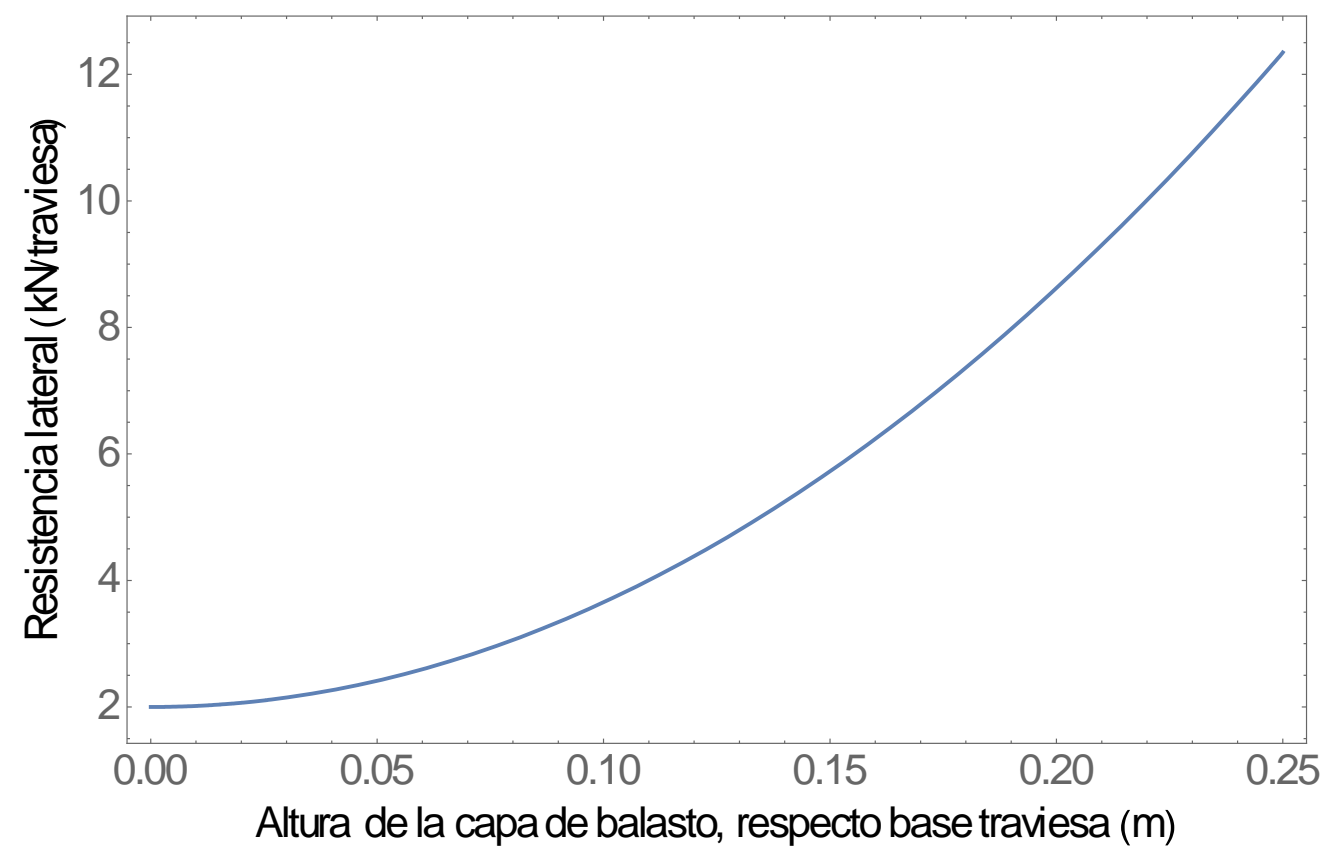

Figura 8.10: Resistencia lateral resultante, según la altura de la capa de balasto sobre la base de la traviesa. Fuente: Elaboración propia.

Con estos valores de resistencia, en la Figura 8.11 se observan los resultados obtenidos, para las condiciones previamente descritas. 


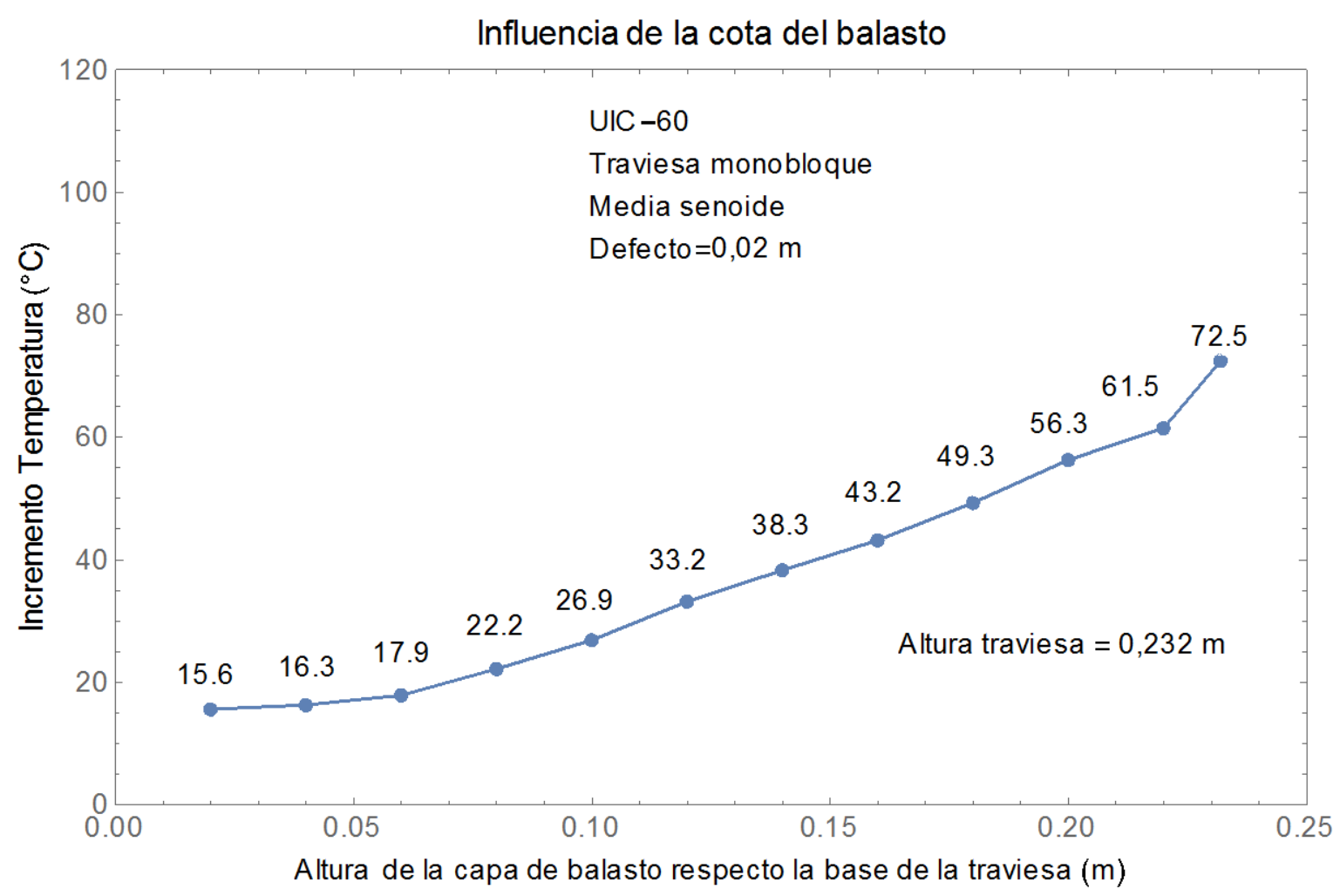

Figura 8.11: Temperatura de pandeo en función de la altura de la capa de balasto. Fuente: Elaboración propia.

Puede comprobarse como, al incrementarse la altura de la capa de balasto, aumenta también la temperatura de pandeo. Este comportamiento resulta coherente con el hecho de que, en la formulación desarrollada, el espesor condiciona el valor del empuje pasivo y, con ello, la resistencia lateral por punta y lateral de la traviesa.

Así, para valores reducidos de la altura de balasto y, con ello, de resistencia lateral, el pandeo se produce para valores de temperatura reducidos. Se observa que al pasar de los $4 \mathrm{~cm}$ a $10 \mathrm{~cm}$ el incremento es únicamente de $10,6^{\circ} \mathrm{C}$, mientras que cuando se pasa de $18 \mathrm{~cm}$ a $24 \mathrm{~cm}$ dicho valor alcanza $23,2^{\circ} \mathrm{C}$.

Este comportamiento muestra que la pérdida de resistencia es más pronunciada para los primeros centímetros, por lo que en la práctica resulta importante asegurar que la traviesa se encuentra suficientemente embebida en la capa de balasto, pues de lo contrario la reducción de la resistencia transversal en los primeros centímetros es bastante significativa. 


\subsubsection{Influencia de las cargas verticales}

Una ventaja más que ofrece la simulación desarrollada es la posibilidad de representar las cargas verticales debidas al peso de los vehículos. Su influencia en el pandeo está relacionada con el estado tenso-deformacional del balasto, así como el coeficiente de rozamiento traviesa-balasto y, en consecuencia, con la resistencia transversal, motivo por el cual se considera en este punto.

Para examinar estos efectos, se ha considerado dos valores de carga por eje, igual a $17 \mathrm{t}$ y 22 t. El espaciado entre cargas seleccionado es de 1,8 m, estando aplicada la carga de 17 t en el ancho ibérico y la de 22 t en el ancho estándar, por ser una situación representativa de los esfuerzos a los que se verá sometida una vía como la que se analiza en este estudio. El resto de parámetros, al igual que en los casos anteriores, se han considerado para sus valores nominales.

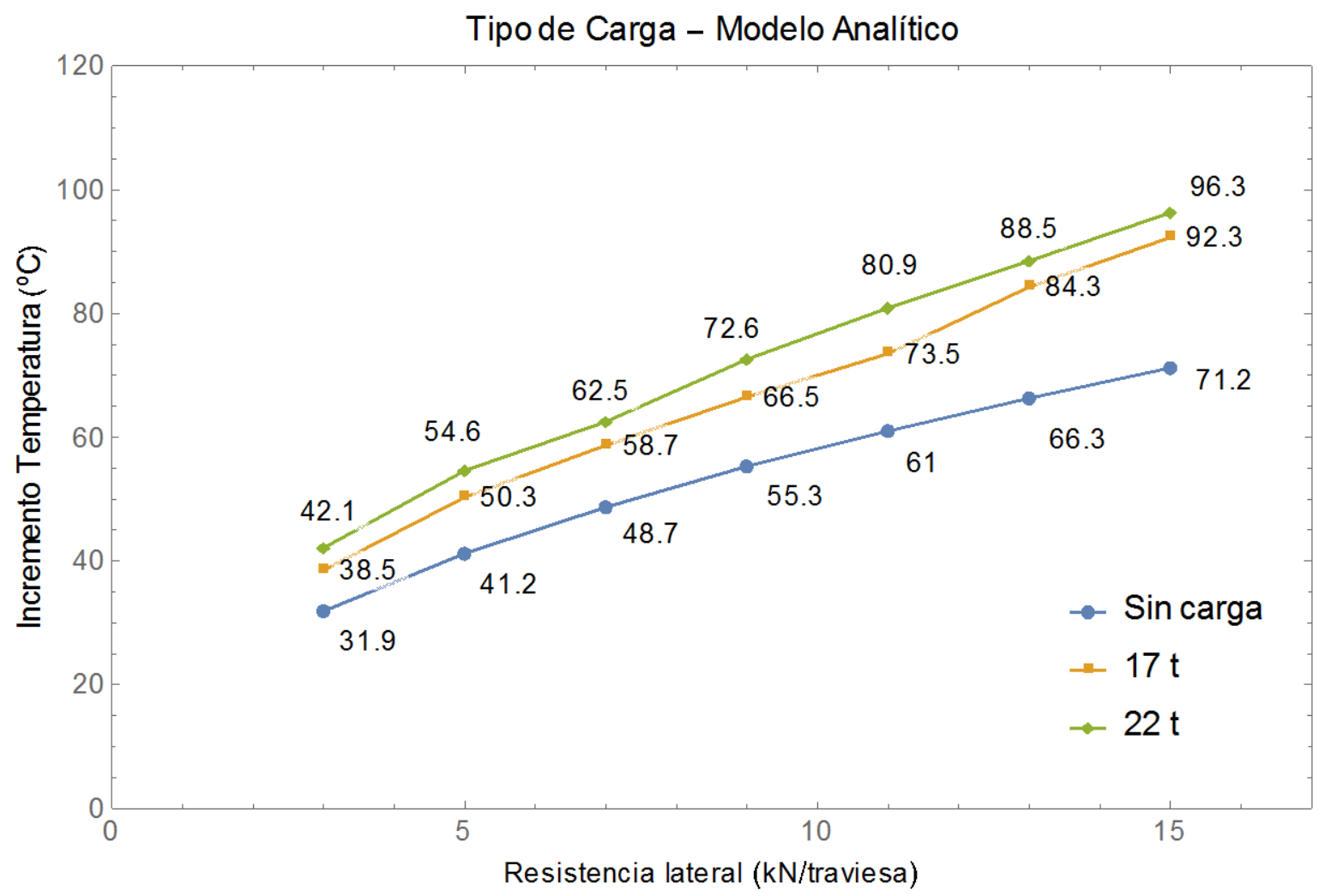

Figura 8.12: Temperatura de pandeo en función de la carga vertical aplicada (modelo analítico). Fuente: Elaboración propia. 


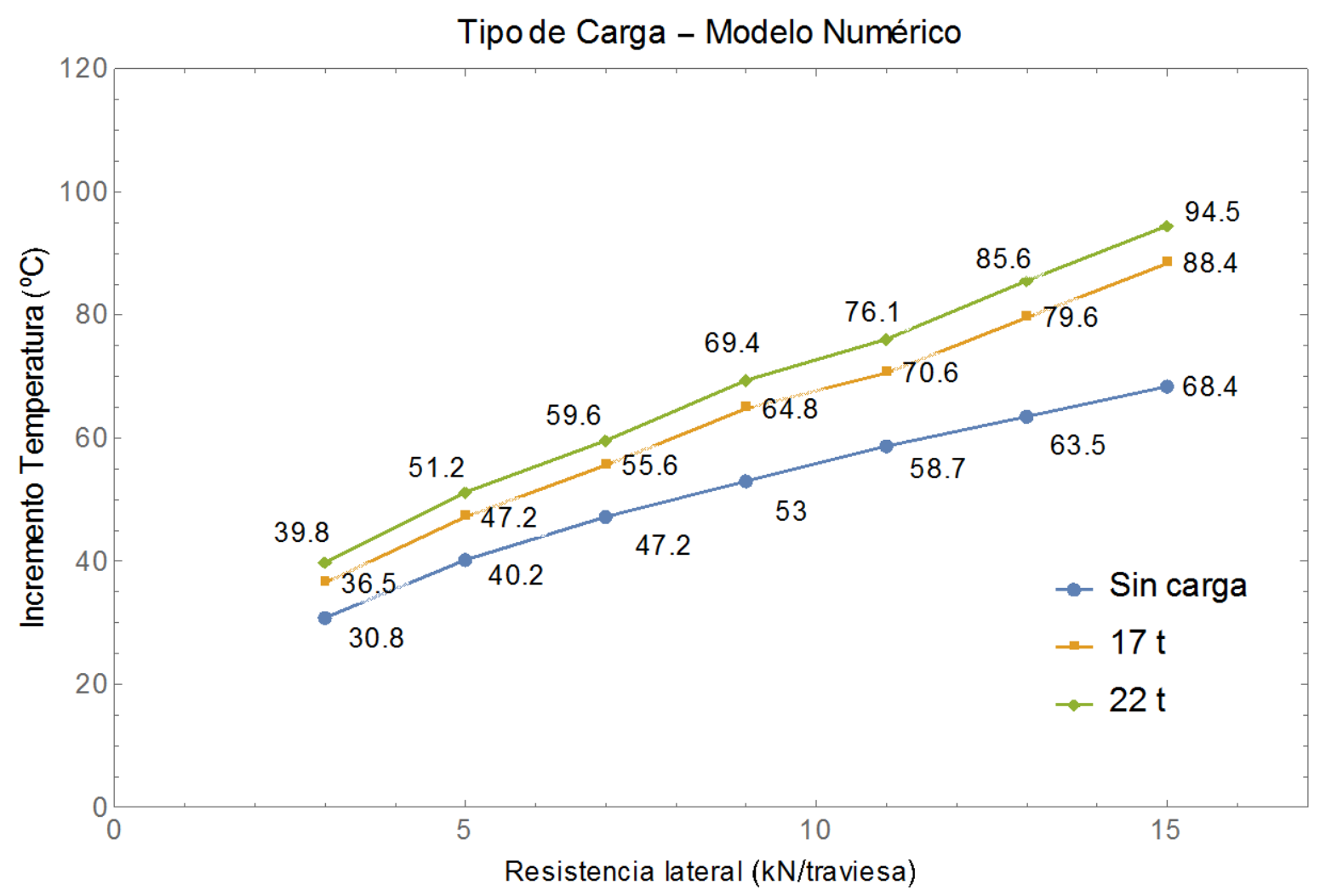

Figura 8.13: Temperatura de pandeo en función de la carga vertical aplicada (modelo numérico). Fuente: Elaboración propia.

En la Figura 8.12 y Figura 8.13 se han obtenido las curvas, para los diferentes casos de carga. En cada uno de las gráficas Se observa cómo, respecto del eje vertical de temperaturas, la curva más baja corresponde a la situación sin carga, mientras que la aplicación de cargas verticales desplaza la curva hacia la parte superior, por lo que aumentan las temperaturas resultantes. En concreto, el aumento de temperatura obtenido respecto de la situación sin carga es, aproximadamente, del 20\% para una carga de 17 t, mientras que aumenta hasta el $30 \%$ al considerar un eje de 22 t. Se observan los mismos resultados en ambos tipos de modelo, con un comportamiento similar.

La primera conclusión que se debe extraer de los resultados es que la consideración de cargas verticales produce una reducción de las temperaturas de pandeo calculadas. Este hecho afecta a la validez de los resultados obtenidos bajo la presencia de cargas verticales, pues la temperatura aquí obtenida está supeditada a que no se produzcan situaciones de despegue de las traviesas, fenómeno que, a priori, no puede ser adecuadamente representado. 
Con ello, el uso de los modelos desarrollados puede incurrir en una estimación no conservadora de la temperatura de pandeo, en el caso de emplear cargas verticales sin mayor consideración.

Teniendo en cuenta este inconveniente y para poder considerar el efecto del levante de la traviesa, se plantea la posibilidad de reducir el valor de la resistencia inicial considerada, lo que permite obtener una estimación del efecto negativo de la aplicación de cargas verticales. Si bien este procedimiento es una aproximación simplificada al mecanismo complejo analizado, permite obtener una estimación inicial, a falta de contrastar dichos valores con mediciones reales en vía. En aras de la brevedad, no se incluye dicho cálculo, por no aportar mayor relevancia al estudio.

\subsection{Análisis del pandeo en función de la amplitud del defecto}

Tal y como se ha descrito en capítulos anteriores, las irregularidades de geométricas de la vía constituyen una fuente importante de problemas estructurales que alteran la respuesta estática y dinámica de la vía, siendo además una de los factores básicos en la determinación de la calidad de la vía. Por ello, en el estudio del pandeo es habitual el empleo de defectos iniciales (Van, 1997, Kish y Samavedam, 1999, Lim et al. 2003; 2004a; 2004훌 2008, Pucillo, 2016), con los que se evalúa la temperatura de pandeo.

El objetivo de esta parte del trabajo es analizar la temperatura de pandeo en función de los defectos geométricos y más concretamente, los defectos de alineación. Para tal fin y siguiendo un procedimiento análogo al desarrollado previamente, se realiza el cálculo de la temperatura de pandeo en función de la amplitud del defecto, para los diferentes escenarios considerados. Para ello, los escenarios definidos se han simulado considerando un defecto geométrico puntual en el centro del tramo de vía, en un rango de valores entre los $0,005 \mathrm{~m}$ y 0,05 m. Este factor determina una deformación previa de la vía, influenciando la fuerza necesaria para desestabilizar la vía y, en consecuencia, la temperatura de pandeo.

Debe hacerse notar que, para los valores más elevados del defecto considerados la vía supera ampliamente los límites máximos permitidos por las normas de las administraciones ferroviarias en los trazados actuales. No obstante, se ha decidido incluir en el análisis el rango de valores seleccionado para, de ese modo, poder analizar desde un punto de vista teórico la influencia que el defecto posee sobre la estabilidad de la vía. 
Con estas premisas, de nuevo se han utilizado los dos modelos elaborados en la presente Tesis. Para facilitar el análisis de los resultados, la Tabla 8.2 recoge los valores de referencia representativos del conjunto de simulaciones realizadas.

\begin{tabular}{|c|c|}
\hline \multicolumn{2}{|c|}{ Condiciones de referencia } \\
\hline Condición & Valor \\
\hline Carril & UIC-60 \\
\hline Traviesa & Monobloque \\
\hline Tipo defecto & Media Senoide / lado 2 carriles \\
\hline Resistencia lateral & Sin carga \\
\hline Carga vertical & Recto \\
\hline Tramo de vía & \\
\hline
\end{tabular}

Tabla 8.2: Condiciones de referencia utilizadas en el cálculo, en función de la amplitud del defecto. Fuente: Elaboración propia.

Los valores de temperatura de pandeo obtenidos se representan en las gráficas correspondientes, analizándose en este caso el efecto del tipo de carril, traviesa y de defecto considerado.

\subsubsection{Variación de tipo de carril}

En primer lugar, la Figura 8.14 y Figura 8.15 muestran los valores de temperatura de pandeo para los diferentes tipos de carril, esta vez en función de la amplitud del defecto.

Los valores obtenidos muestran, de nuevo, el efecto perjudicial que posee el de carriles con mayor sección. Este resultado confirma el comportamiento observado, si bien ya se ha discutido sobre la conveniencia de no utilizar carriles con secciones reducidas por los posibles problemas de fatiga y agotamiento del material que esto conlleva.

En cuanto al comportamiento con una aproximación más genérica, se puede afirmar que la presencia de una mayor imperfección inicial conduce a temperaturas de pandeo menores. A medida que se incrementa el defecto, se requiere una menor energía para desestabilizar el sistema, debido a que la excentricidad de las cargas aumenta y, con ello los esfuerzos. 
Como ejemplo, la temperatura se reduce, aproximadamente, un $40 \%$ cuando se pasa de un defecto inicial de 0,01 $\mathrm{m}$ a un defecto de 0,03 m. Este comportamiento se manifestará, tal y como puede comprobarse más adelante, para todos los casos analizados.

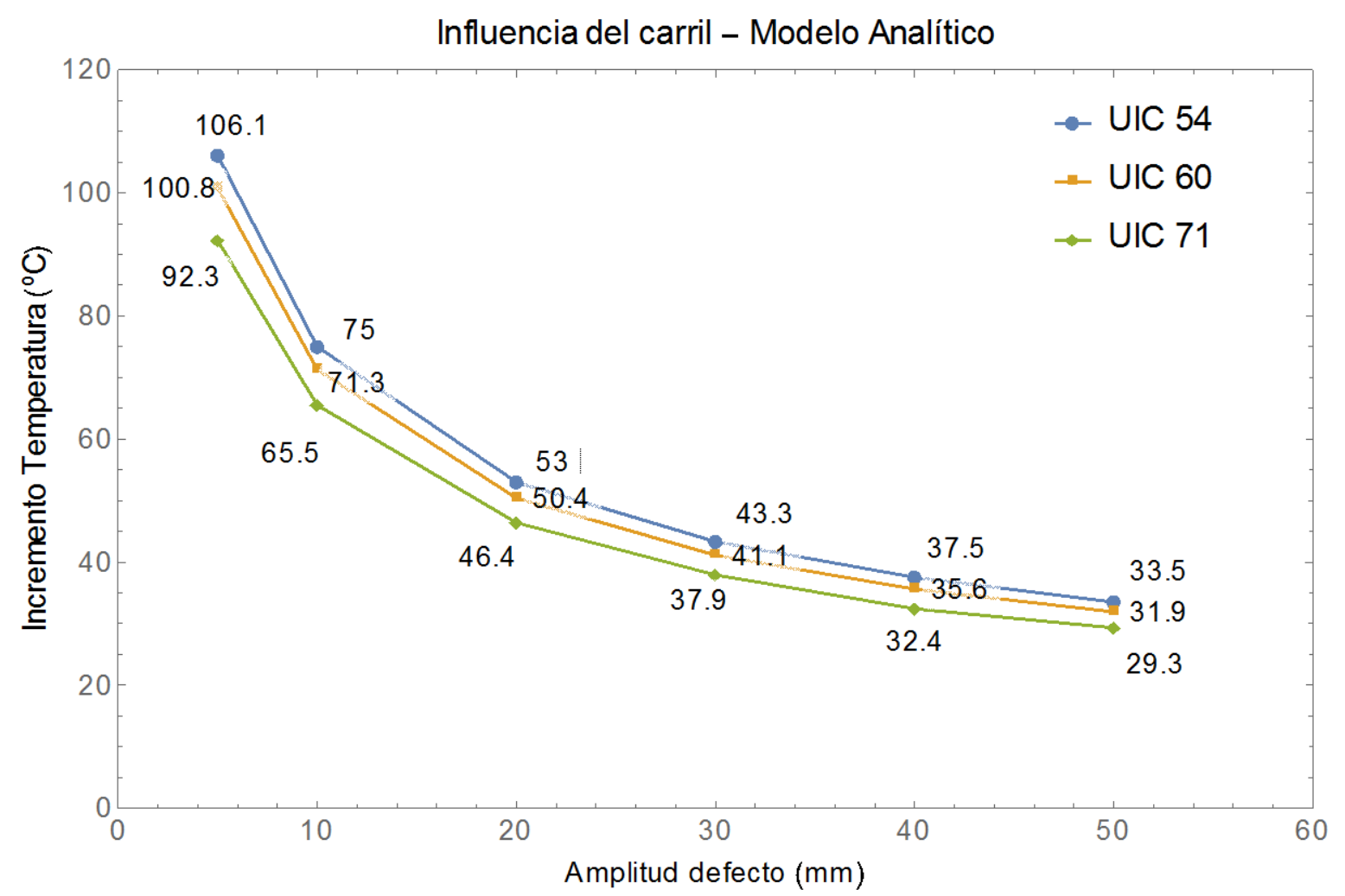

Figura 8.14: Temperatura de pandeo en función del tipo de carril (modelo analítico). Fuente: Elaboración propia. 


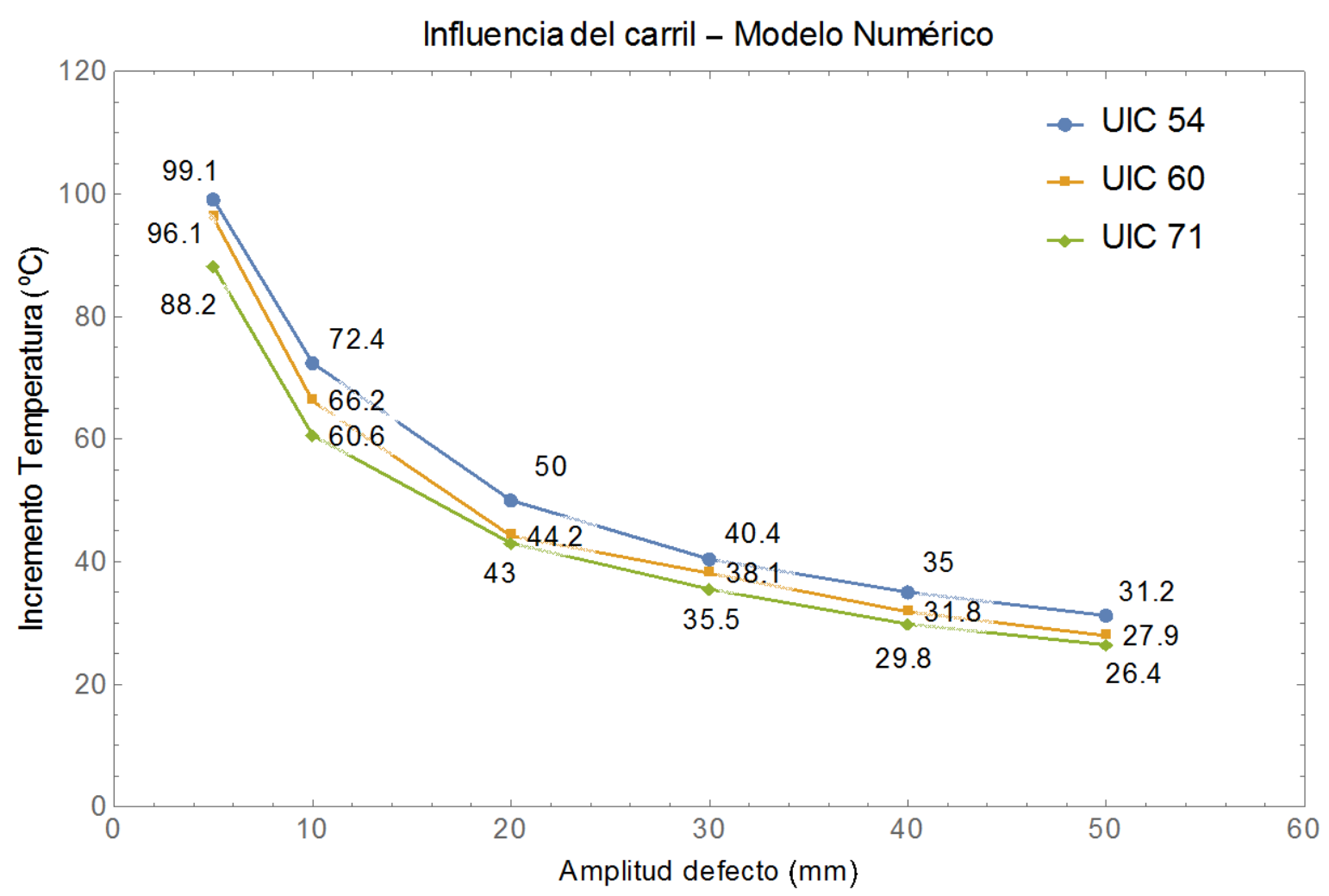

Figura 8.15: Temperatura de pandeo en función del tipo de carril (modelo numérico). Fuente: Elaboración propia.

Además, se comprueba como la respuesta de la vía es mucho más sensible en un rango de defectos entre los 0 y los 0,02 m. A partir de dicho valor, la curva reduce su pendiente, si bien se alcanzan valores de temperatura por debajo de $40^{\circ} \mathrm{C}$, lo que pone en riesgo real la estabilidad de la vía.

De igual forma que sucede con la resistencia lateral, la inclusión de defectos iniciales ocasiona una reducción de la carga de pandeo obtenida, siempre tomando las precauciones oportunas para evitar posibles efectos de interacción con el resto de variables.

\subsubsection{Variación tipo de traviesa}

A continuación, se muestran los resultados, para los dos tipos de traviesa considerados, en función del defecto inicial. La Figura 8.16 y Figura 8.17 muestran los valores de temperatura de pandeo obtenidos, en cada caso. 


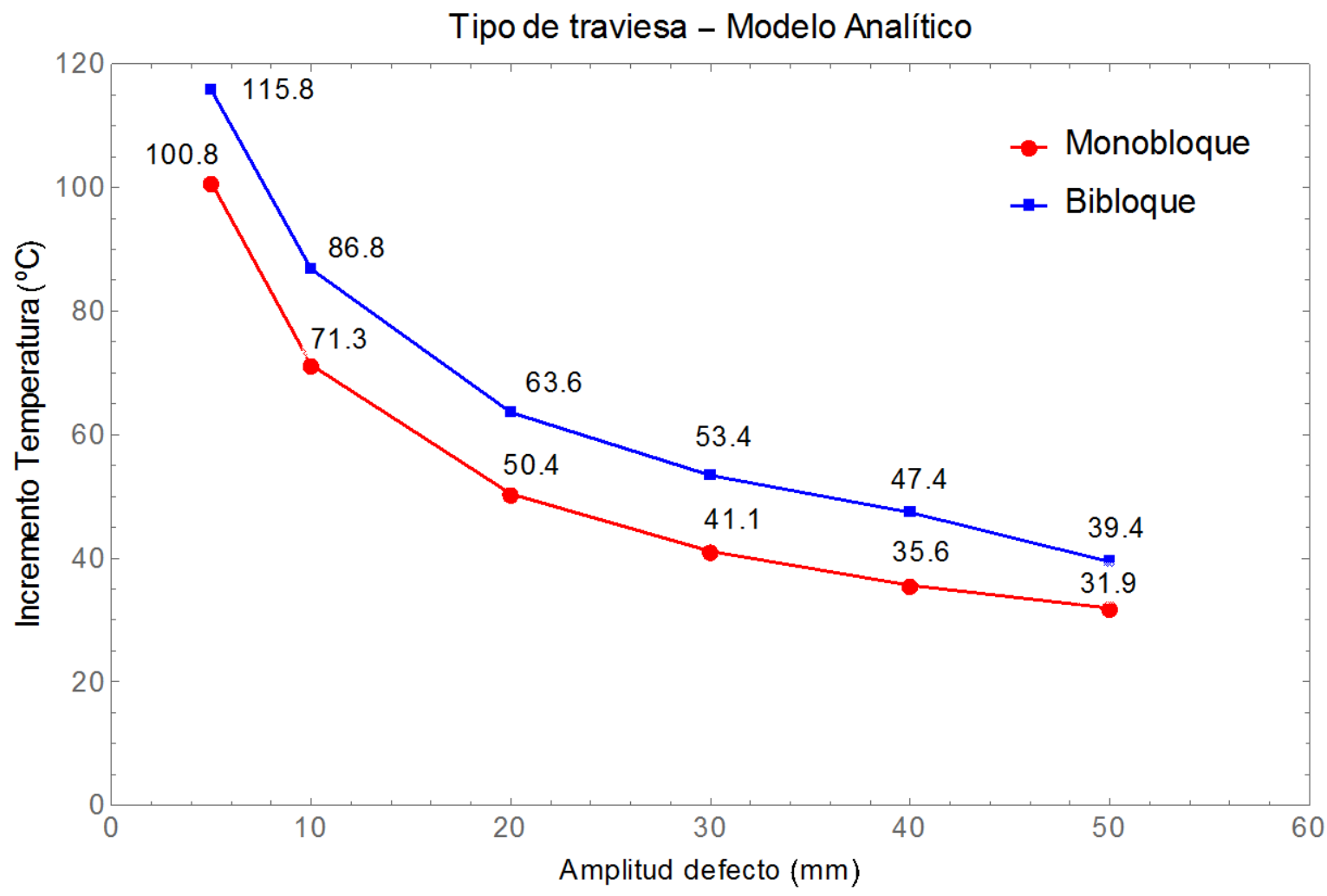

Figura 8.16: Temperatura de pandeo según el tipo de traviesa y de la amplitud del defecto. Fuente: Elaboración propia.

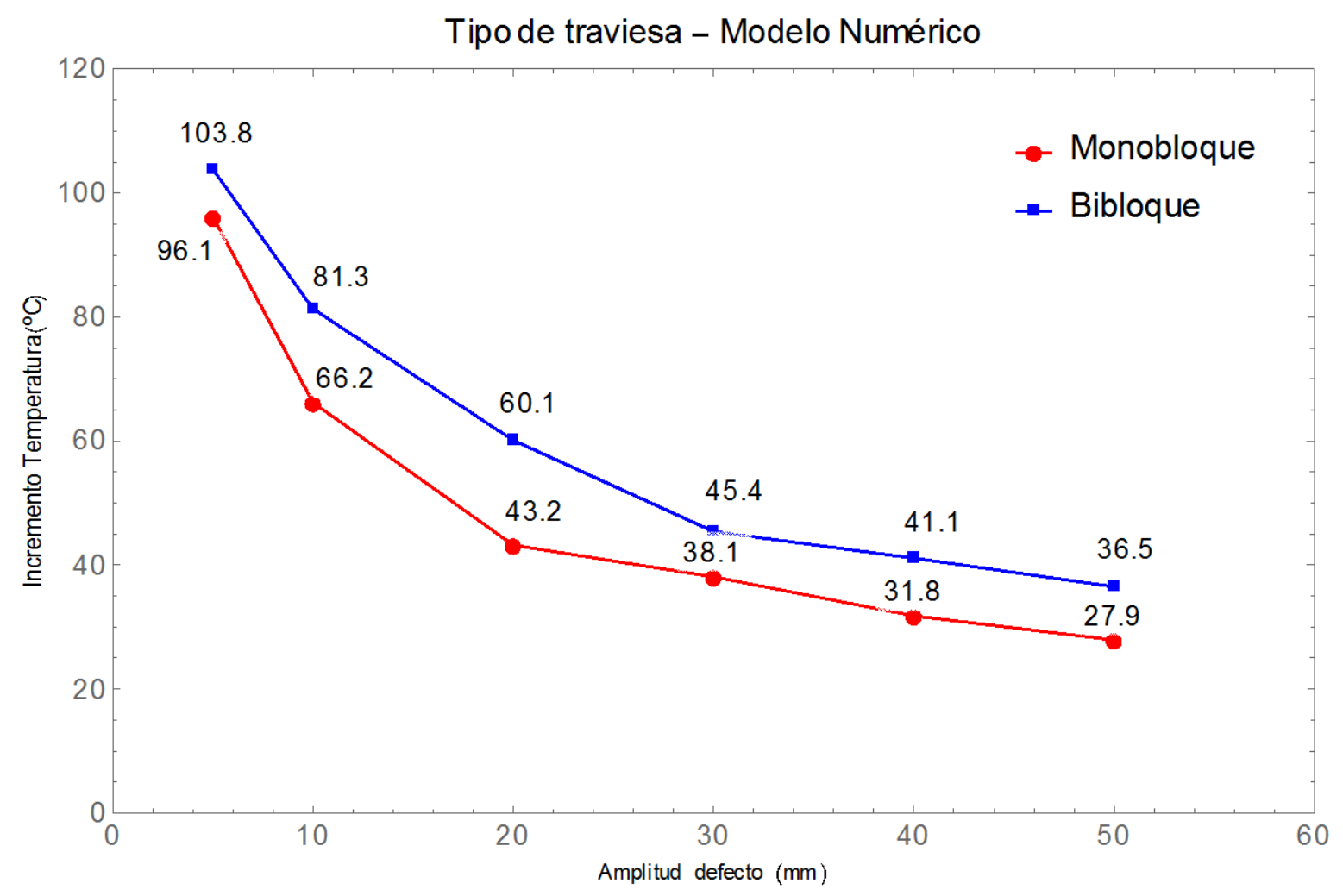

Figura 8.17: Temperatura de pandeo según el tipo de traviesa y de la amplitud del defecto. Fuente: Elaboración propia. 
Se observa que las curvas presentan, para cada tipo de traviesa, resultados consistentes. Las temperaturas evolucionan con el defecto inicial según la tendencia esperada. En cuanto a los valores absolutos, se obtiene unas temperaturas de pandeo por debajo de $40^{\circ} \mathrm{C}$ para valores del defecto del orden de $0,024 \mathrm{~m}$ en las traviesas monobloque, mientras que hay que alcanzar valores por encima de los 0,042 $\mathrm{m}$ en el caso de las traviesas bibloque.

\subsubsection{Variación tipo de defecto}

En este caso se analiza la influencia del tipo de defecto, en función de la amplitud del mismo, haciendo uso del modelo analítico, pues ya se ha comentado la imposibilidad de utilizar el modelo numérico para tal fin.

Tipo de defecto - Modelo Analítico

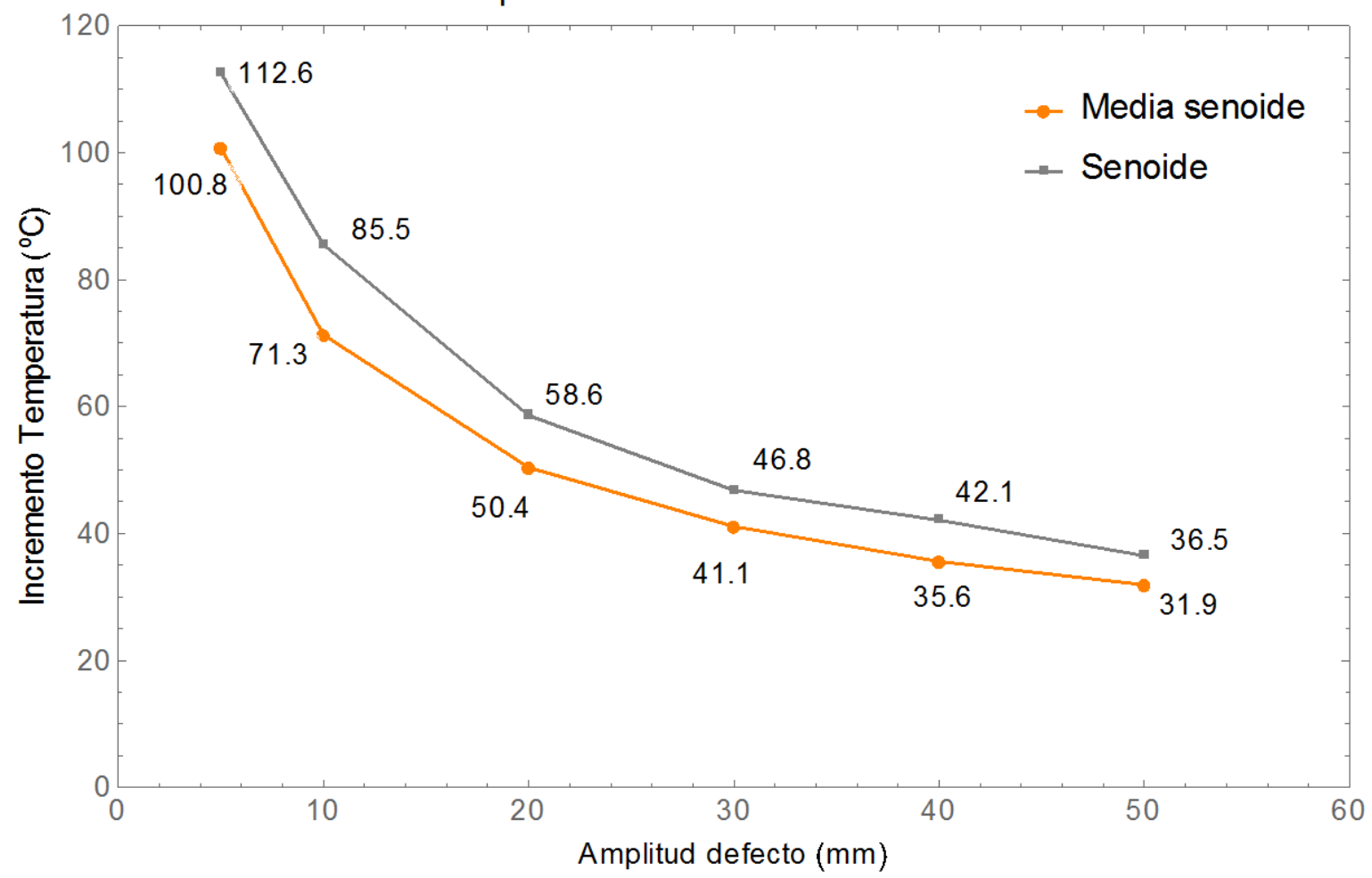

Figura 8.18 Temperatura de pandeo en función del tipo y de la amplitud del defecto. Fuente: Elaboración propia.

Como en los puntos anteriores, en la Figura 8.18 se muestran las temperaturas asociadas al problema de pandeo en el rango considerado y para el tipo de defecto analizado. En 
particular y tomando como referencia los valores para el defecto en forma de media senoide, los valores de temperatura de pandeo para el caso de defectos senoidales son un $15 \%$ superiores.

Estos resultados ponen de manifiesto que la temperatura de pandeo puede está influenciada por los escenarios donde se combina el tipo y la magnitud del defecto.

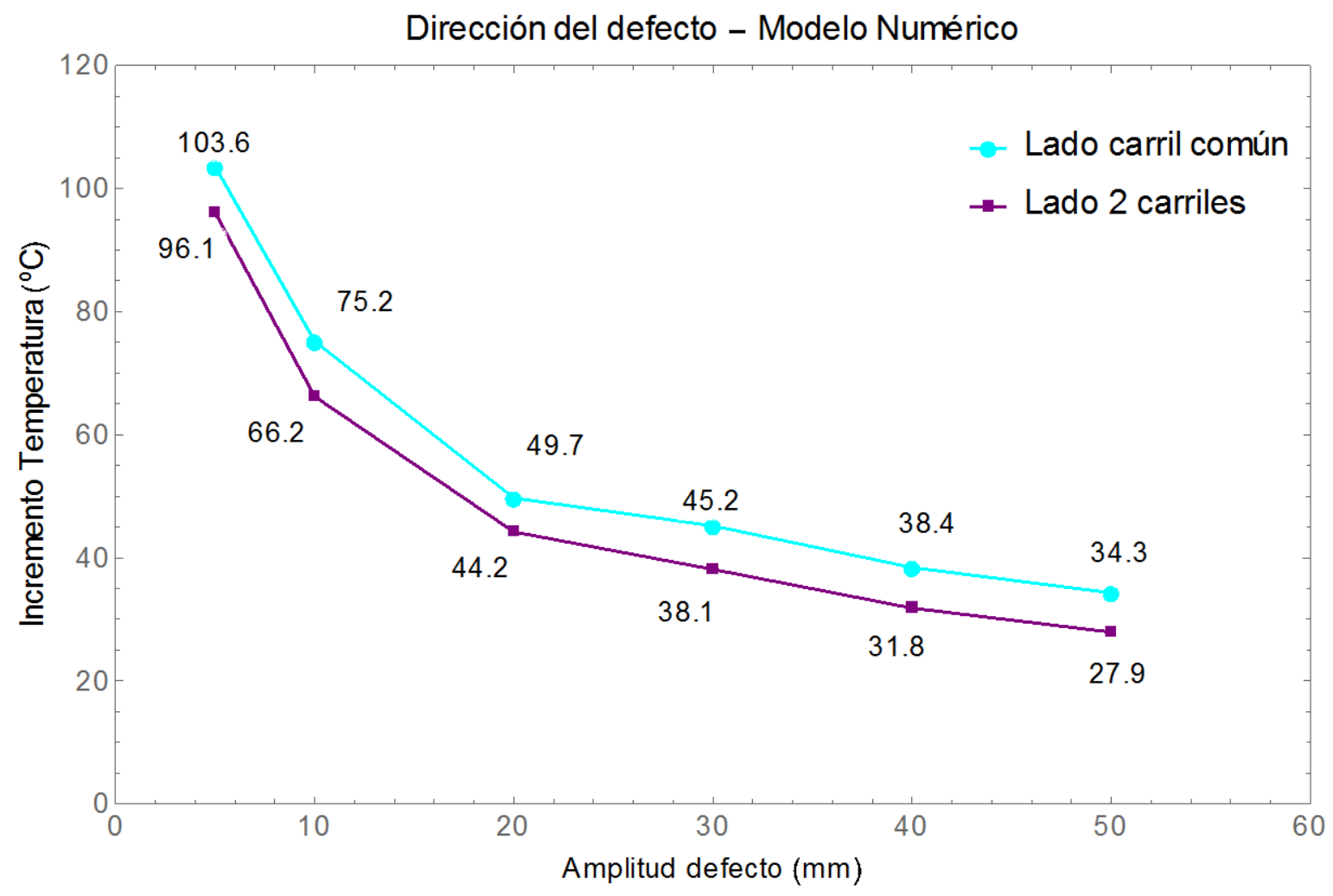

Figura 8.19: Temperatura de pandeo en función del lado del defecto, según la amplitud. Fuente: Elaboración propia.

También resulta interesante y, al igual que se ha realizado anteriormente, el estudio del lado en el que se encuentra el defecto, debido a la asimetría que plante la posición del tercer carril. Para ello y haciendo uso del modelo numérico, en la Figura 8.19 se observa cómo los valores mínimos se obtienen para las irregularidades cuyo defecto se produce hacia el exterior del lado donde se localizan los dos carriles. Ello se debe tal y como se ha justificado anteriormente, a la excentricidad de las cargas, pues el lado más desfavorable es aquel donde la resultante de momentos aumenta en mayor grado. 
Adicionalmente, se ha podido verificar que la metodología empleada para el estudio del pandeo en vías de doble ancho mediante el modelo analítico y numérico presentados resulta una buena aproximación para el cálculo de este tipo particular de superestructura.

Ha podido comprobarse a su vez que las temperaturas de pandeo a las que la vía puede desestabilizarse alcanzan, en los casos más desfavorables, valores alrededor de los $30^{\circ} \mathrm{C}$, las cuales ponen de manifiesto un elevado riesgo de que se produzca el pandeo ante los esfuerzos generados por el aumento de temperatura en los carriles.

\subsection{Comparativa con vías convencionales}

Tanto el modelo analítico como el numérico desarrollado y utilizado en la presente Tesis han sido aplicados mediante el uso de valores que se estiman como representativos de la vía analizada. El objeto de esta aplicación ha sido llevar a cabo un estudio numérico para comparar casos teóricos representativos y analizar la variabilidad de los resultados.

Sin embargo, la gran trascendencia del fenómeno requiere una mayor profundidad de análisis, especialmente por las interacciones resultantes entre los diversos parámetros. En este sentido, hasta el momento no es evidente si la mayor resistencia y rigidez aportada por el nuevo carril llega a ser compensada o superada por el mayor esfuerzo longitudinal que produce el mismo.

Ante esta situación, parece razonable contrastar los resultados obtenidos con los que se obtienen para vías convencionales, de forma que los modelos puedan orientarse a la toma de decisiones prácticas. Al realizar el análisis pormenorizado de las vías de doble ancho, en primer lugar, por separado y, en segundo lugar, mediante su comparativa con vías convencionales, se pueden confrontar y establecer relaciones, lo que permite observar el cambio producido por la presencia de un tercer carril.

Dicho esto y para llevar a cabo la comparativa, en un primer momento se ha pensado utilizar las curvas obtenidas por diversos investigadores, mediante modelos más o menos similares a los planteados en esta Tesis. Pese a que el análisis del pandeo en vías es un aspecto bastante analizado y sigue siendo muy actual (Grisson y Kerr, 2006; Lim et al. 2008; Arbabi, y Khalighi, 2010; Choi y Na, 2010; Yaping et al. 2010; Kish y Samavedam, 2013; Navarro et al. 2015; Pio Pucillo, 2016), los resultados obtenidos en cada caso no son 
directamente comparables, pues no existe un consenso claro respecto a las variables y magnitudes consideradas por cada autor.

Por esta razón, se ha decidido utilizar los modelos desarrollados en la presente Tesis, pues las curvas obtenidas de esta forma sí permiten comparar los resultados bajo los mismos criterios y restricciones, lo que permite llevar a cabo una comparativa mucho más objetiva de los resultados.

Para tal fin, se ha trabajado sobre el modelo analítico y numérico, de forma que se ha suprimido el tercer carril de la modelización, manteniendo el resto de condiciones ya descritas. De esta forma, es posible calcular la curva de pandeo, esta vez en vías de un solo ancho.

Es importante destacar, de nuevo, que los resultados no corresponden a datos reales de las variables, sino que son resultados de simulaciones para las que se han utilizado valores genéricos representativos. Así pues, la comparativa se realiza para un tramo de vía de 50 $\mathrm{m}$ de longitud, con carriles UIC-60 y traviesas de hormigón pretensado, tal y como se recoge en la Tabla 8.3. El cálculo se realiza por partida doble, empleando el modelo analítico y numérico, cuyos resultados se recogen en las gráficas correspondientes.

\begin{tabular}{|c|c|c|}
\hline \multicolumn{3}{|c|}{ Valores característicos de referencia } \\
\hline Parámetros & Vía ancho ibérico & Vía doble ancho \\
\hline Carriles & 2 carriles / UIC 60 & 3 carriles / UIC 60 \\
\hline Traviesas & Monobloque (PR-01) & Monobloque (AM-05) \\
\hline $\begin{array}{c}\text { Condiciones con- } \\
\text { torno }\end{array}$ & Long: $50 \mathrm{~m}$ & Long: $50 \mathrm{~m}$ \\
\hline $\begin{array}{c}\text { Resistencia lateral } \\
\text { Defecto longitudinales }\end{array}$ & Elástico lineal (3-15 kN/trav) & Elástico lineal (3-15 kN/trav) \\
\hline Carga vertical & Media senoide (0,005/ 0,05 m) & Media senoide (0,005 / 0,05 m) \\
\hline Sin carga & Sin carga \\
\hline
\end{tabular}

Tabla 8.3: Valores de referencia utilizados en el cálculo, para vías de 2 y 3 carriles. Fuente: Elaboración propia. 


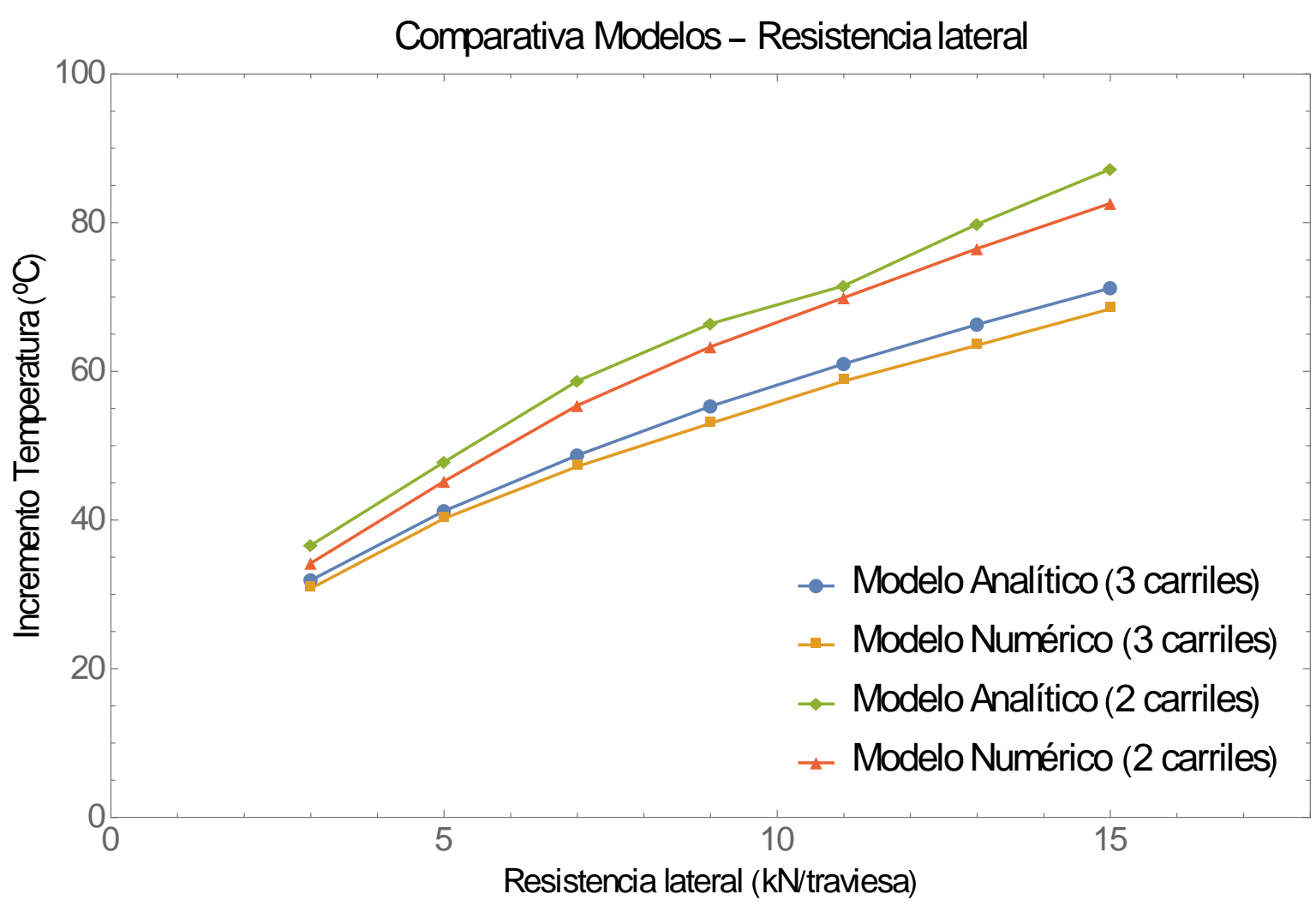

Figura 8.20: Comparativa de temperaturas de pandeo para vías de 2 y 3 carriles, en función de la resistencia transversal. Fuente: Elaboración propia.

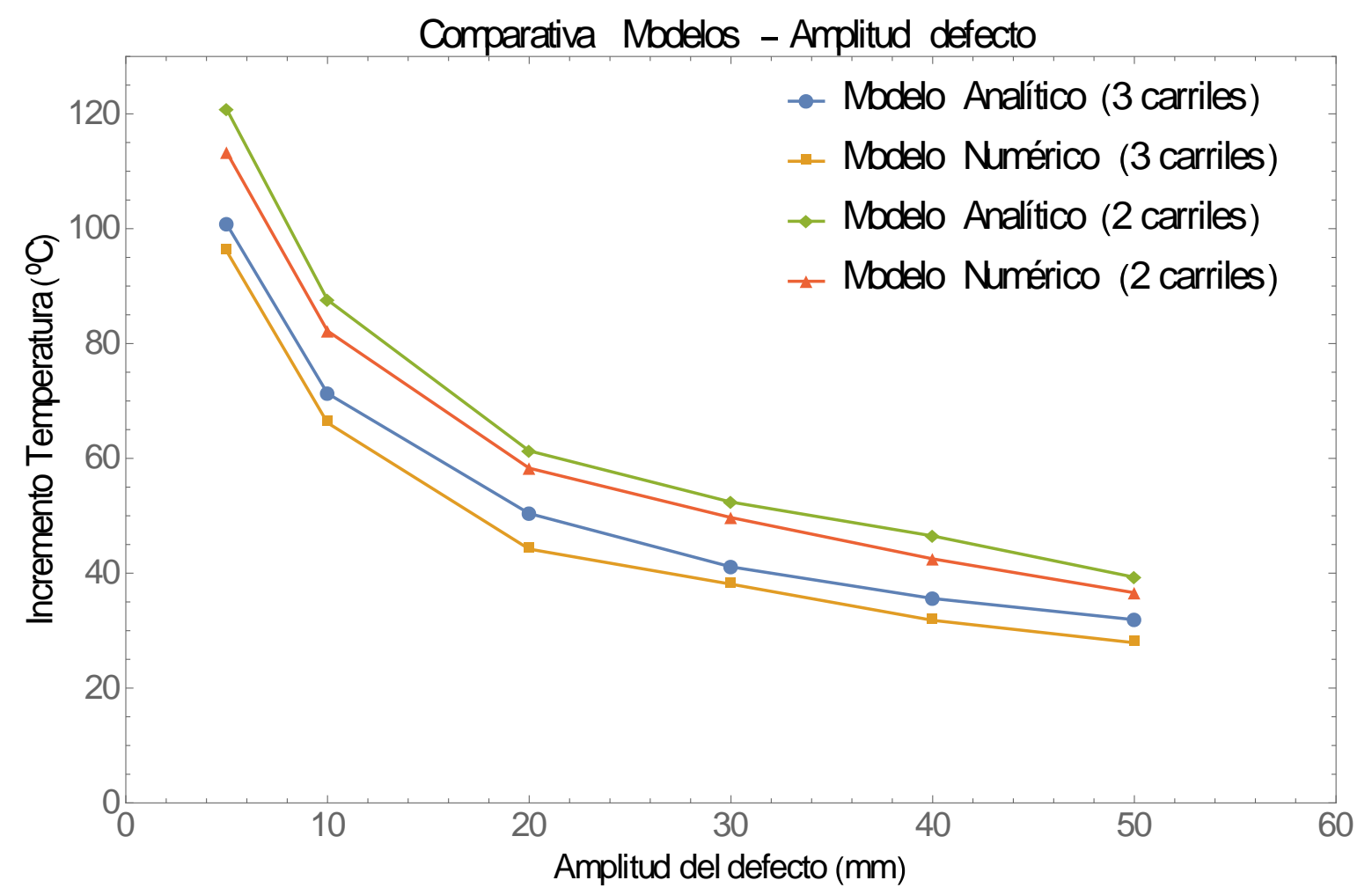

Figura 8.21: Comparativa de temperaturas de pandeo para vías de 2 y 3 carriles, en función del defecto, para diversos modelos. Fuente: Elaboración propia. 
Los resultados comparativos son mostrados gráficamente en la Figura 8.20 y Figura 8.21, en función de la resistencia transversal y la amplitud del defecto. Así pues, de las cuatro curvas que se presentan en cada figura, dos de ellas corresponden a vías convencionales y las otras dos, a vías de doble ancho, estando las temperaturas dominadas por las variables fundamentales utilizadas. Si bien las conclusiones que pueden derivarse se limitan al conjunto de valores obtenidos, no es menos cierto que los resultados permiten obtener algunas conclusiones interesantes.

Comparando los resultados obtenidos, se detectan valores relativamente distintos para cada tipología de vía. En concreto se observa cómo, a igualdad de condiciones, las temperaturas de pandeo para las vías de doble ancho son inferiores a las que se obtienen para vías convencionales. La diferencia observada es algo más acusada cuanto mayor es la resistencia transversal, mientras en el caso de la amplitud del defecto, se mantienen a lo largo de todo el rango estudiado. Estas diferencias (entre vía convencional y mixta) aparece en todos los casos por igual, siendo la máxima diferencia del orden del $20 \%$.

Considerando los resultados obtenidos y teniendo en cuenta lo expuesto en los apartados anteriores, puede concluirse que, para un determinado incremento de temperatura, la fuerza desestabilizante es de mayor magnitud en las vías de doble ancho frente a las vías convencionales de un solo ancho. Este comportamiento se debe al dominio de los esfuerzos frente a la resistencia que produce la presencia de un tercer carril, por lo que la tendencia al pandeo se ve favorecida.

Estos resultados plantean la necesidad de reflexionar sobre la seguridad de la estructura de doble ancho, pues la reducción de las temperaturas de pandeo repercute sobre el margen de seguridad, reduciéndolo si se mantienen las condiciones de instalación y mantenimiento utilizadas hasta el momento.

\subsection{Estudio del riesgo de pandeo}

El estudio realizado hasta el momento ha permitido obtener y determinar los valores de las temperaturas en los carriles por encima de los cuales se produciría el pandeo. El uso de una temperatura crítica o máxima como valor de referencia para prevenir el pandeo está basado en el hecho de que dicho valor "garantiza" la seguridad de la vía con carril continuo soldado, pues solo por encima de dicho valor puede producirse el pandeo. Las investigaciones respecto del pandeo muestran que para esta temperatura la energía necesaria para 
desestabilizar la vía es considerable, por lo que proporciona un valor bastante conservativo asociado a un elevado nivel de seguridad. También se debe tener en cuenta la existencia de otros factores adicionales no considerados en el cálculo como los esfuerzos dinámicos de los vehículos o las cargas de impacto por lo que la determinación de una temperatura mediante la metodología expuesta hasta este momento permite tener un cierto margen de seguridad frente estos esfuerzos adicionales.

Así pues, el análisis realizado previamente conduce a una aproximación determinística, en el sentido que todos los parámetros considerados son expresados mediante valores constantes y preestablecidos. Esta forma de operar posee un cierto riesgo, pues en ocasiones es posible encontrar valores reducidos de la resistencia de la vía que, asociados a eventos con altas temperaturas, pueden conducir al pandeo. Por ello, el análisis determinístico plantea una gran dificultad a la hora de encontrar una metodología práctica de mantenimiento, en la que se pueda incluir en el cálculo a pandeo de forma eficaz. La realidad muestra que tanto la magnitud como la variabilidad de cada uno de los parámetros de vía no suele ser conocido ni constante a lo largo de un determinado tramo de vía.

Para alcanzar una mejor aproximación en cuanto a los parámetros estructurales que se deben controlar y, a su vez, establecer una metodología que permita minimizar los costes de conservación y explotación en vías de doble ancho, es necesario ir un paso más allá.

En condiciones reales, algunas variables como la resistencia lateral, los defectos de vía, la temperatura de los carriles, etc. varían de un punto a otro, por lo que pueden ser modelizadas de forma más adecuada mediante distribuciones estadísticas. El uso de estas distribuciones permite la evaluación del riesgo de pandeo mediante un factor que determina la seguridad de la infraestructura. Este tipo de metodología es habitual en otros campos de la ingeniería, como en el nuclear o la aviación, donde su aplicación ha demostrado tener grandes beneficios.

Así, el enfoque aquí planteado es coherente con los trabajos desarrollados por el comité ERRI D202/RP 10 y la ficha UIC 518, así como con las importantes contribuciones científicas que utilizan metodologías probabilísticas para el estudio del pandeo en vías [Kish y Samavedam (1999; 2004; 2013), Bae et al. 2014].

Mediante esta aproximación probabilística, la capacidad resistente a compresión de una determinada vía no se obtiene como un valor determinístico, sino que se asocia una curva 
que define la probabilidad de fallo bajo unas determinadas condiciones. Este tipo de análisis realmente es importante pues:

- La vía no puede ser diseñada, mantenida y operada para cada posible escenario de vía.

- Existe siempre una pequeña probabilidad de riesgo asociada a ciertos factores externos, así como por la ausencia de medidas reales y continuas de los parámetros que controlan el pandeo.

\subsubsection{Metodología}

Al analizar la probabilidad de fallo de una determinada estructura se confrontan, como norma general, la capacidad resistente y la fuerza aplicada. Cuando la resistencia de la estructura supera considerablemente los esfuerzos resultantes de las fuerzas aplicadas, nos encontramos en una situación favorable respecto a la estabilidad de la misma. Por el contrario, cuando los esfuerzos son claramente superiores a la capacidad de resistir cargas, la estructura colapsa. Entre estas dos situaciones nos encontramos con un conjunto de diferentes escenarios, cuya estabilidad se determina en base a la probabilidad de fallo.

Esta situación puede ser representada de forma gráfica en la Figura 8.22, donde los esfuerzos y la resistencia de la estructura se encuentran sobre el eje de abscisas (eje $X$ ), mientras que su distribución o probabilidad se encuentra en el eje de ordenadas (eje Y).

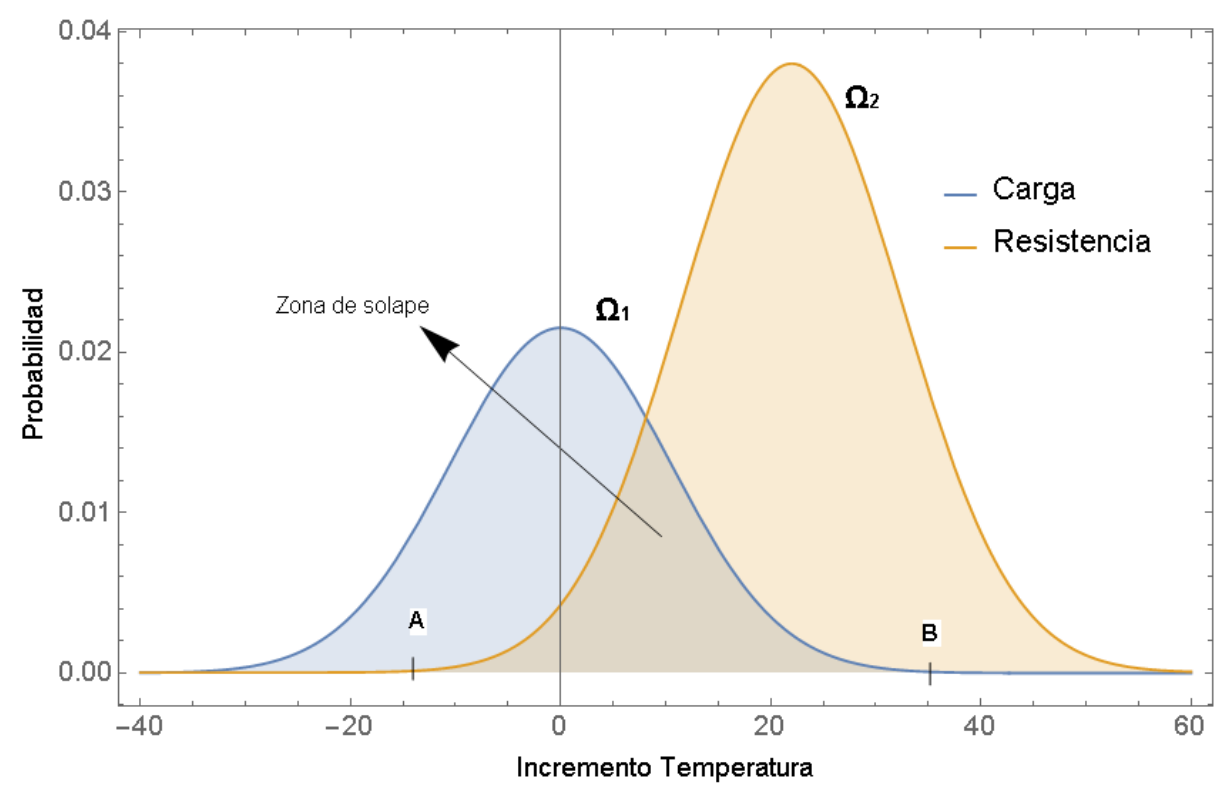

Figura 8.22: Esquema de distribución y zona de interferencia. Fuente: Elaboración propia. 
En el caso del pandeo, la carga o compresión longitudinal puede ser expresada mediante su equivalente como incremento de temperatura respecto de la temperatura de neutralización $\left(\Delta T_{\text {carga }}\right)$, de la misma forma que la resistencia o estabilidad de la vía $\left(\Delta T_{\text {resistencia }}\right)$. Con ello, se tiene:

$$
\begin{gathered}
\Delta T_{\text {carga }}=t_{\text {carril }}-t_{n} \\
\Delta T_{\text {resistencia }}=\Delta T_{\text {calculada }}
\end{gathered}
$$

donde $\Delta T_{\text {calculada }}$ se refiere a la temperatura máxima admisible a partir de la cual se produce el pandeo (calculada mediante modelos de simulación).

En una aproximación clásica, el criterio de pandeo considera estable la vía cuando se verifica $\Delta T_{\text {carga }} \leq \Delta T_{\text {resistencia }}$, mientras que la vía pandea si se alcanza una situación donde $\Delta T_{\text {carga }}>\Delta T_{\text {resistencia }}$.

Bajo una perspectiva probabilística, la zona de solape de ambas curvas representa los estados donde existe la posibilidad de que la fuerza exterior iguale o, en su caso, exceda la resistencia de la vía, pudiendo ocasionar el pandeo. Por ello, la probabilidad de fallo por pandeo respecto de la temperatura viene representada por el área de intersección de ambas curvas (la propia zona de solape), cuya expresión toma la siguiente forma y es conocida como "integral de convolución":

$$
P_{\text {pandeo }}=\int_{A}^{B} \Omega_{1}\left[\Omega_{2} d \Delta T\right] d \Delta T
$$

donde $P_{\text {pandeo }}$ es la convolución de las funciones $\Omega_{1}$ y $\Omega_{2}$

Así pues, la metodología que se propone considera la probabilidad de pandeo en vías de doble ancho mediante el uso de distribuciones estadísticas de los siguientes factores: resistencia lateral, defectos de vía. Tal y como se ha citado previamente, esta metodología es similar a la ya descrita en Kish y Samavedam (1999; 2013). Otros parámetros como la resistencia longitudinal, la resistencia a torsión de las sujeciones, el tipo de carril, etc. tienen una menor influencia en comparación con los dos factores principales, por lo que no son considerados en el estudio probabilístico. 
Recordemos que el objetivo final propuesto es aquel de obtener la probabilidad de pandeo en vías de doble ancho, considerando para ello las variables de resistencia lateral y amplitud del defecto mediante distribuciones de probabilidad. Por lo tanto, no se trata de buscar únicamente una determinada temperatura de pandeo, sino una curva en la que cada incremento de temperatura venga asociado una probabilidad de fallo, bajo unas determinadas condiciones.

La principal dificultad de este proceso es precisamente encontrar la distribución adecuada que representa a cada una de las variables consideradas. La secuencia de cálculo es la siguiente:

1. Para un determinado tramo de estudio, determinación de los parámetros de entrada de la vía como: carriles (áreas, inercias, posición), traviesas, resistencia a torsión, rigidez vertical, etc. necesario para el modelo analítico y/o numérico.

2. Determinación de las funciones de densidad probabilidad para las temperaturas (cargas) y la resistencia de la vía, en función de la resistencia lateral y la amplitud de los defectos.

3. Obtención de la probabilidad de pandeo, para cada valor de temperatura, mediante la integral de convolución.

\subsubsection{Función de densidad de los esfuerzos $\left(\Omega_{1}\right)$}

Cuando se analiza la temperatura de los carriles, son múltiples los factores ambientales y climáticos que condicionan su valor como la localización, la orientación, la exposición al sol y el viento, la presencia de lluvia, la composición del aire, la nubosidad, etc. Generalmente y como simplificación empírica es posible aproximar la temperatura de los carriles como función directa de la temperatura ambiental, a través de la ecuación propuesta por Hunt (1994):

$$
T_{\text {carril }} \approx \frac{3}{2} T_{\text {ambiental }}
$$

donde $T_{\text {carril }}$ y $T_{\text {ambiental }}$ son la temperatura de los carriles y la temperatura ambiental, expresadas en grados centígrados.

Con esta sencilla formula, dado un determinado perfil de temperaturas ambientales máximas a lo largo de un año, es posible obtener la curva de esfuerzos $\Omega_{1}$ haciendo uso de la 
ecuación 8.1, a la que se resta la temperatura de neutralización (recuérdese que la temperatura de neutralización es aquella donde los carriles están libres de esfuerzos), dando como resultado la curva de carga. Para facilitar el entendimiento del proceso, la Figura 8.23 muestra un ejemplo.

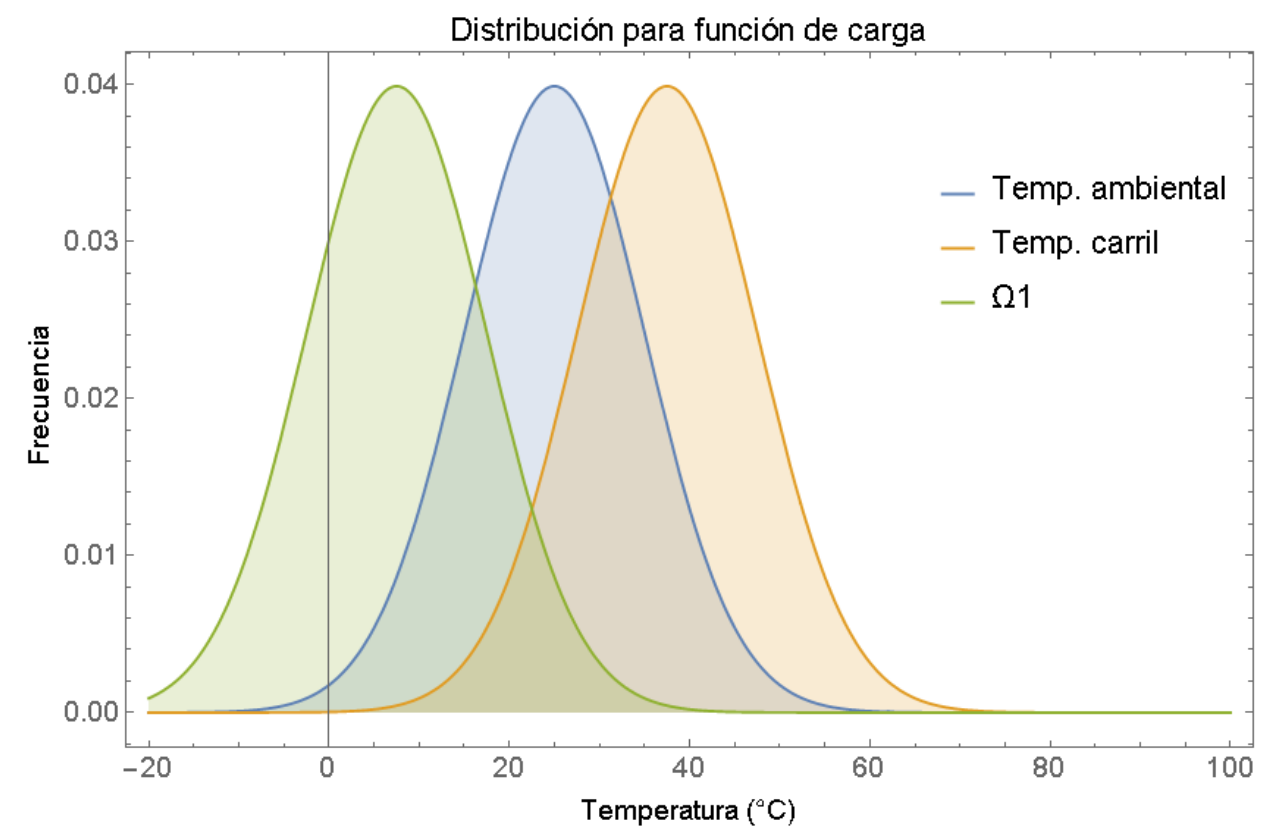

Figura 8.23: Ejemplo de distribución de densidad para la carga. Fuente: Elaboración propia.

\subsubsection{Función de densidad para la resistencia $\left(\Omega_{2}\right)$}

La obtención de la curva de resistencia se obtiene como combinación de las dos variables fundamentales consideradas: resistencia lateral y amplitud del defecto.

\section{$\underline{\text { Resistencia lateral }}$}

La resistencia lateral de cualquier vía no es un valor constante, sino que varía punto a punto, no solo por las diferentes configuraciones del emparrillado (cambios de tipología de traviesa, de sujeciones, diferente consolidación del balasto) sino también por el estado y mantenimiento de sus elementos.

Si bien la variabilidad de la resistencia lateral puede ser muy aleatoria, una buena aproximación se obtiene si se considera distribuida según una función normal o "gaussiana" (Figura 8.24). En este sentido, ensayos como el SPTP puede proporcionar mayor información. 


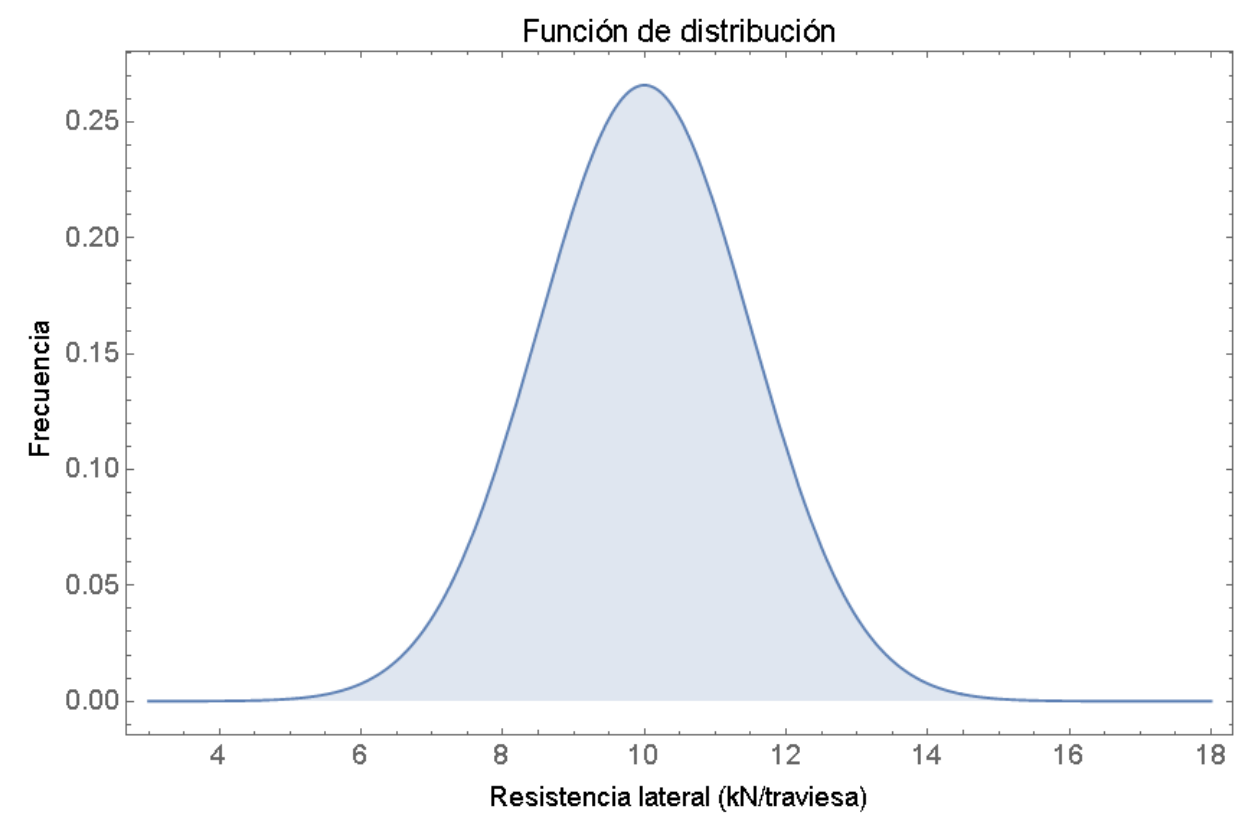

Figura 8.24: Ejemplo de distribución de resistencia lateral. Fuente: Elaboración propia.

\section{Defectos de vía}

Como es bien conocido, las cargas ferroviarias producen movimientos de la vía progresivamente en las direcciones vertical y lateral, causando desviaciones geométricas respecto de su posición ideal. La magnitud permitida depende del tipo de vía y del tráfico que circula por ella, generalmente recogida en tablas y normativa que establece los límites de cada tipo de defecto.

Según la norma europea EN 13848-5:2009 (2009) respecto de la calidad de la geometría de la vía y la UIC-518 (2005) sobre ensayos y homologación de vehículos ferroviarios, se definen tres tramos: D1 (3-25m), D2 (25-70m) y D3 (70-150m), lo que corresponde con longitudes de onda corta, media y larga, respectivamente. Con los valores máximos se determinan aquellos defectos que pueden incidir fundamentalmente en la seguridad de circulación.

En este sentido, los valores umbrales considerados en la norma UIC-518 (2005) para defectos la alineación de onda corta D1 (cuyas longitudes se encuentran en el rango de valores obtenidos para el pandeo) son: 


\begin{tabular}{|c|c|c|c|}
\hline $\begin{array}{c}\text { Maximum isolated error: } \\
\text { lateral alignment }\end{array}$ & $\begin{array}{c}\text { QN 1 } \\
(\mathrm{mm})\end{array}$ & $\begin{array}{c}\text { QN 2 } \\
(\mathrm{mm})\end{array}$ \\
\hline $\mathrm{V} \leq 80 \mathrm{~km} / \mathrm{h}$ & 12,0 & 14,0 \\
\hline $80<\quad \mathrm{V} \leq 120 \mathrm{~km} / \mathrm{h}$ & 8,0 & 10,0 \\
\hline $120<\mathrm{V} \leq 160 \mathrm{~km} / \mathrm{h}$ & 6,0 & 8,0 \\
\hline $160<\quad \mathrm{V} \leq 200 \mathrm{~km} / \mathrm{h}$ & 5,0 & 7,0 \\
\hline $200<\mathrm{V} \leq 300 \mathrm{~km} / \mathrm{h}$ & 4,0 & 6,0 \\
\hline
\end{tabular}

Figura 8.25: Valores máximos pico permitidos, según calidad de vía. Fuente: UIC-518.

Así pues, la distribución de la amplitud de los defectos para una determinada vía depende, en gran mediad, del mantenimiento realizado y del tipo de vía analizado. Una posible distribución tipo se observa en la Figura 8.26.

Figura 8.26: Ejemplo de distribución de defectos de alineación. Fuente: Elaboración propia.

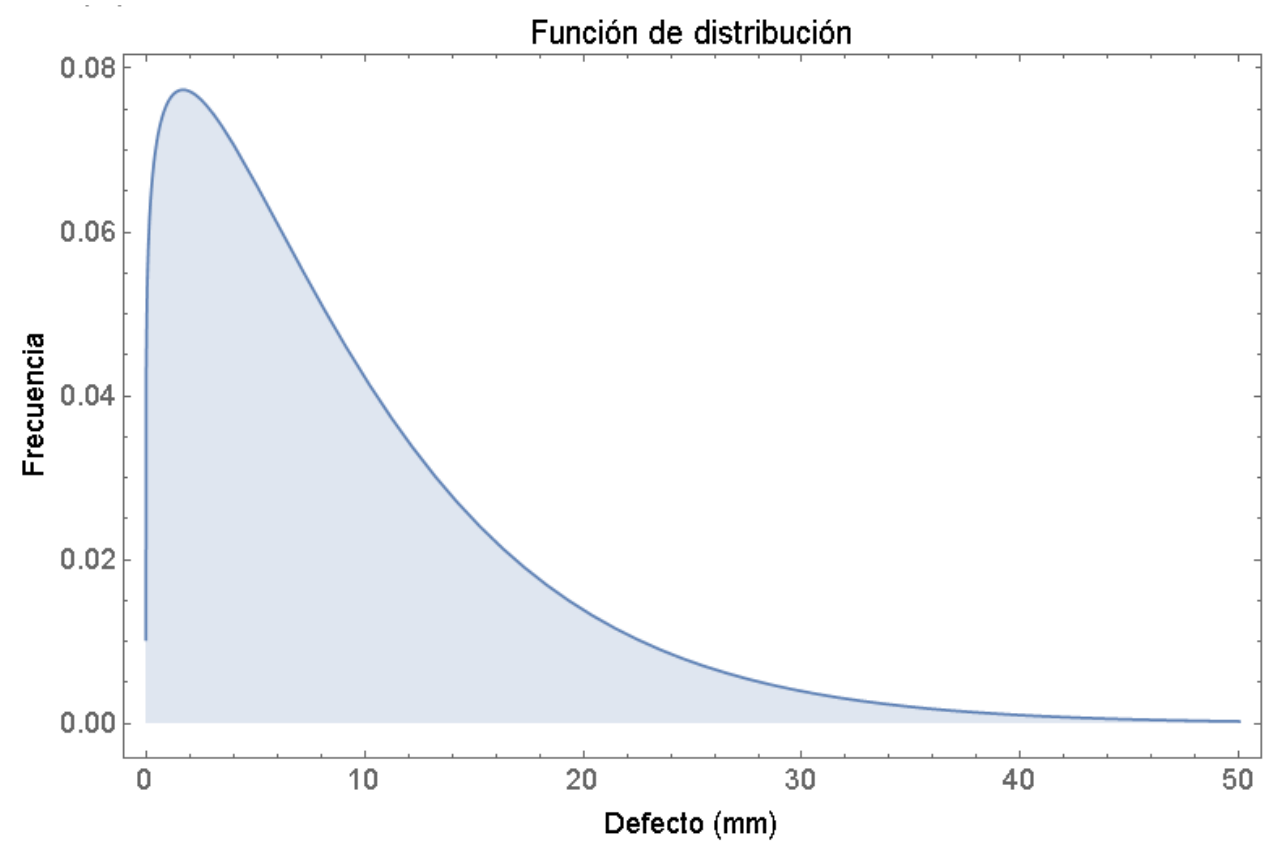

Con estas dos variables expresadas en forma probabilística es posible obtener la curva de densidad para la resistencia de la vía frente a pandeo, expresada en términos de temperatura $\left(\Omega_{2}\right)$, tal que sea posible llevar a cabo la integración. 


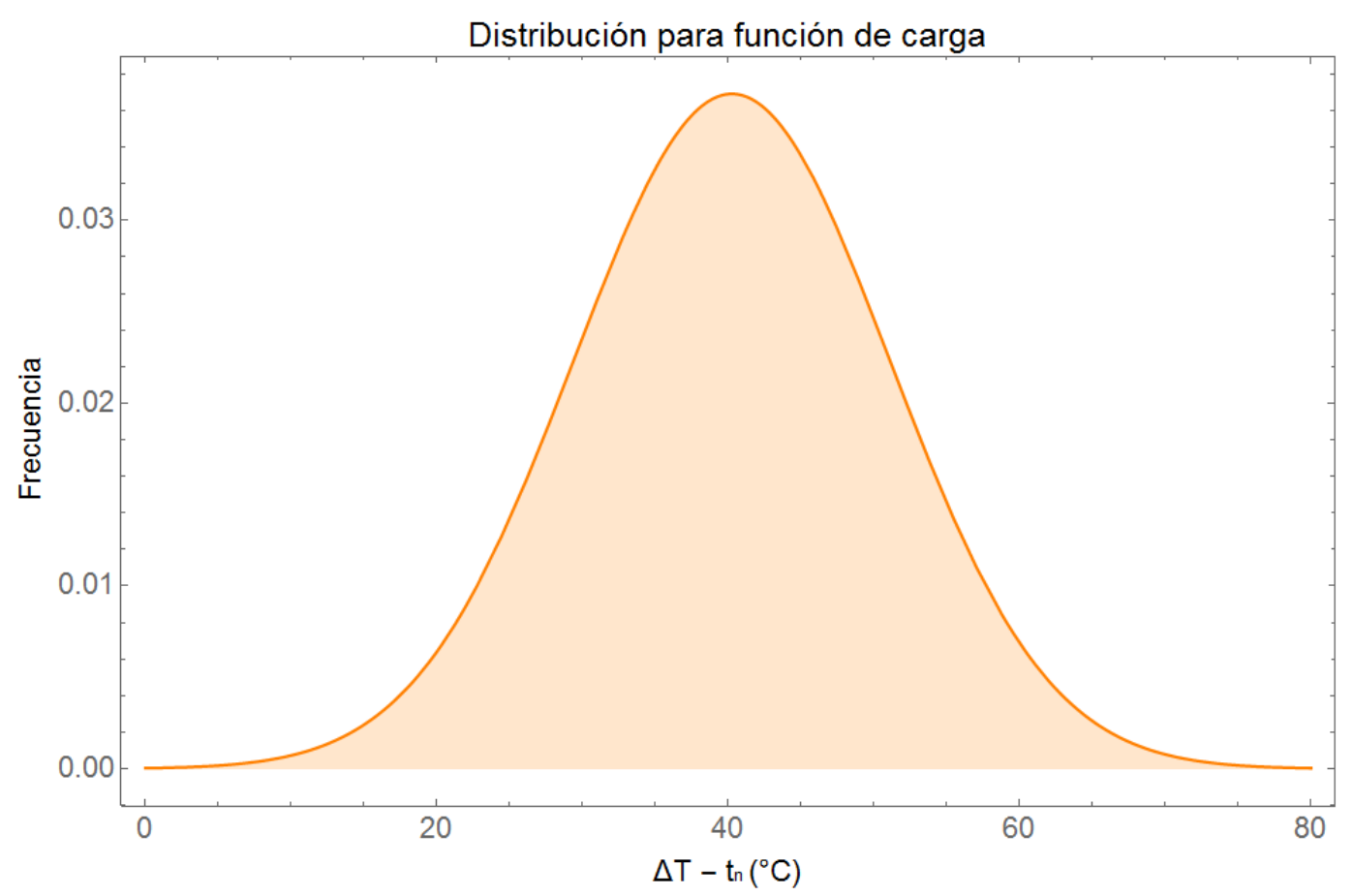

Figura 8.27: Ejemplo de curva de probabilidad de pandeo. Fuente: Elaboración propia.

\subsubsection{Determinación del riesgo aceptado}

Un aspecto importante en la evaluación del riesgo frente a pandeo es la determinación del nivel aceptable de riesgo ( $0 \%, 5 \%$, etc.). Este factor debe ser definido por cada administrador ferroviario en función de las condiciones de operación y de mantenimiento.

Alternativamente, es posible determinar un plan de mantenimiento que permita mantener la uniformidad de los parámetros de vía requeridos, si bien para asegurar su funcionalidad deben llevarse a cabo controles periódicos, cosa que no siempre es posible ni factible.

\subsubsection{Ejemplos numéricos}

A continuación, se presentan cuatro ejemplos numéricos para ilustrar la metodología probabilística propuesta anteriormente. Estos ejemplos numéricos tienen el objetivo de mostrar la influencia en la seguridad de la vía de la resistencia transversal y de los defectos de vía, mediante el estudio del riesgo frente a pandeo.

Como paso previo al cálculo, se definen de forma breve los 4 escenarios de estudio, identificados con el nombre Caso. El Caso 1 se plantea como situación estándar o de comparativa, cuya resistencia lateral y defectos de vía corresponden a una vía bien conservada. 
En cuanto al Caso 2, representa un estado en el que la vía presenta una muy buena resistencia transversal, debido a su mayor resistencia, mientras que el Caso 3 plantea una situación degradada, debido a una vía con mala calidad geométrica (presencia de mayores defectos de alineación). Finalmente, el Caso 4 simula una situación donde las temperaturas de los carriles pueden alcanzar mayores valores. En todos ellos, la temperatura de neutralización considera es de $27^{\circ} \mathrm{C}$ (la media en España oscila entre los $22^{\circ} \mathrm{C}$ y $32^{\circ} \mathrm{C}$ ).

La Tabla 8.4 muestra las diferentes situaciones planteadas, que responden a las características siguientes:

\begin{tabular}{|c|c|c|c|}
\hline Caso & Resistencia lateral (kN/trav) & Defectos de vía (mm) & Esfuerzos $\left({ }^{\circ} \mathrm{C}\right)$ \\
\hline 1 & $\begin{array}{l}\text { Normal } \\
\mu=11 \\
\sigma=1.5\end{array}$ & $\begin{array}{c}\text { Weibull } \\
\begin{array}{c}\alpha=1.15 \\
\beta=10\end{array}\end{array}$ & $\begin{array}{c}\frac{\text { Normal }}{\mu} \\
\mu=25 \\
\sigma=10\end{array}$ \\
\hline 2 & $\begin{array}{l}\text { Normal } \\
\mu=15 \\
\sigma=1.5\end{array}$ & $\begin{array}{c}\text { Weibull } \\
\alpha=1.15 \\
\beta=10\end{array}$ & $\begin{array}{c}\text { Normal } \\
\mu=25 \\
\sigma=10\end{array}$ \\
\hline 3 & $\begin{array}{l}\text { Normal } \\
\mu=11 \\
\sigma=1.5\end{array}$ & $\begin{array}{c}\text { Weibull } \\
\alpha=2.25 \\
\beta=10\end{array}$ & $\begin{array}{c}\frac{\text { Normal }}{\mu=25} \\
\sigma=10\end{array}$ \\
\hline 4 & $\begin{array}{l}\text { Normal } \\
\mu=11 \\
\sigma=1.5\end{array}$ & $\begin{array}{c}\text { Weibull } \\
\begin{array}{c}\alpha=1.15 \\
\beta=10\end{array}\end{array}$ & $\begin{array}{c}\frac{\text { Normal }}{\mu=35} \\
\sigma=10\end{array}$ \\
\hline
\end{tabular}

Tabla 8.4: Distribuciones utilizadas en cada caso. Fuente: Elaboración propia.

A priori y para una determinada temperatura es razonable pensar que el Caso 2 proporcione probabilidades de fallo más reducidas respecto de la situación inicial, mientras que los casos 3 y 4 representan situaciones más desfavorables o degradadas de vía, por lo que en estos casos la probabilidad debería ser más elevada. Para su mayor utilidad, en todos los casos la probabilidad de fallo viene representada en función de la temperatura del carril. 


\section{Caso 1}

El primer evento analizado representa la situación de referencia, sobre la que se compararán el resto de casos analizados. La Figura 8.28 muestra las distribuciones utilizadas, cuyos valores medios y desviaciones han sido indicados en la Tabla 8.4.
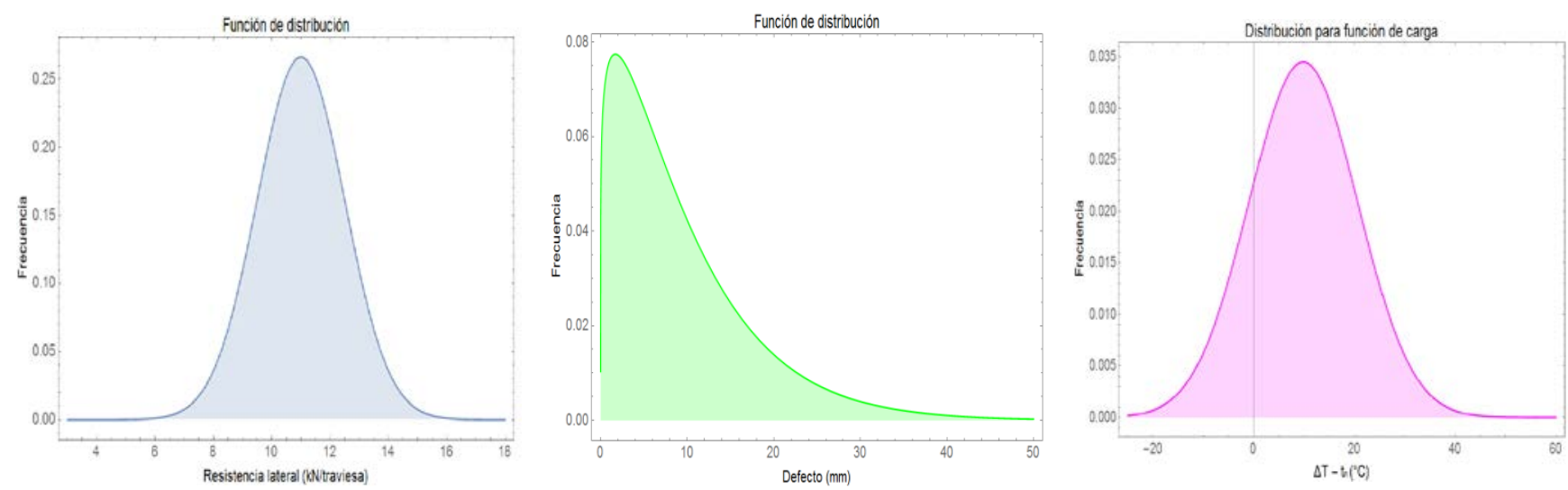

Figura 8.28: Distribuciones según las variables, para el caso 1. Fuente: Elaboración propia.

La Figura 8.29 muestra la curva de probabilidad de pandeo, respecto de la temperatura de los carriles y bajo las condiciones descritas. Con este tipo de gráficos, es posible identificar las temperaturas de pandeo (o temperatura de los carriles), según una determinada probabilidad de fallo. Como ejemplo, fijada una determinada probabilidad de fallo, se obtiene la temperatura máxima que pueden alcanzar los carriles, sin que se supere dicha probabilidad.

De forma genérica, se observa cómo a medida que aumenta la temperatura, la probabilidad de pandeo es mayor. Por otro lado, si se toman como referencia los valores de fallo asociados al $0,1 \%\left(10^{-3}\right)$ y al $0,01 \%\left(10^{-4}\right)$, las temperaturas de pandeo asociadas a dichas probabilidades para el Caso 1 son de $66,0^{\circ} \mathrm{C}$ y de $63,5^{\circ} \mathrm{C}$, respectivamente. Estos valores reducidos de probabilidad de fallo permiten asegurar la integridad de la estructura, pues la gravedad de los daños cuando se produce el fallo es elevada, lo que obliga a considerar un factor de seguridad elevado.

Mediante este tipo de representación gráfica se comprueba cómo es posible identificar de forma sencilla la temperatura admisible en los carriles, dada una determinada probabilidad de fallo. 

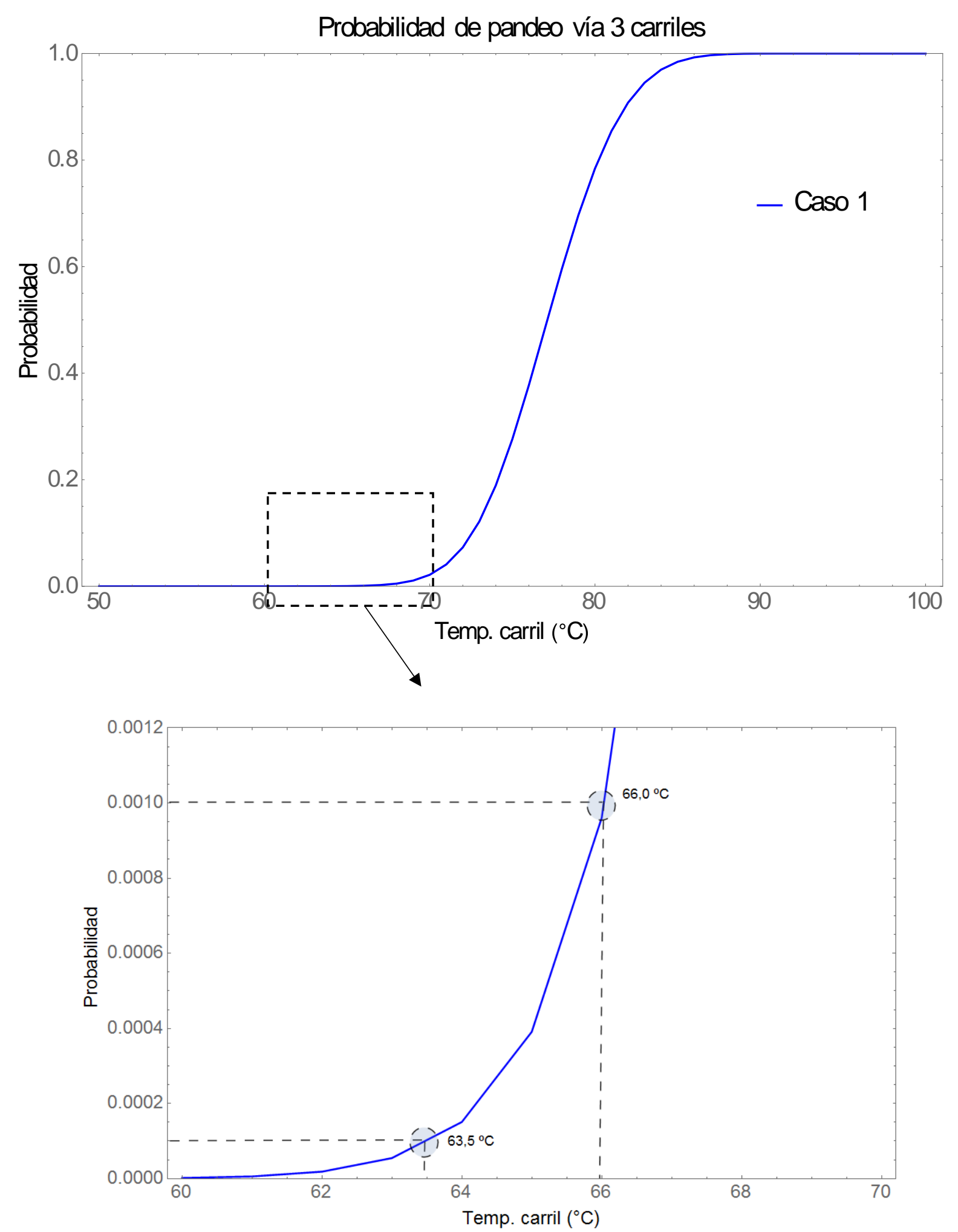

Figura 8.29: Probabilidad de pandeo, en función de la temperatura de los carriles, para el caso 1. Fuente: Elaboración propia. 


\section{Caso 2}

En este segundo caso, se considera una mejor resistencia transversal respecto de la situación de referencia. Esta situación se traduce en una mejor distribución de resistencias laterales, con un aumento del valor medio de la distribución, pasando de una media igual a $\mu=11 \mathrm{kN} /$ traviesa a un valor de $\mu=15 \mathrm{kN} /$ traviesa.

De nuevo, la Figura 8.30 muestra las distribuciones utilizadas, donde la variación se encuentra únicamente en la resistencia transversal, manteniéndose el resto de factores inalterados.
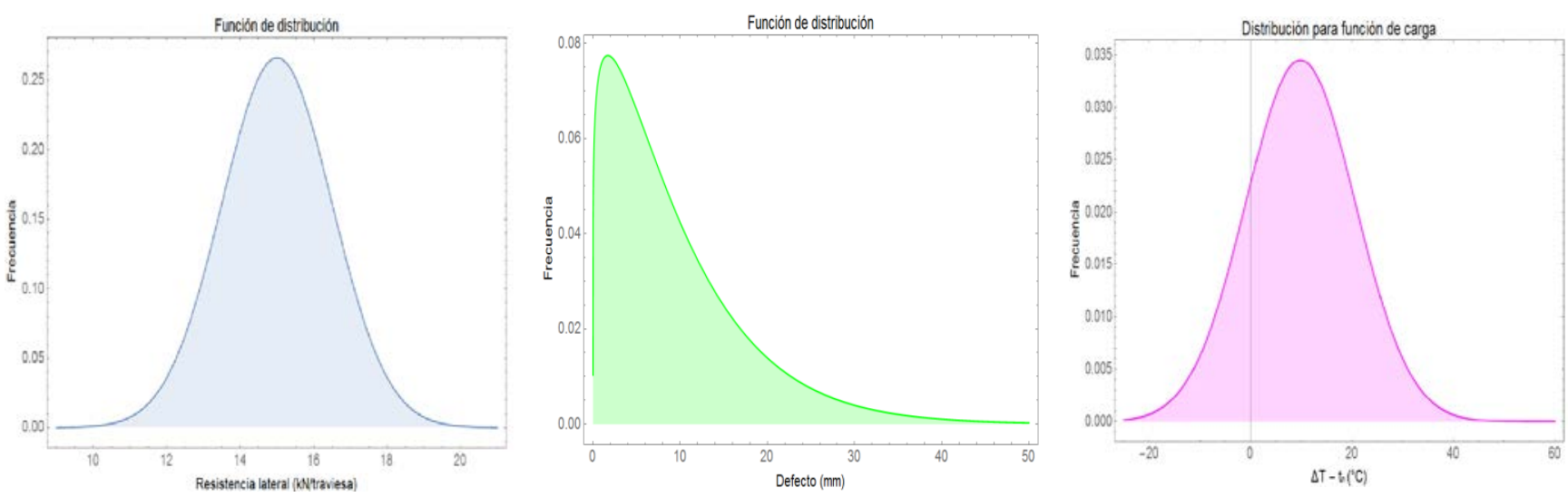

Figura 8.30: Distribuciones según las variables, para el caso 2. Fuente: Elaboración propia.

En la Figura 8.31 se observa cómo debido al aumento de la resistencia lateral y, por ende, de la resistencia frente a pandeo, la curva de probabilidad se desplaza hacia la derecha, lo que supone que para un mismo valor de temperatura la probabilidad de pandeo es menor, o lo que es lo mismo, una determinada probabilidad de fallo resulta en una mayor temperatura, tomando como referencia el caso anterior.

En este caso y asociado a una probabilidad del 0,1\% y del 0,01\% se obtienen unas temperaturas de $71,0^{\circ} \mathrm{C}$ y de $68,5^{\circ} \mathrm{C}$, respectivamente. 

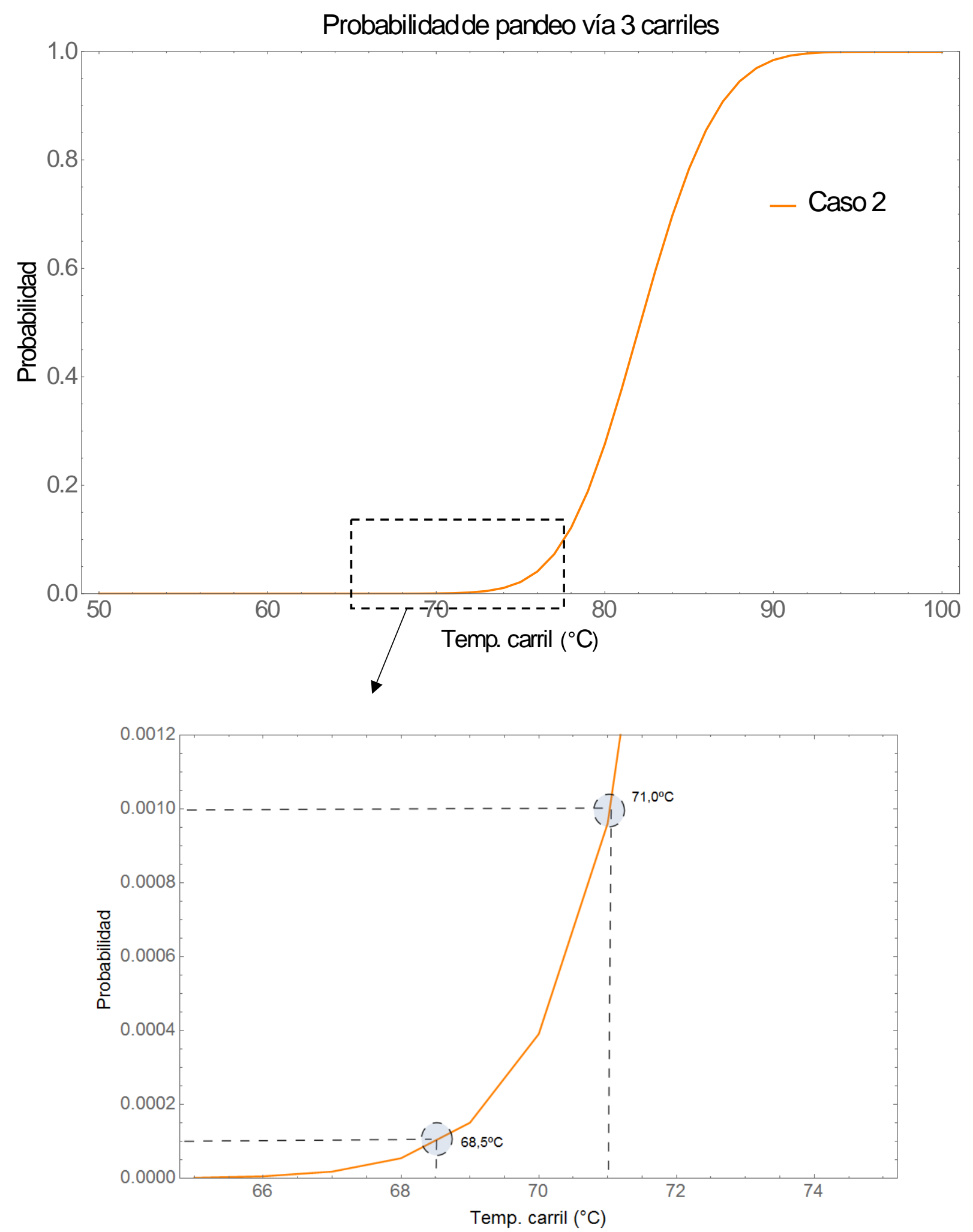

Figura 8.31: Probabilidad de pandeo, en función de la temperatura de los carriles, para el caso 2. Fuente: Elaboración propia. 


\section{Caso 3}

El tercer caso considerado plantea una situación con una vía más irregular respecto de la situación de referencia. Este caso puede representar una situación en la que, debido a la falta de mantenimiento, no se ejecutan las tareas con la frecuencia necesaria para controlar los desplazamientos dentro de valores adecuados.

La distribución que representa a los defectos tiene como parámetro de forma $\alpha=2,25 \mathrm{~mm}$ respecto los $\alpha=1,15 \mathrm{~mm}$ de la situación de referencia. Con ello, en la Figura 8.32 se muestra las distribuciones resultantes, donde el cambio respecto de la situación de partida se da para los defectos de vía, manteniéndose el resto de factores inicialmente utilizados.
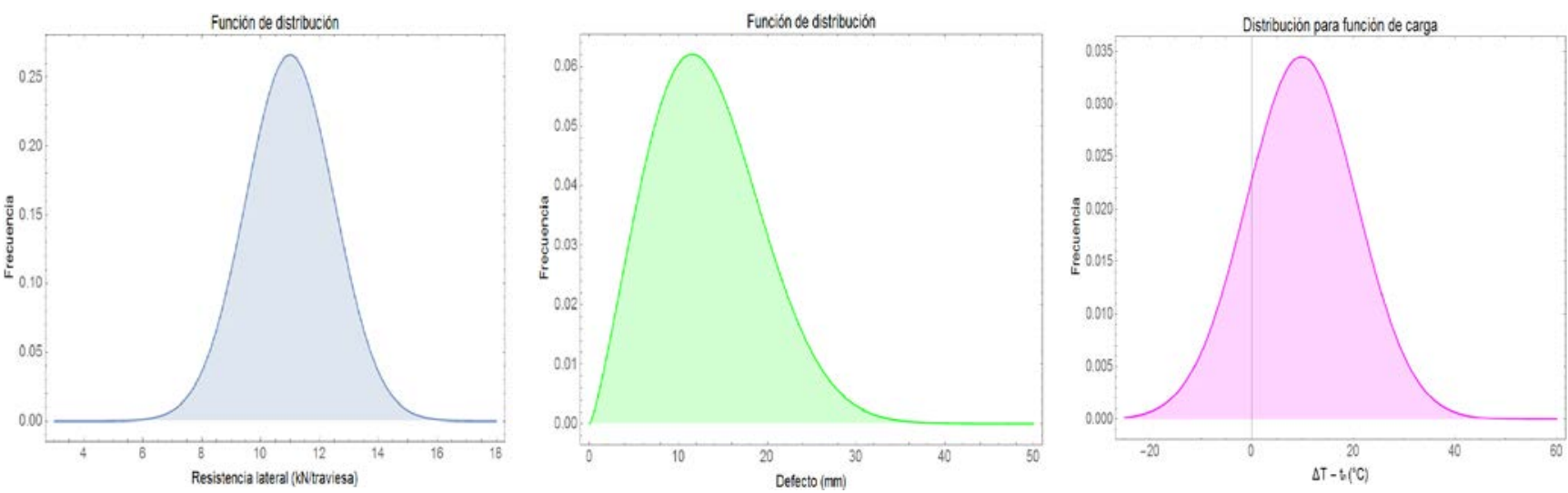

Figura 8.32: Distribuciones para el caso 3. Fuente: Elaboración propia.

Con estos valores, la Figura 8.33 representa de nuevo la probabilidad de fallo. Comparando con la situación de referencia, se observa cómo la curva de probabilidad se desplaza hacia la izquierda, por lo que la probabilidad de pandeo aumenta, a igualdad de temperatura en los carriles.

Así pues, considerado las probabilidades de $0,1 \%$ y del $0,01 \%$ se obtienen unas temperaturas de $59,0^{\circ} \mathrm{C}$ y de $56,9^{\circ} \mathrm{C}$, respectivamente. 

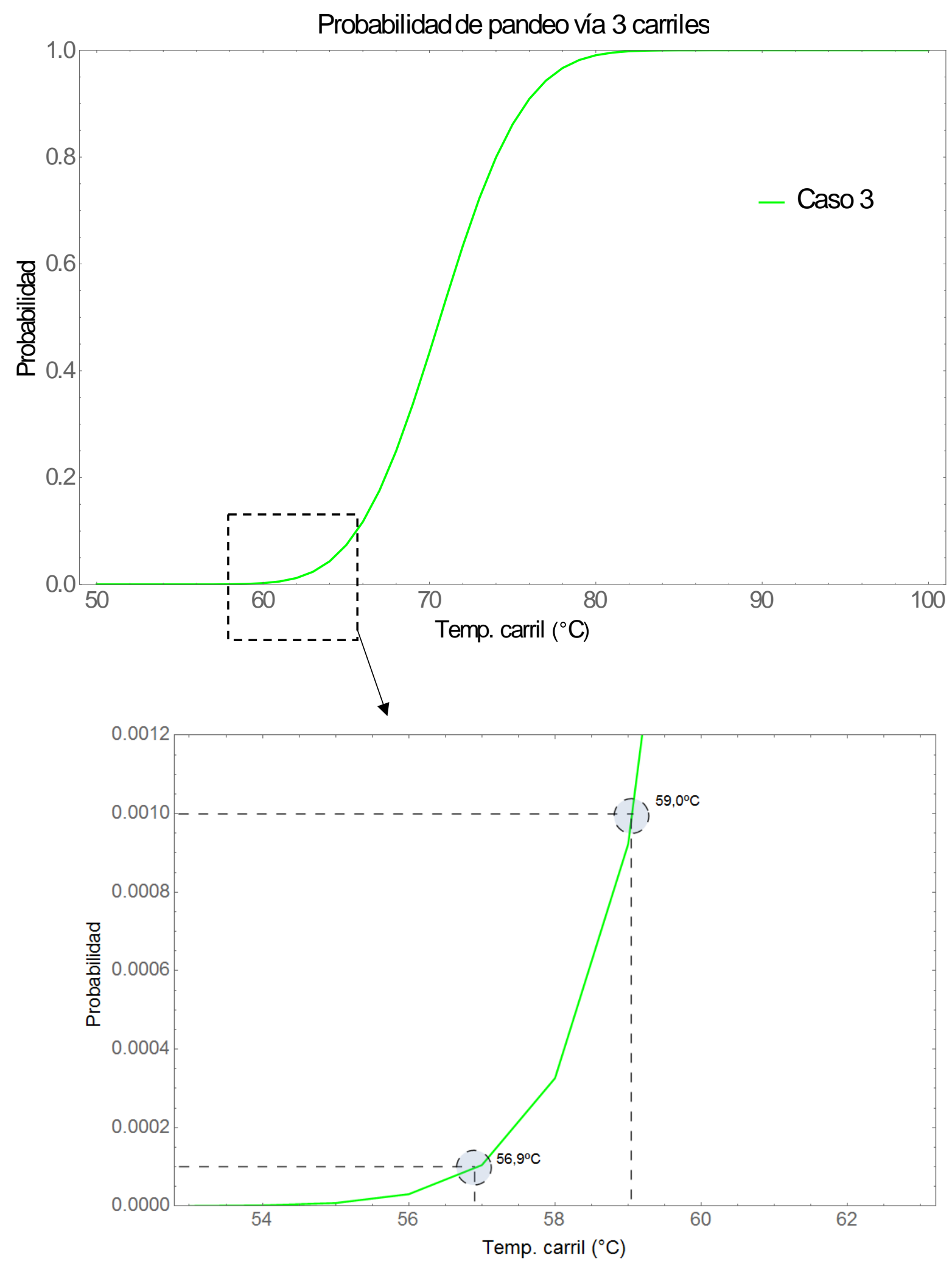

Figura 8.33: Probabilidad de pandeo, en función de la temperatura de los carriles, para el caso 3. Fuente: Elaboración propia. 


\section{Caso 4}

El cuarto y último caso represente un escenario donde las temperaturas alcanzan mayores valores, respecto de la situación de referencia o Caso 1. La variabilidad de la temperatura en un tramo de estudio puede mejorar o empeorar la probabilidad de fallo frente a pandeo, pues a igualdad de condiciones un mayor incremento de temperatura está asociado a una mayor carga y probabilidad de fallo.
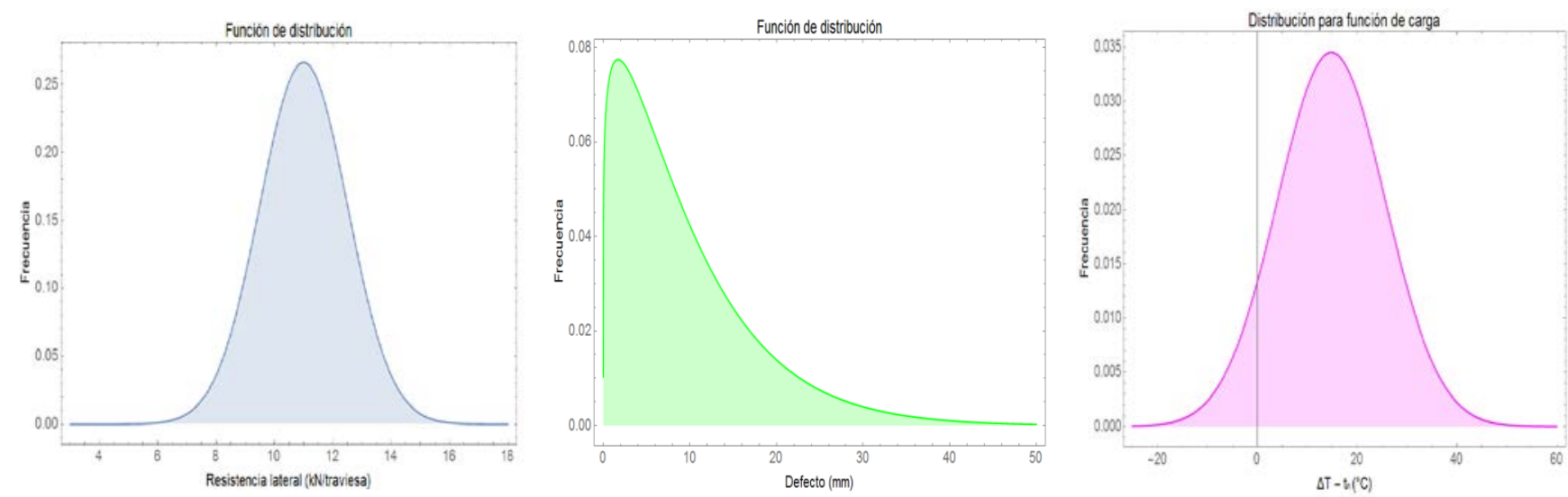

Figura 8.34: Distribuciones para el caso 4. Fuente: Elaboración propia.

En la Figura 8.35 se observa cómo debido al aumento de los esfuerzos, la curva de probabilidad se desplaza hacia la izquierda, respecto de la situación de referencia. Este comportamiento, a priori esperado, confirma el hecho de que una vía sometida a mayores incrementos de temperatura tiene asociado un mayor riesgo frente a pandeo.

Así pues, en este caso y asociado a una probabilidad del $0,1 \%$ y del $0,01 \%$ se obtienen unas temperaturas de $54,1^{\circ} \mathrm{C}$ y de $52,0^{\circ} \mathrm{C}$ respectivamente, lo que supone una variación significativa de la temperatura obtenida respecto de las obtenidas en el caso de referencia. 

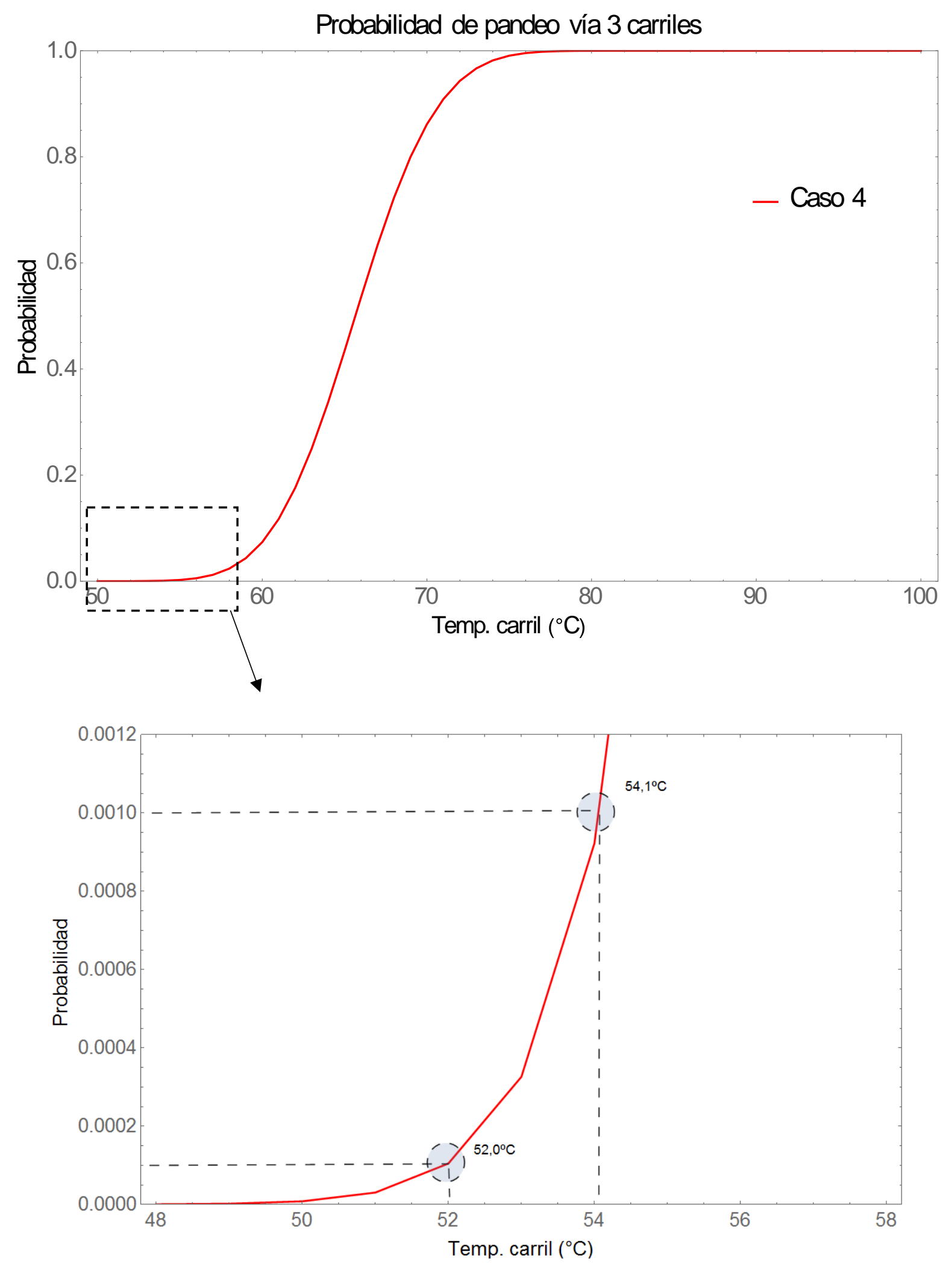

Figura 8.35: Probabilidad de pandeo, en función de la temperatura de los carriles, para el caso 4. Fuente: Elaboración propia. 


\section{Comparativa}

Los casos anteriores ilustran cómo puede ser evaluada la probabilidad frente a pandeo lateral en vías de doble ancho, conociendo o estimando las distribuciones de probabilidad de los parámetros individuales de los que depende.

Por ello, la comparación de la probabilidad de fallo para unas determinadas condiciones de vía tiene un interés tanto teórico como práctico, ya que con la ayuda de este tipo de herramientas y bajo un control de la vía es posible evaluar diferentes estrategias de mantenimiento, lo que permite optimizar los recursos sin comprometer la integridad y seguridad de la infraestructura ferroviaria. Además, es posible utilizar este tipo de herramientas para determinar restricciones de velocidad, con el objetivo de minimizar el riesgo ante eventos que prevean elevadas temperaturas en los carriles (como, por ejemplo, en las "olas de calor").

La Tabla 8.5 muestra los valores de temperatura de los carriles asociados a una determinada probabilidad de fallo seleccionada. Se observa que existen diferencias entre las temperaturas de pandeo, asociadas a una determinada probabilidad de fallo. El escenario que mejor comportamiento frente a pandeo presenta es el del Caso 2, pues supone un estado de resistencia transversal mejorado, respecto de la situación de referencia. En cuanto a los escenarios desfavorables (Casos 3 y 4), las temperaturas resultantes son inferiores a las obtenidas en la situación de referencia. Las temperaturas más reducidas se obtienen en el Caso 4, ya que se ha empleado una distribución de carga (o temperaturas) con valores superiores a la del resto de casos analizados.

\begin{tabular}{|c|c|c|}
\hline \multicolumn{3}{|c|}{ Temperatura límite de pandeo en carriles, para vías de doble ancho } \\
\hline Caso & Probabilidad $=0,1 \%\left(10^{-3}\right)$ & Probabilidad $=0,01 \%\left(10^{-4}\right)$ \\
\hline 1 & $66,0^{\circ} \mathrm{C}$ & $63,5^{\circ} \mathrm{C}$ \\
\hline 2 & $71,0^{\circ} \mathrm{C}$ & $68,5^{\circ} \mathrm{C}$ \\
\hline 3 & $59,0^{\circ} \mathrm{C}$ & $56,9^{\circ} \mathrm{C}$ \\
\hline 4 & $54,1^{\circ} \mathrm{C}$ & $52,0^{\circ} \mathrm{C}$ \\
\hline
\end{tabular}

Tabla 8.5: Valores de temperatura de pandeo asociados a cada caso y probabilidad de fallo. Fuente: Elaboración propia. 
En cuanto a las curvas de probabilidad, la Figura 8.36 muestra de forma agrupada todos los casos de estudio. Se observa como la probabilidad decrece con el aumento de la resistencia trasversal (Caso 2), mientras que se reduce con el incremento de los defectos y de la temperatura ambiental (Caso 3 y 4 ).

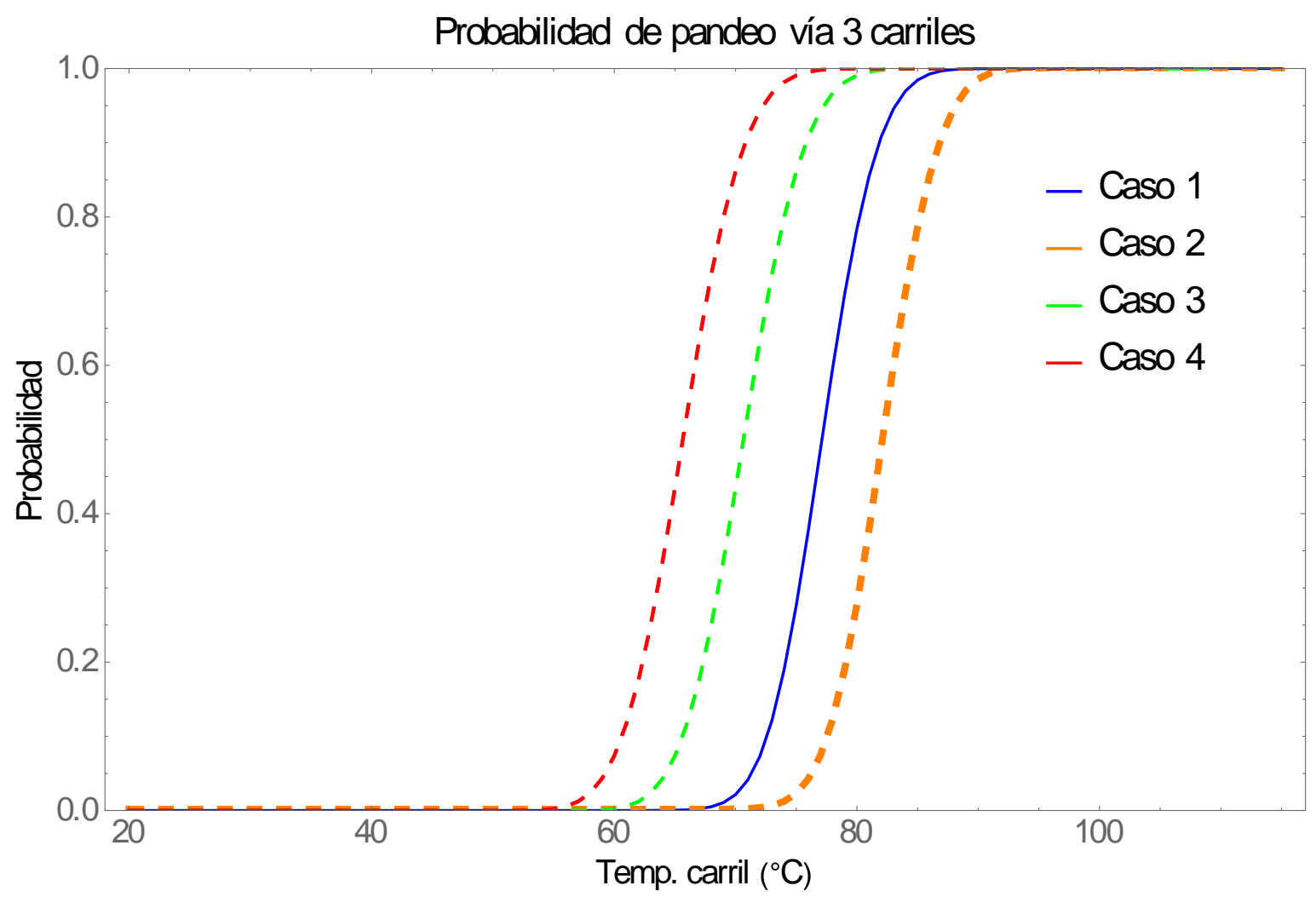

Figura 8.36: Probabilidad de fallo, para todos los casos de estudio. Fuente: Elaboración propia.

Mediante esta formulación probabilística, es posible tener una cierta flexibilidad en el estudio del pandeo, ya que el riesgo se puede determinar en base a la experiencia y tipo de explotación de la vía. En este sentido, algunas de las operaciones de vía encaminadas a reducir la probabilidad de fallo y mejorar la resistencia vienen recogidas en la Tabla 8.6. 


\begin{tabular}{|c|c|}
\hline Parámetro & Actuaciones y actividades \\
\hline Resistencia lateral & $\begin{array}{l}\text { - Obtener resistencia elevadas, a través de un mante- } \\
\text { nimiento adecuado de la capa de balasto y de su } \\
\text { consolidación tras las operaciones de bateo } \\
\text { - Evitar zonas o puntos de debilidad, los cuales contri- } \\
\text { buyen a aumentar la dispersión de los valores } \\
\text { - Control de zonas o puntos sensibles como: Tramos } \\
\text { recién bateados, zonas con presencia de finos y de- } \\
\text { gradación del balasto, etc. }\end{array}$ \\
\hline Defectos de alineación & $\begin{array}{l}\text { - Controlar los defectos de forma periódica, colocando } \\
\text { - la vía en su posición cuando sea necesario } \\
\text { Reducir los esfuerzos laterales mediante el manteni- } \\
\text { miento de los vehículos y aplicando limitaciones de } \\
\text { velocidad, bajo condiciones desfavorables }\end{array}$ \\
\hline Temperatura neutralización & $\begin{array}{l}\text { - Controlar el estado tensional del carril y corregir, en } \\
\text { su caso, la temperatura de fijación. }\end{array}$ \\
\hline
\end{tabular}

Tabla 8.6: Propuesta de actividades para reducir el riesgo de pandeo. Fuente: Elaboración propia.

No obstante, no cabe perder de vista que el enfoque probabilístico aquí planteado necesita de un proceso de validación para poder ser útil y eficaz, cosa que puede lograrse mediante la colaboración con las administraciones y empresas ferroviarias encargados del mantenimiento de vías de doble ancho y gracias a las mediciones y control en vía.

\subsection{Conclusiones}

Tal y como se ha descrito a lo largo de la presente Tesis, la incorporación de un tercer carril en la superestructura de vía clásica plantea nuevos retos, entre los que se encuentra el análisis de la estabilidad frente a cargas térmicas. Este tercer carril produce un desequilibrio en la simetría de la vía, por lo que son necesarios nuevos estudios para analizar y evaluar la estabilidad de la infraestructura frente a las cargas térmicas y de los vehículos a las que estará sometida.

Los principios básicos para el diseño y análisis de una vía con carril continuo soldado se basan en la determinación, en cualquier punto de la vía, de los esfuerzos y de la resistencia de la vía. Para llevar a cabo este tipo de análisis se hace necesario el uso de herramientas y modelos que consideren, de forma específica, tanto las características del fenómeno 
como y las particularidades de la vía. La finalidad, en el ámbito ferroviario, es la de estudiar las temperaturas máximas que pueden alcanzar los carriles sin que se desestabilice lateralmente la vía, en función de los parámetros que determinan su resistencia.

Se han propuesto dos modelos de naturaleza diferente con el uso del software Mathematica $^{\circledR}$ y Ansys $^{\circledR}$, considerando las restricciones habituales además de los principales factores de influencia. A través de los ejemplos y curvas de temperatura mostradas en el presente capítulo se quiere poner de manifiesto la validez y utilidad de dichos modelos para el cálculo de pandeo en vías de doble ancho. Los resultados obtenidos permiten abordar el complejo fenómeno del pandeo ferroviario en vías de doble ancho. Las principales conclusiones obtenidas son:

- En primer lugar, con respecto a la determinación de la temperatura de pandeo en vías de doble ancho, se disponen de resultados obtenidos con un modelo analítico y otro numérico. La aplicación del modelo analítico se realiza mediante la evaluación de la función de energía potencial total del sistema, obteniéndose el incremento de temperatura límite, la longitud de pandeo y la amplitud final del defecto, en la posición deformada de la vía. En cambio, la lógica del modelo numérico de elementos finitos se basa en la resolución matricial de las ecuaciones de rigidez del sistema, lo que proporciona para cada incremento de la carga aplicada el estado tenso-deformacional del sistema estudiado. Con ello, la temperatura se determina como aquel valor tal que, un pequeño incremento de temperatura, produce un aumento considerable de la deformación lateral, desestabilizando por completo la vía. Pese a la naturaleza y lógica bien distinta de cada modelo, proporcionan resultados similares en ambos tipos de análisis, con diferencias menores al 10\%. Se llega a la conclusión que las temperaturas de pandeo son ligeramente superiores cuando se utiliza el modelo analítico, si bien ambos permiten estudiar la estabilidad transversal de la vía de doble ancho, aspecto que los modelos desarrollados hasta la actualidad no permiten abordar.

- En cuanto a la utilidad de cada modelo y de acuerdo con la formulación analítica propuesta, mediante dicho modelo es posible analizar la influencia del tipo de defecto considerado, así como la altura de la banqueta de balasto. Por otro lado, se constata como el modelo numérico permite estudiar aspectos del comportamiento 
de la vía, como por ejemplo la influencia de la posición del defecto. Esta complementariedad justifica la conveniencia del desarrollo y uso de ambos modelos, lo que permite obtener un estudio mucho más amplio y eficaz del fenómeno.

Con todo ello, el análisis realizado ha permitido obtener los incrementos de temperatura en función de las características más representativas de las vías de doble ancho (tipo de carril, traviesa, tipo y posición del defecto, carga aplicada). La correcta determinación de todos y cada uno de estos factores es importante a la hora de obtener un valor que estime adecuadamente la respuesta de la vía, pues de lo contrario la incertidumbre asociada a cada uno de ellos puede condicionar notablemente el resultado obtenido.

Como muestra de la aplicación práctica, se han tomado como valores representativos de las variables fundamentales valores entre los $3 \mathrm{kN} /$ traviesa y los $15 \mathrm{kN} /$ traviesa y entre los 0,5 $\mathrm{mm}$ y $5 \mathrm{~mm}$ para los defectos de alienación. De esta forma, en primer lugar y fijado un valor del defecto igual a $2 \mathrm{~mm}$, con el que se han obtenido los valores críticos de temperatura para los diferentes escenarios de cálculo en función de la resistencia transversal. En segundo lugar, de forma análoga se ha fiado un valor de resistencia transversal e igual a 9 $\mathrm{kN} /$ traviesa, mediante el cual se han ido obteniendo de nuevo las temperaturas de pandeo.

En base a estos resultados, los cuales conforman un conjunto de 248 escenarios diferentes, resulta posible reflexionar sobre el comportamiento a pandeo de vías de doble ancho, siendo las principales conclusiones las siguientes:

- Los incrementos máximos de temperatura obtenidos están condicionados, en gran medida, por el valor de las variables fundamentales: la resistencia transversal y los defectos de alienación. Así pues, los incrementos de temperatura respecto de la temperatura de neutralización oscilan entre los $44,2^{\circ} \mathrm{C}$ y los $100,8^{\circ} \mathrm{C}$, para el rango de resistencias transversales medias (7-13 kN/traviesa) y defectos de amplitud reducidos (<2 mm). En cambio, en condiciones degradadas de vía (por ejemplo, con reducida resistencia lateral y defectos de amplitud importantes), los incrementos de temperatura que producen el pandeo se sitúan por debajo del umbral de los $30^{\circ} \mathrm{C}$, lo que supone un importante riesgo especialmente en periodos cálidos, donde es probable que se alcancen incrementos de temperatura superiores. 
- En cuanto a los elementos que componen la superestructura, el aumento del tamaño del carril produce una disminución de la temperatura, mientras que las traviesas bibloque poseen un mejor comportamiento respecto de las monobloque, por lo que la respuesta calculada evoluciona de forma semejante a la obtenida en vías convencionales.

- Una de las particularidades de este estudio frente a estudios previamente realizados reside en el estudio de la influencia de la forma y, en especial, de la posición del defecto respecto del tercer carril. Tal y como se ha observado, este aspecto resulta importante en el cálculo, pues se comprueba que la situación más desfavorable corresponde con aquella donde los defectos desplazan la vía hacia el exterior del mismo lado donde se encuentran los dos carriles. Esta particularidad, únicamente presente en vías de doble ancho, confirma la necesidad de analizar de forma específica las vías de doble ancho.

- En cuanto a la aplicación de cargas verticales, se ha comprobado que, en todos los casos, se produce un aumento de las temperaturas de pandeo resultantes. Sin embargo, conforme se discutió en el apartado 3.4.2, las traviesas contiguas a la carga sufren un fenómeno de levante que reduce su resistencia, lo que no ha sido posible observar en el cálculo. Por este motivo, no resulta adecuado cuantificar la temperatura de pandeo bajo cargas verticales con los modelos descritos, siendo preferible un mayor estudio y profundización en este aspecto, trabajo que queda pendiente para futuros desarrollos.

Además del estudio previo y para analizar el riesgo desde una perspectiva más amplia, se ha llevado a cabo una comparativa del pandeo en vías convencionales y de doble ancho, modificando los modelos desarrollados para representar la estructura de vía clásica. Pese a que los resultados no abarcan un gran conjunto de escenarios, es posible extraer algunas conclusiones importantes como:

- A igualdad de condiciones, las temperaturas de pandeo en vías de doble ancho son relativamente inferiores a las que se obtienen para vías convencionales, llegando en algunos casos a reducciones cercanas al 20\%. Esta diferencia es más acusada cuanto mayor es la resistencia transversal, por lo que, en términos generales, el 
riesgo de pandeo es mayor en vías de doble ancho respecto de vías convencionales, dadas unas determinadas condiciones de cálculo.

- La reducción obtenida en las temperaturas de pandeo repercute sobre el margen de seguridad, reduciéndolo si se mantienen las condiciones de instalación y mantenimiento tradicionalmente utilizadas hasta el momento. Para contrarrestar dicha tendencia, se recomienda el desarrollo de planes de mantenimiento adecuados, tal que las condiciones de vía se mantengan en condiciones adecuadas, lo que permite asegurar la integridad estructural, incluso para temperaturas elevadas. No obstante, los valores aquí obtenidos deben ser contrastados con datos reales de vía, por lo que las medidas a tomar quedan supeditadas al conocimiento que se adquiera progresivamente con la explotación de este tipo de vías.

Con la idea de ampliar la utilidad del presente trabajo y respecto a la evaluación del riesgo a pandeo, se ha considerado la necesidad de evaluar el pandeo desde una perspectiva probabilística, en la que las variables se definen en base a su probabilidad de ocurrencia. Bajo esta metodología se ha definido un procedimiento de cálculo, lo que constituye una herramienta muy útil para llevar a cabo un mantenimiento eficaz. Las aportaciones más relevantes en este ámbito son:

- El estudio probabilístico requiere el manejo de distribuciones de probabilidad para los diferentes parámetros considerados (resistencia lateral, amplitud de los defectos, temperaturas de los carriles). El manejo de este tipo de datos permite optimizar las estrategias de mantenimiento y minimizar el riesgo de pandeo.

- La estimación del riesgo a pandeo, en cada uno de los cuatro escenarios analizados, da como resultado curvas temperatura-probabilidad, donde para cada temperatura de carril se obtiene un valor de riesgo de pandeo. Dichas curvas tienen asociado un valor prácticamente nulo para valores por debajo de los $50^{\circ} \mathrm{C}$, mientras que la curva tiende de manera asintótica hasta alcanzar un valor igual a 1, cuando la temperatura de los carriles supera los $90^{\circ} \mathrm{C}$.

- Los resultados probabilísticos pueden ser utilizados para definir umbrales de temperatura, por encima de los cuales se aconseja que la explotación se realice a velocidades inferiores, respecto de las condiciones normales de explotación. Este tipo 
de medida viene siendo aplica por algunas administraciones ferroviarias, proponiéndose su extensión a las vías de doble ancho.

Para finalizar, cabe destacar que en todos los casos analizados durante el presente capítulo se ha examinado la influencia de diversos parámetros, considerando para ello valores representativos de cada factor. El estudio basado en datos y medidas reales de vía se pospone como línea de investigación, pues la reciente implantación de este tipo de vías y la poca experiencia en su explotación no permiten en la actualidad profundizar en su análisis. Pese a este inconveniente, ha podido constatarse que las vías de doble ancho tienen una mayor susceptibilidad a las cargas térmicas, lo que aumenta su riesgo y requiere de una mayor atención por parte de los organismos encargados de su mantenimiento. 


\section{Capítulo VI \\ 9. Conclusions and recom- mendations}

The characteristic track gauge of the Spanish railway network is $1.668 \mathrm{~mm}$, wider than the standard track gauge (equals to $1.435 \mathrm{~mm}$ ). The existence of different track gauges on a rail network has been a traditional problem for operators, considering that usually trains cannot pass from one line to another.

To solve interoperability issues, the Spanish government recently proposed the construction and use of dual gauge track solution that allows the passing of trains with two different track gauges with minimum cost and construction time.

In a dual gauge configuration, the addition of a third rail introduces an important modification of the track system and structure. Furthermore, the use of CWR where expansion is restricted produces important compression regimes in the rails, that can led to lateral instability. Therefore, this particular track structure requires an adequate and accurate analysis.

In order to maintain the stability and safety of the rail track, an important number of research studies have been carried out to investigate the effect of different track parameters and establish a safety criterion. The principal objective of a rail track bulking analysis model is to determine the rail temperature at which the track buckles. However, all the studies differ substantially and some specific situations such as dual gauge tracks have not been considered, in which the addition of the third rail increases the steel section and axial forces. In that sense, the most successful buckling models have a rather limited range of applicability. 
On the other hand, past and current maintenance practices were developed for conventional tracks and their application to dual gauge tracks is not straightforward.

With these premises, a different approach was required and as a result, two mathematical models are proposed to deal with the dual gauge track buckling. With these models, a comparative analysis of different parameters for dual gauge track is presented, as well as a probabilistic analysis of CWR stability.

\subsection{Limitations and exclusions}

Despite the advances and progress made in this Thesis, several assumptions and simplifications have been applied:

- Only straight sections are considered. Accordingly, curves are excluded from the analysis performed.

- Special situations such as switches, turnouts and bridges are not considered.

- The analyzed stretch is assumed to be long. The length of the stretch considered is equal to $50 \mathrm{~m}$.

- Although different dual gauge track configurations exist, the research domain is limited to the dual gauge tracks present in the Spanish rail network (1435 / $1668 \mathrm{~mm}$ ).

- Differences in temperature between rails are not considered.

- Considering the analytical and numerical models developed, the lateral resistance between sleeper and ballast has been taken into account with an elasto-plastic constitutive model. In addition, the effect of the lift-up wave of the loaded track is neglected. Therefore, a more precise model is required in order to reproduce the liftup sleeper effect and their effect in lateral resistance.

- In both models, the buckled shape and temperatures obtained are influenced by the shape and magnitude of the initial misalignments.

- Reference values used for calculations are obtained from previous tests and researches conducted on conventional tracks. Therefore, values for dual gauge tracks should be measured and validated with experimental and field tests.

- The probabilistic approach and its application should be demonstrated in real scenarios. This would require testing for the statistical parameters determination within a characteristic or representative rail track segment. 


\subsection{Conclusions}

The use of a new type of rail track structure requires an analysis of its mechanical behavior, in order to enhance the strength and stability of the track. In that sense, knowledge about track buckling fundamentals, track parameter interactions and particularities is essential. In accordance with the objectives proposed and described in Chapter I, some understanding of the lateral track stability in dual gauge tracks obtained during the realization of the doctoral Thesis have been established.

- In the last decades, many special models were developed for the lateral stability of rail tracks. However, dual gauge tracks implies a substantial modification of the conventional track panel, requiring a new approach. To accomplish this task, the present work proposes novel analytical and numerical models for the prediction of buckling temperatures in dual gauge tracks. The results evaluated are the buckling temperature and lateral displacements, taking into account their structural parameters (mechanical properties and geometrical composition).

- In the analytical model, the rail-sleeper structure is replaced by an equivalent beam. Lateral resistance is considered with a fixed value and as the result of the sum of three components (base, crib and shoulder), in order to evaluate the variation of the ballast height. In this model, the rail track is loaded with a mechanical load that simulates the compressive force exerted by temperature variations, and an initial sinusoidal misalignment is assumed.

In the numerical model, rails and sleepers are modelled as 3D beam elements, maintaining their respective positions. Rails are connected to sleepers thought the pad-fastener system, which is modelled as a set of linear and torsional linear spring elements that represents the pad-fastener system. Finally, the ballast lateral resistance is represented using non-linear spring elements with elasto-plastic behavior, while longitudinal and vertical resistances are simulated considering linear elastic springs.

- For both models, the track response in terms of buckling temperature is quite similar. However, temperature from the analytical model is slightly higher than that derived 
from the numerical model. Likewise, the relationship between the two buckling models and their respective results are demonstrated which give better insight to deal with the buckling phenomenon.

With the two models developed, a comparative study on track buckling parameters has been carried out, in order to evaluate the effects of rail size, sleeper type, track lateral resistance, initial misalignment amplitude and form, ballast height and vertical loads. The reliability of these models has been evaluated based on 248 scenarios, providing a qualitative idea about which parameters need to be addressed in dual gauge tracks. Principal conclusions of this study are summarized below:

- Results obtained show that the most important track parameters involved in the dual gauge buckling process are the lateral resistances and the initial misalignments. Due that buckling temperature decreases as the initial misalignment increases or lateral resistance decreases, the effect of gauge irregularity or poor ballast resistance must not be overlooked. Therefore, the knowledge and measurement of these parameters is important.

- Due that buckling usually occurs for weak track conditions, lateral resistances below $6 \mathrm{kN} / \mathrm{sleeper}$ and misalignments above $2 \mathrm{~mm}$ must be controlled in order to reduce the risk of buckling.

- Regarding the rail type, UIC54, UIC 60 and UIC 71 profiles were considered. As rail size increases, the buckling temperature decreases. This is a direct consequence of the increase in steel section and compressive forces, which offsets the corresponding increase in track rigidity and stiffness, thus reducing the global strength of the track. However, their influence on buckling temperatures is negligible, especially when compared with other fundamental parameters.

- With regards to railway sleepers, mono-block and bi-block concrete sleepers were used in the analysis. The buckling temperature for a dual gauge track with bi-block concrete sleepers is approximately $15 \%$ higher than the buckling load for a track with mono-block concrete sleepers. On the one hand, bi-block sleepers provides two ends instead of only one, improving lateral resistance. On the other hand, the crib and base resistance is lower due to their reduced area. As a result of both effects, the lateral resistance associated with bi-block sleepers is lower than expected. 
- Considering the form of the misalignment, calculations were performed using an initial misalignment with a half-wave and full-wave sinusoidal curve form. It can be seen that for a half wave form, the buckling temperature is, approximately, $16 \%$ lower than buckling temperatures for a full wave form.

- In dual gauge tracks, a particular factor that can be analyzed is the direction of the misalignment with respect to the position of the third rail. Numerical results show that, in the considered range, bulking temperatures decreases if the initial misalignment tends to displace the two adjacent outer rails outwards. On the other hand, if track panel displacement moves in the opposite direction, buckling temperatures are higher. This is due to the fact that the resultant bending moment of longitudinal forces increases if the two outer rails move away the longitudinal track axis.

- Finally, the influence of additional vertical forces due to train passage was studied. When vertical loads are applied on rails and considering a low axle loads (17 tonnes), the buckling temperatures are about $20 \%$ higher than for an unloaded track, If the track is loaded by a train with 22 tonnes axle loads, the increase in temperatures obtained is over $30 \%$. Therefore, vertical loads contribute to the track stability. However, although the lateral resistance under vertical loads increases, in the adjacent zones track may uplift thus reducing lateral resistances and buckling temperatures. Therefore, the next step in buckling analysis toward more precise results should take into account the track uplift and its influence in the lateral buckling.

In order to extend the analysis, a comparative analysis between conventional and dual gauge tracks was made. To accomplish this task, UIC-60 rails with monoblock concrete sleepers were considered. The principal conclusions are showed below:

- Buckling temperatures in dual gauge tracks are around $5^{\circ} \mathrm{C}$ to $15^{\circ} \mathrm{C}$ lower than those obtained for conventional tracks, under the same track conditions. Therefore, the risk of buckling is far greater for dual gauge tracks, requiring special attention and more accurate maintenance operations. However, track parameters are based on the analysis of existing field test and databases and their reliability depends on data quantity and quality. Future studies and experimental test will allow us to validate and check the observed track behavior. 
Up to this point, buckling temperatures have been obtained using a deterministic approach. With this method, a track buckles if rail temperature exceeds the critical or maximum value calculated above the neutral temperature. However, these temperatures may be too conservative for railway administrators since they are based on the worst case scenario. Therefore, a more reliable safety criterion is required.

In that sense, a more complex and practical strategy that allows the reduction of maintenance cost is a probabilistic methodology, where track parameters are represented by statistical functions. The probabilistic approach allows rail administrators and maintenance companies to relate rail track conditions with the probability of buckling as a more efficient maintenance and operation scheme. The results can also be used to define a critical or maximum rail temperature and are described below:

- The probability of buckling in dual gauge tracks can be expressed as a function of maximum rail temperature using the convolution integral. This approach provides a more realistic method by adjusting the buckling probability.

- The estimated target buckling probability of the rail tracks can vary with the importance of the tracks and rail services provided. In order to obtain reasonable solutions the probability of failures are assumed to be $10^{-3}$ and $10^{-4}$.

- From the results obtained and for worst-case conditions (Case 4), rail buckling temperatures reach $52^{\circ} \mathrm{C}$ and $54.1^{\circ} \mathrm{C}$, which can be easily overcome during heatwaves. Due that frequency and severity of buckling event depends on the quality and misalignments of the track, the decrease in dual gauge track safety may reduce performance and require more maintenance with respect to conventional tracks.

- In order to minimize the effects that hot weather may have on track conditions in a dual gauge infrastructure, special precautions must be taken into account such as speed restrictions. However, these measures should be defined and approved by rail administrators by assessing the longer term impacts and economic costs of climate change relating to damage and delays.

- Due that longitudinal forces in rails are directly related to the neutral or stress free temperature, a new stress regime can reduce the maximum upcoming stresses. 
However, setting a new neutral temperature regime is not sufficient by itself to reduce the risk of track buckling. To optimize and prevent buckles, rail administrators should manage the risk by:

- The stress free temperature should be periodically monitored and maintained in order to avoid inadmissibly decreased track stability.

- Critical zones such as areas of poor ballast or track condition should be monitored and controlled more frequently.

- Locations that have been recently disturbed through track maintenance should be controlled, imposing speed restrictions on hot days.

The buckling models developed for dual gauge tracks present an important utility in the development of maintenance and security of railway systems. The effects of rails, sleepers, lateral resistance, track misalignments and vertical loads have been analyzed. With the buckling temperatures obtained, a more understandable and safe criteria can be developed. As mentioned previously, the risk of lateral buckling in dual gauge tracks is greater than that of conventional tracks. Therefore, a more precise and practical maintenance should be applied.

\subsection{Further research}

This Thesis has introduced a comprehensive study of the buckling behavior of dual gauge tracks under different track conditions, analyzing different buckling behaviors. Despite the important research efforts already put in understanding track buckling behavior, some aspects are still not understood completely yet. The following areas are suitable for further research.

Improvements to develop within the models application:

- To develop a more precise analytical and numerical models for dual gauge track buckling analysis.

- In order to achieve the accuracy required for optimal maintenance, it is necessary to investigate the interactive effects and the degradations of one single parameters that affect the buckling response and their interactions. This challenge forms the basis for further work to be carried out. 
- To validate track parameters by full-scale field tests. The proposed analytical and numerical models are open to further improvement as more information and data become available. Therefore, buckling temperatures can be improved by validation and calibration, but it is necessary to collect data about the dual gauge track parameters, especially with respect to the lateral resistance and long-term response. In that sense, a simplified SPTP test should be developed.

- To include the uplift regions of the track. As mentioned, the loss of lateral resistance should be determined adequately.

- To introduce additional track parameters in the buckling model, such as the influence of longitudinal forces due to braking and acceleration events, different weather and temperatures, more representative constitutive models used for the trackbed layers, uneven larger range and scenarios of wheel-rail contact conditions, etc.

- Improve and optimize the loads influence by using a distributed vertical load shape function, including lateral forces with representative values.

There are also some validation work to carry out:

- To extend the buckling analysis for curves.

- Full scale experiments should be set up and carried out to determine the track buckling strength as influenced by the range of all key parameters (loading tonnage, traffic, temperature, ground condition, etc.). Validation based on experimental data which takes into account varying track characteristics and different geographic locations (rail stress free temperature range).

- To conduct an in-depth study into the interface between sleeper and ballast layer in terms of stiffness and variability in dual gauge tracks.

- Unlike the case of the deterministic approach, a systematic and comprehensive probabilistic methodology to evaluate the buckling risk should be performed in the future. This would require testing and data collection for the statistical variations. 
- The safety issues related to thermal buckling problems due to climate change should be taken as a critical issue in future studies.

To sum up, improved knowledge about dual gauge tracks with better simulation results will make it possible to evaluate track stability in a more detailed way. Although there are still a lot of improvements to perform, the obtained results are satisfactory and a motivation to keep working. 


\section{Referencias}

APARICIO, A.C. (2004). "Differences in designing high-speed railway bridges and highway bridges". Workshop on Bridges for High-Speed Railways. Proceedings. Porto, 3-4 June, 2004.

ARBABI, F \& KHALIGHI, M. (2010), "Stability of Railroad Tracks under the Effects of Temperature Change and Earthquake", Journal of Seismology and Earthquake Engineering, Vol. 12, (3), pp. 119-129.

BAE, H.U. CHOI, J.Y. MOON, J. \& LIM, N.H. (2014). "Development of a probabilistic buckling analysis scheme for continuous welded rail track." Proceedings of the Institution of Mechanical Engineers, Part F: Journal of Rail and Rapid Transit, Vol. 230, (3), pp. 747-758. (doi: 10.1177/0954409714564001).

BIJL, F. (1964) "Buckling force in gapless track calculated in a nonlinear manner". De Ingenieur. 1964; Vol. 39: pp.119-123.

CHOI, D.H. \& NA H.S. (2010). "Parametric study of thermal stability on continuous welded rail". International Journal of Railway; Vol. 3, (4), pp. 126-133.

Cuadrado, M. Zamorano, C. González, P. Nasarre, J. \& Romo, E. (2008). "Analysis of buckling in dual-gauge tracks". Proceedings of the Institution of Civil Engineers Transport. Vol. 161. (TR4). pp. 177-184. (doi:10.1680/tran.2008.161.4.177)

DE IORIO, A. PuCILlO, G.P. \& ALII, (2014). "Transverse strength of railway tracks: part 3. Multiple scenarios test field". Frattura ed Integrità Strutturale, Vol. 30, pp. 593-601. (doi:10.3221/IGF-ESIS.30.58)

DONLEY, M. \& KERR, A. (1987) "Thermal buckling of curved railroad tracks". International Journal of Nonlinear Mechanics; Vol.22 (3), pp. 175-192.

ECUC PROJECT: "EDDY CURRENT BRAKE COMPATIBILITY". 7th Framework Programme (FP7) -Transport (2012/2015).

EHE-08: Instrucción para el proyecto y la ejecución del hormigón estructural. Ministerio de Fomento. 2008.

Emdal, A. Priol, G. Grimstad, G. \& Lohren, A.H. (2007). "Numerical analysis of the effect of sleepers on the lateral displacement of railway track". Proceedings of the Tenth International Symposium on Numerical Models in Geomechanics (NUMOG X), Rhodes, Greece, 25-27 April 2007.

ENGESSER, F. (1889): "Über die Knickfestigkeit gerader Stäbe, Zeitschrift für Architektur und Ingenieurwesen". Vol.35, Hannover. 
ERRI D202/RP 10: "UIC Leaflet No. 720-R - Laying and Maintenance of CWR Track", Chapter 7, August, 1998.

ERRI D202/RP 12. “Improved knowledge of forces in CWR track (including switches) - Final report", European Rail Research Institute, Utrecht, February 1999.

ESMAEILI, M. HoSSEINI, S.A.S., SHARAVI, M. (2016). "Experimental assessment of dynamic lateral resistance of railway concrete sleeper". Soil Dynamics and Earthquake Engineering; Vol. 82, March 2016, pp. 40-54. (doi:10.1016/j.soildyn.2015.11.011)

Esveld, C. \& Hengstum, L.A. (1988). "Tack stability in tight curves." Rail International; Vol.12: pp.15-20.

EsveLD, C. (2001). "Modern Railway Track", 2nd edition, MRT Productions, 2001, Zaltbommel, ISBN: 90-800324-3-3

EULER, L. (1744) "De Curvis Elasticis, Additamentum I, Methodus Inveniendi Lineas Curvas Maximi Minimive Propietate Gaudentes". Lausanne and Geneval, 744.

EuLER, L. (1759): "Sur la force des colonnes". Memoires de L"Academic de Berlin.

EUROPEAN RAILWAY AGENCY (2012). "Railway safety performance in the European Union". Paris. European Railway Agency.

EUROPEAN RAILWAY AgENCY (2014). "Railway safety performance in the European Union". Paris. European Railway Agency.

EUROPEAN RAILWAY AgENCY (2016). "Railway safety performance in the European Union". Paris. European Railway Agency.

El-Ghazaly, h. Sherbourne, A. \& Arbabi, F. (1991). "Strength and stability of railway tracks-II Deterministic, finite element stability analysis". Computer and Structures; Vol. 39, (1-2): pp.23-45. (doi:10.1016/0045-7949(91)90070-3)

FEnG, Q. ZoNG, D. \& Lel, X. (2005). "Finite Element Model for Analyzing the Stability of Continuously Welded Rail Track". Journal of China Railway Science; Vol.26 (1) pp.7-14

GRISSON, G. \& KERR, A. (2006). "Analysis of lateral track buckling using new frame-type equations". International Journal of Mechanical Sciences; Vol.48 (1), pp. 21-32. (doi:10.1016/i.ijmecsci.2005.09.006)

HUNT, A. (1994). "An analysis of track buckling risk", British Railways, Internal Report RRTM013, 31.

HUNT, D. \& YU, Z. (1998). "Measurement of Lateral Resistance Characteristics for Ballasted Tracks", ERRI D 202/DT 361 Report, February 1998, Utrecht, Netherlands. 
JACKSON, J. BAULD, N. \& RAMESH, M. (1986). "A finite element model for the lateral strength of railroad track structures". Conference on Computational Mechanics, May 25-29, 1986, Tokyo: Vol. 1. pp. 299-304.

JACKSON, J. BAULD, N. RAMESH, M. \& MENON, S. (1988). "A superelement for lateral track deformation." Applied Mechanics Rail Transportation Symposium; Nov. 27- Dic. 2, 1988; Chicago (IL) pp. 7-18.

KERR A. (1976). "An analysis of thermal track buckling in the lateral plane." FRA/ORD76/285, Washington, DC, 1976.

KERR A. (1978). "Analysis of thermal track buckling in the lateral plane". Acta Mechanica; Vol.30, pp.17-50.

KERR A. (1980). "An improved analysis for thermal track buckling". International Journal of Nonlinear Mechanics; Vol.15 (2), pp. 99-114. (doi:10.1016/0020-7462(80)90004-9)

KISH, A. SAmaVedam G, \& JeONG D. (1982). "Analysis of thermal buckling tests on U.S. railroads". FRA/ORD-82/45, Washington, DC, 1982.

KISH A, SAMAVEDAM G, \& JeONG D. (1985). "Influence of vehicle induced loads on the lateral stability of CWR track". DOT/FRA/ORD-85/03, Washington, DC, 1985.

KISH A, \& SAMAVEDAM G. (1999). "Risk analysis based CWR: track buckling safety evaluations" Proceedings of the International Conference on Innovations in the Design \& Assessment of Railway Track; 1999 Dec 2-3; Delft (The Netherlands): Delft University of Technology.

Kish, A. \& Samaveda, G. (2004) "Track Buckling Prevention: Theory, Safety Concepts and Applications", US DOT/FRA Report.

$\mathrm{KISH}, \mathrm{A}$. (2011). "On the Fundamentals of Track Lateral Resistance". American Railway Engineering and Maintenance of Way Association.

KISH, A. \& SAmAVEDAM, G. (2013). "Track buckling prevention: Theory, Safety Concepts and Applications". DOT/FRA/ORD-13/16, U.S. Department of Transportation, Federal Railroad Administration, Office of Research and Development, March 2013.

KISH A, Sussmann T, \& Trosino, M. (2003). "Effects of maintenance operations on track buckling potential". Proceedings of international heavy haul association, Fort Worth, Texas, USA.

Koc, W., WILK, A., ChrostowskI, P., GrulkowskI, S. (2011). "Tests on lateral resistance in railway tracks during the operation of a tamping machine". Proceedings of the Institution of Mechanical Engineers, Part F: Journal of Rail and Rapid Transit, Vol. 225 (3), pp. 325340. 
KOIKE, Y. NAKAMURA, T. HAYANO, K. MOMOYA, Y. (2014). "Numerical method for evaluating the lateral resistance of sleepers in ballasted tracks". Soils and Foundations, Vol. 54 (3), pp. 502-514. (doi:10.1016/j.sandf.2014.04.014)

LIECHTBERGER, B. (2011). "Manual de vía: Infraestructura, superestructura, conservación, rentabilidad", Hamburg, Eurailpress, 2011.

LE Pen, L.M. \& Powrie, W. (2011). "Contribution of base, crib and shoulder ballast to the lateral sliding resistance of railway track: a geotechnical perspective". Proceedings of the Institution of Mechanical Engineers Part F: Journal of Rail and Rapid Transit, 225, (2), pp:113-128. (doi:10.1177/0954409710397094).

Le Pen, L. Bhandari, A. \& Powrie, W. (2014). "Sleeper End Resistance of Ballasted Railway Tracks" Journal of Geotechnical and Geoenvironmental Engineering, American Society of Civil Engineers, Vol. 140 (5). (doi:10.1061/(ASCE)GT.1943-5606.0001088)

LIM, N., PARK, N. \& KANG, Y. (2003). "Stability of Continuous Welded Rail Track". Computers and Structures, Vol. 81 (21-22), pp. 2219-2236. (doi:10.1016/S0045-7949(03)00287-6)

LIM, W. (2004). "Mechanics of railway ballast behaviour". (Tesis doctoral), University of Nottingham.

LIM, N. \& SUNG I. (2004). "Thermal buckling behaviour of continuous welded rail track". Steel Structures; Vol.4, pp. 111-119.

LIM, N. HAN, S. HAN, T. \& KANG, Y. (2008). "Parametric study on stability of continuous welded rail track - ballast resistance and track irregularity". Steel Structures; Vol.8, pp. 171181.

LÓPEZ PITA A. (2006). "Infraestructuras ferroviarias". Spain: Ediciones UPC, 2006.

MANTENImiento de InfRAEstructura Renfe. Dirección Técnica/ Jefatura de vía. (1982) N.R.V. 3-3-0.0.: Juntas de carriles. Bridas y tornillos de bridas, Renfe.

NAV 7-1-4.1 "Montaje de vía.- Neutralización y homogeneización de tensiones en la vía sin junta" Edición 2a, enero 2009.

NAVARRO, I. VilLALBA, I. MARTíneZ, P \& INSA, R. (2015). "Analytical model for predicting the buckling load of continuous welded rail tracks" Proceedings of the Institution of Mechanical Engineers, Part F: Journal of Rail and Rapid Transit; Vol. 229 (5), pp: 542-552 (doi:10.1177/0954409715626957)

Nuevo Central Argentino (2014). "Manual Integral de Vía“. 
PIO PuCILLO, G. (2016). "Thermal buckling and post-buckling behaviour of continuous welded rail track". International Journal of Vehicle Mechanics and Mobility, Vol. 54, (12), pp. 1785-1807. (doi:10.1080/00423114.2016.1237665)

PRuD'Homme, A. \& JANIN, G. (1969). "The stability of tracks laid with long welded rails". Bulletin of the International Railway Association, part 1 and 2.

QueEnSLAND RAILWAYS (2008). Hot Weather Precautions for Track Stability. QR Network.

QUEENSLAND RAILWAYS (2008). Track Stability. QR Network.

SAmAVEDAM, G. (1979). "Buckling and post-buckling analysis of CWR in the lateral plane". Derby (UK): British Railways Board, R\&D Division, Railway Technical Centre; 1979. (Technical Note TNTS-34).

Samavedam, G. Kish, A. \& Jeong, D. (1983). "Parametric studies on lateral stability of welded rail track". Washington (DC): U.S. Department of Transportation, Federal Railroad Administration, Office of Research and Development; 1983. (Report No. DOT/FRA/ORD83/07).

Samavedam, G. Kish, A. Purple, A. \& Schoengart, J. (1993). "Parametric analysis and safety concepts of CWR track buckling". Washington (DC): U.S. Department of Transportation, Federal Railroad Administration, Office of Research and Development; 1993. (Report No. DOT/FRA/ORD-93/26).

SAMAVEDAM G, BLADER F \& THOMSON D. (1996). "Safety of high speed ground transportation systems. Track lateral shift: fundamentals and state-of-the-art review. Final Report". Washington, DC: US Department of Transportation.

So, W. \& MARTIN, G. (1978). "Finite element model for track buckling". Advanced Techniques in Track/Train Dynamics and Design, Conference; Chicago, IL, USA; Sep 27-28. pp. 315-328.

So, W. \& YANG, W. (1978). "Mathematical model for lateral thermal buckling and displacement of curved track". Transportation Research Record, (694), pp. 24-29.

SUNG, W. SHIH, M. LIN, C. \& GO C. (2005). "Critical loading for lateral buckling of continuous welded rail". Journal of Zhejiang University Science, 6A (8) August 2005, pp. 878-885. (doi:10.1631/izus.2005.A0878)

TEW, G. P. Rails \& JefFs, T. SleEpers AND BALLAST \& DOYLE, N. RaILWAY TRACK DESIGN \& RAILWAYS OF AUSTRALIA (1991). "A Review of track design procedures." Railways of Australia, Melbourne Vol. 2. 
TREFFTZ, E. (1933). "Zur Theorie der Stabilitit des elastischen Gleichgewichts", Journal of Applied Mathematics and Mechanics, Vol. 13, (2) pp: 160-165, (doi:10.1002/zamm.19330130224)

TVERgAARD, V. \& NeEDLEMAN, A. (1981). "On localized thermal track buckling", International Journal of Mechechanical Sciencies, Vol. 23, (10), pp. 577-587, 1981.

UIC 518. "Testing and approval of railway vehicles from the point of view of their dynamic behaviour -Safety-Track fatigue-Ride quality." $3^{a}$ edition. Octubre 2005.

UIC 720-R. "Laying and maintenance of CWR track, (2005).

UNE-EN 13848-5:2009. "Aplicaciones ferroviarias. Vía. Calidad de la geometría de la vía. Parte 5: Niveles de calidad geométrica. Plena vía.

UNIÓN EUROPEA. Directiva 2016/798/UE del Parlamento Europeo y del Consejo, de 11 de mayo de 2016, sobre la seguridad ferroviaria (DOUE L 138/102, 26.5.2016)

VAN, M.A. (1997). "Stability of Continuous Welded Rail Track". (Tesis doctoral). Faculty of Civil Engineering and Geosciences, Delft University Press.

Villalba, I. INSA, R. SAlVAdoR, P. \& MARTínez, P. (2017). "Methodology for evaluating thermal track buckling in dual gauge tracks with continuous welded rail". Proceedings of the Institution of Mechanical Engineers Part F Journal of Rail and Rapid Transit; Vol. 231 (3), pp: 269 - 279 (doi:10.1177/0954409715626957)

Volpe NATIONAL TRANSPORTATION SYSTEMS CENTER (2003). "Track buckling research, research and innovative technology administration." Washington: U.S. Department of Transportation.

YANG, G. \& BRADFORD, M. (2016). "Thermal-induced buckling and postbuckling analysis of continuous railway tracks". International Journal of Solids and Structures; Vol. 97-98, pp. 637-649, (doi:10.1016/.ijsolstr.2016.04.037)

YAPING, W. XU, S. WU, C. \& JIANZHONG, S. (2010). "Finite element analysis of Stability of Continuous Welded Rail with Minor Radius Curve". 2010 International Conference on Artificial Intelligence and Computational Intelligence.

ZAKERI, J.A. \& BAKHTIARY, A. (2014). "Comparing lateral resistance to different types of sleeper in ballasted railway tracks". Scientia Iranica. Transaction A, Civil Engineering; Vol.21 (1), pp. 101-107.

ZAND, J. \& MORAAL, J. (1997). "Ballast resistance under three dimensional loading." Technical report, Delft University of Technology. 
ZHU, J. \& ATTARD, M. (2015). "In-plane nonlinear localised lateral buckling under thermal loading of rail tracks modelled as a sandwich column". International Journal of Mechanical Sciences; Vol. 104, pp. 147-161, (doi:10.1016/j.jimecsci.2015.10.009). 


\section{Anexo I. Artículos publicados en re- lación con la Tesis}

En este Anexo se incluyen las referencias de los artículos publicados en relación a la Tesis. Con el fin de no incurrir en problemas por copyright y de acuerdo a las condiciones de publicación de las distintas revistas, no se muestran los artículos.

This annex includes the references of papers, related to the PhD Thesis. In order to avoid copyright problems and according with copyright policies of academic publishers, articles are not reported.

A. NAvarro, I. Villalba, I. Martínez, P \& INSA, R. (2015). "Analytical model for predicting the buckling load of continuous welded rail tracks" Proceedings of the Institution of Mechanical Engineers, Part F: Journal of Rail and Rapid Transit; Vol. 229 (5), pp: 542-552 (10.1177/0954409713518039)

B. Villalba, I. InSA, R. SAlvador, P. \& Martínez, P. (2017). "Methodology for evaluating thermal track buckling in dual gauge tracks with continuous welded rail". Proceedings of the Institution of Mechanical Engineers Part F Journal of Rail and Rapid Transit; Vol. 231 (3), pp: 269-279 (doi:10.1177/0954409715626957)

Paper A present an analytical model with which to calculate the buckling load of a CWR track. The model accounts for different contribution of base, crib and shoulder ballast and includes the affection of vertical loading to each of these components. In addition, a parametrical study was developed, in order to understand how and how much the considered factors affect the track stability.

Paper B present a three-dimensional CWR model to be used for dual gauge track buckling analysis. The CWR dual gauge track model consists of beam, solid and spring elements, in which a non-linear behaviour of the ballast was considered. Factors such as lateral resistance, lateral imperfections, sleeper spacing or torsional stiffness were considered to determine their influence. 


\section{Anexo II. Conclusiones/Conclusions}

En el presente anexo, se exponen las conclusiones de la Tesis traducidas tanto al castellano como al valenciano.

\section{Conclusiones (Castellano)}

El uso de un nuevo tipo de superestructura de vía requiere un análisis de su comportamiento mecánico, con el fin de asegurar y comprobar su resistencia y estabilidad. En este sentido, una mayor comprensión y conocimiento respecto al fenómeno del pandeo, así como las interacciones entre los diferentes parámetros de vía y sus particularidades es totalmente necesaria. De acuerdo con los objetivos planteados y descritos en el Capítulo I, las principales conclusiones obtenidas durante el desarrollo de la Tesis respecto de la estabilidad lateral en vías con doble ancho son:

- Durante las últimas décadas, un gran número de modelos han sido desarrollados para el cálculo de la estabilidad lateral de la vía. No obstante, las vías de doble ancho implican un cambio importante del emparrillado de vía, lo que requiere el uso de un nuevo enfoque y aproximación. Para llevar a cabo esta tarea, en el presente trabajo se propone tanto un nuevo modelo analítico como numérico para el cálculo de la temperatura de pandeo en vías de doble ancho. Los valores resultantes del cálculo son la temperatura de pandeo y el desplazamiento lateral de la vía, teniendo en consideración sus características estructurales (propiedades mecánicas y configuración espacial).

- Por lo que respecta al modelo analítico, el sistema carril-traviesa viene representado por una viga equivalente. Además, la resistencia lateral se simula mediante un resorte o muelle cuya rigidez es el resultado de las tres componentes resistentes (base, laterales y punta), lo que permite evaluar la resistencia en función de la altura de la capa de balasto. En este modelo, el carril se somete a un esfuerzo longitudinal cuya magnitud representa el esfuerzo debido a las variaciones de temperatura, a la vez que se considera un defecto inicial con forma senoidal.

- En cuanto al modelo numérico, los carriles y las traviesas están representados por elementos viga en 3D, por lo que se mantienen sus posiciones relativas en la vía. 
Los carriles están conectados a las traviesas mediante las sujeciones, las cuales se representan mediante un conjunto de resortes lineales y rotacionales, cuya rigidez simula el efecto de apriete de la sujeción. Finalmente, la resistencia lateral del balasto se simula a través de muelles no lineales con comportamiento elasto-plástico, mientras que en las direcciones longitudinal y vertical la resistencia se considera mediante el uso de muelles lineales.

- En ambos modelos, la respuesta de la vía en términos de temperatura de pandeo es muy similar. No obstante, la temperatura que se obtiene cuando se hace uso del modelo analítico es ligeramente superior a la que se obtiene mediante el modelo numérico. Pese a ello, la complementariedad que se obtiene mediante el manejo de ambos tipos de modelo y los escenarios que permiten simular facilitan una mejor aproximación cuando se analiza el pandeo.

Haciendo uso de los modelos construidos previamente se ha llevado a cabo un estudio paramétrico, con el objetivo de evaluar el efecto de los carriles, traviesas, resistencia lateral, amplitud y forma del defecto inicial, altura de balasto, así como de las cargas verticales. La aplicabilidad de estos modelos se ha evaluado en base al estudio de un total de 248 escenarios, proporcionando una idea cualitativa respecto de los factores principales que deben ser considerados en vías de doble ancho. Las principales conclusiones obtenidas se presentan a continuación:

- Los resultados obtenidos muestran que los factores involucrados en el pandeo para vías de doble ancho son la resistencia lateral y los defectos iniciales. Puesto que la temperatura de pandeo disminuye a medida que aumentan los defectos de alineación o se reduce la resistencia lateral, las irregularidades y/o la baja resistencia del balasto deben ser controlados con atención. Por lo tanto, el estudio y control de estos factores es sumamente importante.

- Puesto que el pandeo se ocasiono, generalmente, en condiciones de vía degradadas, valores de resistencia lateral por debajo de los $6 \mathrm{kN} /$ traviesa y defectos superiores a $2 \mathrm{~mm}$ deben ser corregidos y eliminados para reducir el riesgo de pandeo.

- Respecto del tipo de carril, se consideraron carriles tipo UIC 54, UIC 60 y UIC 71. A medida que aumenta el tamaño del carril, la temperatura de pandeo se reduce. Este efecto es consecuencia directa del incremento del área transversal de acero 
en el emparrillado de la vía, lo que produce mayores fuerzas de compresión que contrarrestan el aumento de la rigidez y la resistencia, dando como resultado una reducción de la estabilidad lateral de la vía. Pese a este efecto negativo, su influencia en el pandeo es más bien despreciable, especialmente cuando se compara con otros factores con una mayor influencia.

- Tomando en consideración las traviesas, el análisis se realizó considerando las traviesas monobloque y bi-bloque. La temperatura de pandeo obtenida para vías de doble ancho con traviesa bi-bloque es, aproximadamente, un $15 \%$ superior de la que se obtiene para la misma vía con traviesas monobloque. Por un lado, las traviesas bi-bloque proporcionan dos caras laterales, lo que mejora la resistencia lateral. En contraposición, la superficie lateral y de la base en contacto con el balasto es menor, por lo que la resistencia por fricción se reduce. Como resultado de la combinación de ambos efectos, la resistencia lateral que aportan las traviesas bibloque no es tan elevada como en principio cabría esperar.

- Analizando la forma de los defectos, los cálculos fueron realizados asumiendo un defecto inicial con forma de media senoide y de senoide completa. Se puede comprobar como la temperatura de pandeo resultante para los defectos en forma de media senoide es, aproximadamente, un 16\% inferior de la obtenida para defectos con forma de senoide completa.

- Un aspecto particular y único de las vías de doble ancho que puede ser estudiado es el sentido del defecto con respecto de la posición del tercer carril. Los resultados numéricos muestran que, en el rango de valores analizado, las temperaturas de pandeo son más reducidas si el defecto inicial tiende a desplazar el lado donde se sitúan los dos carriles hacia el exterior del eje longitudinal de la vía. Por el contrario, si la vía se desplaza hacia el sentido opuesto al descrito, las temperaturas resultantes son más elevadas. Este comportamiento es debido a que la excentricidad de las fuerzas aumenta en mayor grado cuando el lado donde se localizan los dos carriles tienen a desplazarse hacia el exterior.

- Finalmente, la influencia adicional que ejercen las cargas verticales debido al paso de trenes fue considerada. Cuando se aplican cargas verticales en los carriles y considerando un eje poco pesado (eje de $17 \mathrm{t}$ ), las temperaturas de pandeo son alrededor de un $20 \%$ superiores respecto de la situación sin ningún tipo de carga 
vertical. Si se considera un eje con mayor carga (eje de $22 \mathrm{t}$ ), el incremento de temperatura alcanza el 30\%. Con estos resultados, se observa como las cargas verticales contribuyen al aumento de la estabilidad. No obstante, pese a que la resistencia lateral en la zona de aplicación de la carga aumenta, en la práctica se ha observado cómo en las zonas adyacentes a la carga se produce un ligero levantamiento del carril, reduciendo en estos puntos la resistencia y, con ello, la temperatura de pandeo. Ante esta situación, una mejora a llevar a cabo en los modelos para el estudio del pandeo es la de ser capaces de representar el efecto de levante de las traviesas, así como su influencia en el pandeo lateral.

Con el objetivo de extender el alcance y las conclusiones del estudio, se realizó una comparativa entre vías convencionales y vías de doble ancho. Las principales conclusiones son:

- $\quad$ Las temperaturas de pandeo para vías de doble ancho son entre $5^{\circ} \mathrm{C}$ y $15^{\circ} \mathrm{C}$ menores de las obtenidas para vías convencionales, bajo las mismas condiciones de cálculo. Por lo tanto, el riesgo de pandeo es mayor en vías de doble ancho, lo que plantea la necesidad de prestar especial atención y realizar un mayor mantenimiento de la vía. No obstante, los parámetros considerados para vías de doble ancho están obtenidos en base a datos teóricos y de vías convencionales existentes, por lo que los resultados dependen de la calidad y precisión de los valores considerados. Futuros estudios y ensayos permitirán comprobar y validar el comportamiento obtenido en los modelos.

Hasta este punto, las temperaturas de pandeo han sido obtenidas utilizando una aproximación determinística. Con este tipo de análisis, en una vía se produce el pandeo cuando la temperatura de los carriles excede el valor calculado respecto de la temperatura de neutralización a la que ha sido instalado. Esta sistemática, sin embargo, puede ser muy conservativa para los administradores de la infraestructura, pues el cálculo de pandeo no considera las incertidumbres de las variables, analizándose por tanto un escenario poco probable y en condiciones de vía muy perjudiciales para la estabilidad. Ante esta situación, generalmente es más recomendable el uso de un criterio de seguridad más práctico. 
En este sentido, una estrategia más completa y práctica que permite reducir los costes de mantenimiento es la del cálculo probabilístico del pandeo, donde los parámetros de vía vienen definidos mediante funciones de probabilidad. El tratamiento probabilístico del pandeo permite a los administradores ferroviarios y a las empresas de mantenimiento relacionar las condiciones de vía con la probabilidad de que se produzca el pandeo, lo que permite una gestión más eficiente de la infraestructura. Los resultados que se obtienen con los modelos previamente descritos permiten definir las temperaturas máximas o límite asociadas a un determinado riesgo predefinido, obteniéndose las siguientes conclusiones:

- La probabilidad de pandeo en vías de doble ancho puede ser expresada como función de la máxima temperatura en los carriles mediante el uso de la integral de convolución. Esta aproximación proporciona un método más adecuado mediante la definición de funciones de probabilidad para las variables fundamentales que condicionan el fenómeno.

- La probabilidad de pandeo objetivo de una determinada vía puede variar en función de la importancia de la línea y de las circulaciones que transitan. Para obtener soluciones con una tasa de fallo razonable se han considerado probabilidades con tasa de fallo de $10^{-3}$ y $10^{-4}$.

- Los resultados obtenidos muestran que, para el peor escenario de cálculo considerado (Caso 4), las temperaturas de pandeo se sitúan en los $52^{\circ} \mathrm{C}$ y $54,1^{\circ} \mathrm{C}$, cuyos valores que pueden ser superados fácilmente durante períodos de calor intensos. Debido a que tanto la frecuencia como la gravedad de un evento de pandeo está controlada por la calidad y de los defectos de vía, la necesidad de mantener la vía en condiciones adecuadas sugiere realizar un mayor control y mantenimiento del que se realiza habitualmente en vías convencionales.

- Para minimizar los efectos que los períodos cálidos pueden tener en vías de doble ancho, se recomienda el uso de medidas especiales como reducciones de velocidad. No obstante, estas medidas deben ser definidas y aprobadas por los administradores de infraestructuras, evaluando los impactos y los costes económicos a largo plazo relacionados con el cambio climático y el aumento global de las temperaturas. 
- Puesto que los esfuerzos longitudinales en los carriles están directamente relacionados con la temperatura de neutralización, un nuevo régimen de temperaturas con mayores temperaturas de neutralización puede reducir los esfuerzos máximos de compresión generados en los carriles. No obstante, el establecimiento de mayores temperaturas de neutralización no es en sí misma una práctica suficiente para reducir el riesgo frente a pandeo. Para optimizar y prevenir el pandeo los administradores deben gestionar y controlar el pandeo mediante una serie de medidas, algunas de las cuales se citan a cnotinuación:

- Control y monitorización de la temperatura de neutralización (estado donde no existen esfuerzos en los carriles) y de los propios carriles, con el objetivo de evitar variaciones de temperatura que puedan afectar a la integridad y seguridad de la infraestructura.

- Control y seguimiento especial de tramos especialmente sensibles como zonas con balasto degradado y/o condiciones de vía deterioradas.

- Control e imposición de restricciones de velocidad en días calurosos para zonas donde se ha realizado recientemente un mantenimiento de la superestructura (especialmente cuando se lleva a cabo el bateo).

Para finalizar, cabe destacar que los modelos de pandeo desarrollados para vías de doble ancho presentan una importante utilidad para el mantenimiento y la seguridad del transporte ferroviario en este tipo de infraestructura. Con su desarrollo, los efectos de los carriles, traviesas, resistencia lateral, defectos de alineación, así como los de las cargas verticales han podido ser estudiados. Las temperaturas de pandeo obtenidas permiten alcanzar un mayor conocimiento del fenómeno, cosa que permitirá desarrollar criterios de mantenimiento más seguros y eficaces. Con todo ello, se ha observado que el riesgo de pandeo asociado a vías de doble ancho es mayor respecto al que se obtiene en vías convencionales, lo que plantea la necesidad de llevar a cabo un mayor mantenimiento y control para asegurar la estabilidad y función de este tipo de vía. 


\section{Conclusions (Valenciano)}

L'ús d'un nou tipus de superestructura de via requereix l'anàlisi de la seua resposta mecànica, amb l'objectiu d'assegurar i comprovar la resistència i estabilitat. En aquest sentit, un major coneixement i compressió respecte del fenomen de pandeig, així com les interaccions entre els diferents paràmetres de via i les seues particularitats és totalment necessària. D'acord amb els objectius plantejats i descrits en el Capítol I, les principals conclusions obtingudes durant el desenvolupament de la Tesi respecte de l'estabilitat lateral en vies de doble ample son:

- Durant les últimes dècades, un gran nombre de models han sigut desenvolupats pel que fa al càlcul de l'estabilitat lateral de la via. No obstant això, les vies amb doble ample impliquen un canvi important de l'engraellat de via, el que requereix l'ús d'un nou enfoc i aproximació. Per dur a terme aquesta feina, en el present treball es proposa tant un model analític com numèric per al càlcul de la temperatura de pandeig en vies de doble ample. Els valors resultants del càlcul són la temperatura de pandeig i el desplaçament lateral de la via, tenint en consideració les seues característiques estructurals (propietats mecàniques i configuració espacial).

- Pel que respecta al model analític, el sistema carril-travessa està representat per mitjà d'una biga equivalent. Així, la resistència lateral se simula mitjançant una molla o resort la rigidesa del qual és el resultat de les tres components resistents (base, lateral i punta), el que permet avaluar la resistència en funció de l'altura de la capa de balast. En aquest model, el carril és sotmés a un esforç longitudinal amb una magnitud que representa l'esforç a causa de les variacions de temperatura, així com un defecte inicial amb forma de sinusoide.

- Respecte del model numèric, els carrils i les travesses estan representats per elements biga en 3D, cosa que permet mantindre les seues posicions relatives en l'engraellat de la via. El carrils estan connectats a les travesses mitjançant les subjeccions, les quals es representen amb un conjunt de molles lineals i rotacionals, la rigidesa de les quals simula l'efecte que posseeix la subjecció. Finalment, la resistència lateral del balast ve representada per molles no lineals amb comportament elasto-plàstic, mentres que en les direccions longitudinal i vertical la resistència es simula mitjançant l'ús de molles lineals. 
- En tots dos models, la resposta de la via en termes de temperatura de pandeig es molt similar. No obstant això, la temperatura que s'obté fent ús del model analític es lleugerament superior a aquella que s'obté utilitzant el model numèric. Malgrat açò, la complementarietat que s'obté fen ús de tots dos models i els escenaris de càlcul que permeten simular faciliten una millor aproximació pel que fa a l'anàlisi del pandeig.

Utilitzant els models plantejats prèviament s' ha dut a terme un estudi paramètric, amb l'objectiu d'avaluar l'efecte dels carrils, travesses, resistència lateral, amplitud i forma del defecte inicial, altura del balast, així como la influència de les càrregues verticals. La aplicabilitat d'aquest models s'ha avaluat en base a l'estudi d'un total de 248 escenari, proporcionant una idea qualitativa respecte dels factors principals que deuen ser considerats en vies d doble ample. Les principals conclusions obtingudes es presenten a continuació:

- El resultats obtinguts mostren que els factors involucrats en el pandeig en vies de doble ample son la resistència lateral i els defectes inicial considerats. Degut a que la temperatura de pandeig es redueix a mesura que creixen els defectes inicials o es redueix la resistència lateral, les irregularitats de alineament i les zones amb una reduïda resistència deuen ser controlades amb atenció. Per tant, l'estudi i control d'aquestos factors es especialment important.

- Degut a que el pandeig es produeix, generalment, en condicions de via degradades, valors de la resistència lateral sota els $6 \mathrm{kN} /$ travessa així como defectes superiors a $2 \mathrm{~mm}$ deuen ser corregits i eliminats per tal de reduir el risc de pandeig.

- Respecte al tipus de carril, es van considerar el carrils tipus UIC54, UIC60 i UIC71. A mesura que creix el tamany del carril, la temperatura de pandeig es redueix. Aquest efecte es conseqüència directa del augment de l'àrea transversal d'acer en l'engraellat de la via, cosa que produeix majors esforços de compressió que contraresten l'increment de la rigidesa i la resistència, donant com a resultat una reducció en l'estabilitat lateral de la via. No obstant aquest efecte negatiu, la seua influència en el pandeig és menyspreable, especialment quan es compara amb altres factors que tenen una major influència. 
- Prenent en consideració les travesses, l'anàlisi es va realitzar considerant les travesses monobloc i bi-bloc. La temperatura de pandeig obtinguda en vies de doble ample amb travessa bi-bloc és, aproximadament, un 15\% superior de la que s'obté per al mateix tipus de via amb travesses monobloc D'una banda, les travesses bibloc proporcionen dos cares laterals, cosa que millora la resistència lateral. En contraposició, la superfície lateral i de la base en contacte amb el balast es més reduïda, el que produeix que la resistència deguda a la fricció siga menor. Com a resultat de la combinació de tots dos efectes, la resistència lateral que proporcionen les travesses bi-bloc no és tan important com en un principi caldria esperar.

- Analitzant la forma dels defectes, els càlculs van ser realitzats considerant un defecte inicial amb forma de mitja sinusoide i de sinusoide completa. Es pot comprovar com la temperatura de pandeig resultant per als defectes en forma de mitja sinusoide són, aproximadament, un 16\% inferiors dels obtinguts quan el defecte considerat té forma de sinusoide completa.

- Un aspecte particular i únic de les vies de doble ample que pot ser estudiat es el sentit del defecte respecte de la posició del tercer carril. Els resultats numèrics mostren com, per al rang de valors analitzat, les temperatures de pandeig són més reduïdes si el defecte inicial tendeix a desplaçar el costat on es troben els dos carrils cap a l'exterior del eix longitudinal de la via. Pel contrari, si la via es desplaça cap al sentit oposat al descrit, les temperatures resultants son més elevades. Aquest comportament es degut al fet que l'excentricitat de les forces augmenta en major proporció quan el costat on es localitzen els dos carrils tendeix a desplaçar-se cap a l'exterior.

- Finalment, la influència addicional que exerceixen les càrregues verticals degut al pas dels trens va ser considerada. Quan s'apliquen càrregues verticals en els carrils i considerant un eix amb un pes reduït (eix de $17 \mathrm{t}$ ), les temperatures de pandeig són aproximadament un 20\% superiors respecte de la situació sense cap càrrega vertical. Si es considera un eix amb un pes més important (eix de 22t), l'increment de temperatura arriba al 30\%. Amb aquestos valors, s'observa com l'efecte de les càrregues verticals contribueix al augment de l'estabilitat. No obstant això, tot i que la resistència lateral en la zona d'aplicació de la càrrega augmenta, en la pràctica s'ha observat com les zones adjacents a la càrrega es produeix una lleugera elevació del carril, reduint en aquestos punts la resistència $y$, amb això, la 
temperatura de pandeig. Davant aquesta situació, una millora a dur a terme en els models per a l'estudi del pandeig es la de ser capaços de representar l'efecte d'elevació de les travesses, així com la seua influència en el pandeig lateral.

Am l'objectiu d'estendre l'abast i les conclusions de l'estudi, es va realitzar una comparativa entre vies convencional i vies de doble ample. Les principals conclusions son:

- Les temperatures de pandeig per a vies de doble ample són entre $5^{\circ} \mathrm{C}$ i $15^{\circ} \mathrm{C}$ menors de les obtingudes per a vies convencionals, baix les mateixes condicions de càlcul. Per tant, el risc de pandeig es major en vies de doble ample, cosa que planteja la necessitat de posar especial atenció i realitzar un major manteniment de la via. No obstant això, els paràmetres considerats en vies de doble ample estan obtinguts en base a dades teòriques i de vies convencionals ja existents, per la qual cosa els resultats depenen de la qualitat i precisió dels valors considerats. Futurs estudis i assajos permetran comprovar i validar el comportament obtingut amb els models.

Fins aquest punt, les temperatures de pandeig han sigut obtingudes fent ús d'una metodologia amb una aproximació determinista. Amb aquest tipus d'anàlisi, en una via es produeix el pandeig en el moment en que la temperatura dels carrils excedeix el valor calculat, considerant sempre la temperatura de neutralització a la que ha sigut instal-lat. Aquesta sistemàtica pot ser molt conservadora per als administradors d'infraestructures, degut al fet que el càlcul de pandeig no considera les incerteses de les variables, analitzant un escenari molt poc probable $\mathrm{i}$ en unes condiciones de via molt poc favorables per a l'estabilitat de la via. Davant d'aquesta situació, generalment és més recomanable l'ús d'un criteri de seguretat més pràctic.

En aquest sentit, una estratègia més completa i pràctica que permet reduir els costos de manteniment és la del càlcul probabilístic del pandeig, on els paràmetres de via venen definits mitjançant funcions de probabilitat. El tractament probabilístic del pandeig permet als administradors ferroviaris i a les empreses de manteniment relacionar les condicions de la pròpia via amb la probabilitat de que es produïsca el pandeig, el que facilita una gestió més eficient de la infraestructura. Els resultats que s'obtenen mitjançant els models prèviament descrits permeten definir les temperatures màximes o límit associades a un cert ris prefixat, obtenint-se les següents conclusions: 
- La probabilitat de pandeig en vies de doble ample pot ser expressada com a funció de la màxima temperatura en els carrils mitjançant l'ús de la integral de convolució. Aquesta aproximació proporciona un mètode més adequat gràcies al maneig de funcions de probabilitats per a les variables fonamentals que condicionen el fenomen.

- La probabilitat de pandeig objectiu de una determinada via pot canviar en funció de la importància de la línia i dels vehicles que circulen. Per tal d'obtindre solucions amb una taxa de fallada raonable han de ser considerades probabilitats amb una taxa de $10^{-3}$ i $10^{-4}$.

- Els resultats obtinguts mostren com, per al pitjor escenari de càlcul considerat (Cas 4), les temperatures de pandeig es situen entorn als $52^{\circ} \mathrm{C}$ i $54,1^{\circ} \mathrm{C}$, xifres que poden ser superats amb certa facilitat durant períodes de calor intensos. Degut a que tant la freqüència com la gravetat d'un esdeveniment de pandeig esta relacionada amb la qualitat i els defectes de via, es important dur a terme un pla de manteniment $i$ control específic que assegure unes condicions adequades.

- Per tal de minimitzar els efectes que períodes càlids poden tindre en les vies de doble ample, es recomana l'ús de mesures especials com reduccions de velocitat. No obstant això, aquestes mesures deuen ser definides i aprovades pels administradors d'infraestructures, avaluant els impactes i costos econòmics a llarg termini relacionats amb el canvi climàtic i l'augment global de les temperatures.

- Degut a que els esforços longitudinals en el carrils estan directament relacionats amb la temperatura de neutralització, un nou règim de temperatures amb valores més elevats de temperatures de neutralització pot contribuir a reduir els esforços màxims de compressió generats als carrils. Am tot, l'establiment de majors temperatures de neutralització no és en si mateix una mesura suficient per a reduir el risc de pandeig. Per tal d'optimitzar i previndre el pandeig els administradors d'infraestructures deuen gestionar i controlar el pandeig mitjançant una sèrie de mesures, algunes de les quals es citen a continuació:

- Control i monitorització d la temperatura de neutralització (estat en el que no existeixen esforços en els carrils) i dels carrils, amb l'objectiu d'evitar 
variacions de temperatura que puguen afectar a la integritat i seguretat de l'infraestructural.

- Control i seguiment especial de trams de via sensibles com zones amb balast degradat i/o condicions de via deteriorades.

- Control i imposició de restriccions de velocitat en dies calorosos per a zones on s'ha realitzat recentment un manteniment del balast (especialment quan es du a terme el bateig de la via).

Per finalitzar, cal destacar que els models de pandeig desenvolupats per a vies de doble ample presenten una important utilitat en quant al manteniment i la seguretat del transport ferroviari en aquest tipus d'infraestructura. Amb el seu desenvolupament, els efectes dels carrils, travesses, resistència lateral, defecte de alineació, així com els de les càrregues verticals han pogut ser estudiats. Les temperatures de pandeig obtingudes permeten assolir un major coneixement del fenomen, cosa que facilitarà l'establiment de criteris de manteniment més segurs i efectius. Amb tot açò, s'ha observat que el risc de pandeig associat a vies amb doble ample es major que aquell que s'obté per a vies convencionals, el que planteja la necessitat de dur a terme un major manteniment i control per tal d'assegurar la estabilitat i funció d'aquest tipus de via. 